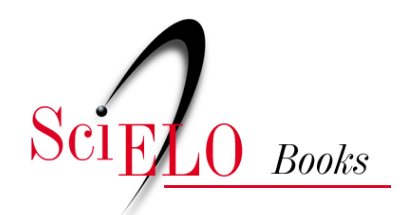

\title{
EdUfSCar
}

\section{Aplicações de química teórica no estudo de materiais: métodos in silico para nanomateriais}

\author{
Luiz Carlos Gomide Freitas \\ Guedmiller Souza de Oliveira \\ (orgs.)
}

\section{SciELO Books / SciELO Livros / SciELO Libros}

FREITAS, L.C.G., and OLIVEIRA, G.S., orgs. Aplicações de química teórica no estudo de materiais: métodos in silico para nanomateriais [online]. São Carlos: EdUFSCar, 2018, 244 p. ISBN 978-6580216-12-3. Avalaible from: doi: 10.7476/9786580216123. Also available in ePUB from: http://books.scielo.org/id/nvnjd/epub/freitas-9786580216123.epub.

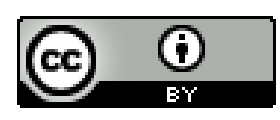

All the contents of this work, except where otherwise noted, is licensed under a Creative Commons Attribution $\underline{4.0 \text { International license. }}$

Todo o conteúdo deste trabalho, exceto quando houver ressalva, é publicado sob a licença Creative Commons Atribição 4.0.

Todo el contenido de esta obra, excepto donde se indique lo contrario, está bajo licencia de la licencia $\underline{\text { Creative }}$ Commons Reconocimento 4.0. 


\section{APLICAÇÕES DE QUÍMICA TEÓRICA NO ESTUDO DE MATERIAIS}




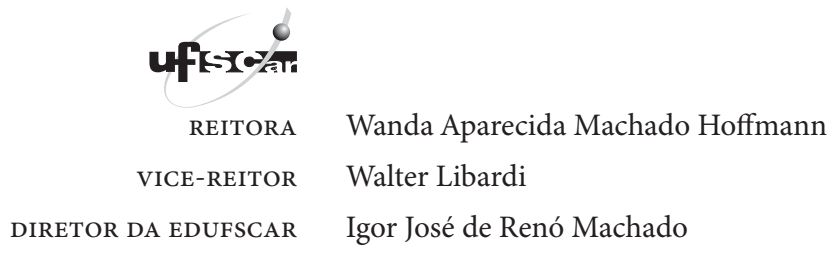

EdUFSCar - Editora da Universidade Federal de São Carlos

CONSELHO EDITORIAL Ana Lúcia Brandl

Alessandra de Almeida Lucas

Arthur Autran Franco de Sá Neto

Gladis Maria de Barcellos Almeida

Igor José de Renó Machado (Presidente)

Larissa Pires de Andrade

Maria Leonor Ribeiro Casimiro Lopes Assad

Odete Rocha

Piero de Camargo Leirner

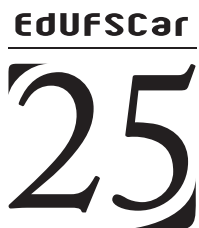

$\frac{\mathrm{A} \mathrm{N} \mathrm{O}}{\text { DESDE } 1993}$

UNIVERSIDADE FEDERAL DE SÃO CARLOS

Editora da Universidade Federal de São Carlos

Via Washington Luís, km 235

13565-905 - São Carlos, SP, Brasil

Telefax (16) 3351-8137

www.edufscar.com.br

edufscar@ufscar.br

Twitter: @EdUFSCar

Facebook: @editora.edufscar 


\section{APLICAÇÕES DE QUÍMICA TEÓRICA NO ESTUDO DE MATERIAIS}

métodos in silico para nanomateriais

Luiz Carlos Gomide Freitas

Guedmiller Souza de Oliveira

(Organizadores) 
(C) 2018 , dos autores

\section{Capa}

Renan Alcantara

\section{Projeto gráfico}

Vitor Massola Gonzales Lopes

Preparação e revisão de texto

Marcelo Dias Saes Peres

Daniela Silva Guanais Costa

Vivian dos Anjos Martins

\section{Editoração eletrônica}

Walklenguer Oliveira

Bianca Brauer

\section{Coordenadoria de administração, finanças e contratos}

Fernanda do Nascimento

Apoio

FAPESP

Processo no 2017/15292-8, Fundação de Amparo à Pesquisa do Estado de São Paulo (FAPESP). As opiniões, hipóteses e conclusões ou recomendações expressas neste material são de responsabilidade dos autores e não necessariamente refletem a visão da FAPESP.

Ficha catalográfica elaborada pelo DePT da Biblioteca Comunitária da UFSCar

Freitas, Luiz Carlos Gomide.

Aplicações de química teórica no estudo de materiais : métodos in silico para nanomateriais / Luiz Carlos Gomide Freitas, Guedmiller Souza de 01 iveira. -- São Carlos : EdUFSCar, 2018.

$244 \mathrm{p}$.

ISBN - 978-85-7600-500-1

1. Físico-química. 2. Métodos computacionais. 3.

Química quântica. 4. Dinâmica molecular. 5. Nanomateriais

I. Título.

$$
\begin{aligned}
& \text { CDD }-541 \quad\left(20^{\mathrm{a}}\right) \\
& \operatorname{CDU}-541.1
\end{aligned}
$$

Todos os direitos reservados. Nenhuma parte desta obra pode ser reproduzida ou transmitida por qualquer forma e/ou quaisquer meios (eletrônicos ou mecânicos, incluindo fotocópia e gravação) ou arquivada em qualquer sistema de banco de dados sem permissão escrita do titular do direito autoral. 


\section{SUMÁRIO}

\section{PREFÁCIO 9}

\section{DINÂMICA MOLECULAR DE BORN-OPPENHEIMER: METODOLOGIA E}

APLICAÇÕES EM MECANISMOS E SELETIVIDADES DE REAÇÕES QUÍMICAS 13

Miguel Angelo F. de Souza e Ricardo L. Longo

1.1 INTRODUÇÃO 15

1.2 BREVE INTRODUÇÃO À METODOLOGIA BOMD 16

1.2.1 Integrando as equações de movimento 18

1.2.2 Algoritmo predictor-corrector com base na aproximação harmônica local 18

1.2.3 Comparações entre algoritmos de propagação 21

1.3 Selecionando a superfície de energia POTEnCial 23

1.3.1 Métodos de estrutura eletrônica 24

1.3.2 Métodos pós-HF 25

1.3.3 Métodos alternativos 26

1.3.4 Métodos para simulação de trajetórias quase clássicas em dinâmica direta 28

1.3.5 Condições iniciais das trajetórias 30

1.3.6 Reações unimoleculares 31

1.3.7 Reações bimoleculares 34

1.3.8 Amostragem a partir do estado de transição (TS) 35

1.3.9 Crítica à literatura: dinâmica ab initio 37

1.3.10 Comparações com a dinâmica quântica: limitações da BOMD 38

1.3.11 Programas para simulações BOMD 38

1.4 EXPLORANDO MECANISMOS E SELETIVIDADES DE REAÇõES QUÍMICAS 39

1.4.1 Reação de desidratação do álcool pinacolílico protonado: mecanismo dirigido pela dinâmica 41

1.4.2 Resultados da superfície de energia potencial 42

1.4.3 Resultados das simulações de BOMD 42

1.4.4 Comportamento estático versus dinâmico 47 
1.4.5 A reação $\mathrm{CH}_{3} \mathrm{ONO}_{2}+\mathrm{OH}^{-}$: seletividade dirigida pela dinâmica 48

1.4.6 Resultados da superfície de energia potencial combinados com cálculos RRKM 50

1.4.7 Resultados das simulações BOMD 51

1.4.8 Comportamento fora das condições estatísticas na reação $\mathrm{CH}_{3} \mathrm{ONO}_{2}+\mathrm{OH}^{-} \quad 55$

1.4.9 Conclusão e perspectivas 55

REFERÊNCIAS 56

\section{ALGORITMOS PARA 0 MÉTODO MONTE CARLO QUÂNTICO: 0 AJUSTE VARIACIONAL 63}

Rogério Custodio

2.1 INTRODUÇÃ̃ 65

2.2 DesCRIÇÃO GERAL DO MCV 67

2.3 Utilizando o Algoritmo de Metropolis 70

2.4 DeFININDO A Função DE ONDA TENTATIVA 73

2.5 Construindo determinantes de SLATER 76

2.6 FunçõES DE CORRELAÇ̃̃o EXPLÍCITAS 78

2.7 EXPRESSÕES PARA 0 CÁLCULO DA ENERGIA CINÉTICA 80

2.80 GRADiente E 0 LAPLACIANO DE UM DETERMINANTE DE SLATER 84

2.9 MÉTOdOS DE OTIMIZAÇÃO DE PARÂMETROS DAS FUNÇõES DE ONDA 86

2.10 Perspectivas e aplicações do MCV 90

REFERÊNCIAS 93

\section{ESTUDO DE ESTRUTURA DE LÍQUIDOS PELO MÉTODO EPSR 99}

João Manuel Marques Cordeiro

3.1 InTRoduÇ̃̃o 101

3.2 Empirical Potential Structure Refinement 103

3.3 EPSR EM N-METLFORMAMIDA 107

3.4 EPSR Na MISTURA N-METLFORMAMIDA-DIMETILSULFóXIDO 111

3.5 CONCLUSÃO E PERSPECTIVAS 115

REFERÊNCIAS 115

\section{DESENVOLVIMENTO DE NANODISPOSITIVOS BASEADOS EM BIOMOLÉCULAS:} ABORDAGENS COMPUTACIONAIS 117

Eduardo de Faria Franca, Guedmiller Souza de Oliveira, Jéssica Cristiane Magalhães lerich, Ana Carolina Araújo Vig, Caroline P. Brandini, Ariana de Souza Moraes e Fábio de Lima Leite

4.1 INTRODUÇ̃̃O 119

4.2 NANOBIOSSENSORES E APLICABILIDADE 120

4.2.1 Microscopia de tunelamento 120

4.2.2 Microscopia de força atômica 122

4.2.3 Desenvolvimento de nanobiossensores: imobilização de biomoléculas em nanossuperfícies 124 
4.2.4 Técnicas computacionais aplicadas ao estudo e à representação de compostos

imobilizados 124

4.2.5 Modelagem por homologia 127

4.2.6 Docking molecular 134

4.2.7 Dinâmica molecular 137

4.2.8 Cálculos híbridos de mecânica quântica e mecânica molecular 138

4.2.9 Steered Molecular Dynamics (SMD) 140

4.3 APLICAÇÃO DAS TÉCNICAS COMPUTACIONAIS NOS ESTUDOS DE MICROSCOPIA DE FORÇA ATÔMICA E PANORAMA ATUAL DAS PESQUISAS 142

4.4 CONSIDERAÇ̃̃ES FINAIS 145

REFERÊNCIAS 146

\section{MODELAGEM COMPUTACIONAL DE LÍQUIDOS IÔNICOS 157}

Luciano T. Costa e Eudes Eterno Fileti

5.1 INTRODUÇÃO 159

5.2 Metodologias COMPUTACIONAIS 161

5.3 DinÂMICA MOLECULAR ATOMÍSTICA 162

5.4 CÁlCULO DE PROPRIEDADES 163

5.4.1 Estruturais 163

5.4.2 Dinâmicas 165

5.5 DinÂMICA MOLECULAR COARSE-GRAINED 169

5.6 MODELAGEM DE LÍQUIDOS IÔNICOS: APLICAÇÕES 170

5.6.1 Solvatação em líquidos iônicos 170

5.6.2 Captura e separação de gases 173

5.7 CONSIDERAÇõES FINAIS 178

REFERÊNCIAS 179

\section{ESTUDO COMPUTACIONAL DE NANOTUBOS DE $\left[\left(\mathrm{SnO}_{2}\right)_{\mathrm{n}}\right]_{\mathrm{m}} 185$}

José Divino Santos e Júnio César Fonseca Silva

6.1 INTRODUÇ̃̃o 187

6.2 Metodologia e métodos 188

6.3 ANálISES DE RESULTADOS E DISCUSSÕES 198

6.4 ConCLUSÃO 224

REFERÊNCIAS 225

7 SIMULAÇÃO POR DINÂMICA MOLECULAR DA ENZIMA CRUZAÍNA DO TRYPANOSOMA CRUZI 227

Osmair Vital de Oliveira

7.1 INTRODUÇÃO 229

7.2 Doença de Chagas 230

7.3 Protocolo de diNÂMICA MOLECULAR 233 
7.4 ANÁLISES DE DINÂMICA MOLECULAR 235

7.4.1 Análise estrutural 235

7.4.2 Ligações de hidrogênio 238

7.4.3 Análise do sítio ativo 239

7.4.4 Geração de ensemble docking 240

7.5 CoNSIDERAÇõ̃E FINAIS 241

REFERÊNCIAS 242 


\title{
Prefácio
}

Na próxima década, em 2029, completará um século a famosa afirmação de Paul Adrien Maurice Dirac:

\begin{abstract}
As leis físicas subjacentes à teoria matemática de uma larga parte da Física e de toda a Química são, portanto, completamente conhecidas, sendo a única dificuldade o fato de a aplicação destas leis conduzir a equações demasiado complicadas para serem resolvidas. É por isso desejável desenvolver métodos práticos de aplicação da mecânica quântica que ofereçam uma explicação das principais características dos sistemas atômicos complexos sem recorrer a muitos cálculos.
\end{abstract}

Existe um forte cunho reducionista nesta afirmação, mas é instigante refletir se, ao proclamá-la, Dirac não considerava também o desenvolvimento da Mecânica Estatística e suas correlações com a Termodinâmica. Cabe ressaltar que, à época, além dos sucessos obtidos com a espectroscopia atômica, eram conhecidas as contribuições seminais de Walter Heitler e Fritz London ${ }^{1}$ sobre a estrutura e estabilidade da molécula de $\mathrm{H} 2$ e o trabalho de Max Born e Robert Oppenheimer, "On the quantum theory of molecules", apresentando uma aproximação geral para explorar o estado quântico de moléculas. Outra contribuição importante, de Max Born, "Volume and heat of hydration of ions", evidenciava a potencialidade de modelos híbridos, atomístico e contínuo dielétrico para calcular propriedades termodinâmicas. Ainda no limiar da

1 Heitler, W.; London, F. Interaction of neutral atoms and homopolar binding by quantum mechanics. Zeitschrift für Physik, n. 44, p. 455-472, 1927.

2 Born, M.; Oppenheimer, R. On the quantum theory of molecules. Ann. Phys., n. 84, p. 457, 1927.

3 Born, M. Volume and heat of hydration of ions. Zeitschrift für Physik, n. 1, p. 45-48, 1920. 
primeira metade do século XX, obras importantes, tais como as de Linus Pauling ${ }^{4}$ e de Charles Coulson, ${ }^{5}$ descortinaram horizontes conceituais para correlacionar ligação química e processos moleculares. Estes avanços iniciais, somados à argúcia e precisão reveladas nos trabalhos de Paul Dirac, contribuíram para que a afirmação fosse aceita com certa naturalidade.

O histórico do "é desejável desenvolver métodos práticos de aplicação", preconizado por Paul Dirac, é constituído por inúmeros avanços que, acrescidos das facilidades advindas dos computadores, estabelecem na atualidade um amplo cenário de potencialidades para a investigação de sistemas moleculares complexos agrupados na terminologia "métodos para simulação computacional". Com estas metodologias, utilizando parâmetros semiempíricos e/ou ab initio, experimentos in silico podem ser realizados. Partes significativas destes avanços foram reconhecidas com outorgas da premiação Nobel para desenvolvedores de conceitos e métodos em Química Teórica: Linus Pauling (1954); Kenechi Fukui e Roald Hoffmann (1981); John Pople e Walter Kohn (1998); Arieh Warshel, Martin Karplus, Michael Levitt (2013). Utilizando os conceitos e metodologias, estudos diversos têm sido realizados com sucesso, evidenciando a contribuição da Química Teórica para a abordagem atomística de problemas básicos e tecnológicos.

Este livro apresenta aplicações de métodos de Química Teórica na investigação de sistemas físico-químicos complexos, enfatizando estudos em ciências de materiais, sistemas biológicos etc. Métodos quânticos e clássicos já "tradicionais", bem como a formulação de métodos híbridos que incorporam abordagens clássica e quântica, são discutidos. Os capítulos foram escritos por pesquisadores da área, formulados com redação independente, compondo um amplo espectro de aplicações. É uma pequena amostragem da diversidade e fecundidade alcançadas pela Química Teórica no país.

No cenário atual, que agrega disponibilidade de métodos e recursos computacionais, um novo desafio pode ser proposto para os pesquisadores brasileiros: dado a expertise da Química Teórica na compreensão do comportamento da matéria, como utilizá-la em projetos visando agregação de valor, buscando diminuir a histórica dependência econômica do país com relação à exportação de produtos primários?

Esta questão remete a uma reflexão profunda sobre objetivos da pesquisa, a colaboração entre pesquisadores e a interface com projetos tecnológicos. Uma tarefa complexa, mas que possui paralelos significativos com empreendimentos que obtiveram sucesso em outras nações. Esperamos que o conteúdo apresentado neste livro contribua para estas reflexões.

Nesta perspectiva, ensejamos que no aniversário de um século da afirmação de Paul A. M. Dirac, pesquisadores brasileiros possam elencar contribuições de pesquisas envolvendo Química Teórica para o avanço do Índice de Desenvolvimento Humano (IDH) deste país.

4 The nature of chemical bond, 1939.

5 Valence, 1952 
Será uma grande homenagem à afirmação de Paul A. M. Dirac, que, além de uma síntese científica genial, antecipou, com raro otimismo, potencialidades da Química Teórica na investigação de propriedades da matéria.

Luiz Carlos Gomide Freitas 


\section{DINÂMICA MOLECULAR DE BORN-OPPENHEIMER}

metodologia e aplicações em mecanismos e seletividades de reações químicas

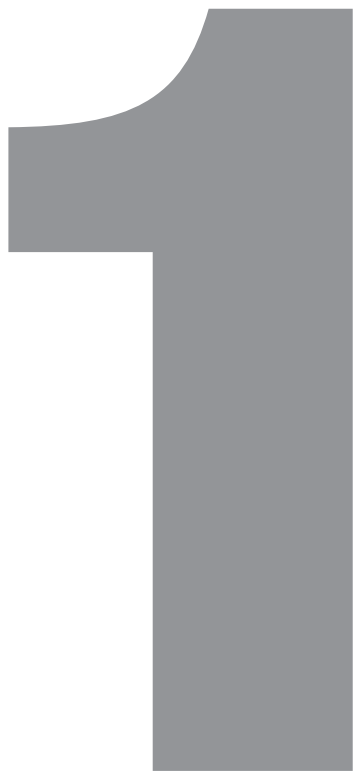

Miguel Angelo F. de Souza ${ }^{1}$ e Ricardo L. Longo²

\footnotetext{
1 Departamento de Química Fundamental da Universidade Federal de Pernambuco (UFPE), Recife-PE. Instituto de Química da Universidade Federal do Rio Grande do Norte (UFRN), Natal-RN. E-mail: <migranthy@yahoo.com.br>.

2 Departamento de Química Fundamental da UFPE. E-mail: <longo@ufpe.br>.
} 


\subsection{INTRODUÇ̃̃̃ $0^{3}$}

Nas duas últimas décadas, os aprimoramentos do desempenho computacional e os desenvolvimentos de algoritmos e métodos eficientes tornaram possíveis as investigações computacionais dos mecanismos de reações com métodos de dinâmica molecular direta ou on the fly, também denominada dinâmica molecular de Born-Oppenheimer. ${ }^{4}$ Essa área está alcançando grande importância e relevância em química teórica/computacional, pois permite interpretar e prever mecanismos e seletividades de reações químicas em escala atômico-molecular, fornecendo, por exemplo, informações inacessíveis ou muito difíceis de serem obtidas experimentalmente, bem como tem facilitado a interpretação de experimentos de dinâmica de reações.

De fato, a dinâmica direta tem sido utilizada em vários estudos para interpretar resultados experimentais de espalhamentos reativos e, assim, descobrir novos mecanismos de reações ${ }^{5}$ e racionalizar as seletividades que apresentam controles não convencionais. ${ }^{6}$ Mais amplamente, esses métodos têm facilitado a compreensão das dinâmicas de reações químicas, o que está permitindo mostrar as limitações de teorias consagradas, como a teoria do estado de transição (TST, do inglês Transition State Theory) e a teoria RRKM, ${ }^{7}$ e da aproximação estática, como a coordenada de reação intrínseca (IRC, do inglês Intrinsic Reaction Coordinate). ${ }^{8}$

Duas aproximações de dinâmica molecular direta se destacam nos estudos de reações químicas, a saber: a dinâmica molecular de Born-Oppenheimer (BOMD,

\footnotetext{
3 Os autores agradecem às agências de fomento CNPq, CAPES, FACEPE e Finep, além do inct-InAmi e Pronex-FaCEPe-CNPq (APQ-0859-1.06/08), pelos auxílios financeiros, aos CENAPAD-PE e CENAPAD-CE pela disponibilidade computacional, assim como ao Departamento de Química Fundamental da UFPE pelo ambiente de trabalho.

4 Paranjothy et al. (2012).

5 Mikosch et al. (2008).

6 Manikandan, Zhang e Hase (2012).

7 Rehbein e Carpenter (2011), Bachrach (2007), Carpenter (1992, 1998, 2005), Hase (1994).

8 Ammal et al. (2003), Sun, Song e Hase (2002).
} 
do inglês Born-Oppenheimer Molecular Dynamics $)^{9}$ e a dinâmica molecular de Car-Parrinello (CPMD, do inglês Car-Parrinello Molecular Dynamics). ${ }^{10}$ As simulações realizadas com BOMD são semelhantes às de dinâmica molecular clássica tradicional, exceto pela necessidade de cálculos quânticos da estrutura eletrônica. Nessa dinâmica, em cada passo de integração da trajetória, a energia potencial, seu gradiente (primeira derivada) e, às vezes, até sua hessiana (segunda derivada) são calculados com métodos de estrutura eletrônica. Já na CPMD, equações de movimento fictícias para os orbitais moleculares (ou os orbitais de Kohn-Sham) são propagadas simultaneamente com as equações de movimento clássicas para os núcleos.

As vantagens e desvantagens da propagação de trajetórias usando as técnicas BOMD e CPMD são ainda tema de investigação da comunidade científica especializada. ${ }^{11}$ No entanto, a desvantagem principal do método CPMD, já relatada na literatura, está relacionada ao fato de um possível fluxo de energia a partir das coordenadas nucleares para os graus de liberdade eletrônicos (fictícios) e vice-versa, ${ }^{12} \mathrm{o}$ que pode levar a resultados não físicos, pois, dentre outros problemas, essas trocas de energia não são quantizadas. Tem sido relatado na literatura que CPMD é mais eficiente computacionalmente que BOMD, ${ }^{13}$ pois, na CPMD, não é necessário recalcular a função de onda em cada passo de integração da trajetória. No entanto, precauções devem ser tomadas quando se buscam resultados precisos e livres de efeitos não físicos com CPMD, pois tem sido mostrado que, geralmente, é necessário tornar a massa fictícia $(\mu)$ associada aos graus de liberdade eletrônicos infinitesimal para obter resultados adequados. ${ }^{14}$ Entretanto, valores muito pequenos de $\mu$ diminuem o passo de integração, o que causa diminuição significativa da eficiência computacional da CPMD, tornando-a semelhante à BOMD.

Neste capítulo, a metodologia BOMD para simular trajetórias quase clássicas será abordada brevemente e aplicada a dois estudos de mecanismos e seletividades de reações químicas. Mais detalhes sobre as metodologias BOMD e CPMD podem ser encontrados em revisões ${ }^{15}$ e capítulos de livros. ${ }^{16}$

\subsection{BREVE INTRODUÇÃO À METODOLOGIA BOMD}

A dinâmica molecular consiste em tratar os movimentos dos núcleos ou dos átomos classicamente, e suas equações de movimento são resolvidas numericamente, fornecendo suas posições e os momentos com o tempo, isto é, a trajetória. Em

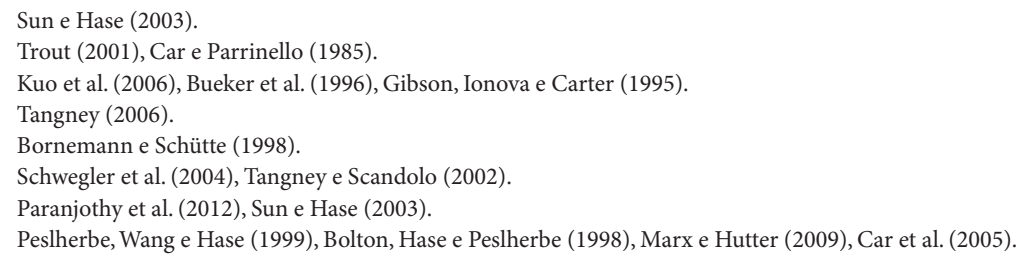


termos matemáticos, isso equivale à resolução das equações de movimento descritas pelas equações de Newton,

$$
m_{i} \frac{\mathrm{d}^{2} q_{i}}{\mathrm{~d} t^{2}}=-\frac{\partial V(q)}{\partial q_{i}}
$$

ou pelas equações de Hamilton,

$$
\frac{\mathrm{d} p_{i}}{\mathrm{~d} t}=-\frac{\partial H}{\partial q_{i}} \text { e } \frac{\mathrm{d} q_{i}}{\mathrm{~d} t}=\frac{\partial H}{\partial p_{i}}
$$

em que $q_{\mathrm{i}}$, $p_{\mathrm{i}}$ e $m_{\mathrm{i}}$ são a coordenada, seu momento conjugado e a massa do átomo $i$, respectivamente; $H$ é a função hamiltoniana dada pela soma da energia cinética e da energia potencial, $V(q)$; e $t$ é a variável tempo.

Em síntese, para resolver as equações de movimento (Equação 1.1 ou 1.2), é necessário responder a três perguntas: (i) como será realizado o procedimento de integração numérica?; (ii) como a energia potencial será calculada?; e (iii) quais serão as condições iniciais do espaço de fase (momento e posição) de cada trajetória? As subseções a seguir discutirão esses assuntos.

As simulações de dinâmica molecular clássicas são comumente conhecidas por aplicações aos sistemas, em que apenas interações descritas por campos de forças entre as partículas (átomos ou grupos de átomos) são suficientes para fornecer várias propriedades de interesse. Por exemplo, propriedades macroscópicas (termodinâmicas) e estruturais podem ser obtidas a partir de simulações atomísticas com base em uma abordagem da mecânica estatística. ${ }^{17}$ No entanto, quando o objetivo é o estudo da dinâmica de reações químicas, é necessária uma descrição quântica que trate adequadamente rearranjos da densidade eletrônica, especialmente aqueles envolvendo a ruptura e a formação de ligações químicas. Na aproximação da dinâmica molecular de Born-Oppenheimer - que é suficiente para se estudar um conjunto amplo de reações térmicas - utiliza-se um método quântico para tratar especificamente a estrutura eletrônica, enquanto a parte nuclear é descrita classicamente. É possível também a utilização de métodos híbridos, como QM/MM (do inglês Quantum Mechanics/ Molecular Mechanics), ${ }^{18}$ ou de extrapolação da energia, como ONIOM, ${ }^{19}$ para estudar reações químicas em fase condensada. Nesses casos, pequenas regiões do sistema associadas à quebra/formação das ligações são tratadas quanticamente, enquanto o restante do sistema e a fase condensada são tratados por campos de força. Portanto, à pergunta do item (ii) acima - como a energia potencial será calculada? - deve-se acrescentar: qual método quântico de estrutura eletrônica será utilizado?

17 Frenkel e Smit (2002), Allen e Tisdesley (1991).

18 Gao (1996).

19 Maseras e Morokuma (1995), Svensson et al. (1996). 


\subsubsection{Integrando as equações de movimento}

Para um dado sistema molecular, o procedimento de integração numérica é comumente realizado em coordenadas cartesianas. Entretanto, é possível realizar esse procedimento nas coordenadas dos modos normais instantâneos. ${ }^{20}$

Independentemente do sistema de coordenadas utilizado, a integração de equações diferenciais, como, por exemplo, a equação 1.1 ou 1.2, é uma área já bem desenvolvida em análise numérica. ${ }^{21}$ Diversos algoritmos são comumente utilizados para integrar numericamente as equações de movimento, por exemplo, Runge-Kutta, Verlet, Adams-Moulton, Gear, predictor-corrector, entre outros. Contudo, tem-se reportado na literatura que a técnica que utiliza o passo de predição e, em seguida, o de correção é um método bastante acurado e pode ser o mais rápido e eficiente, quando conduzido de forma adequada nas coordenadas dos modos normais instantâneos. ${ }^{22}$ De fato, esse esquema tem sido amplamente utilizado em aplicações BOMD nos estudos de diversas reações químicas. ${ }^{23}$ Alguns detalhes do algoritmo predictor-corrector utilizando a aproximação harmônica local serão analisados a seguir. As técnicas associadas à integração numérica utilizando coordenadas cartesianas já estão bem estabelecidas na dinâmica molecular clássica e, portanto, não serão abordadas, pois serão ainda discutidas em outros capítulos deste livro.

\subsubsection{Algoritmo predictor-corrector com base na aproximação harmônica local}

A ideia central da maioria das técnicas de integração numérica que são usadas corriqueiramente em dinâmica molecular direta consiste em ajustar uma superfície modelo na superfície de energia potencial (PES, do inglês Potential Energy Surface), de modo que esta possa ser factível numericamente. Nesse caso, a expansão em série (de potência) de Taylor é utilizada,

$$
f(x)=\sum_{n=0}^{\infty} \frac{f^{(n)}(a)}{n !}(x-a)^{n}
$$

em que $f^{(n)}(a)$ denota a $n$-ésima derivada de $f(x)$ no ponto $a$.

Ao truncar a expansão de Taylor em segunda ordem $(n=2)$, adequando a equação para um sistema molecular genérico e utilizando coordenadas cartesianas (denotadas coletivamente por $q$ ), tem-se a seguinte forma para o potencial:

20 Uggerud e Helgaker (1992), Helgaker, Uggerud e Jensen (1990).

21 Press et al. (1992), Stoer e Bulirsch (1980), Gear (1971).

22 Millam et al. (1999).

23 Paranjothy et al. (2012), Sun e Hase (2003), Peslherbe, Wang e Hase (1999), Bolton, Hase e Peslherbe (1998). 


$$
V(q)=V^{0}+G^{0^{t}} \Delta q+\frac{1}{2} \Delta q^{t} F^{0} \Delta q
$$

em que $V^{0}, G^{0}$ e $F^{0}$ são a energia potencial, o gradiente e a hessiana, respectivamente, na geometria de referência $q^{0} ; \Delta q\left(=q-q^{0}\right)$ são os deslocamentos das coordenadas ao redor dessa geometria; e o sobrescrito $(\ldots)^{t}$ denota a transposta.

Logo, substituindo a Equação 1.4 na Equação 1.1, será obtida a seguinte aproximação para o movimento do $i$-ésimo átomo:

$$
m_{i} \frac{\mathrm{d}^{2} q_{i}}{\mathrm{~d} t^{2}} \cong-\frac{\partial}{\partial q_{i}}\left[V^{0}+G^{0^{t}} \Delta q+\frac{1}{2} \Delta q^{t} F^{0} \Delta q\right]=-G_{i}^{0}-\sum_{j} \mathrm{~F}_{i j}^{0} \Delta q_{j}
$$

Utilizando uma aproximação local harmônica, ou seja, na aproximação das coordenadas dos modos normais instantâneos, as coordenadas cartesianas são transformadas no espaço dos vetores ponderados pela massa, e as equações de movimento aproximadas (1.5) se tornam separáveis, de modo que

$$
\frac{\mathrm{d}^{2} Q_{\alpha}}{\mathrm{d} t^{2}}=-g_{\alpha}-\omega_{\alpha}^{2} Q_{\alpha}
$$

para cada modo normal $\alpha$, em que $Q_{\alpha}$ é correspondente aos deslocamentos dos modos normais, com seus respectivos momentos conjugados $P_{\alpha}$, sendo

$$
\begin{gathered}
Q_{\alpha}=U_{\alpha}^{t} m^{1 / 2} \Delta q \\
g_{\alpha}=U_{\alpha}^{t} m^{1 / 2} G \\
\omega_{\alpha}=U_{\alpha}^{t} m^{1 / 2} \mathrm{Fm}^{1 / 2} U_{\alpha}^{t}=h_{\alpha} \delta_{\alpha \beta}
\end{gathered}
$$

em que $m$ é a matriz diagonal com as massas dos átomos; $U_{\alpha}$ é o autovetor da matriz hessiana; $h_{\alpha}$ é o autovalor correspondente que fornece a frequência angular $\omega_{\alpha}$; e $\delta_{\alpha \beta}$ é o delta de Kronecker.

O conjunto de equações 1.7, 1.8 e 1.9 pode ser resolvido analiticamente, ${ }^{24}$ de modo que as equações de movimento podem ser integradas de acordo com as seguintes condições iniciais: 


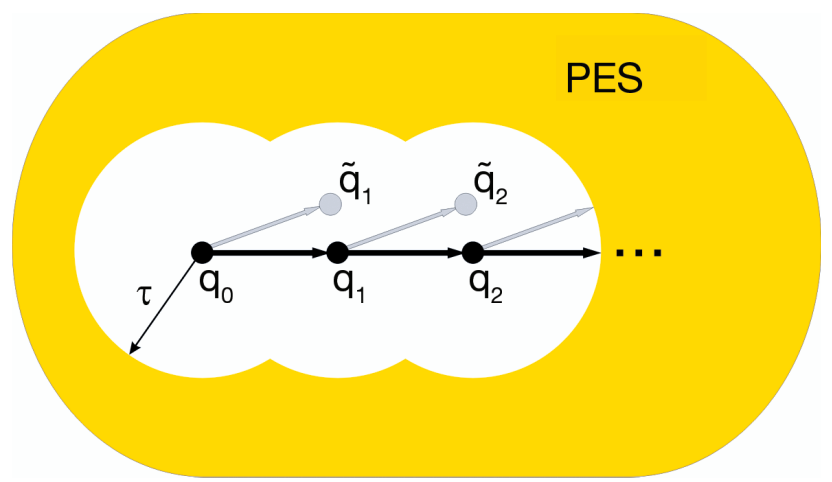

Figura 1.1 Diagrama esquemático do algoritmo predictor-corrector para a integração das equações de movimento em uma trajetória. No passo de predição (seta cinza), a aproximação quadrática é usada no ponto inicial $q_{0}$ para obter o ponto $\tilde{q}_{1}$. Note que esse passo requer um raio de confiança $\tau$. Em seguida, o passo de correção (seta preta) é então realizado na PES, encontrando o ponto $q_{1}$. O procedimento é repetido no novo passo, sendo que o ponto $q_{1}$ é a nova referência para obter $\tilde{q}_{2}$. O procedimento é repetido até o último passo da trajetória.

$$
\begin{array}{ll}
Q_{\alpha}(t)=\frac{P_{\alpha}^{0}}{\omega_{\alpha}} \operatorname{sen}\left(\omega_{\alpha} t\right)-\frac{g_{\alpha}}{\omega_{\alpha}^{2}}\left[1-\cos \left(\omega_{\alpha} t\right)\right] & \omega_{\alpha}>0 \\
Q_{\alpha}(t)=P_{\alpha}^{0} t-\frac{1}{2} g_{\alpha} t^{2} & \omega_{\alpha}=0 \\
Q_{\alpha}(t)=\frac{P_{\alpha}^{0}}{\left|\omega_{\alpha}\right|} \operatorname{senh}\left(\left|\omega_{\alpha}\right| t\right)-\frac{g_{\alpha}}{\left|\omega_{\alpha}\right|^{2}}\left[1-\cosh \left(\left|\omega_{\alpha}\right| t\right)\right. & \omega_{\alpha}<0
\end{array}
$$

e

$$
\begin{array}{ll}
P_{\alpha}^{0}(t)=P_{\alpha}^{0} \cos \left(\omega_{\alpha} t\right)-\frac{g_{\alpha}}{\omega_{\alpha}} \operatorname{sen}\left(\omega_{\alpha} t\right) & \omega_{\alpha}>0 \\
P_{\alpha}^{0}(t)=P_{\alpha}^{0} t-g_{\alpha} t & \omega_{\alpha}=0 \\
P_{\alpha}^{0}(t)=P_{\alpha}^{0} \cosh \left(\left|\omega_{\alpha}\right| t\right)-\frac{g_{\alpha}}{\left|\omega_{\alpha}\right|} \operatorname{senh}\left(\left|\omega_{\alpha}\right| t\right) & \omega_{\alpha}<0
\end{array}
$$

em que $P_{\alpha}{ }^{0}$ é o momento em $t=0$. O procedimento de integração nas coordenadas dos modos normais se torna simples quando os gradientes e as constantes de forças são conhecidos, sendo que para o passo de integração é utilizado o algoritmo predictor-corrector. 
Uma sequência dos passos do algoritmo predictor-corrector está ilustrada na Figura 1.1. Nesta, a primeira etapa é o passo de predição (seta cinza) - nesse passo, a energia potencial, o gradiente e a hessiana são calculados no início $\left(q_{0}\right)$ e no final $\left(\tilde{q}_{1}\right)$. Esses valores são ajustados por uma função polinomial de quarta ou quinta ordem ou por uma função racional, com a finalidade de se obter uma melhor aproximação da PES. Em seguida, ocorre o passo de correção (seta preta, na Figura 1.1), realizado na superfície com o auxílio de um método de integração, como, por exemplo, Bulirsch-Stoer. ${ }^{25}$ Assim, é obtido o ponto corrigido $q_{1}$, que, por sua vez, é agora utilizado como o ponto inicial para o próximo passo de predição $\left(\tilde{q}_{2}\right)$, e o procedimento é então repetido até que o último passo seja alcançado.

Uma das principais vantagens em utilizar coordenadas cartesianas é que a matriz hessiana não é, necessariamente, requerida para o procedimento de integração. Portanto, pergunta-se: qual seria a vantagem de se utilizar a aproximação dos modos normais instantâneos que utiliza a hessiana, sabendo que, em geral, na química quântica, a determinação da hessiana requer elevada demanda computacional (memória RAM e tempo de CPU)? Certamente, a técnica com base na hessiana é mais exata, pois, na aproximação harmônica, o truncamento da série de Taylor é de segunda ordem, e as equações de movimento aproximadas têm soluções analíticas. Além disso, ela pode ser mais rápida e eficiente em alguns casos, pois os passos temporais podem ser maiores e a hessiana pode ser calculada somente após um dado número de passos.

Para qualquer sistema de coordenadas utilizado na dinâmica, a eficiência da integração numérica é limitada, pois um passo pequeno é requerido para manter uma exatidão razoável. Em geral, esse passo é válido somente para uma região pequena ao redor, $q_{0}$ (ilustrativamente, $\tau$, na Figura 1.1, representa o raio de confiança na PES usado no procedimento do passo de integração). Trabalhos descritos na literatura têm demonstrado que a técnica com base na hessiana se torna mais rápida porque o tamanho do passo nas simulações pode ser mais longo, sem comprometer a exatidão dos resultados. Além disso, também tem sido reportado que a matriz hessiana não precisa ser calculada em cada passo, pois, dependendo do sistema, pode-se utilizar a mesma hessiana por vários passos consecutivos da trajetória, o que diminui a demanda computacional, sem comprometer a exatidão. $\mathrm{O}$ número de passos que utiliza a mesma hessiana indica em que intervalo ocorre a sua atualização (do inglês updating the Hessian). ${ }^{26} \mathrm{O}$ acompanhamento da conservação da energia total e do momento angular total é uma forma de verificar se a atualização da hessiana empregada é adequada.

\subsubsection{Comparações entre algoritmos de propagação}

A Tabela 1.1 mostra uma comparação entre os algoritmos de integração usuais, geralmente utilizados na simulação de trajetórias BOMD. As trajetórias

25 Stoer e Bulirsch (1980)

26 Bakken, Millam e Schlegel (1999), Lourderaj et al. (2007). 
simuladas estão associadas à reação de decomposição do formaldeído $\left(\mathrm{H}_{2} \mathrm{CO}\right)$ em di-hidrogênio $\left(\mathrm{H}_{2}\right)$ e monóxido de carbono $(\mathrm{CO})$. As trajetórias são iniciadas na estrutura do estado de transição $\left(\mathrm{H}_{2} \mathrm{CO}^{\ddagger}\right)$ em direção ao produto.

Na Tabela 1.1 apresenta-se o erro médio na energia, durante a integração, e o tempo de CPU requerido para completar a trajetória com os algoritmos de integração: predictor-corrector, velocity-Verlet e Adams-Moulton. Em resumo, o algoritmo predictor-corrector apresenta as melhores relações custo/benefício, ou seja, menor tempo de CPU versus menor erro relativo na energia total durante a trajetória. Para obter o mesmo grau de exatidão, os algoritmos velocity-Verlet e Adams-Moulton requerem três ou quatro vezes mais tempo de CPU quando comparados ao predictor-corrector. Isso ocorre devido ao maior passo temporal utilizado com o algoritmo predictor-corrector, além de ser possível usar um esquema de atualização da Hessiana variando entre cinco e sete passos temporais, sem comprometer a exatidão.

Tabela 1.1 Comparação de integradores com base nos algoritmos predictor-corrector $(\mathrm{p}-\mathrm{c})$, velocity-Verlet (v-V) e Adams-Moulton (A-D) para a reação $\mathrm{H}_{2} \mathrm{CO}^{\ddagger} \rightarrow \mathrm{H}_{2}+\mathrm{CO}$.

\begin{tabular}{|c|c|c|c|c|c|c|c|}
\hline \multirow[b]{2}{*}{ Integrador } & \multirow{2}{*}{$\begin{array}{c}\text { Passo } \\
\text { (fs) }\end{array}$} & \multirow{2}{*}{$\begin{array}{l}R_{c} \\
(\AA)\end{array}$} & \multirow{2}{*}{$\begin{array}{c}\text { Número } \\
\text { de update }\end{array}$} & \multicolumn{2}{|c|}{ Cálculos $^{2}$} & \multirow[b]{2}{*}{$\begin{array}{l}\text { Tempo de } \\
\text { CPU (s) }{ }^{3}\end{array}$} & \multirow{2}{*}{$\begin{array}{c}\text { Energia }^{4} \\
\text { Média do erro (\%) }\end{array}$} \\
\hline & & & & Grad. & Hess. & & \\
\hline \multirow[t]{6}{*}{$\mathrm{p}-\mathrm{c}$} & & 0,20 & 5 & 31 & 6 & 173 & $0,08(3)^{5}$ \\
\hline & & 0,20 & 6 & 29 & 5 & 158 & $0,05(3)$ \\
\hline & & 0,20 & 7 & 29 & 4 & 147 & $0,04(3)$ \\
\hline & & 0,25 & 5 & 27 & 5 & 162 & $0,03(3)$ \\
\hline & & 0,25 & 6 & 27 & 4 & 152 & $0,13(3)$ \\
\hline & & 0,25 & 7 & 25 & 4 & 140 & $0,16(3)$ \\
\hline \multirow[t]{3}{*}{$\mathrm{v}-\mathrm{V}$} & 0,1 & & & 240 & & 730 & $0,01(2)$ \\
\hline & 0,2 & & & 120 & & 374 & $0,3(2)$ \\
\hline & 0,4 & & & 60 & & 204 & $1,2(1)$ \\
\hline \multirow[t]{3}{*}{ A-D } & 0,1 & & & 480 & & 1086 & $0,001(4)$ \\
\hline & 0,2 & & & 240 & & 618 & $0,04(3)$ \\
\hline & 0,4 & & & 120 & & 379 & $1,15(1)$ \\
\hline
\end{tabular}

1) Número de atualizações (updates) da hessiana entre os passos da trajetória. 2) Número total de cálculos com o método $\mathrm{HF} / 6-31+\mathrm{G}(\mathrm{d}, \mathrm{p})$, em que os gradientes (grad.) são calculados em cada passo e as hessianas (hess.) estão correlacionadas com o número de atualizações (updates). 3) Tempo de CPU para uma trajetória. 4) Energia total de 17,918 kcal mol ${ }^{-1}$. 5) Número de casas decimais obtido na conservação da energia total, durante a trajetória.

Fonte: adaptada de Lourderaj et al. ${ }^{27}$ 


\subsection{Selecionando a SuPerfície de enerGia POTENCIAL}

Desde o início da década de 1960, simulações de trajetórias clássicas têm sido usadas em estudos da dinâmica de reações químicas. ${ }^{28}$ Tradicionalmente, as simulações das trajetórias com a finalidade de estudar a dinâmica de reações químicas são computadas em PES analíticas predefinidas. ${ }^{29}$ Nessa metodologia, as PES são construídas por funções analíticas empíricas ou, principalmente, por meio de ajustes das energias obtidas com métodos de estrutura eletrônica. Nesse caso, a vantagem principal é que as derivadas do potencial (gradiente e hessiana) são obtidas prontamente. Entretanto, a obtenção de bons resultados se relaciona geralmente com a construção de uma PES com um número muito grande de pontos (dezenas de milhares) e com o ajuste adequado. ${ }^{30}$

Para sistemas reacionais pequenos (com três ou quatro átomos), os resultados da dinâmica obtidos com as PES analíticas se mostram satisfatórios, porém um problema intrínseco surge para sistemas com vários graus de liberdade em razão do significativo aumento do número de cálculos necessários e das variedades topológicas das PES. Na maioria das vezes, deve-se fazer uma separação entre graus de liberdade críticos e não críticos, ou seja, a PES analítica é agora construída a partir de poucas coordenadas escolhidas como as mais importantes entre muitas outras. No entanto, em muitas reações, essa seleção pode ser ambígua e não satisfatória, limitando, assim, o uso dessa metodologia.

Com o aumento da velocidade dos computadores e o aprimoramento e desenvolvimento de novos algoritmos, tornou-se possível o uso dos métodos de estrutura eletrônica diretamente nas simulações de trajetórias clássicas, sem a necessidade de uma construção prévia da PES e, melhor, sem eleger graus de liberdade críticos e realizar ajustes extremamente complexos de superfícies multidimensionais com dezenas de milhares de pontos. Nessa metodologia, as trajetórias são integradas "on the fly" ou "em voo" (durante o movimento), quer dizer, a energia potencial e suas derivadas são obtidas em cada passo da trajetória. Esse tipo de método é conhecido pelo termo "dinâmica direta" ou "on the fly" e foi usado pela primeira vez em 1973, no estudo da reação $\mathrm{CH}_{2}+\mathrm{H}_{2} \rightarrow \mathrm{CH}_{4} \cdot{ }^{31}$

De fato, essa mudança na forma de se obterem as informações da PES nas simulações de trajetórias da dinâmica direta representou talvez o passo mais importante na difusão e popularização dessa técnica na química computacional, a partir de meados de 1990. Com a dinâmica direta, as possíveis diferenças entre os resultados dinâmicos e experimentais não podem necessariamente ser atribuídas à construção inadequada da PES analítica. Atualmente, um dos problemas reside na limitação da exatidão de alguns métodos quânticos.

28 Bunker (1962, 1971), Blais e Bunker (1962).

29 Hirst (1985).

30 Gargano (2003), Murrell et al. (1984).

31 Wang e Karplus (1973). 


\subsubsection{Métodos de estrutura eletrônica}

O objetivo central dos métodos de estrutura eletrônica é obter as soluções da equação de Schrödinger eletrônica (equação 1.12) para determinar, com adequada exatidão, as propriedades de sistemas moleculares, dentro da separação de Born-Oppenheimer:

$$
\hat{\mathrm{H}} \Psi=E \Psi
$$

em que $\hat{H}$ é a parte eletrônica do operador hamiltoniano molecular; $\Psi$ é a função de onda eletrônica; e $E$ é a energia eletrônica.

Geralmente, a solução exata não é factível, tornando necessária a utilização de métodos aproximados. Entre os diversos métodos que podem ser utilizados, o método Hartree-Fock (HF) é o mais popular. Tal método também é conhecido como aproximação do campo médio autoconsistente, termo este que identifica a aproximação principal (campo médio) e o procedimento computacional (autoconsistente). Além de ser capaz de fornecer uma boa solução aproximada (com fins mais qualitativos que quantitativos) para os problemas de muitos elétrons, o método HF tem a vantagem de servir como ponto de partida para outros métodos mais acurados. Esta última característica é a utilidade principal desse método atualmente: seja, por um lado, para métodos semiempíricos - em que são incluídas aproximações adicionais, com o propósito de diminuir a demanda computacional - ou, por outro lado, para os métodos ab initio (pós-HF) - os quais acrescem correções à solução HF, com o intuito de se aproximar da solução exata.

A limitação principal do método HF está no fato de aproximar a função de onda eletrônica por um único determinante de Slater, o que leva ao tratamento do potencial de interação elétron-elétron por um potencial médio efetivo, em que cada elétron interage com o campo médio gerado pelos outros elétrons.

A diferença entre a energia exata não relativística $\left(E_{\text {exata }}\right)$ e a energia $\mathrm{HF}\left(E_{\mathrm{HF}}\right)$ é denominada energia de correlação eletrônica $\left(E_{\text {corr }}\right)$ :

$$
E_{\text {corr }}=E_{\text {exata }}-E_{H F}
$$

Esta é a principal meta dos métodos pós-HF: resgatar ao máximo a $E_{\text {corr }}$.

A seguir, será feita uma breve discussão sobre os métodos de estrutura eletrônica usuais na química computacional, apontando alguns aspectos positivos e negativos sobre cada classe de métodos. Existe uma quantidade enorme de livros (introdutórios ou avançados) que apresentam os métodos de estrutura eletrônica, ${ }^{32}$ assim como há diversas referências (livros, capítulos de livro e artigos) contidas nesses mesmos livros. Obviamente, estes são mais indicados para uma compreensão mais aprofundada sobre os métodos de estrutura eletrônica.

32 Morgon e Coutinho (2008), Jensen (2007), Dykstra et al. (2005), Cramer (2004), Szabo e Ostlund (1989). 


\subsubsection{Métodos pós-HF}

Dois esquemas têm dominado os cálculos pós-HF. De um lado, métodos que usam a combinação linear de determinantes de Slater (configurações), como interação de configurações (CI, do inglês Configuration Interaction), e os métodos do campo autoconsistente com múltiplos determinantes (MCSCF, do inglês Multi-Configurational Self-Consistent Field, e CASSCF, do inglês Complete Active Space $S C F)$; de outro lado estão os métodos de muitos corpos, como a teoria de perturbação (MPn, com $n=2,3$, 4 etc.) e o coupled-cluster (CC). Os primeiros são métodos variacionais, mas não extensivos, e, basicamente, a função de onda $(\mathrm{Y})$ destes pode ser escrita da seguinte forma:

$$
\Psi=\sum_{I}^{N_{\text {conf }}} c_{I} \Phi_{I}=c_{1} \Phi_{1}+c_{2} \Phi_{2}+c_{3} \Phi_{3}+\ldots+c_{N_{\text {conf }}} \Phi_{N_{\text {conf }}}
$$

em que $c_{I}$ é o coeficiente associado à configuração $\Phi_{I}$. A soma é feita sobre as $N_{\text {conf }}$ configurações (excitações) de um estado de referência $\Phi_{0}$, as quais normalmente são escritas por combinações lineares de determinante de Slater. O determinante HF, em geral, é utilizado como a $\left(\Phi_{0}\right)$ referência para a expansão.

A diferença principal entre CI e MCSCF (ou CASSCF) está na determinação variacional dos coeficientes. Na expansão CI, apenas os coeficientes das configurações $\Phi_{I}$ são determinados de maneira variacional, enquanto no MCSCF (ou CASS$\mathrm{CF}$ ), além destes, os coeficientes dos próprios orbitais são também otimizados. Por isso, para fins práticos, o número de determinantes utilizados no método MCSCF (ou CASSCF) deve ser muito menor que no método CI.

Diferentemente, os métodos de muitos corpos não são variacionais, mas são extensivos e apresentam construções bem distintas. O método de perturbação consiste em separar o operador hamiltoniano em uma primeira parte, que possui autofunções conhecidas, e uma parte restante, denominada perturbação. O sucesso desse método está na partição do hamiltoniano tal que a perturbação seja pequena, ou seja, a solução exata seja próxima da solução não perturbada (mas nem sempre isso é possível), de modo que a representação matemática básica é expressa por:

$$
\begin{gathered}
\hat{\mathrm{H}}=\hat{\mathrm{H}}^{(0)}+\lambda V \\
E_{0}=E_{0}^{(0)}+\lambda E_{0}^{(1)}+\lambda^{2} E_{0}^{(2)}+\ldots \\
\Psi_{0}=\Phi_{0}^{(0)}+\lambda \Phi_{0}^{(1)}+\lambda^{2} \Phi_{0}^{(2)}+\ldots
\end{gathered}
$$

em que $\lambda$ é o parâmetro de ordem introduzido para ordenar as correções na energia e na função de onda; $\hat{H}(0)$ é o hamiltoniano de referência (não perturbado); e $V$ é a perturbação. O método perturbativo mais aplicado na química quântica é o Møller-Plessett (MP), em que $\hat{\mathrm{H}}(0)$ é o operador de Fock. Pode-se demonstrar que, para essa partição MP, a correção de primeira ordem é justamente a energia obtida pelo 
método HF, isto é, a energia HF é correta até segunda ordem. Daí, então, tem-se a nomenclatura dos níveis de cálculo da metodologia MPn: MP2, correção de segunda ordem; MP3, correção de terceira ordem; e assim sucessivamente.

O método CC consiste em tratar o sistema com muitos elétrons, separando-os em vários aglomerados (cluster) com poucos elétrons. Basicamente, calculam-se as interações entre os vários elétrons de um mesmo aglomerado e depois entre aglomerados diferentes. O mecanismo matemático que permite essa abordagem é escrever a função de onda coupled-cluster como:

$$
\begin{gathered}
\Psi=e^{T} \Phi_{0} \\
T=T_{1}+T_{2}+T_{3}+\ldots+T_{p} \\
e^{-T} \hat{\mathrm{H}} e^{T} \Psi=E \Psi
\end{gathered}
$$

em que $T$ é denominado operador de cluster e, como mostrado, pode ser escrito em termos dos operadores de substituição simples $\left(T_{1}\right)$ - S, duplas $\left(T_{2}\right)-\mathrm{D}$, triplas $\left(T_{3}\right)$ - T, até $T_{p}$, sendo $p$ o número de elétrons correlacionados. Isso dá origem à seguinte hierarquia, em direção à solução exata: CCS, CCSD, CCSDT, CCSDTQ, e assim sucessivamente. Dada a relação custo/exatidão, o método $\operatorname{CCSD}(\mathrm{T})$ é considerado o estado da arte em estrutura eletrônica de moléculas no estado fundamental.

Além das características computacionais, os métodos de muitos corpos (CC e MP) são extensivos, enquanto os métodos CI e MCSCF (ou CASSCF) não são extensivos. Tem sido reportado na literatura que a falta de extensividade desses métodos pode ser uma limitação importante para sua exatidão.

Por fim, os métodos CI, MP e CC podem ser combinados com uma referência de múltiplos determinantes (MR), gerando, respectivamente, os métodos MRCI (do inglês Multi-Reference Configuration Interaction), MRMP (do inglês Multi-Reference Møller-Plessett) e MRCC (do inglês Multi-Reference Coupled-Cluster). Esses métodos apresentam demanda computacional tão elevada que são praticáveis apenas para sistemas pequenos; no entanto, são, sem dúvida, os métodos mais acurados, principalmente para descrever estados excitados e quebra/formação de ligações.

\subsubsection{Métodos alternativos}

Outras opções de menor custo computacional, comparativamente com os métodos pós-HF, são os métodos de funcionais da densidade e os métodos semiempíricos (estes são muito mais rápidos).

A demanda computacional (tempo de CPU, memória RAM e armazenamento de disco rígido HD) dos cálculos HF tradicionais depende da potência de quarta ordem $\left(\sim M^{4}\right)$ do número de funções de bases $(M)$. Para comparação, o método pós-HF com menor demanda computacional (MP2) tem dependência aproximada de $M^{5}$. Nos métodos semiempíricos, o custo computacional é diminuído pela redução 
do número de integrais. Essa redução é consequência de dois aspectos principais: (i) descrição apenas dos elétrons de valência, com a utilização de base mínima (STO, do inglês Slater Type-Orbitals); e (ii) desprezo das integrais que envolvem produtos entre funções de base em átomos diferentes. Para corrigir essas aproximações (severas), os métodos semiempíricos utilizam parâmetros em suas equações que são ajustados para reproduzir as propriedades moleculares (geometria, entalpia de formação, energia de ionização, momento dipolar, energia de excitação, força de oscilador etc.) de um conjunto de dados experimentais e/ou computacionais.

Os métodos semiempíricos podem ser divididos de acordo com a abordagem teórica, a aplicação da aproximação ZDO (do inglês Zero Differential Overlap), as expressões utilizadas no cálculo das diversas integrais e, por fim, o procedimento de parametrização. A história dos métodos semiempíricos é bastante extensa e acompanha o surgimento da química computacional. Dessa longa história, um número grande de métodos foi criado, porém alguns poucos métodos têm uso difundido atualmente, destacando-se: AM1 (Austin Model 1), PM3 (Parameterized Model Number 3), PM6 (Parameterized Model Number 6) e RM1 (Recife Model 1), para estruturas moleculares e termoquímica de reações; e ZINDO (Zerner's Intermediate Neglect of Differential Overlap), para propriedades espectroscópicas. ${ }^{33}$

O intuito principal de vários métodos semiempíricos é calcular com exatidão adequada diversas propriedades (geometria, entalpia de formação, momento de dipolo etc.) de mínimos locais (reagentes e produtos); entretanto, a caracterização de outros pontos da PES, por exemplo, estados de transição e espécies transientes, pode não ser confiável. Nesses casos, comparações com resultados de métodos ab initio são indispensáveis.

Outra metodologia alternativa que tem aplicação ampla na química computacional são os métodos com base na teoria do funcional da densidade (DFT, do inglês Density Functional Theory). Contrastando com os métodos que procuram aproximações cada vez mais próximas da função de onda exata (todos aqueles pós-HF, além de outros tais como métodos com base na teoria da ligação de valência, em Monte Carlo quântico etc.), a DFT é fundamentada nos teoremas de Hohenberg-Kohn, em que as propriedades moleculares do estado fundamental são determinadas pela densidade eletrônica. Entretanto, o funcional universal da densidade é desconhecido, e, portanto, modelos aproximados são utilizados. A implementação mais utilizada da DFT é a proposta por Kohn e Sham, que descreve o funcional da energia, $E_{\mathrm{KS}}[\rho]$ de um sistema multieletrônico como:

$$
E_{\mathrm{KS}}[\rho]=T_{S}[\rho]+E_{e e}[\rho]+E_{X C}[\rho]
$$

em que $T_{s}[\rho]$ é o funcional da energia cinética de elétrons não interagentes com a mesma densidade $\rho$ do sistema real; $E_{e e}[\rho]$ é o funcional da energia eletrostática; e $E_{X C}[\rho]$ é o funcional da energia de troca-correlação, que inclui, ainda, correções da

33 Morgon e Coutinho (2008), Jensen (2007). 
energia cinética para elétrons interagentes. De fato, este termo, $E_{X C}[\rho]$, é o que diferencia os diversos tipos de métodos DFT. Aproximações como a da densidade local (LDA ou LSD, do inglês Local Density Approximation ou Local Spin Density), a de gradiente generalizado (GGA, do inglês Generalized Gradient Approximation), a conexão adiabática e as parametrizações utilizando dados experimentais podem ser combinadas para tratar o termo $E_{X C}[\rho]$. Todas essas possibilidades levam a centenas de possibilidades, por exemplo, os métodos "puros", descritos pelos funcionais GGA e meta-GGA: B88, BLYP, PW91, PBE etc.; "híbridos" GGA e meta-GGA: B3LYP, PBE1PBE, M06-2X etc.; e "duplo-híbridos": B2PLYP, mPW2PLYP etc., entre inúmeros outros. Os funcionais híbridos utilizam a energia de troca HF como parte do funcional, enquanto os duplo-híbridos incluem ainda a energia de correlação MP2 como parte do funcional. Cabe notar que muitos métodos DFT utilizam parâmetros, universais ou específicos, ajustados a conjuntos de dados selecionados.

Do ponto de vista prático, a demanda computacional dos métodos DFT (exceto duplo-híbridos) é similar ao método HF $\left(\sim M^{4}\right)$, no entanto incluem efeitos de correlação eletrônica. Isso faz com que esses métodos tenham aplicações largamente difundidas nos estudos computacionais de diversos tipos de propriedades de moléculas (isoladas ou em fase condensada) e sólidos.

\subsubsection{Métodos para simulação de trajetórias quase clássicas em dinâmica direta}

A escolha do método de estrutura eletrônica a ser aplicado em dinâmica direta deve tomar como base os seguintes aspectos: (i) o número de trajetórias desejado; e (ii) o passo temporal de integração de cada trajetória.

Uma única trajetória indica apenas um caminho dentre vários, em que os reagentes podem evoluir para os produtos. Portanto, para uma descrição adequada da dinâmica de uma reação, deve-se realizar um conjunto de trajetórias contendo algumas centenas ou milhares de trajetórias, dependendo do objetivo da simulação. Considerando que o passo temporal da integração numérica nas simulações das trajetórias quase clássicas (ou semiclássicas) no estudo de reações químicas é tipicamente $\Delta t=10^{-16} \mathrm{~s}$, têm-se, então, no mínimo, $10^{4}$ cálculos da energia e suas derivadas (gradiente e hessiana) para uma trajetória de $1 \mathrm{ps}\left(10^{-12} \mathrm{~s}\right)$. Caso um conjunto pequeno de 100 trajetórias seja aceitável, então, ao todo, na simulação, serão necessários $10^{6}\left(=10^{4} \times 100\right)$ cálculos de estrutura eletrônica.

Portanto, nas simulações de dinâmica direta para o estudo de reações químicas, a escolha do método de estrutura eletrônica desempenha papel fundamental, implicando na possibilidade ou não de realizar as simulações em tempo hábil. Como visto nas subseções anteriores, o número de métodos de estrutura eletrônica é enorme. Logo, a escolha dos métodos de estrutura eletrônica para realizar as simulações vai, geralmente, depender da relação custo/benefício, ou seja, demanda computacional versus exatidão. Os métodos pós-HF, particularmente os métodos 
MR-CISD, MRMP e CCSD(T), apresentam alta exatidão e alta demanda computacional. Diferentemente, métodos como funcionais da densidade e semiempíricos são conhecidos pela menor demanda computacional, porém é necessário ter garantias (que algumas vezes não são possíveis de se obter) da aplicabilidade com sucesso desses métodos em tipos específicos de propriedades e sistemas moleculares.

Um procedimento que tem dominado a aplicação dos métodos DFT e ab initio em dinâmica direta é validar métodos de menor demanda computacional, ou seja, encontrar uma combinação do método DFT ou ab initio (HF, CASSCF e MP2) com um conjunto pequeno de funções de base que seja adequada para descrever as principais propriedades de interesse da reação. ${ }^{34} \mathrm{O}$ procedimento de validação, geralmente, consiste em descrever as propriedades estruturais e energéticas dos pontos estacionários da reação e, possivelmente, da IRC, com métodos de referência (CCSD(T), MRMP2, MRCISD), e comparar as descrições com os métodos de menor demanda. Portanto, a principal finalidade é eleger o método com menor demanda e mais exato para ser utilizado nas simulações das trajetórias na dinâmica.

Os métodos semiempíricos já foram bastante usados em dinâmica direta, principalmente na década de 1990, quando simulações BOMD de reações químicas começaram a se tornar populares. Entretanto, diferentemente dos métodos DFT e $a b$ initio, a aplicação desses métodos geralmente está associada a um procedimento de reparametrização do método para descrever a reação de interesse. Como já mencionado, o intuito principal dos métodos semiempíricos é calcular diversas propriedades (estrutura, entalpia de formação, momento de dipolo etc.) de mínimos locais (reagentes, intermediários e produtos) com adequada exatidão. No entanto, outros pontos da PES, por exemplo, estados de transição, espécies transientes e complexos intermoleculares, podem não ser confiáveis. Logo, essa deficiência dos métodos semiempíricos em caracterizar adequadamente regiões relevantes da PES, particularmente no que se refere a um mecanismo de reação, faz com que seu uso em dinâmica direta seja muito limitado.

Então, Rossi e Truhlar ${ }^{35}$ sugeriram que os métodos semiempíricos poderiam ser ajustados ou reparametrizados, a partir de dados ab initio obtidos com métodos de referência, para se estudarem reações específicas. Assim, esse método semiempírico reparametrizado poderia descrever com maior precisão os aspectos e as características de uma PES ab initio de uma reação específica. Esse método é conhecido como SRP (do inglês Specific Reaction Parameters). Uma grande variedade de estudos de dinâmica molecular direta tem utilizado o procedimento SRP - uma lista ampla pode ser obtida em Bolton, Hase e Peslherbe. ${ }^{36}$ Características em comum dessas aplicações de dinâmica direta são os estudos detalhados de mecanismos e das seletividades de reações com centenas e/ou milhares de trajetórias simuladas.

\footnotetext{
34 Quijano e Singleton (2011), Goldman, Glowacki e Carpenter (2011), Glowacki, Marsden e Pilling (2009), Gunaydin e Houk (2008), Hamaguchi et al. (2007), Liu et al. (2004), Singleton et al. (2003), Mann e Hase (2002).

35 Rossi e Truhlar (1995).

36 Bolton, Hase e Peslherbe (1998).
} 


\subsubsection{Condições iniciais das trajetórias}

Uma trajetória, isto é, a dependência temporal das posições e dos momentos dos átomos em uma dinâmica, é calculada integrando as equações de movimento a partir de certas condições iniciais. A trajetória pode ser comparada a um filme, cujo fotograma $j$ contém a posição e o momento de todos os átomos no tempo $t$. Portanto, a sucessão de fotogramas pode gerar um "espetáculo" de moléculas evoluindo com o passar do tempo.

Uma única trajetória indica apenas um caminho dentre vários, em que os reagentes podem evoluir para os produtos, tendo, portanto, valor limitado em termos mecanísticos e de seletividade. Logo, um conjunto (ensemble) de trajetórias deve ser obtido de modo estatisticamente relevante, para prover uma visão mais detalhada e coerente do sistema reacional. Tipicamente, uma simulação de dinâmica molecular terá centenas ou milhares de trajetórias, dependendo do tipo de propriedade e refinamento de detalhes desejados. Por exemplo, para o estudo da seletividade de canais em um sistema reativo de interesse, um conjunto de uma ou duas centenas de trajetórias pode ser representativo; ${ }^{37}$ porém, para a determinação de constantes de velocidade com adequada exatidão, o número de trajetórias pode facilmente chegar a milhares. ${ }^{38}$ Entretanto, poucas dezenas de trajetórias podem ser simuladas se uma interpretação limitada é aceitável, como, por exemplo, em colisões reativas entre feixes moleculares com energias e orientações bem estabelecidas. ${ }^{39}$

As trajetórias podem, em princípio, ser iniciadas a partir de qualquer ponto da PES. Por se tratar de equações diferenciais de segunda ordem (ou dois conjuntos de equações diferenciais de primeira ordem), para se iniciar uma dinâmica, são necessários a geometria inicial do sistema, isto é, as coordenadas iniciais dos átomos, e seus respectivos momentos (conjugados). Essa última parte da inicialização pode ser feita de várias formas, as quais têm dependência com o tipo de reação que se está simulando: unimolecular, bimolecular, gás-superfície, entre outros. Os aspectos básicos dos procedimentos de inicialização de trajetórias associadas a reações unimoleculares, bimoleculares e a partir do estado de transição serão discutidos a seguir. Mais detalhes, incluindo outros tipos de situações químicas em procedimento de inicialização de trajetórias, podem ser encontrados nas revisões e capítulos de $\operatorname{livros}^{40}$ e suas diversas referências.

37 Quijano e Singleton (2011), Sun, Song e Hase (2002).

38 Sun e Hase (2004).

39 Mikosch et al. (2008).

40 Paranjothy et al. (2012), Sun e Hase (2003), Peslherbe, Wang e Hase (1999), Bolton, Hase e Peslherbe (1998). 


\subsubsection{Reações unimoleculares}

Para que uma reação unimolecular ocorra, é necessário que o reagente seja excitado com uma energia acima de um limiar - este sendo geralmente associado ao estado de transição - para que possa evoluir para os produtos. Uma teoria amplamente difundida e bem aceita na descrição das reações unimoleculares é a RRKM,${ }^{41}$ em que a constante de velocidade $k(E)$ de uma reação unimolecular pode ser estimada a partir de um conjunto microcanônico dos estados dos reagentes.

A teoria RRKM é fundamentada nas seguintes suposições: (i) colisões entre as próprias moléculas da amostra, com gás inerte ou por absorção de fótons levam uma molécula reagente a obter uma energia interna, $E$, distribuída nos graus de liberdade rotacionais e vibracionais, resultando em uma molécula com energia para reagir; (ii) essa energia interna é distribuída estatisticamente em todos os graus de liberdade, em um tempo relativamente curto, comparado com o tempo de reação, até que uma quantidade suficiente é acumulada em um modo crítico denominado TS; e (iii) a constante de velocidade $k(E)$ é dependente da energia interna da molécula de reagente e é determinada considerando que não há recruzamento através do TS. Essa última suposição é o equivalente dinâmico em assumir que os estados (reagente e TS) estão em equilíbrio.

De fato, essa suposição fundamental da teoria RRKM implica que o movimento clássico do reagente é suficientemente caótico para manter o conjunto microcanônico dos estados. Essa suposição é frequentemente referida como a rápida redistribuição intramolecular da energia vibracional. A identificação de reações que não segue esse tipo de comportamento - não RRKM ou não estatístico - tem dominado os estudos da dinâmica de reações unimoleculares. ${ }^{42}$ Para isso, a dinâmica requer que a seleção das condições iniciais do espaço de fase (momento e coordenada) seja fundamentada em uma amostragem microcanônica dos estados associados aos graus de liberdade rotacionais e vibracionais.

Uma amostragem microcanônica bastante utilizada é fundamentada no hamiltoniano do oscilador harmônico e rotor rígido. Nesse procedimento, supõe-se que um conjunto microcanônico pode ser amostrado pela representação de uma molécula energizada, isto é, um rotor rígido simétrico com $3 N-6$ modos normais, em que $N$ é o número de átomos. O hamiltoniano dessa molécula é a soma das energias do oscilador harmônico, $E_{\mathrm{v}}$, e do rotor rígido simétrico, $E_{\mathrm{r}}$, sem os termos de acoplamento rotovibracional:

$$
H=E=E_{r}+E_{v}
$$

41 Baer e Hase (1999).

42 Lourderaj e Hase (2009), Carpenter (2003, 2005). 


$$
\begin{gathered}
E_{v}=\sum_{\alpha=1}^{3 N-6} \varepsilon_{\alpha}=\sum_{\alpha=1}^{3 N-6} \frac{P_{\alpha}^{2}+\omega_{\alpha}^{2} Q_{\alpha}^{2}}{2} \\
E_{r}=\frac{J(J+1) \hbar^{2}}{2 I_{x}}+\frac{\mathrm{K}^{2} \hbar^{2}}{2}\left(\frac{1}{I_{z}}-\frac{1}{I_{\mathrm{x}}}\right)
\end{gathered}
$$

em que $P_{\alpha}, Q_{\alpha}$ e $\omega_{\alpha}$ é o momento (conjugado), a coordenada e a frequência angular, respectivamente, do modo normal $\alpha$; $J$ e $K$ são os números quânticos rotacionais; $I_{x}$ e $I_{z}$, as componentes do momento de inércia ao longo dos eixos principais do rotor simétrico; e $\hbar=h / 2 \pi$, sendo $h$ a constante de Planck.

Para formar o conjunto microcanônico, valores aleatórios de $P_{\alpha}$ e $Q_{\alpha}$ são escolhidos de modo que exista uma distribuição uniforme no espaço de fase clássico de $H(P, Q)$. A metodologia usual para realizar a distribuição é com base na amostragem de Monte Carlo. ${ }^{43}$ Por exemplo, para gerar uma distribuição uniforme, as energias dos modos normais, $\varepsilon_{\alpha}$, são selecionadas de acordo com Hase e Buckowski: ${ }^{44}$

$$
\varepsilon_{\alpha}=\left[E_{v}-\sum_{\beta=1}^{\alpha-1} \varepsilon_{\beta}\right]\left(1-R_{\alpha}^{\frac{1}{(n-\alpha)}}\right)
$$

em que $R_{\alpha}$ é um número aleatório uniforme entre 0 e 1 , e $n$ é o número de modos normais. Além disso, um segundo número aleatório $R_{\alpha}$ 'é escolhido para designar as fases de cada modo vibracional.

$$
\begin{gathered}
Q_{\alpha}=\left[\frac{\sqrt{2 \varepsilon_{\alpha}}}{\omega_{\alpha}}\right] \cos \left(2 \pi R_{\alpha}{ }^{\prime}\right) \\
P_{\alpha}=-\sqrt{2 \varepsilon_{\alpha}} \operatorname{sen}\left(2 \pi R_{\alpha}^{\prime}\right)
\end{gathered}
$$

Para os números quânticos rotacionais $J$ e $K$, o procedimento para gerar uma distribuição aleatória uniforme é similar ao descrito para os modos normais.

Esse tipo de amostragem aleatória descrita não representa uma condição experimental real, em que, normalmente, a temperatura é mantida constante. Geralmente, esse tipo de amostragem é utilizado para identificar reações unimoleculares que seguem um comportamento não RRKM. Para representar condições experimentais usuais, o tipo de amostragem não deve ser aleatório; deve, geralmente, representar uma temperatura específica (conjunto canônico). Além disso, mesmo 
que os núcleos se movam classicamente, pode ser também necessário que os estados clássicos sejam amostrados como seus análogos em mecânica quântica, sendo, portanto, necessário adicionar a energia vibracional de ponto zero (ZPE, do inglês Zero-Point Energy). Para as simulações de dinâmica que utilizam esse tipo de amostragem, o termo quase clássico (do inglês quasiclassical) é utilizado.

A energia de uma molécula poliatômica em um estado rotovibracional específico pode ser aproximada pelos modelos de oscilador harmônico e rotor rígido simétrico,

$$
E=\sum_{\alpha=1}^{3 N-6} E_{\alpha}+E_{r}=\sum_{\alpha=1}^{3 N-6}\left(n_{\alpha}+\frac{1}{2}\right) h v_{\alpha}+E_{r}(J, K)
$$

em que $n_{\alpha}$ e $v_{\alpha}$ são o número quântico e a frequência vibracional do modo normal $\alpha$, respectivamente, e $E_{r}$ é a energia rotacional do rotor simétrico apresentada na Equação 1.20.

Nas simulações de dinâmica com trajetórias quase clássicas, as energias rotacionais e vibracionais para um dado reagente são escolhidas a partir de uma distribuição de Boltzmann na temperatura T. Assim, as energias dos modos normais podem ser amostradas usando uma distribuição de probabilidade, como, por exemplo,

$$
P\left(n_{\alpha}\right)=\mathbb{Q}_{\alpha}^{-1}(T) e^{-\frac{\left(\mathrm{n}_{\alpha}+\frac{1}{2}\right) h v_{\alpha}}{k_{\mathrm{B}} T}}
$$

em que $n_{\alpha}$ e $v_{\alpha}$ continuam sendo o número quântico e a frequência do $\alpha$-ésimo modo normal; $\mathbb{Q}_{\alpha}(T)$ é a função de partição vibracional do modo normal $\alpha$; e $k_{\mathrm{B}}$ é a constante de Boltzmann. Uma amostragem análoga é realizada para os números quânticos rotacionais, utilizando um rotor rígido simétrico caracterizado pelas componentes $I_{x}$ e $I_{z}$ do momento de inércia. Nesse caso, as componentes do momento angular $j$ da molécula e sua projeção $j_{z}$ são amostradas a partir de suas distribuições de Boltzmann clássicas, usando distribuições de probabilidade, como, por exemplo:

$$
\begin{array}{ll}
P\left(j_{z}\right)=e^{\left(-\frac{j_{z}^{2}}{2 I_{z} k_{\mathrm{B}} T}\right)} & 0 \leq j_{z} \leq \infty \\
P(j)=j e^{\left(-\frac{j^{2}}{2 I_{z} k_{\mathrm{B}} T}\right)} & j_{z} \leq j \leq \infty
\end{array}
$$

As relações dos números quânticos rotacionais $J$ e $K \operatorname{com} j$ e $j_{z}$ são expressas por:

$$
j=\sqrt{J(J+1) \hbar} \text { e } j_{z}=K \hbar .
$$




\subsubsection{Reações bimoleculares}

O tipo de amostragem utilizado nas reações bimoleculares é fundamentado na teoria das colisões. ${ }^{45}$ Nessa teoria, a seção de choque (transversal) de reação, entre os reagentes A e B, para formar o produto $\mathrm{P}$, pode ser determinada em função das velocidades relativas, $v_{r e l}$ e dos estados rotovibracionais de A e B. Para reações em equilíbrio térmico, as seções de choque reacionais devem ser ponderadas pela distribuição de Boltzmann para fornecer a constante de velocidade $k(T)$ da reação.

Para moléculas poliatômicas A e B, a seção de choque reativa pode ser expressa como $\sigma_{r}=\sigma_{r}\left(\mathrm{v}_{r e l}, n_{\mathrm{A}}, J_{\mathrm{A}}, K_{\mathrm{A}}, n_{\mathrm{B}}, J_{\mathrm{B}}, K_{\mathrm{B}}\right)$, em que $n_{\mathrm{A}(\mathrm{B})}, J_{\mathrm{A}(\mathrm{B})}$ e $K_{\mathrm{A}(\mathrm{B})}$ são os números quânticos vibracional e rotacionais, respectivamente, da molécula $A(B)$. Admitindo equilíbrio térmico entre os reagentes em uma temperatura $T$, a seção de choque reacional torna-se:

$\sigma_{r}\left(v_{r e l} ; T\right)=\sum_{n_{\mathrm{A}}, n_{\mathrm{B}}} \sum_{\substack{\mathrm{A}_{\mathrm{A}}, \mathrm{B}_{\mathrm{B}} \\ \mathrm{K}_{\mathrm{A}}, K_{\mathrm{B}}}} \sigma_{r}\left(v_{r e l}, n_{\mathrm{A}}, J_{\mathrm{A}}, K_{\mathrm{A}}, n_{\mathrm{B}}, J_{\mathrm{B}}, K_{\mathrm{B}}\right) P\left(n_{\mathrm{A}}, n_{\mathrm{B}}, T\right) P\left(J_{\mathrm{A}}, J_{\mathrm{B}}, K_{\mathrm{A}}, K_{\mathrm{B}}, T\right)$

em que $P\left(n_{\mathrm{A}}, n_{\mathrm{B}}, T\right)$ e $P\left(J_{\mathrm{A}}, J_{\mathrm{B}}, K_{\mathrm{A}}, K_{\mathrm{B}}, T\right)$ são as distribuições de Boltzmann normalizadas para os graus de liberdade vibracionais, $n_{\mathrm{A}(\mathrm{B})}$, e rotacionais, $J_{\mathrm{A}(\mathrm{B})}$ e $K_{\mathrm{A}(\mathrm{B})}$, na temperatura T. A multiplicação da Equação 1.28 por $v_{\text {rel }}$ resultará na constante de velocidade para uma velocidade relativa fixa:

$$
k\left(v_{r e l} ; T\right)=v_{r e l} \sigma_{r}\left(v_{r e l} ; T\right)
$$

Integrando a constante de velocidade sobre todas as velocidades ponderadas pela distribuição de Boltzmann, tem-se a constante de velocidade de uma reação térmica bimolecular.

$$
k(T)=\int_{0}^{\infty} v_{r e l} \sigma_{r}\left(v_{r e l} ; T\right) P\left(v_{r e l} ; T\right) \mathrm{d} v_{r e l}
$$

A expressão clássica da seção de choque de reação é expressa por:

$$
\sigma_{r}=\int_{0}^{b_{\max }} P_{r}(b) 2 \pi b \mathrm{~d} b
$$

em que $b$ é o parâmetro de impacto; $b_{\text {máx }}$ é o maior valor do parâmetro de impacto que produz a reação; e $P_{r}(b)$ é a probabilidade de reação em uma função do parâme-

45 Henriksen e Hansen (2008). 
tro de impacto. Para valores de $b$ escolhidos aleatoriamente entre 0 e $b_{\text {máx }}$, a média da probabilidade de reação é $N_{r} / N$, em que $N$ é o número total de trajetórias e $N_{r}$ são as trajetórias reativas. Desse modo, a seção de choque de reação é:

$$
\sigma_{r}=\frac{N_{r}}{N} \pi b_{\text {máx }}^{2}
$$

Logo, a amostragem em reações bimoleculares é realizada variando-se o parâmetro de impacto $(b)$, as orientações relativas $\left(\Omega_{\mathrm{A}}, \Omega_{\mathrm{B}}\right)$ e a velocidade $\left(v_{\text {rel }}\right)$ ou a correspondente energia de colisão $\left(E_{c o l}\right)$. Se a amostragem é realizada de forma adequada, pode-se determinar a seção de choque de reação e, por consequência, a constante de velocidade. Além disso, para cada conjunto de $b,\left(\Omega_{\mathrm{A}}, \Omega_{\mathrm{B}}\right)$ e $v_{\text {rel }}$ ou $E_{c o l}$, amostragens nas condições iniciais dos números quânticos $n_{\mathrm{A}(\mathrm{B})}, J_{\mathrm{A}(\mathrm{B})}$ e $K_{\mathrm{A}(\mathrm{B})}$ devem ser feitas de modo similar às realizadas nas simulações de reações unimoleculares.

\subsubsection{Amostragem a partir do estado de transição (TS)}

Simulações de dinâmica direta com métodos de estrutura eletrônica acurados podem ser realizadas para se estudar eventos químicos determinados por efeitos que ocorrem após o estado de transição (pós-TS). De fato, tais eventos são limitações inerentes, por exemplo, à teoria do estado de transição, pois não considera os efeitos da PES após o TS. Em particular, bifurcações na PES, após o TS, são determinantes na proporção de produtos, isto é, determinam a seletividade da reação. ${ }^{46}$ Apesar da alta demanda computacional, em razão do uso de métodos acurados de estrutura eletrônica em cada passo de integração da trajetória, o número de passos é relativamente pequeno, pois a trajetória se inicia na estrutura do TS.

Uma questão interessante que surge nesse tipo de procedimento da dinâmica a partir do TS está associada ao tipo de amostragem a ser utilizado. Os avanços da espectroscopia de femtossegundos têm tornado possível excitar e selecionar estados específicos do complexo ativado de certos sistemas reacionais, ${ }^{47}$ e, portanto, a escolha das condições iniciais da dinâmica consistentes com as populações desses estados permite simular as condições experimentais. No entanto, esses experimentos são muito difíceis de serem realizados e, em geral, considera-se que as populações dos estados rotacionais e vibracionais do TS podem ser amostradas utilizando teorias estatísticas.

A teoria do estado de transição (TST) convencional considera que existe uma distribuição de equilíbrio dos estados do TS e dos reagentes. A constante de velocidade TST é expressa por:

46 Rehbein e Carpenter (2011).

47 Polanyi e Zewail (1995). 


$$
k(T)=\frac{k_{\mathrm{B}} T}{h} \frac{\mathbb{Q}^{\ddagger}}{\mathbb{Q}_{r}} e^{-\frac{E_{a}}{k_{\mathrm{B}} T}}
$$

em que $\mathbb{Q}^{\ddagger}$ e $\mathbb{Q}_{r}$ são a função de partição molecular do TS e dos reagentes, respectivamente, e $E_{a}$ é a energia crítica ou, aproximadamente, a energia de ativação. O modelo semiclássico rotor-rígido/modo-normal pode ser utilizado para amostrar os estados do TS. Logo, as amostragens nas condições iniciais dos números quânticos $n$ (vibracional), J e $K$ (rotacionais) são realizadas de modo similar àquelas apresentadas para as reações unimoleculares. Nessa aproximação, a coordenada de reação, associada à frequência imaginária do TS, é tratada como uma coordenada translacional com energia $E_{t}^{\ddagger}$, sendo amostrada de maneira clássica. Os valores de $E_{t}^{\ddagger}$ são selecionados de acordo com a seguinte função de distribuição:

$$
P\left(E_{t}^{\ddagger}\right)=\frac{1}{k_{\mathrm{B}} T} e^{-\frac{E_{t}^{\ddagger}}{k_{\mathrm{B}} T}}
$$

os quais podem ser amostrados por uma função de distribuição cumulativa:

$$
E_{t}^{\ddagger}=-k_{\mathrm{B}} T \ln (1-R)
$$

em que $R$ é um número aleatório. $\mathrm{O}$ momento da coordenada de reação é expresso por $P_{t}^{\ddagger}=2\left(E_{t}^{\ddagger}\right)^{1 / 2}$.

$\mathrm{Na}$ formulação microcanônica, por exemplo, com base na teoria RRKM, considera-se que todos os estados rotacionais e vibracionais dos graus de liberdade ortogonais à coordenada de reação têm igual probabilidade de serem populados. Ao considerar um rotor rígido simétrico, a energia do TS é escrita como:

$$
E^{\ddagger}=E_{n J K}^{\ddagger}+E_{t}^{\ddagger}
$$

em que $E^{\ddagger}$ é a altura da barreira; $E_{t}^{\ddagger}$ é a energia da coordenada translacional; e $E_{n J K}^{\ddagger}$ é a energia dos níveis rotacionais e vibracionais dos graus de liberdade ortogonais à coordenada de reação. $O$ primeiro passo é selecionar aleatoriamente a energia do TS, $E^{\ddagger}$, sendo a energia restante, $E^{\ddagger}-E_{n J K}^{\ddagger}$, alocada na coordenada translacional, $E_{t}^{\ddagger}$.

Uma aplicação interessante desse tipo de simulação a partir do TS está na possibilidade de corrigir o valor da constante de velocidade obtida pelas teorias estatísticas, ${ }^{48}$ isso porque a TST canônica ou microcanônica fundamenta-se na suposição de as trajetórias cruzarem a superfície do TS apenas uma vez. Portanto, os recruzamentos de barreira não são considerados pela TST. O procedimento realizado para corrigir a constante de velocidade consiste em determinar o número 
de recruzamentos de barreira, que podem ser contabilizados iniciando trajetórias a partir do TS com amostragens dos graus de liberdade a partir de uma distribuição de Boltzmann apropriada.

\subsubsection{Crítica à literatura: dinâmica ab initio}

A utilização do termo ab initio para descrever métodos dinâmicos precisa ser considerada de modo mais aprofundado ${ }^{49}$ Em estrutura eletrônica, assume-se que um método é $a b$ initio quando não utiliza dado ou parâmetro experimental, exceto pelas constantes fundamentais, e que, por algum procedimento hierárquico (bem definido e único), possa levar à solução exata da equação de Schrödinger eletrônica, independentemente do tempo. Assumindo os mesmos critérios para métodos dinâmicos, estes, para serem ab initio, teriam que fornecer a solução exata da equação de Schrödinger, dependente do tempo para elétrons e núcleos. Logo, a simples utilização de métodos $a b$ initio para calcular a energia eletrônica e suas derivadas em uma dada configuração nuclear não fornece um método de dinâmica $a b$ initio, pois não há um procedimento para seu aprimoramento que leve à solução exata da equação de Schrödinger, dependente do tempo. Mesmo que os graus de liberdade eletrônicos sejam tratados dinamicamente, por uma lagrangiana extendida, por exemplo, não caracteriza um método de dinâmica $a b$ initio, pois o requisito apresentado anteriormente não é satisfeito. De fato, existe um formalismo denominado dinâmica de elétrons e núcleos (END, do inglês Electron-Nuclear Dynamics), que é $a b$ initio, pois satisfaz os critérios citados. Foram propostos doze níveis de aproximações hierárquicas que fornecem um procedimento único para a solução exata. ${ }^{50}$ O nível mais simples consiste em descrever a função de onda eletrônica por um determinante e a função de onda nuclear por funções gaussianas com larguras nulas (núcleos clássicos). Note, entretanto, que, mesmo nessa aproximação mais simples, os movimentos eletrônicos e nucleares são acoplados.

Com essas observações, tem-se que os métodos de dinâmica molecular, isto é, aqueles que tratam os graus de liberdade nuclear classicamente, não podem ser considerados $a b$ initio, pois não fornecem a solução exata da equação de Schrödinger, dependente do tempo. Assim, os métodos de "dinâmica molecular ab initio" apresentados na literatura são, de fato, métodos de dinâmica clássica nuclear que utilizam cálculos ab initio (nem sempre no sentido aqui empregado para esses métodos de estrutura eletrônica) da energia eletrônica e suas derivadas. O termo ab initio, contudo, praticamente se tornou sinônimo de método preciso ou acurado ou de referência, e muitos autores o utilizam, por vezes inadequadamente, para designar métodos de dinâmica molecular que utilizam potenciais quânticos, em contraste com métodos de dinâmica molecular que utilizam potenciais clássicos com base em campos de força.

49 Marx e Hutter (2009), Car et al. (2005).

50 Öhrn e Deumens (1999). 


\subsubsection{Comparações com a dinâmica quântica: limitações da BOMD}

Por se basear na aproximação de Born-Oppenheimer, esse tipo de dinâmica direta não pode ser utilizada, sem modificações, para descrever regiões da PES próximas às interseções cônicas, ou melhor, nas reações em que os termos de acoplamento elétron-núcleo não podem ser desprezados.

Outra limitação desse método, e dos métodos de dinâmica molecular em geral, está na utilização de trajetórias clássicas para simular sistemas quânticos. Nesse caso, alguns efeitos intrínsecos da mecânica quântica não são considerados, como tunelamento, interferências e trocas de energia quantizada entre os graus de liberdade. Além disso, não existe um análogo clássico para a ZPE. Assim, em uma trajetória clássica, um modo normal pode ter energia menor que sua respectiva $\mathrm{ZPE}$, sendo uma situação impossível quanticamente..$^{51}$

Comparações realizadas na literatura têm mostrado que os resultados obtidos de dinâmicas quase clássicas com tempo curto de simulação estão frequentemente de acordo com os observados nas simulações de dinâmica quântica e com os resultados experimentais. Entretanto, quando as trajetórias quase clássicas são conduzidas por longos tempos de propagação, podem-se notar, em alguns casos, divergências acentuadas com os resultados obtidos por dinâmica quântica, ${ }^{52}$ sendo a troca de energia não quantizada entre os graus de liberdade a causa principal para essas divergências.

\subsubsection{Programas para simulações BOMD}

Nesses últimos vinte anos, é inegável que a popularidade do método BOMD para o estudo de reações químicas vem associada à implementação dos códigos de dinâmica direta em programas populares de cálculos de estrutura eletrônica, como GAMESS, Gaussian, DALTON, ORCA, NWChem, MOPAC, entre outros.

Os programas Gaussian, GAMESS, DALTON e ORCA apresentam rotinas específicas para cálculos de dinâmica molecular direta, enquanto os programas NWChem e MOPAC apresentam interface com o código VENUS..$^{53}$ O VENUS é, sem dúvida, o programa mais completo de dinâmica direta. Nele existe um conjunto amplo de opções, entre as quais estão:

i. Rotinas apropriadas para realizar amostragens iniciais - sejam clássicas, sejam quase clássicas (canônicas ou microcanônicas), além da possibilidade de incluir as contribuições translacionais, rotacionais e vibracio-

51 Stock e Müller (1999).

52 Peslherbe, Wang e Hase (1995), Wyatt, Iung e Leforestier (1992), Sibert, Reinhardt e Hynes (1984), Hase e Buckowski (1982).

53 Hase et al. (1996). 
nais - dos sistemas moleculares, específicas para os diferentes tipos de reações unimoleculares, bimoleculares, a partir do TS etc.;

ii. Diferentes tipos de algoritmos para integrar as equações de movimento nuclear, com base ou não na hessiana;

iii. Rotinas para analisar propriedades moleculares - distâncias e ângulos entre átomos, cargas atômicas, entre outros tipos de análises - ao longo das trajetórias;

iv. Procedimentos que transformam os valores de momento e posição, associados às condições finais de cada trajetória, em propriedades que possam ser comparadas com os dados experimentais;

v. Interface com programas gráficos para visualização dos movimentos dos átomos durante a dinâmica da reação.

Os programas Gaussian e GAMESS apresentam, em contraste, um conjunto menor de opções para esse tipo de dinâmica direta, se comparados, por exemplo, com a interface NWChem/VENUS. Portanto, para possíveis utilizações dos módulos de dinâmica direta dos programas Gaussian e GAMESS, tornam-se indispensáveis as construções de rotinas para realizar as amostragens iniciais dos sistemas moleculares adequadas ao tipo de reação unimolecular, ${ }^{54}$ bimolecular, entre outras, bem como para analisar as propriedades moleculares ao longo das trajetórias e das condições finais.

\subsection{EXPLORANDO MECANISMOS E SELETIVIDADES DE REAÇõES QUíMICAS}

Entender os aspectos que controlam a seletividade química é fundamental tanto para esclarecer como os mecanismos de reação ocorrem quanto para modificar as condições reacionais a fim de obter o produto desejado. Comumente, a seletividade química pode ser entendida considerando dois fatores: a variação da energia livre do sistema (que atua no controle termodinâmico da reação) e a velocidade de conversão de reagentes em produtos (relacionada ao controle cinético). ${ }^{55}$ Quando as reações estão sob controle termodinâmico, a seletividade é completamente estabelecida pela relação da energia livre de Gibbs entre os produtos, sendo os mecanismos de reação irrelevantes na razão dos produtos. Entretanto, quando as reações são conduzidas em condições em que aos produtos não é permitido estarem em equilíbrio ou em condições em que o controle termodinâmico não pode ser estabelecido, ${ }^{56}$ os mecanismos de reações desempenham papel essencial no controle da seletividade, sendo que para essas situações diz-se que o controle cinético da seletividade se estabelece.

\footnotetext{
54 É bem verdade que no programa Gaussian existe um bom conjunto de opções apenas para reações unimoleculares, similar ao programa VENUS.

55 Anslyn e Dougherty (2006).

56 Riveros, Maria José e Takashima (1985).
} 
Convencionalmente, na química moderna, o controle cinético da seletividade, por muito tempo, foi apenas associado à barreira de energia na superfície de energia potencial que os reagentes têm que ultrapassar para atingir os produtos. Geralmente, a compreensão do controle cinético da seletividade passa pelo entendimento de como a energia livre de Gibbs da "espécie" estado de transição responde às mudanças das condições reacionais (solvente, temperatura, substituintes etc.). Nesse sentido, a química teórica/computacional tem sido uma ferramenta importante no entendimento e na antecipação da seletividade química. $\mathrm{Na}$ construção do entendimento do controle cinético da seletividade ao longo da história da química moderna, a metodologia computacional dita estática tem fornecido um bom arcabouço conceitual para o entendimento de muitas reações químicas. ${ }^{57} \mathrm{~A}$ metodologia estática é composta de dois tratamentos que se complementam, a saber: (i) varredura da superfície de energia potencial (PES), determinando e caracterizando pontos críticos na PES - os reagentes, produtos, intermediários e TS são analisados em função de suas propriedades estruturais e energéticas; e (ii) as teorias estatísticas do estado de transição (TST) e RRKM, que permitem interpretar de forma qualitativa e (semi)quantitativa as velocidades e seletividades de reações químicas.

É inegável o sucesso do tratamento estático no estudo de reações químicas. Entretanto, nos últimos anos, tornou-se evidente que, para muitas reações químicas, o controle cinético da seletividade não pode ser reduzido simplesmente a uma comparação das alturas de barreiras dos diferentes canais reacionais, particularmente com os estudos de dinâmica de reações computacionais e experimentais. ${ }^{58}$

Os estudos de dinâmica das reações químicas têm sugerido que, além do controle cinético convencional da seletividade, ou seja, com base apenas nas alturas das barreiras de energia, o controle cinético da seletividade pode também ser estabelecido por variáveis intrinsecamente dinâmicas ou por comportamentos que só podem ser descritos pela dinâmica, quais sejam: (i) mecanismos e seletividades de reações dirigidas pelo momento; ${ }^{59}$ (ii) seletividades em bifurcações na PES pós-TS; ${ }^{60}$ e (iii) reações que evitam o caminho de energia mínima na $\mathrm{PES}^{61}$ e com o comportamento da seletividade fora das condições estatísticas. ${ }^{62}$

Aplicações da metodologia BOMD, em duas reações químicas, com foco no entendimento mais completo dos mecanismos e seletividades reacionais, serão apresentadas nas próximas seções. Mais detalhes sobre esses estudos podem ser encontrados em De Souza e De Souza et al. ${ }^{63}$ Todas as simulações e os cálculos de estrutura eletrônica que serão apresentados foram realizados com o programa Gaussian 09.

57 Bachrach (2007).

58 Manikandan, Zhang e Hase (2012), Mikosch et al. (2008), López et al. (2007), Carpenter (2003, 2005), Chabinyc et al. (1998).

59 Mikosch et al. (2008).

60 Rehbein e Carpenter (2011).

61 Ammal et al. (2003), Sun, Song e Hase (2002).

62 De Souza et al. (2012), Quijano e Singleton (2011).

63 De Souza (2012), De Souza et al. (2012). 


\subsubsection{Reação de desidratação do álcool pinacolílico protonado: mecanismo dirigido pela dinâmica}

Nos estudos cinéticos, muito tem sido feito para compreender como distinguir um mecanismo concertado daquele em etapas. Esse é aparentemente um problema bem definido - mecanismos concertados ocorrem por uma via, envolvendo um único TS, enquanto um mecanismo em etapas passa necessariamente por pelo menos dois TS, com um intermediário interveniente. No entanto, um trabalho importante de simulações $\mathrm{BOMD}^{64}$ mostrou que, em reações que evitam o caminho de energia mínima na PES, a distinção entre o mecanismo em etapas e o concertado utilizando critérios estáticos, isto é, números de estados de transição, não fornece resultados adequados.

A reação estudada está relacionada com a desidratação do álcool protonado 3,3-dimetilbutan-2-ol (álcool pinacolílico), $\left[\mathrm{Me}_{2}(\mathrm{Me}) \mathrm{C}-\mathrm{CH}\left(\mathrm{OH}_{2}\right) \mathrm{Me}\right]^{+}, \mathrm{Me}$, seguido de um rearranjo para a formação do carbocátion mais estável (terciário). Dois mecanismos reacionais limites são propostos para essa reação, a saber: (i) concertado - sendo representado por um único TS -, em que a saída da molécula de água e a migração do grupo metila ocorrem de forma concertada; e (ii) em etapas - sendo representativa para esse caminho há a formação do intermediário reacional -, inicialmente sai a molécula de água e a formação de um carbocátion secundário; em seguida, em um passo distinto, ocorre a migração da metila. Esses dois mecanismos estão ilustrados esquematicamente na Figura 1.2.

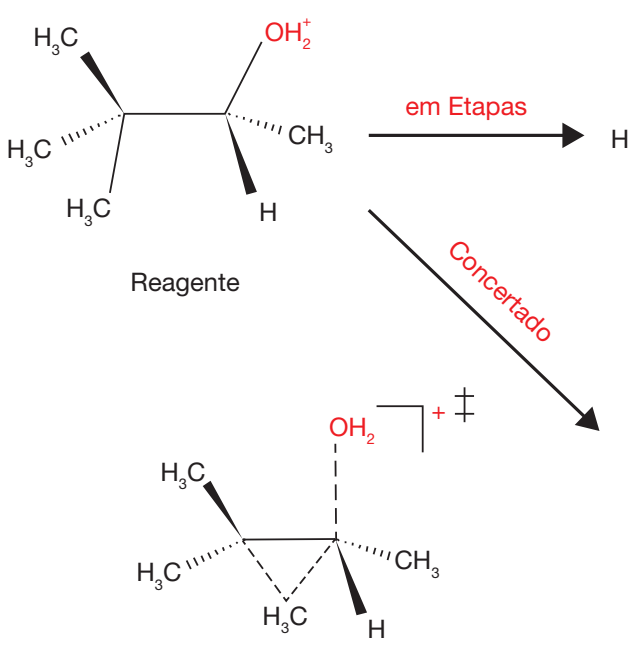

TS

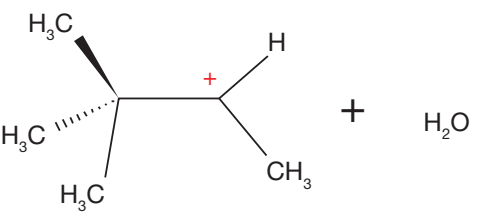

Intermediário

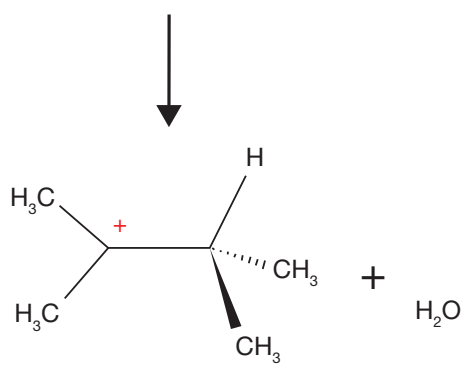

Produto

Figura 1.2 Representação esquemática de dois mecanismos de reações limites do álcool pinacolílico protonado, a saber: em etapas e concertado.

64 Ammal et al. (2003). 
Os cálculos de estrutura eletrônica (varredura na PES, determinação dos pontos estacionários e cálculo IRC) sugerem um mecanismo concertado referente ao caminho de energia mínima na PES. No entanto, as simulações BOMD mostram que a maioria das trajetórias segue um caminho em etapas, sendo inicialmente formado o carbocátion secundário. Assim, em efeito, o mecanismo de reação é dirigido pelos aspectos dinâmicos.

A seguir serão confrontadas as duas interpretações oriundas das metodologias estática (determinação de pontos críticos e cálculos IRC) e dinâmica (simulações BOMD) do mecanismo de reação de desidratação do álcool pinacolílico protonado.

\subsubsection{Resultados da superfície de energia potencial}

Na Figura 1.3 está mostrado o contorno tridimensional da PES para a desidratação do álcool pinacolílico protonado, bem como as estruturas dos principais pontos estacionários. Nessa superfície de contorno estão projetadas curvas pontilhadas (em cor branca) relacionadas ao comportamento de $\mathrm{R}_{\mathrm{C} 2-\mathrm{O}}$ versus $\theta_{\mathrm{C} 2-\mathrm{C} 3-\mathrm{C} 4}$ ao longo da IRC. Nesta figura, as cores servem de base para diferenciar as três regiões mais relevantes da PES, a saber: em azul estão o reagente $\left(\mathrm{R}_{\mathrm{C} 2-\mathrm{O}} \approx 1,6 \AA\right.$ e $\theta_{\mathrm{C} 2-\mathrm{C} 3-\mathrm{C} 4} \approx$ $\left.105^{\circ}\right)$ e o complexo dos produtos $\left(\mathrm{R}_{\mathrm{C} 2-\mathrm{O}} \approx 3,5 \AA\right.$ e $\left.\theta_{\mathrm{C} 2-\mathrm{C} 3-\mathrm{C} 4} \approx 40^{\circ}\right)$; em verde está o TS $\left(\mathrm{R}_{\mathrm{C} 2-\mathrm{O}} \approx 2,8 \AA\right.$ e $\left.\theta_{\mathrm{C} 2-\mathrm{C} 3-\mathrm{C} 4} \approx 73^{\circ}\right)$ e o intermediário $\left(\mathrm{R}_{\mathrm{C} 2-\mathrm{O}} \approx 3,8 \AA\right.$ e $\left.\theta_{\mathrm{C} 2-\mathrm{C} 3-\mathrm{C} 4} \approx 98^{\circ}\right)$; e em vermelho e laranja as regiões de maior energia da PES, associadas a uma estrutura em que o carbono ligado à molécula da água está rodeado por cinco grupos.

O caminho de energia mínima obtido na reação se caracteriza por um mecanismo concertado, em que a saída da molécula da água é concomitante com a migração do grupo alquila. Um caminho de reação alternativo em etapas, relacionado ao canal de eliminação-rearranjo, foi também exaustivamente estudado. No entanto, nenhum mínimo local associado ao carbocátion secundário foi localizado nos três sistemas reacionais: $\left[\mathrm{Me}_{2}(\mathrm{Me}) \mathrm{C}-\mathrm{CH}\left(\mathrm{OH}_{2}\right) \mathrm{Me}\right]^{+}, \mathbf{M e},\left[\mathrm{Me}_{2}(\mathrm{Et}) \mathrm{C}-\mathrm{CH}\left(\mathrm{OH}_{2}\right) \mathrm{Me}\right]^{+}, \mathbf{E t}$, e $\left[\mathrm{Me}_{2}(\mathrm{i}-\mathrm{Pr}) \mathrm{C}-\mathrm{CH}\left(\mathrm{OH}_{2}\right) \mathrm{Me}\right]^{+}$, i-Pr, em que somente o primeiro sistema será analisado. Várias tentativas foram realizadas com a geometria inicial dos sistemas na região I da PES (Figura 1.3), porém, em todos os casos, os processos de minimização das estruturas levaram aos reagentes.

\subsubsection{Resultados das simulações de BOMD}

As trajetórias de BOMD foram iniciadas na estrutura do reagente. Ao todo, foram realizadas 100 trajetórias em que se computaram as energias, os gradientes e as hessianas (com a opção "update $=5$ ", isto é, a hessiana é recalculada a cada cinco passos de integração), com o método B3LYP/6-31+G(d). O procedimento de inicialização das trajetórias consistiu em distribuir aleatoriamente, para todos os modos 
normais, dois diferentes valores de energia: 20,0 e 35,0 kcal mol${ }^{-1}$. A amostragem quase clássica, a qual incluiu a ZPE, foi usada para selecionar as condições iniciais dos momentos, sendo considerados apenas os graus de liberdade vibracionais (não foram incluídas as energias rotacional e translacional). As trajetórias simuladas foram propagadas por um tempo entre 0,5 e 1,5 ps.

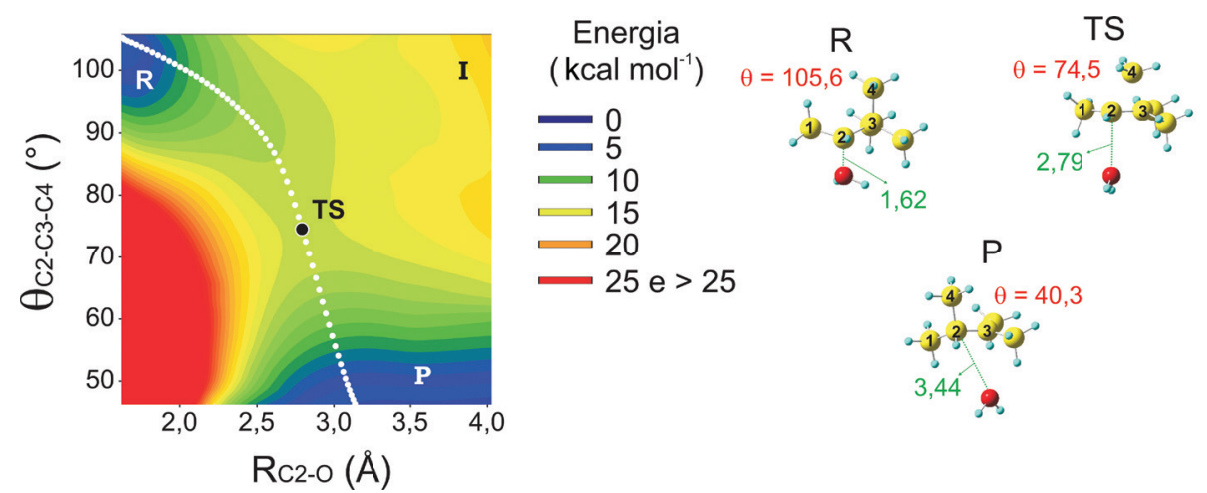

Figura 1.3 $\mathrm{R}_{\mathrm{C} 2-\mathrm{O}}$ e $\theta_{\mathrm{C} 2-\mathrm{C} 3 \mathrm{C} 4}$ em termos de contornos da PES, obtidos para a reação de desidratação do álcool pinacolílico protonado, seguido de rearranjo para o carbocátion mais estável. A PES foi calculada pelo procedimento de varredura relaxada, sendo as minimizações restritas realizadas para as coordenadas $\mathrm{R}_{\mathrm{C} 2-\mathrm{O}}$ e $\theta_{\mathrm{C} 2-\mathrm{C} 3-\mathrm{C} 4}$. Todos os cálculos foram realizados com o método B3LYP/6-31G(d). As regiões mais relevantes das PES estão denominadas por R, P, TS e I. As estruturas dos pontos estacionários principais estão ilustradas da seguinte forma: reagente $(\mathrm{R})$, estado de transição (TS) e produto $(\mathrm{P})$.

Inicialmente, as trajetórias foram propagadas até 0,5 ps. Nesse período, um número muito pequeno de trajetórias reativas foi obtido: $18 \%$ e $36 \%$, para $E_{i n i}=$ 20,0 e $35,0 \mathrm{kcal} \mathrm{mol}^{-1}$, respectivamente. Esse percentual de trajetórias reativas não é satisfatório, já que a eficiência de reação é pequena, o que poderia não suportar uma estatística significativa para a predição do mecanismo reacional. Portanto, as trajetórias foram propagadas por mais tempo, aproximadamente 1,0 ps. Com esse maior tempo de simulação, um número considerável de trajetórias deixou a região dos reagentes, sendo $62 \%$ e $78 \%$ para as duas energias $E_{i n i}=20,0$ e $35,0 \mathrm{kcal} \mathrm{mol}^{-1}$, respectivamente. Para algumas trajetórias foi necessário propagar por mais tempo, sendo que o tempo máximo de propagação foi de 1,5 ps. 

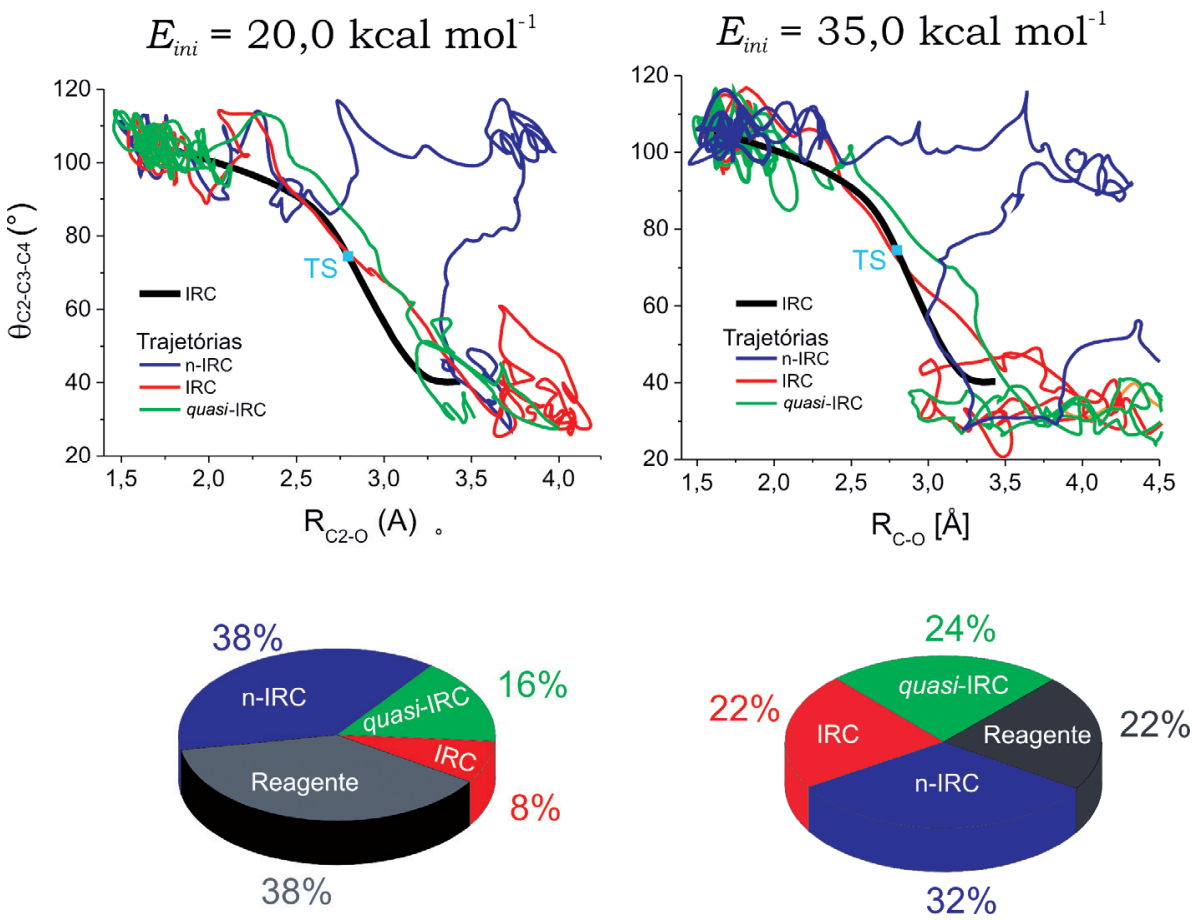

Figura 1.4 Comportamento de trajetórias reativas típicas observadas nas simulações da reação $\left[\mathrm{Me}_{2}(\mathrm{Me}) \mathrm{C}-\mathrm{CH}\left(\mathrm{OH}_{2}\right) \mathrm{Me}\right]^{+}$, tendo como condição inicial da dinâmica as energias $E_{i n i}=20,0$ e 35,0 $\mathrm{kcal} \mathrm{mol}^{-1}$, distribuídas aleatoriamente, juntamente com a ZPE, nos modos normais (quase clássica). Na parte superior são mostradas as variações de $\theta_{\mathrm{C} 2-\mathrm{C} 3-\mathrm{C} 4}\left({ }^{\circ}\right)$ versus $\mathrm{R}_{\mathrm{C} 2-\mathrm{O}}(\AA)$, para os três tipos de trajetórias reativas observadas: IRC, n-IRC e quasi-IRC, representadas pelas linhas nas cores vermelho, azul e verde, respectivamente. Além disso, neste gráfico é mostrado também o comportamento de $\theta_{\mathrm{C} 2-\mathrm{C} 3-\mathrm{C} 4}$ versus $\mathrm{R}_{\mathrm{C} 2-\mathrm{O}}$ do caminho de energia mínima (IRC) na PES (linha mais cheia em cor preta) e o valor de $\theta_{\mathrm{C} 2-\mathrm{C} 3-\mathrm{C} 4}$ versus $\mathrm{R}_{\mathrm{C} 2-\mathrm{O}}$ do TS (ponto em cor azul). Já na parte inferior desta figura, os gráficos mostram as porcentagens em função dos tipos de trajetórias obtidas nas simulações para as duas energias $E_{i n i}$.

A Figura 1.4 apresenta três tipos de trajetórias reativas observadas nas simulações, as quais foram classificadas de acordo com a proximidade ao comportamento IRC no tratamento estático, a saber:

i. Trajetória IRC - com comportamento similar ao da IRC, no método estático. Logo, nessa trajetória a reação ocorre de maneira concertada;

ii. Trajetória n-IRC - com comportamento bem diferente da IRC da PES. Nesse caso, a reação ocorre em etapas, ou seja, ocorre inicialmente a formação do carbocátion secundário; 
iii. Trajetória quasi-IRC - que apresenta um comportamento próximo ao da IRC no método estático.

Na Figura 1.4 estão apresentados também gráficos das porcentagens dos tipos de trajetórias observados nas simulações: IRC, n-IRC e quasi-IRC. De fato, para $E_{\text {ini }}$ $=20,0 \mathrm{kcal} \mathrm{mol}^{-1}$, o número de trajetórias n-IRC é bem maior do que aqueles observados nas outras trajetórias reativas. Este resultado é bastante similar ao obtido por Ammal et al. ${ }^{65}$ Entretanto, para a energia $E_{i n i}=35,0 \mathrm{kcal} \mathrm{mol}^{-1}$, o resultado é bastante surpreendente. $\mathrm{O}$ número de trajetórias IRC e quasi-IRC se torna maior, quer dizer, o aumento de energia distribuída aleatoriamente aos modos normais favoreceu o caminho concertado.

Na Figura 1.5 é mostrado o comportamento da distância $\mathrm{R}_{\mathrm{C} 2-\mathrm{O}}$ e do ângulo $\theta_{\mathrm{C2}-\mathrm{C} 3-\mathrm{C} 4}$, em função do tempo de simulação, para quatro trajetórias reativas típicas observadas, para $\left[\mathrm{Me}_{2}(\mathrm{Me}) \mathrm{C}-\mathrm{CH}\left(\mathrm{OH}_{2}\right) \mathrm{Me}\right]^{+}$, Me. Para três trajetórias reativas - IRC, quasi-IRC e n-IRC -, verifica-se que, entre 500 e 600 fs, a distância $\mathrm{R}_{\mathrm{C} 2-\mathrm{O}}$ se torna superior a 2,8 $\AA$, indicando que a ligação $\mathrm{C}-\mathrm{O}$ já está rompida. A partir desse período da dinâmica, as três trajetórias reativas têm comportamentos bem distintos, que podem ser verificados analisando a relação entre $\theta_{\mathrm{C} 2-\mathrm{C} 3-\mathrm{C} 4}$ e $\mathrm{R}_{\mathrm{C} 2-\mathrm{O}}$ no restante do percurso, a saber:

i. Na trajetória IRC, o ângulo $\theta_{\mathrm{C2}-\mathrm{C} 3 \mathrm{C} 4}$ é aproximadamente $75^{\circ}$ (é o menor valor comparado com os ângulos $\theta_{\mathrm{C} 2-\mathrm{C} 3-\mathrm{C} 4}$ das outras trajetórias), indicando que a metila já está em processo de migração, de modo que a evolução dessa trajetória para o produto $\left(\mathrm{R}_{\mathrm{C}-\mathrm{O}}>3,5 \AA\right.$ e $\theta_{\mathrm{C} 2-\mathrm{C} 3-\mathrm{C} 4}$ oscilando em torno de $30^{\circ}$ ) é quase instantânea, sendo menor que um período vibracional de uma ligação simples típica ( $30 \mathrm{fs})$;

ii. Nas trajetórias quasi-IRC e n-IRC, os ângulos $\theta$ estão em torno de $90^{\circ}$, indicando que o carbocátion secundário está formado. A diferença das duas trajetórias está justamente no tempo de formação do produto. Enquanto na trajetória quasi-IRC o produto é formado em aproximadamente $100 \mathrm{fs}$, na n-IRC a estrutura permanece na região do carbocátion secundário por um tempo aproximado de $500 \mathrm{fs}$. 

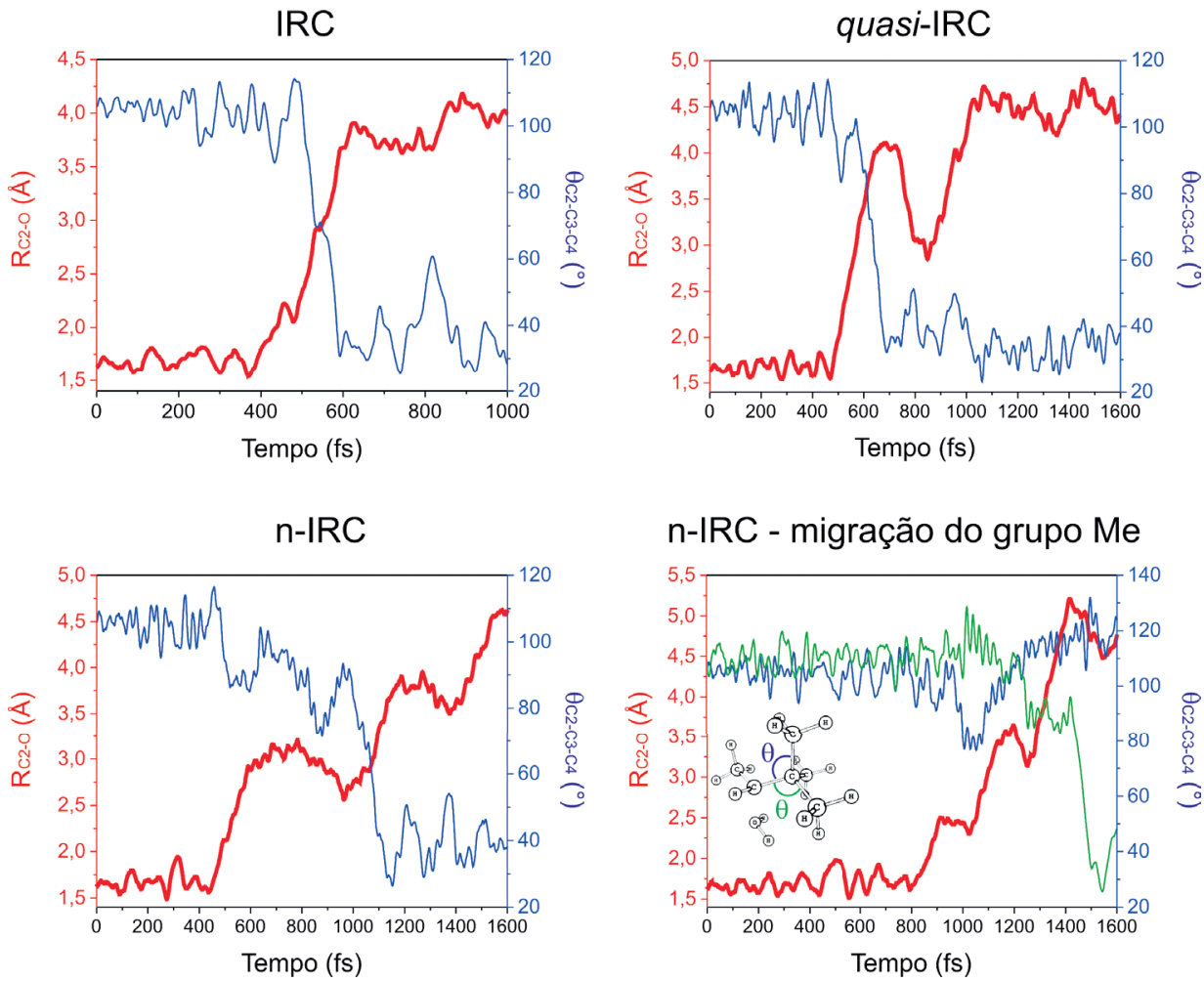

Figura 1.5 Dependência temporal de $\theta_{\mathrm{C} 2-\mathrm{C} 3-\mathrm{C} 4}\left({ }^{\circ}\right)$ e $\mathrm{R}_{\mathrm{C} 2-\mathrm{O}}(\AA)$ de quatro trajetórias reativas típicas observadas nas simulações IRC, quasi-IRC e duas n-IRC. Todas essas quatro trajetórias foram obtidas com a condição inicial de energia $E_{i n i}=20,0 \mathrm{kcal} \mathrm{mol}{ }^{-1}$, para $\left[\mathrm{Me}_{2}(\mathrm{Me})-\mathrm{C}-\mathrm{CH}-\right.$ $\left.\mathrm{Me}-\mathrm{OH}_{2}\right]^{+}, \mathrm{Me}$. Na outra trajetória n-IRC mostrada, o grupo metila migra em orientação syn ao hidrogênio (ver inserção no gráfico, $\theta_{\mathrm{C} 2-\mathrm{C} 3-\mathrm{C} 4}$, em cor verde).

Para as energias $E_{i n i}=20,0$ e $35 \mathrm{kcal} \mathrm{mol}^{-1}, 19$ e 16 trajetórias foram classificadas como n-IRC nas simulações, respectivamente. Dessas trajetórias n-IRC, 10 e 9 , respectivamente para $E_{i n i}=20,0$ e $35 \mathrm{kcal} \mathrm{mol}^{-1}$, formaram o carbocátion terciário esperado, estando associado à migração da metila em orientação anti à molécula $\mathrm{H}_{2} \mathrm{O}$. Nas três trajetórias restantes o produto esperado também foi obtido, porém ocorreu a migração das outras metilas. O comportamento de $\mathrm{R}_{\mathrm{C} 2-\mathrm{O}}$ e $\theta_{\mathrm{C} 2-\mathrm{C} 3-\mathrm{C} 4}$ de uma dessas três trajetórias é apresentado na Figura 1.5. Nessa trajetória percebe-se um comportamento típico n-IRC, mostrando que o carbocátion secundário tem um tempo de vida de aproximadamente $400 \mathrm{fs}$.

Pelo menos dois dos méritos do trabalho de Ammal et al ${ }^{66}$ estão em mostrar: (i) uma reação que tem comportamento dinâmico não IRC; e (ii) que um intermediário pode apresentar um tempo de vida muito longo, mesmo em uma região da PES 
que não apresenta um mínimo local. Segundo esse trabalho, em muitas trajetórias da reação de eliminação-rearranjo do álcool protonado, o carbocátion secundário permaneceu ativo por um período longo, por exemplo, de até $4000 \mathrm{fs}(=4,0 \mathrm{ps})$, em uma das trajetórias. Diferentemente, os resultados obtidos no estudo aqui apresentado mostram tempos de vida mais curtos para o carbocátion secundário. Para as energias $E_{i n i}=20,0$ e $35 \mathrm{kcal} \mathrm{mol}^{-1}$, foram obtidas ao todo 35 trajetórias n-IRC, sendo que o maior tempo de vida do carbocátion secundário foi de aproximadamente 530 fs. Particularmente, para 19 trajetórias n-IRC obtidas com $E_{\text {ini }}=20,0 \mathrm{kcal} \mathrm{mol}^{-1}$, em 12 delas o tempo de vida do carbocátion secundário variou entre aproximadamente 100 e $300 \mathrm{fs}$, enquanto apenas sete trajetórias tiveram tempo de vida entre 300 e 600 fs. Já para as 16 trajetórias n-IRC obtidas com $E_{i n i}=35,0 \mathrm{kcal} \mathrm{mol}^{-1}$, apenas duas trajetórias tiveram tempo de vida entre aproximadamente 300 e $600 \mathrm{fs}$; o restante ficou entre aproximadamente 100 e 300 fs.

É bastante interessante observar os efeitos que o aumento da energia cinética distribuída inicialmente aos modos normais promoveu na reação de eliminação-rearranjo do álcool protonado: (i) diminuir (em média) o tempo de vida do carbocátion secundário para as trajetórias n-IRC; e (ii) aumentar a porcentagem de trajetórias IRC e quasi-IRC.

\subsubsection{Comportamento estático versus dinâmico}

Na metodologia estática, o mecanismo de reação é concertado, ou seja, a saída da molécula de $\mathrm{H}_{2} \mathrm{O}$ é concomitante à migração do grupo metila. Diferentemente, no tratamento dinâmico, a etapa inicial da reação é o rompimento da ligação $\mathrm{C} 2-\mathrm{O}$ e a consequente saída da molécula $\mathrm{H}_{2} \mathrm{O}$. Além disso, os resultados da dinâmica mostram que o movimento inicial de migração do grupo metila não está, preferencialmente, acoplado com a saída da molécula $\mathrm{H}_{2} \mathrm{O}$.

Uma das limitações do tratamento estático, que neste estudo do mecanismo de reação do álcool pinacolílico protonado se torna relevante, é que ela se fundamenta na determinação e caracterização dos pontos críticos. Para os sistemas estudados, a determinação de um possível ponto crítico associado ao mecanismo de reação em etapas - caminho preferencial das trajetórias simuladas - não foi possível. Talvez o motivo principal para o insucesso na determinação do ponto crítico esteja na natureza da PES na região associada ao intermediário. Note que a figura - que apresenta a superfície de contorno da PES construída pelo procedimento de varredura relaxada - mostra que as diferenças de energia entre as regiões do TS e do intermediário são relativamente pequenas. Desse modo, uma possível interpretação dos resultados da dinâmica é que, em contraste com a PES, a superfície corrigida com a ZPE dê preferência ao mecanismo em etapas. Isso ocorre porque no tratamento estático, com base na IRC, os efeitos da ZPE e entrópicos não são considerados na determinação da PES. Talvez, se esses efeitos forem 
incluídos na descrição estática, os resultados sejam similares àqueles obtidos pelas simulações BOMD.

Nessa reação, a dinâmica prefere o caminho em etapas em vez do concertado, porque o movimento vibracional inicial da espécie reagente é em direção à região do cátion menos estável. Portanto, este estudo apresenta uma inovação no que se refere ao entendimento de algumas reações orgânicas, já que para a reação aqui estudada a região do TS tem importância limitada no mecanismo de reação.

\subsection{5 $\mathrm{A}$ reação $\mathrm{CH}_{3} \mathrm{ONO}_{2}+\mathrm{OH}^{-}$: seletividade dirigida pela dinâmica}

Um caso interessante, no contexto de o comportamento da seletividade estar fora das condições estatísticas, é a reação íon-molécula $\mathrm{CH}_{3} \mathrm{ONO}_{2}+\mathrm{OH}^{-},{ }^{67}$ cuja proporção dos produtos, observados experimentalmente, não é descrita adequadamente pela teoria RRKM. Essa reação foi estudada experimentalmente em condições de alto vácuo, com o espectrômetro de massa acoplado ao FT-ICR ${ }^{68}$

A cinética dessa reação é apresentada na Figura 1.6. $\mathrm{O}$ ataque nucleofílico de $\mathrm{OH}^{-}$ao nitrato de metila produziu os íons nitrito $\left(\mathrm{NO}_{2}^{-}\right)$e nitrato $\left(\mathrm{NO}_{3}^{-}\right)$, sendo que a proporção observada de $\mathrm{NO}_{2}^{-}: \mathrm{NO}_{3}^{-}$foi $0,86: 0,14$. Os produtos dessa reação podem ser racionalizados pelos mecanismos de deslocamento nucleofílico bimolecular no carbono (mecanismo $\mathrm{S}_{\mathrm{N}}$ @C), bem como uma abstração do próton seguida por dissociação (mecanismo $\mathrm{E}_{\mathrm{CO}} 2$, em que o subscrito ${ }_{\mathrm{CO}}$ está associado à eliminação da molécula de formaldeído). Entretanto, também foi considerada a possibilidade de uma substituição nucleofílica bimolecular no nitrogênio (mecanismo $\mathrm{S}_{\mathrm{N}} 2 @ \mathrm{~N}$ ), que gera o produto $\mathrm{NO}_{3}{ }^{-}$. Para investigar separadamente os mecanismos $\mathrm{S}_{\mathrm{N}} 2 @ \mathrm{C}$ e $\mathrm{S}_{\mathrm{N}} 2 @ \mathrm{~N}$, foram realizados estudos experimentais com o nucleófilo marcado isotopicamente ${ }^{18} \mathrm{OH}^{-}$. Porém, dentro do limite de detecção (valores menores que 4\%), não foi observada a incorporação do ${ }^{18} \mathrm{O}$ no produto $\mathrm{NO}_{3}{ }^{-}$. Ou seja, não há formação do íon ${ }^{18} \mathrm{ONO}_{2}^{-}\left(\mathrm{m} / z\right.$ 64) em nenhuma das reações, sugerindo que a reação $\mathrm{S}_{\mathrm{N}} 2$ ocorre exclusivamente no carbono. Os caminhos reacionais possíveis estão ilustrados no Esquema 1.1. 


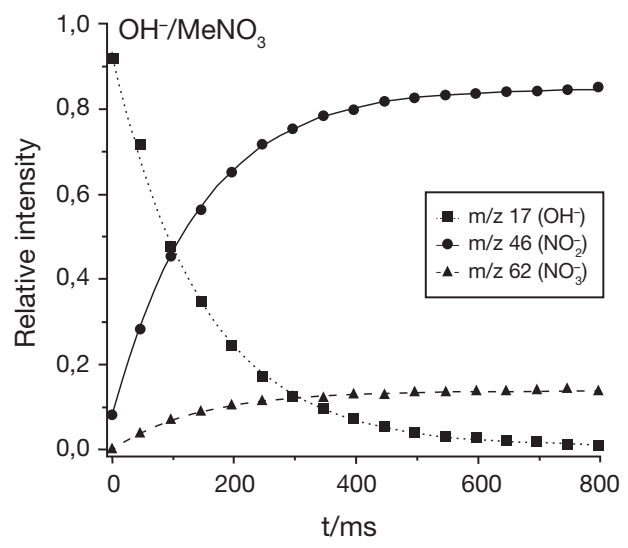

Figura 1.6 Cinética da reação do sistema $\mathrm{OH}^{-} / \mathrm{CH}_{3} \mathrm{ONO}_{2}$ obtida para uma pressão total de $1,8 \times 10^{-8}$ torr. $\mathrm{Na}$ ordenada, deve-se ler intensidade relativa (do inglês relative intensity) e, na abscissa, representa-se o tempo (ms). Figura adaptada de Correra e Riveros. ${ }^{69}$

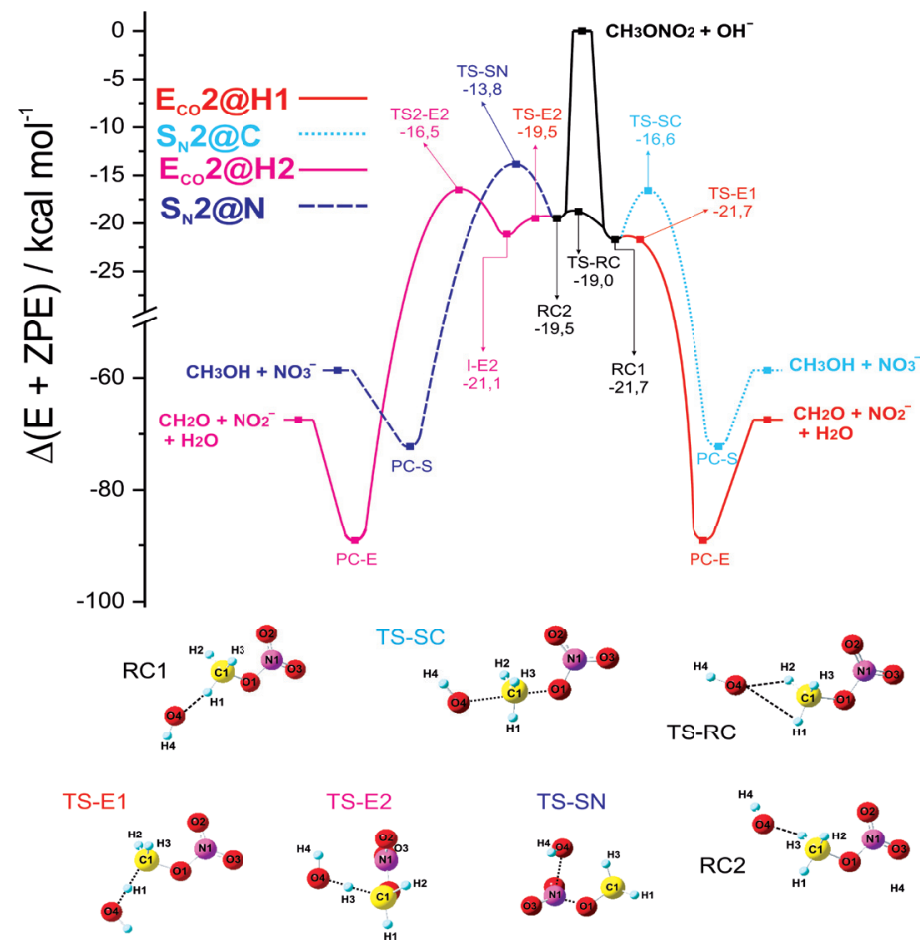

Figura 1.7 Lado esquerdo, diagrama de energia da reação $\mathrm{CH}_{3} \mathrm{ONO}_{2}+\mathrm{OH}^{-}$obtido com o método $\mathrm{CCSD}(\mathrm{T}) / \mathrm{CBS} / / \mathrm{MP} 2 / 6-311+\mathrm{G}(3 \mathrm{df}, 2 \mathrm{p})$. As energias dos pontos estacionários estão em $\mathrm{kcal} \mathrm{mol}^{-1}$ (ZPE está incluída), sendo relativas ao reagente $\left(0,0 \mathrm{kcal} \mathrm{mol}^{-1}\right)$. O complexo RC1

69 Id. ibid. 
está relacionado aos mecanismos $\mathrm{E}_{\mathrm{CO}} 2 @ \mathrm{H} 1$ e $\mathrm{S}_{\mathrm{N}} 2 @ \mathrm{C}$, enquanto $\mathrm{RC} 2$ deve ser associado aos mecanismos $\mathrm{E}_{\mathrm{CO}} 2 @ \mathrm{H} 2 \mathrm{e} \mathrm{S}_{\mathrm{N}} 2 @ \mathrm{~N}$. Lado direito, estruturas dos pontos estacionários principais.

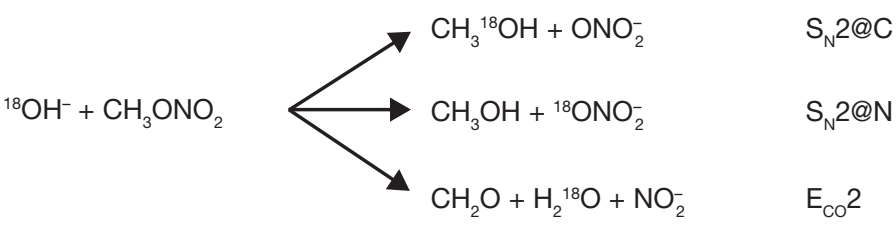

Esquema 1.1 Caminhos de reação entre ${ }^{18} \mathrm{OH}^{-}$e $\mathrm{CH}_{3} \mathrm{ONO}_{2}$ para o nucleófilo marcado isotopicamente.

\subsubsection{Resultados da superfície de energia potencial combinados com cálculos RRKM}

Uma melhor racionalização e compreensão dos resultados obtidos experimentalmente deve ser adquirida possivelmente com cálculos de estrutura eletrônica combinados com estimativas das constantes de velocidade. Para reações íon-molécula em fase gás, é bem comum a utilização da teoria $R R K M,{ }^{70}$ sendo que nessa aproximação o complexo dos reagentes é considerado uma molécula estável e que pode seguir um comportamento de reação unimolecular.

A caracterização da PES realizada com um método combinado de estrutura eletrônica de alto nível, CCSD(T)/CBS//MP2/6-311+G(3df,2p), se encontra na Figura 1.7. Uma característica da reação $\mathrm{CH}_{3} \mathrm{ONO}_{2}+\mathrm{OH}^{-}$é a elevada exotermicidade de todos os canais reacionais caracterizados, o que significa que o controle termodinâmico da seletividade pode ser ignorado.

De maneira geral, os resultados apresentados na Figura 1.7 mostram um acordo qualitativo entre os dados experimentais e as estimativas computacionais das barreiras. Os resultados experimentais mostram que os ataques nucleofílicos de $\mathrm{OH}^{-}$ao $\mathrm{CH}_{3} \mathrm{ONO}_{2}$ produziram os íons nitrito $\left(\mathrm{NO}_{2}^{-}\right)$e nitrato $\left(\mathrm{NO}_{3}^{-}\right)$nas proporções de 0,86 e 0,14 , respectivamente. Essa relação de produtos demonstra a maior preferência do canal de reação $\mathrm{E}_{\mathrm{CO}} 2$ com relação aos canais $\mathrm{S}_{\mathrm{N}} 2$ (no carbono e no nitrogênio). Os resultados computacionais sugerem que essa preferência é consequência de as barreiras de ativação dos canais de reação de eliminação $\left(\mathrm{E}_{\mathrm{CO}} 2 @ \mathrm{H} 1 \mathrm{e}\right.$ $\left.\mathrm{E}_{\mathrm{CO}} 2 @ \mathrm{H} 2\right)$ serem menores que aquelas observadas nos deslocamentos nucleofílicos.

A distribuição dos produtos $\left(\mathrm{NO}_{2}^{-}: \mathrm{NO}_{3}^{-}\right)$foi estimada a partir de cálculos RRKM das constantes de velocidade para cada caminho reacional. O primeiro resultado importante a partir desses cálculos é que as constantes de velocidade para os canais de eliminação são aproximadamente duas ordens de magnitude mais favoráveis do que os canais de substituição. Portanto, os cálculos RRKM indicam que a reação deve ocorrer por meio do mecanismo $\mathrm{E}_{\mathrm{CO}} 2 @ \mathrm{H} 1$, ou seja, 100\% do produto

70 Lourderaj e Hase (2009). 
$\mathrm{NO}_{2}^{-}$. Um esquema mais completo da cinética, como mostrado no Esquema 1.2, que permite a interconversão de RC1 e RC2, produz resultados semelhantes com ambos $\mathrm{RC} 1$ e RC2, favorecendo exclusivamente as vias de eliminação.
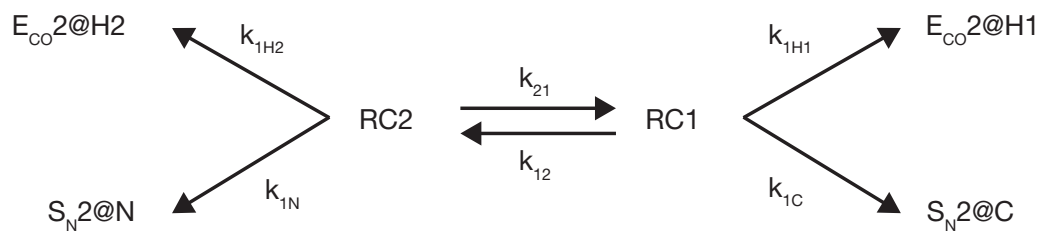

Esquema 1.2 Cinéticas completas das reações unimoleculares associadas aos vários canais provenientes dos complexos de reagentes RC1 e RC2.

Esse modelo cinético com as estimativas RRKM das constantes de velocidade se revela incapaz de descrever a proporção dos produtos observada experimentalmente. De fato, essa abordagem puramente estatística não descreve a razão de o caminho reacional $\mathrm{S}_{\mathrm{N}}$ 2@C ser observado experimentalmente. Além disso, a ausência do caminho $\mathrm{S}_{\mathrm{N}} 2 @ \mathrm{~N}$ é inexplicável, pois, de acordo com o perfil da PES, esse canal reacional tem barreira energética comparável à do canal $\mathrm{S}_{\mathrm{N}} 2 @ \mathrm{C}$. Daí a utilização de simulações de dinâmica direta desse sistema.

\subsubsection{Resultados das simulações BOMD}

O procedimento dinâmico empregado consistiu em realizar espalhamentos do nucleófilo $\mathrm{OH}^{-}$na espécie $\mathrm{CH}_{3} \mathrm{ONO}_{2}$, variando as energias de colisão e as orientações relativas dos dois fragmentos. As trajetórias simuladas foram iniciadas na região dos reagentes, isto é, $\mathrm{OH}^{-} \cdots \mathrm{CH}_{3} \mathrm{ONO}_{2}$ separados por uma distância grande o suficiente para as interações intermoleculares serem desprezíveis. A amostragem quase clássica, que inclui a ZPE, foi usada para selecionar as condições iniciais dos graus de liberdade vibracionais dos fragmentos $\mathrm{OH}^{-}$e $\mathrm{CH}_{3} \mathrm{ONO}_{2}$, sendo selecionadas a partir de suas distribuições de Boltzmann em $300 \mathrm{~K}$. A energia rotacional também foi considerada e selecionada a partir de suas distribuições de Boltzmann em $300 \mathrm{~K}$, considerando cada fragmento como um rotor rígido simétrico. Para a energia translacional relativa (energia de colisão, $E_{c o l}$ ) entre os fragmentos, foi considerado o valor de $1,0 \mathrm{kcal} \mathrm{mol}^{-1}$, consistente com a temperatura de $300 \mathrm{~K}$. Ao todo, foram simuladas 130 trajetórias, sendo propagadas por 2,0 ps. Em razão da demanda computacional, o método M062X/6-31+G(d) foi empregado nas simulações das trajetórias. No entanto, esse método passou por um processo de validação com relação ao método de referência CCSD(T)/CBS//MP2/6-311+G(3df,2p), conforme descrito anteriormente (subseção 1.3.4).

Apesar do pequeno número de trajetórias, ao todo, nas simulações, foram obtidas $74,3 \%$ de trajetórias com colisões reativas. Esse número é bastante satisfatório, o 
que conduz a uma eficiência de reação que suporta uma estatística significativa para a predição da seletividade. Experimentalmente, a proporção de produtos foi 0,86:0,14 $\left(\mathrm{NO}_{2}^{-}: \mathrm{NO}_{3}^{-}\right) .^{71} \mathrm{~A}$ proporção entre produtos $0,72: 0,28$ obtida nas simulações concorda relativamente bem com os resultados experimentais. Um resultado bastante satisfatório e surpreendente nas simulações foi a contribuição do canal de reação $\mathrm{S}_{\mathrm{N}} 2 @ \mathrm{~N}$ ser menor do que 4\%, o que é comparável com o limite de deteç̧ão experimental.

A dinâmica do sistema $\mathrm{CH}_{3} \mathrm{ONO}_{2}+\mathrm{OH}^{-}$é muito rica e diversificada. Ao examinar em detalhes o comportamento das trajetórias, encontra-se uma série de eventos bem distintos dinamicamente. Na Figura 1.8 estão classificadas as trajetórias simuladas quanto ao número de eventos importantes observados na dinâmica. Essa atribuição utilizada na classificação dos eventos dinâmicos das trajetórias observadas enfatiza os aspectos de comportamento fora das condições estatísticas desse sistema reacional.

De fato, a Figura 1.8 mostra um conjunto amplo de eventos em que se justifica um comportamento de natureza fora das condições estatísticas do sistema reacional $\mathrm{CH}_{3} \mathrm{ONO}_{2}+\mathrm{OH}^{-}$:

i. Em $21,5 \%$ das trajetórias foram observados espalhamentos reativos com apenas uma colisão;

ii. O número de recruzamentos de barreira é bastante significativo: ao todo, nas 130 trajetórias, foram observados 49 recruzamentos de barreira, todos associados ao mecanismo $\mathrm{E}_{\mathrm{CO}} 2$;

iii. Aproximadamente 64\% das trajetórias são classificadas como "complexo intermolecular", sendo " $<1$ ps", ou seja, um número significativo das trajetórias reativas levou poucos períodos vibracionais intermoleculares para formar os produtos.

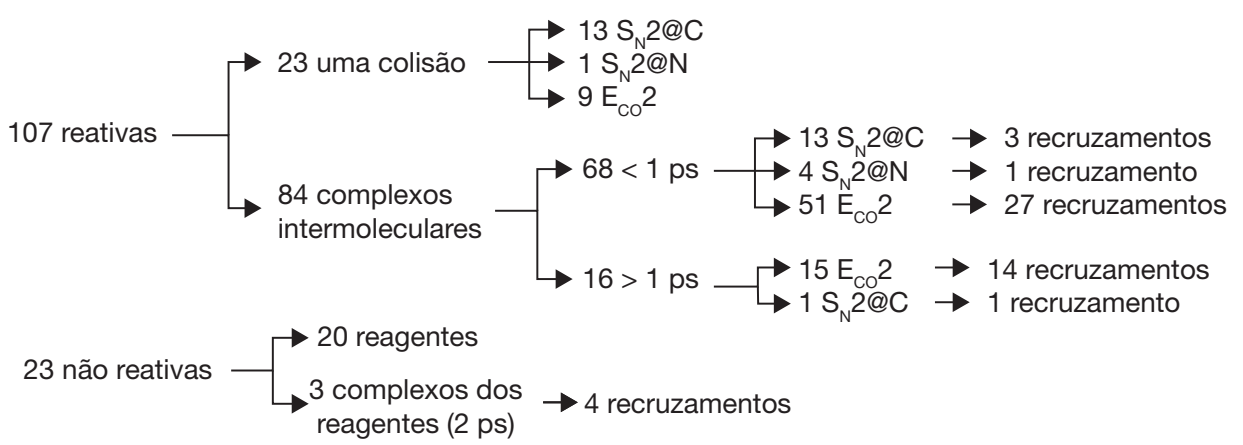

Figura 1.8 Distribuição das trajetórias reativas e não reativas, sendo as primeiras classificadas nos canais de reação caracterizados. Notação: "uma colisão" representa trajetórias que formam os produtos diretamente em um único evento de colisão; "complexo intermolecular" representa as trajetórias que levam pelo menos um período vibracional intermolecular para formar os produtos, sendo classificadas em " $<1$ ps" ou " $>1$ ps", ou seja, o tempo (maior ou menor que

71 Correra e Riveros (2010). 
1,0 ps) necessário para a formação dos produtos; "reagente" são trajetórias que voltam para os reagentes; "complexo reagente ( 2 ps)" são trajetórias que permaneceram na região do complexo dos reagentes por um período de 2,0 ps; e "recruzamento" representa o número total de ocorrência de recruzamento de barreira observado durante as trajetórias do canal especificado.

A Figura 1.9 ilustra trajetórias típicas observadas nas simulações para os canais de reação $\mathrm{S}_{\mathrm{N}} 2 @ \mathrm{C}, \mathrm{E}_{\mathrm{CO}} 2 @ \mathrm{H} 1, \mathrm{E}_{\mathrm{CO}} 2 @ \mathrm{H} 2$ e $\mathrm{S}_{\mathrm{N}} 2 @ \mathrm{~N}$. Nesta figura, estão representadas as dependências temporais de algumas distâncias relevantes no entendimento dinâmico dos mecanismos de reação. Além disso, "fotogramas", ou seja, as estruturas de eventos relevantes da dinâmica, são mostrados ao longo das trajetórias.

A Figura 1.9(i) descreve uma trajetória típica $\mathrm{S}_{\mathrm{N}} 2 @ \mathrm{C} . \mathrm{O}$ detalhe dinâmico em 970 fs mostra o evento da bipirâmide trigonal distorcida. Tal estrutura é encontrada comumente na descrição estática do TS associada ao mecanismo $\mathrm{S}_{\mathrm{N}} 2$. Além disso, essa mesma figura ilustra um recruzamento de barreira rápido (570 fs). De fato, na aproximação inicial dos fragmentos ocorrem três espalhamentos, com a diminuição gradativa da intensidade de espalhamento (acompanhar as variações de $\mathrm{C}-\mathrm{O}_{\mathrm{a}}$ no gráfico). No entanto, antes de o sistema passar pela barreira de ativação do canal de reação $\mathrm{S}_{\mathrm{N}} 2 @ \mathrm{C}$, ocorre uma abstração próton pelo nucleófilo, seguida rapidamente de um recruzamento.
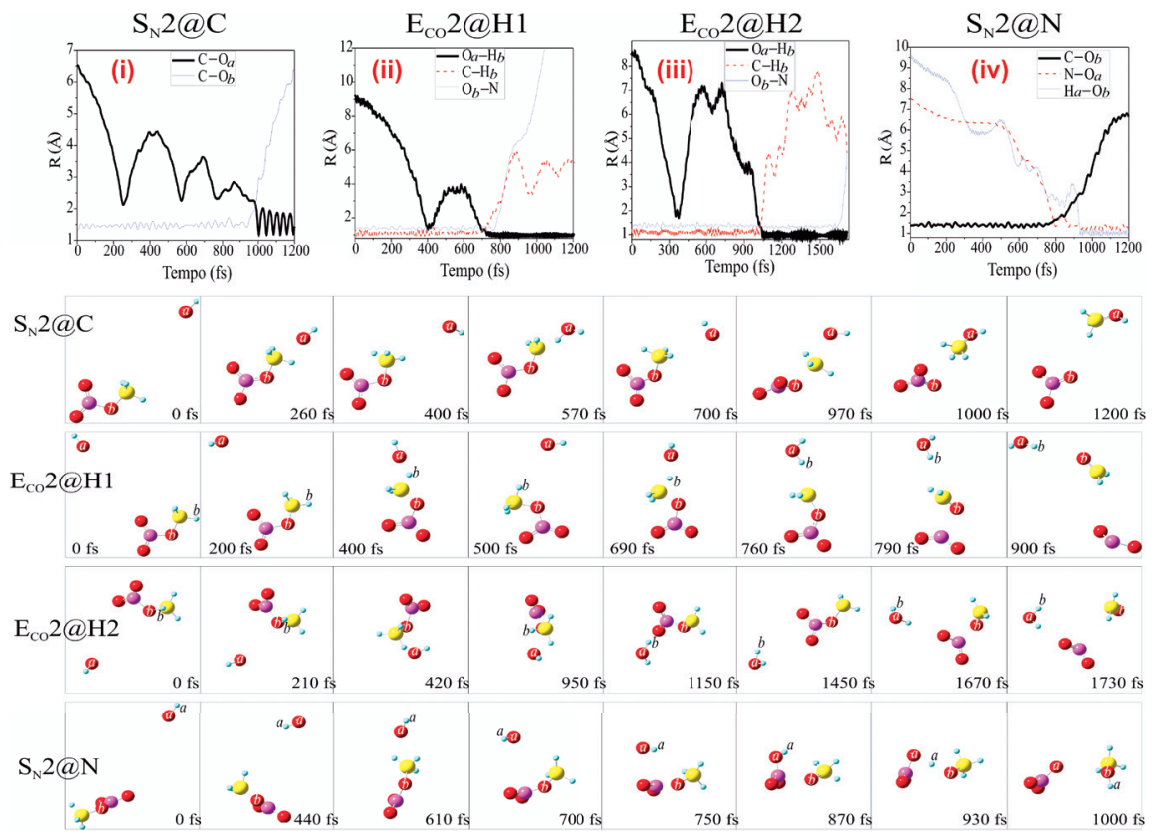

Figura 1.9 No painel superior: distâncias interatômicas relevantes em função do tempo de simulação para as trajetórias associados aos canais (i) $\mathrm{S}_{\mathrm{N}} 2 @ \mathrm{C}$, (ii) $\mathrm{E}_{\mathrm{CO}} 2 @ \mathrm{H} 1$, (iii) $\mathrm{E}_{\mathrm{CO}} 2 @ \mathrm{H} 2 \mathrm{e}$ (iv) $\mathrm{S}_{\mathrm{N}} 2 @ \mathrm{~N}$. No painel inferior: estruturas relevantes ao longo das trajetórias $\mathrm{S}_{\mathrm{N}} 2 @ \mathrm{C}, \mathrm{E}_{\mathrm{CO}} 2 @ \mathrm{H} 1$, $\mathrm{E}_{\mathrm{CO}} 2 @ \mathrm{H} 2$ e (iv) $\mathrm{S}_{\mathrm{N}} 2 @ \mathrm{~N}$. Os rótulos dos átomos encontram-se nas figuras do painel inferior. 
As figuras 1.9(ii) e (iii) retratam os mecanismos de reação rotulados no tra-

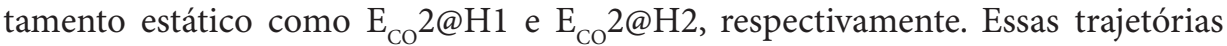
foram escolhidas para enfatizar os aspectos da natureza sincronizada e concertada desses mecanismos. Observe que os eventos reacionais do canal $\mathrm{E}_{\mathrm{CO}} 2 @ \mathrm{H} 1$ são mais rápidos do que os do canal $\mathrm{E}_{\mathrm{CO}} 2 @ \mathrm{H} 2$. Tais eventos estão relacionados com dois passos: a abstração de próton pelo nucleófilo e a fragmentação da ligação $\mathrm{N}-\mathrm{O}$ na espécie $\left[\mathrm{O}_{2} \mathrm{~N}-\mathrm{OCH}_{2}\right]^{-}$.

Por fim, a Figura 1.9(iv) ilustra a trajetória que produziu o produto associado ao canal $\mathrm{S}_{\mathrm{N}} 2 @ \mathrm{~N}$. Inicialmente, observa-se uma rotação da molécula $\mathrm{CH}_{3} \mathrm{ONO}_{2}$ para maximizar a atração entre o nucleófilo $\mathrm{OH}^{-}$e o grupo $-\mathrm{CH}_{3}$. Note que, no tratamento dinâmico, a conservação do momento angular conduz os fragmentos a uma geometria que se assemelha à estrutura RC2, que ocorre em $610 \mathrm{fs}$, e, em seguida, passa por uma estrutura similar ao TS-SN, em 700 fs. Por fim, uma rotação interna da porção $\mathrm{OH}^{-}$, durante um período de $\sim 100 \mathrm{fs}$, culmina com a transferência de próton e a dissociação nos produtos (metanol e íon nitrato).

Uma questão importante no sistema reacional $\mathrm{CH}_{3} \mathrm{ONO}_{2}+\mathrm{OH}^{-}$está na seletividade $\mathrm{S}_{\mathrm{N}} 2 @ \mathrm{C}: \mathrm{S}_{\mathrm{N}} 2 @ \mathrm{~N}$, observada nos experimentos e suportada pelas simulações BOMD. A racionalização dos resultados obtidos nas simulações pode ser atribuída a duas contribuições distintas: (i) o controle dinâmico exercido pelas interações eletrostáticas de longo alcance; e (ii) o comportamento fora das condições estatísticas que privilegia o canal de reação $\mathrm{S}_{\mathrm{N}} 2 @ \mathrm{C}$ em detrimento do $\mathrm{S}_{\mathrm{N}} 2 @ \mathrm{~N}$.

O mapa do potencial eletrostático do nitrato de metila está ilustrado na Figura 1.10. Deve-se notar que o potencial eletrostático perto do átomo de nitrogênio é, relativamente, mais positivo do que aquele observado no átomo de carbono. No entanto, o potencial altamente positivo no átomo de nitrogênio é blindado por um potencial eletrostático muito mais negativo gerado pelos átomos de oxigênio. Essa blindagem eletrostática gerada pelos átomos de oxigênio se torna importante em regiões de longo alcance, o que pode ser observado em "cortes" do mapa do potencial eletrostático do nitrato de metila (Figura 1.10). Portanto, essa proteção eletrostática deve restringir as possibilidades do ataque nucleofílico ao átomo de nitrogênio.

Portanto, como consequência do controle dinâmico exercido pelas interações eletrostáticas de longo alcance, as trajetórias são induzidas, no movimento inicial de aproximação dos fragmentos, a provocar um espalhamento inicial na região da metila. No entanto, se, por um lado, esse efeito eletrostático diminui a possibilidade de deslocamento nucleofílico no átomo de nitrogênio, por outro lado, deve ativar significativamente o canal de reação $\mathrm{S}_{\mathrm{N}} 2 @ \mathrm{C}$. 

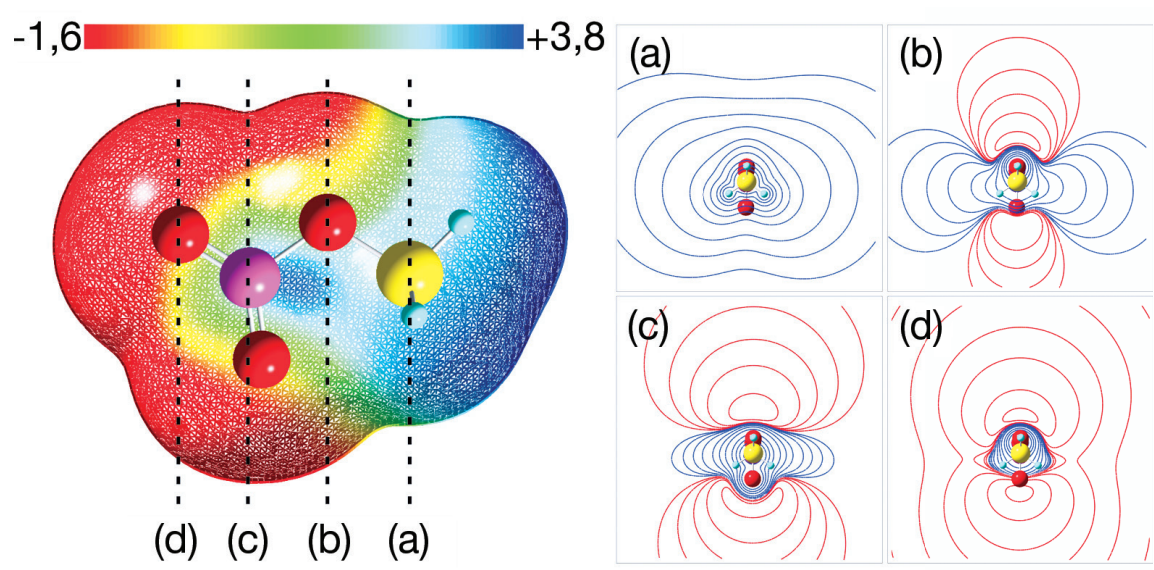

Figura 1.10 Representação do potencial eletrostático de nitrato de metila calculado com o método MP2/6-311+G(3df,2p). No lado direito, (a), (b), (c) e (d) são gráficos de contorno do potencial eletrostático sobre os planos que passam através do átomo de carbono, oxigênio $(\mathrm{N}-\mathrm{O}-\mathrm{C})$, nitrogênio e oxigênio (terminal), respectivamente. Os "cortes" do potencial eletrostático são perpendiculares em relação ao plano de simetria da molécula.

\subsubsection{Comportamento fora das condições estatísticas na reação $\mathrm{CH}_{3} \mathrm{ONO}_{2}+\mathrm{OH}^{-}$}

$\mathrm{Na}$ reação $\mathrm{CH}_{3} \mathrm{ONO}_{2}+\mathrm{OH}^{-}$, a proporção dos produtos, observada experimentalmente, não é descrita adequadamente pela teoria RRKM. De fato, as simulações BOMD produziram uma proporção $\mathrm{S}_{\mathrm{N}} 2 @ \mathrm{C}: \mathrm{E}_{\mathrm{CO}} 2: \mathrm{S}_{\mathrm{N}} 2 @ \mathrm{~N}$, que está em boa concordância com os resultados experimentais. A partir da observação das trajetórias, acredita-se que a falha da abordagem estatística RRKM é consequência de uma combinação de fatores: (i) o controle do potencial eletrostático gerado pelos átomos de oxigênio do grupo $\mathrm{ONO}_{2}$; (ii) reagentes complexos ( $\mathrm{RC} 1$ e RC2) aparentemente não equilibrados; (iii) um número excessivo de recruzamentos de barreira; e (iv) um número considerável de trajetórias diretas (sem a formação do complexo de reagente), isto é, o complexo produto é obtido a partir de apenas uma colisão.

\subsubsection{Conclusão e perspectivas}

As simulações de dinâmica direta, particularmente BOMD, tratada neste capítulo, têm fornecido um entendimento mais completo dos eventos em escala atômico-molecular de mecanismos e seletividades de reações, o que inclui processos unimoleculares, bimoleculares e eventos que ocorrem após o estado de transição, entre outros.

A metodologia dinâmica fornece uma visão mais completa, pois sonda outras regiões da $\mathrm{PES}$ que praticamente não são consideradas na metodologia convencional 
da química computacional (varredura na superfície de energia potencial, na busca por pontos estacionários, combinada com estimativas das constantes de velocidade com base em aproximações estatísticas) no estudo de reações. Assim, a dinâmica descreve os efeitos da superfície de energia potencial e aspectos intrínsecos da dinâmica (a conservação do momento angular, os efeitos associados à energia cinética e a transferência de energia intermolecular e intramolecular). De fato, a aplicação de métodos dinâmicos se torna indispensável para sistemas reacionais que apresentam comportamentos fora das condições estatísticas.

O futuro das simulações de dinâmica direta focará certamente na exatidão, bem como na possibilidade de tratar sistemas cada vez maiores e reações mais complexas. Contudo, para realizar tais avanços, serão necessários a popularização, o desenvolvimento e o aprimoramento de aspectos estratégicos, entre os quais se destacam:

i) A possibilidade de realizar dinâmica direta com métodos de estrutura eletrônica de alto nível, principalmente envolvendo estados excitados e interseções cônicas. No entanto, para isso, torna-se essencial o desenvolvimento de processadores (CPU) de alto desempenho mais poderosos, assim como programas e linguagens de programação científica que acompanhem a evolução desses processadores. Nesse ponto, o conceito CUDA (plataforma de computação paralela) tem se destacado nos últimos anos; $; 2$

ii) O tratamento mais apropriado de alguns efeitos intrínsecos da mecânica quântica, os quais não são considerados na dinâmica direta quase clássica, tais como: interferências entre trajetórias e trocas quantizadas de energia entre os graus de liberdade. Alguns avanços têm sido realizados no tratamento da ZPE. ${ }^{73}$

\section{REFERÊNCIAS}

Allen, M. P.; Tisdesley, D. J. Computer simulation of liquids. Oxford: Clarendon Press, 1991. Ammal, S. C.; Yamataka, H.; Aida, M.; Dupuis, M. Dynamics-driven reaction pathway in an intramolecular rearrangement. Science, 299, p. 1555-1557, 2003.

Anslyn, E. V.; Dougherty, D. A. Modern physical organic chemistry. Sausalito: University Science Book, 2006.

BaChrach, S. M. Computational organic chemistry. Nova York: John Wiley \& Sons, 2007. BAeR, T.; Hase, W. L. Unimolecular reaction dynamics: theory and experiments. 2. ed. Nova York: Oxford University Press, 1999.

72 Wolf (2010).

73 Guo, Thompson e Sewell (1996). 
Bakken, V.; Millam, J. M.; Schlegel, H. B. Ab initio classical trajectories on the Born-Oppenheimer surface: updating methods for Hessian-based integrators. J. Chem. Phys., 111 , p. 8773-8777, 1999.

Blais, N. C.; Bunker, D. L. Monte Carlo calculations. II. The reactions of alkali atoms with methyl iodide. J. Chem. Phys., 37, p. 2713-2720, 1962.

Bolton, K.; Hase, W. L.; Peslherbe, G. H. Direct dynamics simulations of reactive systems. In: Thompson, D. L. (Ed.). Modern methods for multidimensional dynamics computations in chemistry. Londres: World Scientific, 1998. p. 143-189.

Bornemann, F. A.; Schütte, C. A mathematical investigation of the Car-Parrinello method. Numer. Math., 78, p. 359-376, 1998.

Bueker, H.-H.; Helgaker, T.; Ruud, K.; Uggerud, E. Energetics and dynamics of intermolecular proton-transfer processes. 2. Ab initio direct dynamics calculations of the reaction $\mathrm{H}_{3} \mathrm{O}^{+}+\mathrm{NH} 3 \rightarrow \mathrm{NH}^{+}+\mathrm{H} 2 \mathrm{O}$. J. Phys. Chem., 100, p. 15388-15392, 1996.

Bunker, D. L. Monte Carlo calculation of triatomic dissociation rates. I. N2O and O3. J. Chem. Phys., 37, p. 393-403, 1962.

. Classical trajectory methods. Methods Comput. Phys., 10, p. 287-325, 1971.

CAR, R.; DE Angelis, F.; Giannozzi, P.; MARZARI, N. First-principles molecular dynamics. In: YiP, S. (Ed.). Handbook of materials modeling. Amsterdã: Springer, 2005. v. I, p. 59-76.

CAR, R.; PARrinello, M. Unified approach for molecular dynamics and density-functional theory. Phys. Rev. Lett., 55, p. 2471-2474, 1985.

Carpenter, B. K. Intramolecular dynamics for the organic chemist. Acc. Chem. Res., 25, p. $520-528,1992$.

. Dynamic behavior of organic reactive intermediates. Angew. Chem. Int. Ed., 37, p. 3340-3350, 1998.

. Nonexponential decay of reactive intermediates: new challenges for spectroscopic observation, kinetic modeling and mechanistic interpretation. J. Phys. Org. Chem., 16, p. 858-868, 2003.

. Nonstatistical dynamics in thermal reactions of polyatomic molecules. Annu. Rev. Phys. Chem., 56, p. 57-89, 2005.

Chabinyc, M. L.; Craig, S. L.; Regan, C. K.; Brauman, J. I. Gas-phase ionic reactions: dynamics and mechanism of nucleophilic displacements. Science, 279, p. 1882-1886, 1998.

Correra, T. C.; Riveros, J. M. Gas-phase nucleophilic and elimination reactions in simple alkyl nitrates. J. Phys. Chem. A, 114, p. 11910-11919, 2010.

CrAmer, C. J. Essentials of computational chemistry: theory and models. 2. ed. Chichester: Wiley, 2004.

De SouzA, M. A. Estudo computacional de dinâmica de reações químicas. Recife: UFPE, 2012. 
De Souza, M. A.; Correra, T. C.; Riveros, J. M.; Longo, R. L. Selectivity and mechanisms driven by reaction dynamics: the case of the gas-phase $\mathrm{OH}^{-}+\mathrm{CH} 3 \mathrm{ONO} 2$ reaction. J. Am. Chem. Soc., 134, p. 19004-19010, 2012.

Dykstra, C.; Frenking, G.; Kim, K.; Scuseria, G. (Ed.). Theory and applications of computational chemistry: the first forty years. Amsterdã: Elsevier, 2005.

Frenkel, D.; Smit, B. Understanding molecular simulation: from algorithms to applications. Londres: Academic Press, 2002.

GAO, J. Methods and applications of combined quantum mechanical and molecular mechanical potentials. In: Lipkowitz, K. B.; Boyd, D. B. Reviews in computational chemistry. Nova York: John Wiley \& Sons, 1996. v. 7, p. 119-185.

GARGANO, R. Superfície de energia potencial: conexão entre a estrutura eletrônica e a dinâmica molecular. In: Santos, H. F.; Coura, P. Z.; Dantas, S. O.; Barone, P. M. (Ed.). Escola brasileira de estrutura eletrônica. 1. ed. São Paulo: Livraria da Física, 2003. p. 38-66.

GEAR, C. W. Numerical initial value problems in ordinary differential equations. Englewood Cliffs: Prentice Hall, 1971.

Gibson, D. A.; Ionova, I. V.; CARter, E. A. A comparison of Car-Parrinello and Born-Oppenheimer generalized valence bond molecular dynamics. Chem. Phys. Lett., 240, p. 261-267, 1995.

Glowacki, D. R.; Marsden, S. P.; Pilling, M. J. Significance of nonstatistical dynamics in organic reaction mechanisms: time-dependent stereoselectivity in cyclopentyne-alkene cycloadditions. J. Am. Chem. Soc., 131, p. 13896-13897, 2009.

Goldman, L. M.; Glowacki, D. R.; Carpenter, B. K. Nonstatistical dynamics in unlikely places: $[1,5]$ hydrogen migration in chemically activated cyclopentadiene. J. Am. Chem. Soc., 133, p. 5312-5318, 2011.

Gunaydin, H.; Houk, K. N. Molecular dynamics simulation of the HOONO decomposition and the HO•/NO2• Caged radical pair in water. J. Am. Chem. Soc., 130, p. 1003610037, 2008.

Guo, Y.; Thompson, D. L.; Sewell, T. D. Analysis of the zero-point energy problem in classical trajectory simulations. J. Chem. Phys., 104, p. 576-582, 1996.

Hamaguchi, M.; Nakaishi, M.; Nagai, T.; Nakamura, T.; Abe, M. Notable effect of an electron-withdrawing group at $\mathrm{C} 3$ on the selective formation of alkylidenecyclobutanes in the thermal denitrogenation of 4-spirocyclopropane-1-pyrazolines. Nonstatistical dynamics effects in the denitrogenation reactions. J. Am. Chem. Soc., 129, p. 12981-12988, 2007. Hase, W. L. Simulations of gas-phase chemical reactions: applications to SN2 nucleophilic substitution. Science, 266, p. 998-1002, 1994.

Hase, W. L.; Buckowski, D. G. Monte Carlo sampling of a microcanonical ensemble of classical harmonic oscillators. Chem. Phys. Lett., 74, p. 284-287, 1980.

. Dynamics of ethyl radical decomposition. II. Applicability of classical mechanics to large-molecule unimolecular reaction dynamics. J. Comput. Chem., 3, p. 335-343, 1982. 
Hase, W. L.; Duchovic, R. J.; Hu, X.; Komornicki, A.; Lim, K. F.; Lu, D. H. et al. Venus. Quantum Chemistry Program Exchange Bulletin, 16, p. 671, 1996.

Helgaker, T.; Uggerud, E.; Jensen, H. J. Integration of the classical equations of motion on ab initio molecular potential energy surfaces using gradients and hessians: application to translational energy release upon fragmentation. Chem. Phys. Lett., 173, p. 145-150, 1990.

Henriksen, N. E.; Hansen, F. Y. Theories of molecular reaction dynamics: the microscopic foundation of chemical kinetics. Nova York: Oxford University Press, 2008.

Hirst, D. M. Potential energy sufarces: molecular structure and reaction dynamics. Londres: Taylor and Francis, 1985.

Jensen, F. Introduction to computational chemistry. 2. ed. Chichester: Wiley, 2007.

Kuo, I.-F. W.; Mundy, C. J.; McGrath, M. J.; Siepmann, J. I. Time-dependent properties of liquid water: a comparison of Car-Parrinello and Born-Oppenheimer molecular dynamics simulations. J. Chem. Theory Comput., 2, p. 1274-1281, 2006.

Liu, J.; Song, K.; Hase, W. L.; Anderson, S. L. Direct dynamics trajectory study of vibrational effects: can polanyi rules be generalized to a polyatomic system? J. Am. Chem. Soc., 126, p. 8602-8603, 2004.

López, J. G.; Vayner, G.; Lourderaj, U.; Addepalli, S. V.; Kato, S.; de Jong, W. A. et al. A direct dynamics trajectory study of $\mathrm{F}^{-}+\mathrm{CH} 3 \mathrm{OOH}$ reactive collisions reveals a major non-IRC reaction path. J. Am. Chem. Soc., 129, p. 9976-9985, 2007.

LourderaJ, U.; Hase, W. L. Theoretical and computational studies of non-RRKM unimolecular dynamics. J. Phys. Chem. A, 113, p. 2236-2253, 2009.

Lourderaj, U.; Song, K.; Windus, T. L.; Zhuang, Y.; Hase, W. L. Direct dynamics simulations using hessian-based predictor-corrector integration algorithms. J. Chem. Phys., 126, p. 044105-1-044105-11, 2007.

Manikandan, P.; Zhang, J.; Hase, W. L. Chemical dynamics simulations of $\mathrm{X}^{-}+\mathrm{CH} 3 \mathrm{Y}$ $->\mathrm{XCH} 3+\mathrm{Y}^{-}$gas-phase SN2 nucleophilic substitution reactions. Nonstatistical dynamics and nontraditional reaction mechanisms. J. Phys. Chem. A, 116, p. 3061-3080, 2012.

Mann, D. J.; Hase, W. L. Ab initio direct dynamics study of cyclopropyl radical ring-opening. J. Am. Chem. Soc., 124, p. 3208-3209, 2002.

Marx, D.; Hutter, J. Ab initio molecular dynamics: theory and implementation. Cambridge: Cambridge University Press, 2009.

Maseras, F.; Morokuma, M. IMOMM - A new integrated ab-initio plus molecular mechanics geometry optimization scheme of equilibrium structures and transition-states. J. Comput. Chem., 16, p. 1170-1179, 1995.

Mikosch, J.; Trippel, S.; Eichhorn, C.; Otto, R.; Lourderaj, U.; Zhang, J. X. et al. Imaging nucleophilic substitution dynamics. Science, 319, p. 183-186, 2008.

Millam, J. M.; Bakken, V.; Chen, W.; Hase, W. J.; Schlegel, H. B. Ab initio classical trajectories on the Born-Oppenheimer surface: hessian-based integrators using fifth-order polynomial and rational function fits. J. Chem. Phys., 111, p. 3800-3805, 1999. 
Morgon, N. H.; Coutinho, K. (Ed.). Métodos de química teórica e modelagem molecular. São Paulo: Livraria da Física, 2008.

Murrell, J. N.; Carter, S.; Farantos, S. C.; Huxley, P.; Varandas, A. J. Molecular potential energy functions. Chichester: Wiley, 1984.

ÖHrn, Y.; Deumens, E. Towards an ab initio treatment of the time-dependent Schrödinger equation of molecular systems. J. Phys. Chem. A, 103, p. 9545-9551, 1999.

Paranjothy, M.; Sun, R.; Zhuang, Y.; Hase, W. L. Direct chemical dynamics simulations: coupling of classical and quasiclassical trajectories with electronic strucuture theory. Interdisciplinary Reviews: Computational Molecular Science, 3, p. 296-316, 2012.

Peslherbe, G. H.; Wang, H.; Hase, W. L. Unimolecular dynamics of $\mathrm{Cl}^{-}$...CH3Cl intermolecular complexes formed by $\mathrm{Cl}^{-}+\mathrm{CH} 3 \mathrm{Cl}$ association. J. Chem. Phys., 102, p. 5626$5635,1995$.

Monte Carlo sampling for classical trajectory simulations. In: Ferguson, D. M.; Siepmann, J. I.; Truhlar, D. G. (Ed.). Advances in chemical physics: Monte Carlo methods in chemical physics. Nova York: Wiley, 1999. v. 105, p. 171-202.

Polanyi, J. C.; Zewail, A. H. Direct observation of the transition state. Acc. Chem. Res., 28, p. 119-132, 1995.

Press, W. H.; Teukolsky, S. A.; Vetterling, W. T.; Flannery, B. P. Numerical recipes in fortran: the art of scientific computing. Cambridge: University Press, 1992.

Quijano, L. M.; Singleton, D. A. Competition between reaction and intramolecular energy redistribution in solution: observation and nature of nonstatistical dynamics in the ozonolysis of vinyl ethers. J. Am. Chem. Soc., 133, p. 13824-13827, 2011.

Rehbein, J.; CARPenter, B. K. Do we fully understand what controls chemical selectivity? Phys. Chem. Chem. Phys., p. 20906-20922, 2011.

Riveros, J. M.; Maria José, S.; Takashima, K. Gas-phase nuclephilic displacement reactions. In: Gold, V.; Bethell, D. (Ed.). Advances in physical organic chemistry. Londres: Academic Press, 1985. v. 21, p. 197-240.

Rossi, I.; TRuhlar, D. G. Parameterization of NDDO wavefunctions using genetic algorithms. An evolutionary approach to parameterizing potential energy surfaces and direct dynamics calculations for organic reactions. Chem. Phys. Lett., 233, p. 231-236, 1995.

Schwegler, E.; Grossman, J. C.; Gygi, F.; Galli, G. Towards an assessment of the accuracy of density functional theory for first principles simulations of water. II. J. Chem. Phys., 121, p. 5400-5409, 2004.

Sibert, E. L.; Reinhardt, W. P.; Hynes, J. T. Intramolecular vibrational relaxation and spectra of $\mathrm{CH}$ and $\mathrm{CD}$ overtones in benzene and perdeuterobenzene. J. Chem. Phys., 81, p. 1115-1134, 1984.

Singleton, D. A.; Hang, C.; Szymanski, M. J.; Greenwald, E. E. A new form of kinetic isotope effect: dynamic effects on isotopic selectivity and regioselectivity. J. Am. Chem. Soc., 125, p. 1176-1177, 2003. 
STOCK, G.; Müller, U. Flow of zero-point energy and exploration of phase space in classical simulations of quantum relaxation dynamics. J. Chem. Phys., 111, p. 65-76, 1999.

Stoer, J.; Bulirsch, R. Introduction to numerical analysis. Nova York: Springer-Verlag, 1980.

Sun, L.; Hase, W. L. Born-Oppenheimer direct dynamics classical trajectory simulations. In: Lipkowitz, K. B.; LARTER, R.; CUndARI, T. R. (Ed.). Reviews in computational chemistry. Hoboken: John Wiley \& Sons, 2003. v. 19, p. 79-146.

. Ab initio direct dynamics trajectory simulation of $\mathrm{C} 2 \mathrm{H} 5 \mathrm{~F}->\mathrm{C} 2 \mathrm{H} 4+\mathrm{HF}$ product energy partitioning. J. Chem. Phys., 121, p. 8831-8845, 2004.

Sun, L.; Hase, W. L.; Song, K. Trajectory studies of SN2 nucleophilic substitution. 8. Central barrier dynamics for gas phase $\mathrm{Cl}^{-}+\mathrm{CH} 3 \mathrm{Cl}$. J. Am. Chem. Soc., 123, p. 5753-5756, 2001.

Sun, L.; SonG, K.; HASE, W. L. SN2 reaction that avoids its deep potential energy minimum. Science, 296, p. 875-878, 2002.

Svensson, M.; Humbel, S.; Froese, R. D.; Matsubara, T.; Sieber, S.; Morokuma, K. ONIOM: a multi-layered integrated $\mathrm{MO}+\mathrm{MM}$ method for geometry optimizations and single point energy predictions. A test for Diels-Alder reactions and $[\mathrm{Pt}(\mathrm{P}(\mathrm{t}-\mathrm{Bu}) 3) 2]+\mathrm{H} 2$ oxidative addition. J. Phys. Chem., 100, p. 19357-19363, 1996.

Szabo, A.; Ostlund, N. S. Modern quantum chemistry: introduction to advanced eletronic structure theory. Nova York: Dover, 1989.

TAngney, P. On the theory underlying the Car-Parrinello method and the role of the fictitious mass parameter. J. Chem. Phys., 124, p. 044111-1-044111-14, 2006.

Tangney, P.; Scandolo, S. How well do Car-Parrinello simulations reproduce the Born-Oppenheimer surface? Theory and examples. J. Chem. Phys., 116, p. 14-24, 2002.

Trout, B. L. Car-Parrinello methods in chemical engineering: their scope and potential. In: WEI, J.Advances in Chemical Engineering. San Diego: Academic Press, v. 28, p. 353-397, 2001.

Uggerud, E.; Helgaker, T. Dynamics of the reaction $\mathrm{CH}_{2} \mathrm{OH}^{+}-->\mathrm{CHO}^{+}+\mathrm{H} 2$. Translational energy release from ab initio trajectory calculations. J. Am. Chem. Soc., 114, p. $4265-$ 4268, 1992.

Wang, I. S.; Karplus, M. Dynamics of organic reactions. J. Am. Chem. Soc., 95, p. 8160$8164,1973$.

Wolf, L. K. The GPU revolution. Chemical \& Engineering News, 88, p. 27-29, 2010.

WyAtT, R. E.; IUng, C.; LeForestier, C. Quantum dynamics of overtone relaxation in benzene. II. 16 mode model for relaxation from CH(v=3). J. Chem. Phys., 97, p. 3477-3486, 1992. 


\section{ALGORITMOS PARA O MÉTODO MONTE CARLO QUÂNTICO}

0 ajuste variacional

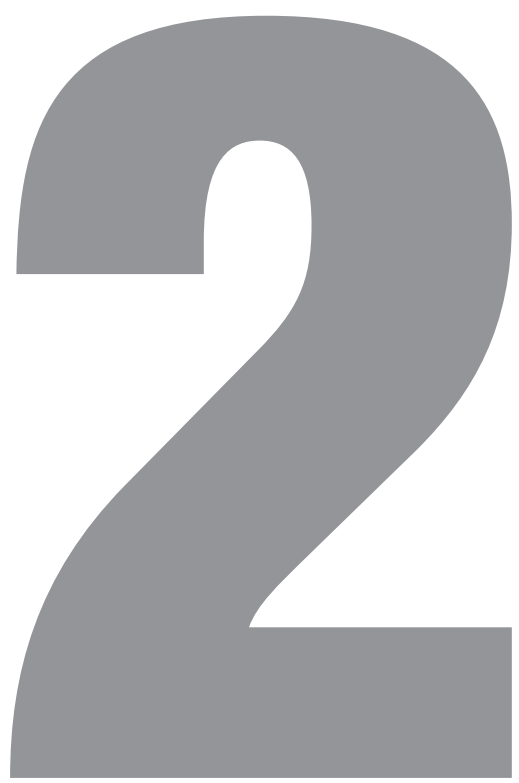

Rogério Custodio 


\subsection{INTRODUÇÃO}

Cálculos de estrutura eletrônica representam um desafio e um dos primeiros sucessos no estabelecimento da mecânica quântica. A solução do espectro eletrônico do átomo de hidrogênio por Bohr foi um dos marcos da ciência do século XX. Apesar do modelo equivocado, a utilização das hipóteses de quantização da energia e do momento angular, desenvolvidas por Planck ${ }^{2}$ e Einstein, ${ }^{3}$ indicava que o universo deveria ser representado por uma nova visão mecânica. A teoria capaz de descrever rigorosamente todos os fenômenos vem confirmando a formulação de Schrödinger/Heisenberg ${ }^{4}$ como a representação fundamental a ser utilizada para representar, por exemplo, a distribuição eletrônica. Em resumo, a natureza do universo deve ser resolvida a partir da equação de Schrödinger, independente ou dependentemente do tempo.

Especificamente em relação aos problemas de estrutura eletrônica, o que se pretende é encontrar uma função de onda que represente da melhor maneira possível o sistema físico em questão e por meio da qual serão determinadas suas propriedades estacionárias e/ou dinâmicas. De acordo com os postulados da mecânica quântica, as exigências fundamentais para que se tenha uma função de onda aceitável são que seja bem comportada e que satisfaça a equação de Schrödinger. ${ }^{5}$ Usualmente, analisa-se o problema físico em questão, constrói-se a equação de Schrödinger apropriada ao sistema, definem-se as condições de contorno apropriadas e procuram-se as soluções bem comportadas. No tratamento de elétrons, é necessário, ainda, que a função de onda represente um estado que caracterize uma distribuição de férmions. Matematicamente, essa restrição determina que a função

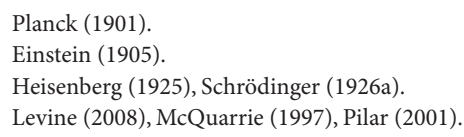


de onda troque de sinal quando dois elétrons quaisquer tenham suas coordenadas trocadas. Quando se considera mais de um estado eletrônico, ou seja, mais de uma função de onda para representar cada um desses estados, essas funções de onda devem ainda ser ortogonais entre si.

Tais condições são sempre consideradas para se desenhar a função de onda ideal ou aproximada a fim de representar um sistema eletrônico qualquer. Não existe um único caminho para o desenvolvimento de uma função de onda ideal. Em alguns casos, busca-se a solução por meio da equação diferencial de Schrödinger ou considera-se o uso do princípio variacional, que determina que qualquer função de onda tentativa produzirá uma energia maior do que a energia exata do sistema e, na melhor das hipóteses, reproduzirá a energia exata.

Grande parte dos métodos matemáticos utilizados para descrever estados eletrônicos teve seu desenvolvimento inicial nos primeiros 15 anos após as formulações de Heisenberg, em 1925, ${ }^{6}$ e de Schrödinger, em 1926, ${ }^{7}$ sobre a mecânica quântica. Essa afirmação pode ser verificada na literatura nos trabalhos seminais da teoria do funcional de densidade desenvolvidos por Thomas ${ }^{8}$ e Fermi, ${ }^{9}$ o método autoconsistente de Hartree, ${ }^{10}$ o modelo de ligação de valência de Heitler ${ }^{11}$ e a teoria de orbitais moleculares por meio da combinação linear de orbitais atômicos por Mulliken, em 1927, ${ }^{12}$ e Hückel, em $1930,{ }^{13}$ a formulação relativística de Dirac, em $1928,{ }^{14}$ o método de interação de configurações por Hylleraas, em $1929,{ }^{15}$ a teoria de perturbação desenvolvida por Schrödinger ${ }^{16}$ e Møller e Plesset,${ }^{17}$ o método multiconfiguracional de Hartree, em $1939,{ }^{18}$ etc.

Muitos dos desenvolvimentos que ocorreram na tentativa de resolver a equação de Schrödinger estão associados com a evolução dos recursos computacionais. Pode-se dizer que a escala de evolução dos métodos de solução teve um avanço considerável a partir do desenvolvimento de computadores. Diferente do método Hartree-Fock, ${ }^{19}$ algumas alternativas numéricas ficaram esquecidas por falta de recursos computacionais para sua solução. Uma dessas alternativas foi indicada pelo próprio Schrödinger, que observou uma enorme semelhança entre sua equação dependente do tempo e a equação de difusão definida pelas leis de Fick. ${ }^{20}$ Essa percepção levou Schrödinger a considerar a possibilidade de tratar sistemas quânticos

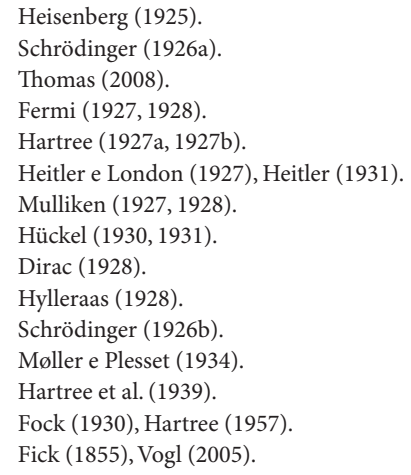


a partir de procedimentos semelhantes aos usados em métodos de difusão. Embora tenha notado a semelhança, Schrödinger não conseguiu imaginar a utilidade dessa constatação, mas concluiu suas observações, otimista de que isso provavelmente ocorreria no futuro. ${ }^{21}$

Próximo do final do século XX, são iniciadas tentativas de tratar a equação de Schrödinger dependente do tempo como um processo de difusão para férmions ou bósons. Esses métodos foram denominados Monte Carlo Quântico (MCQ), uma vez que usam processos estocásticos para determinar a solução da equação de Schrödinger. ${ }^{22}$ Ao longo dos últimos anos, diferentes versões do método MCQ foram desenvolvidas e várias revisões aparecem na literatura indicando o sucesso das aplicações em uma diversidade de sistemas, abrangendo desde átomos e moléculas até sistemas periódicos. ${ }^{23} \mathrm{O}$ método mais popular dentre as versões do MCQ é conhecido como Monte Carlo de Difusão (MCD). ${ }^{24}$ Para utilizar o MCD para férmions, é necessário utilizar uma função de onda que descreva a superfície nodal da distribuição. Quanto mais próxima da superfície nodal exata, mais próxima da solução exata estará a solução obtida pelo MCD. Uma maneira de gerar funções de onda com superfícies nodais precisas é feita por meio do método denominado Monte Carlo Variacional (MCV). ${ }^{25}$

Nessa versão do método $\mathrm{MCQ}$, a função de onda é desenvolvida em qualquer nível de sofisticação e submetida ao cálculo da energia, empregando o teorema do valor médio. Uma vez que funções de onda são dependentes de parâmetros arbitrários, deve-se minimizar a energia do sistema de interesse em relação a esses parâmetros, o que corresponde a empregar o princípio variacional. Os resultados obtidos com o MCV, por si só, são utilizáveis para a análise de propriedades atômicas e moleculares em geral. Mesmo com a possibilidade de se desenvolverem funções de onda extremamente complexas, o método MCV usualmente é visto apenas como um gerador de funções de onda tentativa para o MCD. Neste texto serão apresentados detalhes do método MCV, que pode muito bem ser considerado como um método extremamente poderoso para o cálculo de propriedades eletrônicas para funções de onda de alto nível de sofisticação.

\subsection{DesCrição Geral do MCV}

O método MCV se inicia com o teorema do valor médio de uma propriedade descrita pelo operador $\hat{o}$ :

\footnotetext{
21 Schrödinger (1931).

22 Angelotti et al. (2008).

23 Lester e Hammond (1990), Luchow e Anderson (2000), Austin et al. (2012), Foulkes et al. (2001).

24 Manten e Lüchow (2001), Reynolds e Ceperley (1982), Caffarel e Claverie (1988).

25 Bahnsen et al. (2001), Bressanini e Reynolds (1998), Eckstein e Schattke (1995), Pratt (1989), Schmidt e Moskowitz (1990), Moskowitz e Kalos (1981), Yoshida e Iguchi (1989).
} 


$$
\langle o\rangle=\frac{\int \psi^{\star} \hat{o} \psi d \tau^{\prime}}{\int \psi^{\star} \psi d \tau^{\prime}}
$$

sendo $\Psi$ a função de onda que descreve o sistema, e a integração sendo realizada sobre todas as coordenadas espaciais e de spin de todas as partículas do sistema. Quando o operador $\hat{o}$ for o operador hamiltoniano, $\hat{\mathrm{H}}$, tem-se a energia média do sistema:

$$
E=\frac{\int \psi^{\star} \hat{\mathrm{H}} \psi \mathrm{d} \tau^{\prime}}{\int \psi^{\star} \psi \mathrm{d} \tau^{\prime}}
$$

A Equação 2.2 pode ser reescrita dividindo-se e multiplicando-se o lado direito do operador hamiltoniano pela função de onda, mantendo a equação inalterada:

$$
E=\frac{\int \psi^{\star} \psi\left(\frac{\hat{\mathrm{H}} \psi}{\psi}\right) \mathrm{d} \tau^{\prime}}{\int \psi^{\star} \psi \mathrm{d} \tau^{\prime}}
$$

O termo entre parênteses é definido como sendo a energia local do sistema:

$$
E_{\text {local }}=\frac{\hat{\mathrm{H}} \psi}{\psi}
$$

ou seja, se a função de onda for autofunção do operador hamiltoniano, a energia local será constante e, caso a função de onda não seja autofunção desse operador, ela dependerá das coordenadas instantâneas de cada partícula considerada na função de onda.

Uma vez que o operador hamiltoniano é definido como a soma dos operadores de energia cinética $(\hat{T})$ e potencial $(\hat{V})$, a Equação 2.4 será escrita como:

$$
E_{\text {local }}=\frac{\hat{\mathrm{T}} \psi}{\psi}+\frac{\hat{\mathrm{V}} \psi}{\psi}
$$

Sendo o operador de energia potencial um operador multiplicativo, a Equação 2.5 pode ser simplificada para:

$$
E_{\text {local }} \frac{\hat{T} \psi}{\psi}+V
$$


A definição de energia local expressa pela Equação 2.6 mostra que a componente de energia potencial local é determinada a partir de sua definição clássica e é calculada de forma trivial a partir das coordenadas instantâneas das partículas distribuídas no espaço. Dessa forma, ao contrário do que usualmente ocorre com os métodos quânticos convencionais, a etapa mais complicada do cálculo da energia local está na componente cinética, e não na potencial. Obviamente, o esforço para o cálculo da energia cinética local é consideravelmente menor do que, por exemplo, o cálculo das energias de repulsão de Coulomb ou de troca nos métodos convencionais.

Substituindo a Equação 2.6 na Equação 2.3, chega-se a:

$$
E=\frac{\int \psi^{\star} \psi\left(\frac{\hat{T} \psi}{\psi}+V\right) \mathrm{d} \tau^{\prime}}{\int \psi^{*} \psi \mathrm{d} \tau^{\prime}}
$$

Um aspecto normalmente não explicitado na Equação 2.7 é que a ela pode ser integrada considerando a densidade de probabilidade normalizada expressa por:

$$
P=\frac{\psi^{\star} \psi}{\int \psi^{\star} \psi \mathrm{d} \tau^{\prime}}
$$

Se as coordenadas de todas as partículas forem deslocadas aleatoriamente, mapeando as regiões de maior probabilidade, as equações 2.7 ou 2.3 poderão ser escritas como:

$$
E \cong \sum_{i=1}^{k}\left(\frac{\hat{T} \psi}{\psi}+V\right)_{\psi^{*} \psi}
$$

Ou simplesmente:

$$
E \cong \sum_{i=1}^{k}\left(\frac{\hat{H} \psi}{\psi}\right)_{\psi^{*} \psi}=\sum_{i=1}^{k}\left(E_{\text {local }}\right)_{\psi^{*} \psi}
$$

sendo $k$ o número de passos em que as coordenadas de todas as partículas foram modificadas. Se o número de passos tende ao infinito, a energia obtida tende ao valor exato da integral. $O$ erro nesse cálculo é expresso pelo desvio padrão calculado convencionalmente como: 


$$
\sigma=\sqrt{\frac{\left\langle E_{L}^{2}\right\rangle_{|\psi|^{2}}-\left\langle E_{L}\right\rangle_{|\psi|^{2}}^{2}}{k-1}}
$$

em que $\left\langle E_{L}^{2}>\right.$ corresponde ao valor médio da energia local elevada ao quadrado e $\left\langle E_{L}\right\rangle^{2}=E^{2}$ ao quadrado do valor médio da energia total.

As equações 2.9 ou 2.10 são a essência do método MCV. O espaço de coordenadas de todas as partículas é mapeado aleatoriamente, utilizando a densidade de probabilidade (Equação 2.8), e a melhor função de onda tentativa que foi criada para descrever o sistema de interesse será aquela que apresentar a menor energia média, isto é, o MCV. Pode-se perceber que, por mais sofisticada que seja a função de onda, a maior dificuldade técnica está na determinação da energia cinética local.

\subsection{Utilizando o Algoritmo de Metropolis}

Embora a descrição do método seja bastante simples, existem algumas questões formais ou práticas a serem resolvidas. Em primeiro lugar, é necessário definir como o espaço de configurações será mapeado; em segundo lugar, quais funções de onda poderão ser utilizadas para se obter uma solução numérica apropriada.

A resposta para a primeira questão é bem conhecida, e o mapeamento do espaço de configurações é definido pelo Algoritmo de Metropolis. ${ }^{26}$ Por espaço de configurações entende-se um retrato instantâneo das coordenadas de todas as partículas do sistema descritas pela função de onda. Em outras palavras, considere que está sendo estudada a estrutura eletrônica de um sistema contendo $\mathrm{N}$ elétrons. Cada um desses elétrons pode ser representado por um conjunto de 3 coordenadas espaciais $(x, y, z)$ e 1 coordenada de spin $(\zeta)$. A função de onda eletrônica total do sistema será escrita como:

$$
\Psi=\Psi\left(\mathrm{x}_{1}, \mathrm{y}_{1}, \mathrm{z}_{1}, \zeta_{1}, \mathrm{x}_{2}, \mathrm{y}_{2}, \mathrm{z}_{2}, \zeta_{2}, \ldots, \mathrm{x}_{\mathrm{N}}, \mathrm{y}_{\mathrm{N}}, \mathrm{z}_{\mathrm{N}}, \zeta_{\mathrm{N}}\right)
$$

Aqui surge uma dificuldade fundamental que será resolvida mais adiante. Enquanto as coordenadas espaciais podem ser representadas por valores numéricos, $\mathrm{o}$ mesmo não é possível em relação às coordenadas de spin. Existem duas maneiras de se resolver esse problema, mas será considerado, em um primeiro momento, que a função de onda será descrita apenas pelas coordenadas espaciais, ou seja:

$$
\Psi=\Psi\left(\mathrm{x}_{1}, \mathrm{y}_{1}, \mathrm{z}_{1}, \mathrm{x}_{2}, \mathrm{y}_{2}, \mathrm{z}_{2}, \ldots, \mathrm{x}_{\mathrm{N}}, \mathrm{y}_{\mathrm{N}}, \mathrm{z}_{\mathrm{N}}\right)
$$

26 Metropolis et al. (1953). 
Uma configuração será entendida como um retrato instantâneo de todos os elétrons do sistema em coordenadas espaciais arbitrárias. Esse retrato instantâneo eletrônico definirá uma função de onda que será denominada $\Psi_{\text {old }}$ e permitirá calcular a densidade de probabilidade:

$\Psi_{\text {old }}^{*} \Psi_{\text {old }}=\Psi_{\text {old }}^{*}\left(\mathrm{x}_{1}, \mathrm{y}_{1}, \mathrm{z}_{1}, \mathrm{x}_{2}, \mathrm{y}_{2}, \mathrm{z}_{2}, \ldots, \mathrm{x}_{\mathrm{N}}, \mathrm{y}_{\mathrm{N}}, \mathrm{z}_{\mathrm{N}}\right) \Psi_{\text {old }}\left(\mathrm{x}_{1}, \mathrm{y}_{1}, \mathrm{z}_{1}, \mathrm{x}_{2}, \mathrm{y}_{2}, \mathrm{z}_{2}, \ldots, \mathrm{x}_{\mathrm{N}}, \mathrm{y}_{\mathrm{N}}, \mathrm{z}_{\mathrm{N}}\right)$

Para se aplicar o Algoritmo de Metropolis nesse estado eletrônico, é necessário que as coordenadas sejam modificadas aleatoriamente. Existem duas possibilidades de se fazer essa modificação nas coordenadas. Podem-se modificar as coordenadas de todos os elétrons ao mesmo tempo ou podem-se modificar as coordenadas de cada um dos elétrons de cada vez. Usualmente, em função da eficiência computacional, emprega-se a segunda opção, ou seja, modificam-se as coordenadas do primeiro elétron, depois as coordenadas do segundo elétron e assim sucessivamente, até que todos os elétrons tenham sido testados.

A modificação nas coordenadas espaciais também pode ser feita de diferentes maneiras. Em termos práticos, uma alternativa para criar novas coordenadas para, por exemplo, o elétron 1 seria:

$$
\begin{aligned}
& x_{1}^{\prime}=x_{1}+(0,5-\text { rand }) \delta \\
& y_{1}^{\prime}=y_{1}+(0,5-\text { rand }) \delta \\
& z_{1}^{\prime}=z_{1}+(0,5-\text { rand }) \delta
\end{aligned}
$$

sendo rand um gerador de números aleatórios com distribuição uniforme entre 0 e 1 e $\delta$ um parâmetro que define o intervalo máximo de modificação para cada coordenada. Se $\delta=1$, as coordenadas serão modificadas dentro do intervalo de $\pm 0,5$; se $\delta$ $=2$, as coordenadas serão modificadas dentro do intervalo de \pm 1 etc. A escolha apropriada do valor de $\delta$ será feita adiante. Com as novas coordenadas para o elétron 1 , pode-se calcular uma nova densidade de probabilidade com a função de onda, que representa agora uma nova configuração para o sistema:

$\Psi_{\text {new }}^{*} \Psi_{\text {new }}=\Psi_{\text {new }}^{*}\left(\mathrm{x}_{1}, \mathrm{y}_{1}, \mathrm{z}_{1}, \mathrm{x}_{2}, \mathrm{y}_{2}, \mathrm{z}_{2}, \ldots, \mathrm{x}_{\mathrm{N}}, \mathrm{y}_{\mathrm{N}}, \mathrm{z}_{\mathrm{N}}\right) \Psi_{\text {new }}\left(\mathrm{x}_{1}, \mathrm{y}_{1}, \mathrm{z}_{1}, \mathrm{x}_{2}, \mathrm{y}_{2}, \mathrm{z}_{2}, \ldots, \mathrm{x}_{\mathrm{N}}, \mathrm{y}_{\mathrm{N}}, \mathrm{z}_{\mathrm{N}}\right)$

Com as duas densidades de probabilidade (equações 2.14 e 2.16), o Algoritmo de Metropolis estabelece o critério se a mudança de coordenadas deve ser aceita ou não a partir do que se denomina probabilidade de transição. A probabilidade de transição $(P)$ é expressa por:

$$
P=\frac{\psi_{\text {new }}^{*} \Psi_{\text {new }}}{\psi_{\text {old }}^{*} \psi_{\text {old }}}
$$


Se a densidade de probabilidade com as novas coordenadas for maior do que com as coordenadas antigas, a probabilidade de transição será maior do que $1(P>1)$, e as novas coordenadas são aceitas. Caso a probabilidade de transição seja menor do que 1, ela será comparada com um número aleatório com distribuição uniforme entre 0 e 1 (rand). Se a probabilidade de transição for maior ou igual ao número aleatório $(P \geq$ rand), as novas coordenadas serão aceitas, mesmo tendo apresentado uma densidade de probabilidade menor do que a anterior. Se a probabilidade de transição for menor do que o número aleatório $(P<$ hand $)$, as novas coordenadas serão descartadas e preservam-se as coordenadas antigas.

Esse procedimento será repetido várias vezes para todos os elétrons do sistema. Quando todos os elétrons tiverem suas coordenadas submetidas ao Algoritmo de Metropolis, calcula-se a energia local (Equação 2.6), com a função de onda e todas as coordenadas modificadas ou não. Para cada ciclo de Metropolis, ou seja, depois que todos os elétrons tiverem suas coordenadas reavaliadas, a energia local é calculada. O valor médio da energia eletrônica total é obtido utilizando a Equação 2.10. O número de passos é definido de tal forma que a energia média convirja para um valor praticamente constante. Em cálculos MCV, este número de passos usualmente se refere a milhares de ciclos. É possível dizer ainda que várias informações estatísticas podem ser calculadas a partir dos milhares de valores de energias locais, definindo a precisão do cálculo realizado, tais como desvios padrões, variâncias etc.

Resumidamente, pode-se sistematizar o Algoritmo de Metropolis por meio do seguinte conjunto de instruções:

1. Crie um conjunto de pontos, coordenadas ou configurações $\left\{\mathbf{r}_{1}, \mathbf{r}_{2}, \ldots\right.$ $\left.\ldots, \mathbf{r}_{\mathrm{M}}\right\}$ arbitrárias e calcule o valor de $\mathrm{g}_{\text {old }}(\mathbf{r})=\left|\Psi_{\text {old }}\left(\mathbf{r}_{1}, \mathbf{r}_{2}, \ldots, \mathbf{r}_{\mathrm{M}}\right)\right|^{2}$, sendo $\mathbf{r}_{1}=\left\{x_{1}, y_{1}, z_{1}\right\}, \mathbf{r}_{2}=\left\{x_{2}, y_{2}, z_{2}\right\}$, e assim sucessivamente, ou qualquer outro sistema de coordenadas apropriado.

2. Altere o valor das coordenadas aleatoriamente e calcule o valor de $\mathrm{g}_{\text {new }}(\mathbf{r})=\left|\Psi_{\text {old }}\left(\mathbf{r}_{1}, \mathbf{r}_{2}{ }_{2}, \ldots, \mathbf{r}_{\mathrm{M}}\right)\right|^{2}$ com as coordenadas modificadas. Pode-se considerar a mudança das coordenadas de partículas individualmente ou todo o conjunto de elétrons.

3. Efetue a razão entre a densidade de probabilidade com as coordenadas novas pela obtida com as coordenadas antigas, $g_{\text {new }}\left(\mathbf{r}_{1}, \mathbf{r}_{2}, \ldots, \mathbf{r}_{\mathrm{M}}\right) /$ $g_{\text {old }}\left(\mathbf{r}_{1}, \mathbf{r}_{2}, \ldots, \mathbf{r}_{\mathrm{M}}\right)=P$.

4. Compare a probabilidade de transição $P$ com um número aleatório com distribuição uniforme entre 0 e 1 . Se $P$ for maior do que o número aleatório, então as novas coordenadas devem ser aceitas e substituir as antigas. Se a razão $P$ for menor do que o número aleatório, as novas coordenadas devem ser descartadas e as coordenadas antigas, preservadas. Se as coordenadas de apenas uma partícula foram alteradas, será necessário voltar à etapa 2 e repetir esse processo para outra partícula, até que todas tenham sido avaliadas. 
5. Com todas as coordenadas de todas as partículas testadas, calcule o valor da energia local usando a Equação 2.4 ou a Equação 2.5. Outras propriedades podem ser calculadas com a respectiva definição de propriedade local. Tanto para a energia quanto para outra propriedade, acumule o resultado para determinar uma média.

6. Se a média não tiver alcançado um valor constante, volte à etapa $2 \mathrm{e}$ repita todo o processo.

Um último detalhe a ser mencionado se refere ao controle desse processo por meio de uma taxa de aceitação, tx, a qual se refere à razão entre o número de vezes em que as modificações nas coordenadas foram aceitas dividido pelo número total de tentativas realizadas, ou seja, tx $=N_{\text {aceitos }} / N_{\text {total }}$. Essa taxa de aceitação pode ser controlada em função dos deslocamentos produzidos nas coordenadas eletrônicas. $\mathrm{Na}$ Equação 2.15, o intervalo permitido de alteração de cada coordenada é definido pelo parâmetro $\delta$. Modificando o parâmetro $\delta$, modifica-se a taxa de aceitação. Sem incluir recursos mais sofisticados ao método $\mathrm{MCV}$, costuma-se estabelecer o valor de $\delta$ de forma a proporcionar uma taxa de aceitação de 0,5 , ou seja, $50 \%$ das modificações das coordenadas eletrônicas são aceitas.

A grande vantagem do método Monte Carlo Variacional está no fato de que, para se determinar o valor da energia ou qualquer outra propriedade de um sistema empregando o teorema do valor médio, basta utilizar o Algoritmo de Metropolis e calcular o valor da propriedade local em um número grande de possíveis configurações. Usualmente, as propriedades locais exigem a determinação de uma derivada ou simplesmente a definição clássica do operador utilizado.

A desvantagem está na necessidade de ter que definir a função de onda tentativa e testar diferentes alternativas que levem à representação de menor energia possível.

\subsection{DEFININDO A FUNÇ̧̃̃O DE ONDA TENTATIVA}

Uma vez definido o procedimento MCV geral, o aspecto mais importante a ser resolvido é estabelecer a forma apropriada da função de onda tentativa a ser utilizada. Deve-se lembrar que, para o estudo de estruturas eletrônicas, a função de onda deve representar uma distribuição de férmions e, portanto, ser antissimétrica com relação à troca de coordenadas entre duas partículas quaisquer. Qualquer função de onda tentativa deve ainda ser "bem comportada" e apresentar um comportamento assintótico apropriado.

A energia local calculada com a função de onda tentativa deve ter um valor finito para qualquer conjunto de coordenadas espaciais. As singularidades que possam surgir no potencial pela sobreposição de coordenadas durante as simulações devem ser compensadas pelo termo de energia cinética local. Essa condição particular de singularidade é conhecida como cúspide nuclear ou eletrônico, dependendo 
das partículas às quais o potencial se refere. ${ }^{27}$ Para que a condição de cúspide seja corrigida, no caso da sobreposição núcleo-elétron, verifica-se que uma função de onda bem comportada satisfaz a relação:

$$
\left.\frac{1}{\Psi\left(r_{i \mathrm{~A}}=0\right)} \frac{\partial \Psi}{\partial r_{i \mathrm{~A}}}\right|_{r_{\mathrm{A}}=0}=-Z_{\mathrm{A}}
$$

sendo $Z_{\mathrm{A}}$ a carga nuclear do núcleo $A$ e $r_{i \mathrm{~A}}$ correspondente à distância do elétron $i$ em relação ao núcleo $A$. Para a sobreposição de coordenadas eletrônicas, as condições de cúspide a serem obedecidas são:

$$
\begin{aligned}
& \left.\frac{1}{\Psi\left(r_{i j}=0\right)} \frac{\partial \Psi}{\partial r_{i j}}\right|_{r_{i j}=0}=\frac{1}{4} \quad \text { (para elétrons com spins paralelos) } \\
& \left.\frac{1}{\Psi\left(r_{i j}=0\right)} \frac{\partial \Psi}{\partial r_{i j}}\right|_{r_{i j}=0}=\frac{1}{2} \quad \text { (para elétrons com spins opostos) }
\end{aligned}
$$

sendo $r_{i j}$ a distância intereletrônica.

Existem diferentes possibilidades de construção de funções de onda bem comportadas e antissimétricas que também satisfazem as condições de cúspide. Em relação ao método MCQ, as alternativas mais utilizadas são fundamentadas em funções de onda tentativa escritas como um determinante de Slater multiplicado por uma função de correlação explícita ou, então, uma combinação linear de determinantes de Slater (funções de onda multiconfiguracionais ou de interação de configurações - CI), multiplicado ou não por uma função de correlação explícita. Porém, além das questões relacionadas ao cúspide eletrônico e nuclear, que estão intimamente relacionadas com questões de correlação eletrônica, o método MCQ considera uma aproximação para a função de onda que exige atenção. Qualquer uma das alternativas sugeridas aqui terá que solucionar o problema de caracterização das funções de spin. $\mathrm{O}$ desconhecimento da forma funcional das funções de spin impede que, por exemplo, a energia local definida pela Equação 2.5 seja calculada por meio de funções de onda que apresentem dependência com a coordenada de spin. A função de onda tentativa típica em simulações MCQ, que permite o cancelamento das coordenadas de spin e corrige as condições de cúspide eletrônico e nuclear, é escrita como um produto entre determinantes de Slater de funções de spins opostos ou uma combinação linear destas. ${ }^{28}$ Matematicamente, essas alternativas são escritas como:

$$
\Psi=\Psi_{\alpha} \Psi_{\beta} \Psi_{\text {corr }}
$$

27 Helgaker et al. (2012), Kato (1957).

28 Foulkes et al. (2001), Ceperley (1980). 
ou

$$
\Psi=\Psi_{\text {corr }} \sum_{k} c_{k} \Psi_{\alpha, k} \Psi_{\beta, k}
$$

Funções de onda como essas permitem fatorar as funções de spin das funções espaciais, possibilitando o cancelamento delas no cálculo das propriedades locais. Para ilustrar essa importante aproximação, considere uma estrutura eletrônica qualquer, constituída por três elétrons com spin $\alpha$ e dois elétrons com spin $\beta$ e representados por uma função de onda como definido na Equação 2.20. Considere ainda que dois elétrons $\beta$ são representados pelas mesmas funções orbitais com spin $\alpha$. A Equação 2.20, para essa distribuição eletrônica, será escrita como:

$$
\Psi=\frac{1}{\sqrt{3 !}}\left|\begin{array}{lll}
\phi_{1}(1) \alpha(1) & \phi_{1}(2) \alpha(2) & \phi_{1}(3) \alpha(3) \\
\phi_{2}(1) \alpha(1) & \phi_{2}(2) \alpha(2) & \phi_{2}(3) \alpha(3) \\
\phi_{3}(1) \alpha(1) & \phi_{3}(2) \alpha(2) & \phi_{3}(3) \alpha(3)
\end{array}\right| \frac{1}{\sqrt{2 !}}\left|\begin{array}{ll}
\phi_{1}(4) \beta(4) & \phi_{1}(5) \beta(5) \\
\phi_{2}(4) \beta(4) & \phi_{2}(5) \beta(5)
\end{array}\right| \Psi_{\text {corr }} 2.22
$$

que pode ser fatorada, levando a:

$$
\Psi=\frac{1}{\sqrt{3 !}}\left|\begin{array}{lll}
\phi_{1}(1) & \phi_{1}(2) & \phi_{1}(3) \\
\phi_{2}(1) & \phi_{2}(2) & \phi_{2}(3) \\
\phi_{3}(1) & \phi_{3}(2) & \phi_{3}(3)
\end{array}\right| \alpha(1) \alpha(2) \alpha(3) \frac{1}{\sqrt{2 !}}\left|\begin{array}{ll}
\phi_{1}(4) & \phi_{1}(5) \\
\phi_{2}(4) & \phi_{2}(5)
\end{array}\right| \beta(4) \beta(5) \Psi_{\text {corr }} 2.23
$$

Ao substituir a Equação 2.23 nas equações 2.4, 2.5 ou 2.6, pode-se calcular a energia local ou qualquer propriedade local eliminando-se as funções de spin, ou seja:

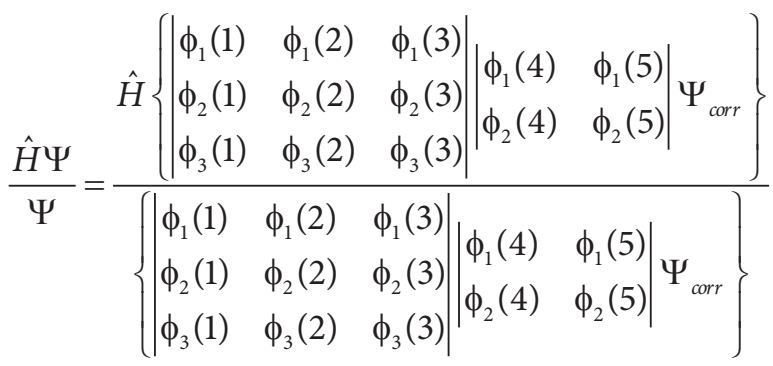

Para o cálculo das probabilidades de transição (Equação 2.6), apenas os determinantes representados pelas funções espaciais são necessários.

Em cálculos envolvendo a função de onda, Equação 2.21, os determinantes a serem combinados possuem sempre o mesmo número de elétrons com spins $\alpha$ e $\beta$ e, portanto, podem ser fatorados de forma semelhante. 
Embora a descrição da função de onda tentativa proporcione a determinação de propriedades locais e a aplicação do Algoritmo de Metropolis, as equações 2.20 e 2.21 levantam aspectos fundamentais que devem ser questionados. A vantagem do uso dessas representações para funções de onda tentativa está no fato de que os determinantes não precisam ser normalizados. Como as propriedades locais ou probabilidades de transição são obtidas como razões envolvendo os mesmos determinantes, os fatores de normalização são desnecessários.

Outro aspecto que chama a atenção é o fato de que as funções de onda tentativa diferenciam elétrons com spins $\alpha$ de elétrons com spins $\beta$. Os dois tipos de elétrons são diferenciados e especificadas coordenadas espaciais para um conjunto de elétrons que possuirão spins $\alpha$, durante toda a simulação, e outro conjunto de coordenadas será atribuído aos elétrons com spins $\beta$. Nesse exemplo, os elétrons de um a três terão spins $\alpha$ e os elétrons quatro e cinco, spins $\beta$. Elétrons $\alpha$ são distintos de elétrons $\beta$.

Finalmente, deve-se considerar que as alternativas de funções de onda tentativa definidas pelas equações 2.20 e 2.21 não são formalmente antissimétricas. A antissimetria é preservada para os dois conjuntos de elétrons $\alpha$ e $\beta$, mas o produto de duas funções antissimétricas não é uma função total antissimétrica. $O$ argumento para o uso dessas alternativas considera que os termos envolvendo spins cruzados no cálculo das energias, empregando determinantes de Slater, são nulos e, portanto, não afetam o resultado final das energias calculadas. ${ }^{29}$ Historicamente, Wigner utilizou essa simplificação para funções de onda sem o termo de correlação explícito para calcular energias de metais alcalinos com razoável sucesso. ${ }^{30}$ É possível trabalhar com determinantes de Slater preservando a indistinguibilidade eletrônica e a antissimetria da função de onda. Para isso, deve-se considerar o uso de matrizes densidade, realizar a integração das propriedades locais e da densidade de probabilidade nas coordenadas de spin para, finalmente, calcular as propriedades locais em função apenas das coordenadas espaciais. ${ }^{31} \mathrm{O}$ inconveniente desse procedimento está na dificuldade em construir algoritmos eficientes para a realização das simulações.

\subsection{Construindo determinantes de Slater}

As funções de onda representadas pelas equações 2.20 e 2.21 são alternativas utilizadas em cálculos Monte Carlo Quântico. Para sua completa utilização, definem-se quais são os orbitais, as funções de correlação explícitas e as configurações a serem consideradas.

As funções orbitais a serem utilizadas para a construção dos determinantes de Slater com spins $\alpha$ e $\beta$, como esperado, são definidas como combinação linear de

29 Foulkes et al. (2001).

30 Wigner (1934).

31 Santos Politi e Custodio (2003). 
funções de base. Diferentemente do que ocorre em cálculos convencionais ab initio ou empregando a teoria do funcional de densidade, em cálculos MCQ, não há dificuldades na realização das simulações em relação às funções de base. É possível utilizar qualquer definição de função de base, uma vez que a operação mais sofisticada a ser realizada será a aplicação de uma derivada primeira ou segunda sobre a função de base. Portanto, diferentemente dos métodos convencionais, é comum considerar o uso de funções de Slater como funções de base. Uma das funções de base mais utilizadas em cálculos MCV ou MCD são funções de Slater cartesianas, ou seja:

$$
\chi(\zeta ; x, y, z)=N_{a b c k}(x-X)^{a}(y-Y)^{b}(z-Z)^{c} r^{k-1} e^{-\zeta r}
$$

sendo $x, y$ e $z$ as coordenadas eletrônicas e $X, Y$ e $Z$ as coordenadas do centro da função de Slater, $r=\sqrt{(x-X)^{2}+(y-Y)^{2}+(z-Z)^{2}}$ é a distância eletrônica em relação ao centro da função, $a, b$ e $c$ são números inteiros maiores ou iguais a zero, e sua soma, $(a+b+c)=l$, define a simetria ou o número quântico de momento angular da função de base, ou seja, se $l=0$, tem-se uma função de base do tipo $s$; se $l=1$, tem-se uma função $p$; se $l=2$, uma função $d$ etc., $k=n$ - $l$, e será definido pelos números inteiros $l$ e $n$, sendo $n>0$; $\zeta$ é um parâmetro associado ao tamanho da função de base, usualmente ajustado variacionalmente, e $N_{\text {abck }}$ corresponde ao fator de normalização, expresso por:

$$
N_{a b c k}=\sqrt{\frac{(2 \zeta)^{2 k+1}}{(2 k) !} \frac{(2 \mathrm{a}+2 \mathrm{~b}+2 \mathrm{c}+1) ! !}{4 \pi(2 a-1) ! !(2 b-1) ! !(2 c-1) ! !}}
$$

Uma das vantagens no uso de funções de Slater está na boa descrição em regiões próximas aos núcleos atômicos e, consequentemente, da cúspide nuclear. Funções gaussianas também são utilizadas, mas devem ser corrigidas para evitar erros de cúspide.

Uma vez selecionada a função de base adequada, deve-se proceder à construção dos orbitais atômicos ou moleculares por meio da combinação linear dessas funções de base, ou seja:

$$
\phi_{i}(j)=\sum_{\mu=1}^{k} c_{i \mu} \chi_{\mu}\left(\zeta_{\mu} ; \mathrm{x}_{j}, y_{j}, z_{j}\right)=\sum_{\mu=1}^{k} c_{i \mu} \chi_{\mu}(j)
$$

sendo $c_{\mathrm{i \mu}}$ os coeficientes de combinação linear das funções de base. Tais coeficientes de combinação linear, assim como os parâmetros $\zeta$, são obtidos variacionalmente.

Uma vez que os processos de otimização de expoentes e coeficientes de combinação linear consomem um tempo computacional considerável, é comum realizar a otimização dos expoentes de funções de base a partir de cálculos Hartree-Fock-Roothaan ou algum outro nível de cálculo desejado. 
Os coeficientes de combinação linear também são frequentemente obtidos de cálculos Hartree-Fock-Roothaan. Como a maior parte dos programas ab initio é desenvolvida com funções de base de gaussianas, realizam-se cálculos STO-NG em nível Hartree-Fock, com funções de base que representem apropriadamente as funções de Slater a serem utilizadas nos cálculos Monte Carlo Quântico, e transferem-se os coeficientes de combinação linear para as simulações deste último. Deve-se chamar a atenção para o fato de que expansões STO-NG com $\mathrm{N} \leq 6$ não produzem coeficientes de combinações lineares apropriados para representar funções de base de Slater. Os coeficientes só se tornam aceitáveis com expansões STO-NG representados por dez ou mais funções gaussianas. Os procedimentos para a obtenção dos coeficientes de expansão para gerar as funções STO-10G, STO-15 etc. são bem conhecidos na literatura e têm sua origem no trabalho clássico de Huzinaga. ${ }^{32}$

Esse é o procedimento frequentemente seguido em cálculos MCV quando não se dispõe de coeficientes de combinação linear de funções de Slater. Porém, em vez de utilizar coeficientes e expoentes provenientes de cálculos Hartree-Fock, é possível a otimização dos expoentes de funções de base, coeficientes de combinação linear das funções de base, coeficientes de combinação linear das expansões de interação de configurações $(\mathrm{CI})$ e parâmetros das funções de correlação explícitas. Uma possibilidade de otimizar esses parâmetros será discutida neste texto.

\subsection{FunçõeS DE CORRELAÇÃO EXPLÍCITAS}

A condição de cúspide eletrônica (Equação 2.19) não pode ser satisfeita por funções de onda compostas de um único determinante de Slater porque este não apresenta dependência com a distância intereletrônica $\left(r_{\mathrm{ij}}\right)$. Como sugerido, multiplica-se a função de onda construída por um único determinante (Equação 2.20) ou por uma combinação linear de determinantes (Equação 2.21) por funções de correlação explícitas, as quais apresentam uma representação exponencial e são frequentemente denominadas funções do tipo Jastrow. ${ }^{33}$ Existem diferentes alternativas para descrever funções de correlação explícitas. ${ }^{34}$ A função de correlação usada com maior frequência é denominada fator de correlação de Boys-Handy ou, muitas vezes, apenas fator de Jastrow ou função de correlação de Jastrow, e é escrita genericamente como: ${ }^{35}$

$$
\Psi_{c o r r}=\exp \left(\sum_{A} \sum_{i} \sum_{j>i} U_{A i j}\right)=\exp \left(\sum_{A}\left[\frac{1}{2} \sum_{i} \sum_{j \neq i} U_{A i j}\right]\right)
$$

32 O-Ohata et al. (1966).

33 Jastrow (1955).

34 Umrigar et al. (1988), Moskowitz e Schmidt (1992), Huang et al. (1990), Flad e Savin (1995).

35 Schmidt e Moskowitz (1990), Boys e Handy (1969). 
em que:

$$
U_{A i j}=\sum_{k} \Delta\left(m_{k A}, m_{k A}\right) c_{k A}\left[\bar{r}_{i A}^{m_{k A}} \bar{r}_{j A}^{n_{k A}}+\bar{r}_{j A}^{m_{k A}} \bar{r}_{i A}^{n_{k A}}\right] \bar{r}_{i j}^{o_{k A}}
$$

sendo:

$$
\bar{r}_{i A}=\frac{b_{A} r_{i A}}{1+b_{A} r_{i A}} \text { e } \bar{r}_{i j}=\frac{d_{A} r_{i j}}{1+d_{A} r_{i j}}
$$

Os fatores de distâncias $r_{\mathrm{iA}}$ e $r_{\mathrm{ij}}$, na Equação 2.30, são distâncias elétron-núcleo e elétron-elétron, respectivamente, definidas como:

$$
\begin{aligned}
r_{i A} & =\sqrt{\left(x_{i}-x_{A}\right)^{2}+\left(y_{i}-y_{A}\right)^{2}+\left(z_{i}-z_{A}\right)^{2}} \\
r_{i j} & =\sqrt{\left(x_{i}-x_{j}\right)^{2}+\left(y_{i}-y_{j}\right)^{2}+\left(z_{i}-z_{j}\right)^{2}}
\end{aligned}
$$

Os parâmetros $b_{\mathrm{A}}$ e $d_{\mathrm{A}}$, na Equação 2.30, são ajustados variacionalmente ou definidos para satisfazer as condições de cúspide expressas pelas equações 2.18 e 2.19. ${ }^{36}$ Os valores de $m_{\mathrm{kA}}, n_{\mathrm{kA}}$ e $o_{\mathrm{kA}}$ são números inteiros maiores ou iguais a zero e refletem combinações de possíveis correlações elétron-núcleo ou elétron-elétron. ${ }^{37}$

O termo $\Delta\left(m_{\mathrm{kA}}, m_{\mathrm{kA}}\right)$ é definido para manter consistência com as funções de correlação originais de Boys-Handy e podem assumir os seguintes valores:

$$
\Delta\left(m_{k A}, m_{k A}\right)=\left\{\begin{array}{cc}
1, & m_{k A}=n_{k A} \\
1 / 2, & m_{k A}=n_{k A}
\end{array}\right.
$$

Um nível de exatidão apropriado para efeitos de correlação dinâmica é obtido para funções de Boys-Handy contendo nove parâmetros, ou seja:

$$
\begin{aligned}
& U_{A i j}=c_{1 A} \bar{r}_{i j}+c_{2 A} \bar{r}_{i j}^{2}+c_{3 A} \bar{r}_{i j}^{3}+c_{4 A} \bar{r}_{i j}^{4}+c_{5 A}\left(\bar{r}_{i A}^{2}+\bar{r}_{j A}^{2}\right)+c_{6 A}\left(\bar{r}_{i A}^{3}+\bar{r}_{j A}^{3}\right)+c_{7 A}\left(\bar{r}_{i A}^{4}+\bar{r}_{j A}^{4}\right)+ \\
& +c_{8 A}\left(\bar{r}_{i A}^{2} \bar{r}_{j A}^{2}\right)+c_{9 A}\left(\bar{r}_{i A}^{2}+\bar{r}_{j A}^{2}\right) \bar{r}_{i j}^{2}
\end{aligned}
$$

Os quatro primeiros termos à direita da igualdade, na Equação 2.33, correspondem à correlação dinâmica elétron-elétron; o quinto, sexto e sétimo termos correspondem à correlação elétron-núcleo; e os dois últimos termos, a efeitos de 
correlação elétron-elétron-núcleo. Todos os parâmetros devem ser otimizados variacionalmente. Dos nove parâmetros da Equação 2.33, os quatro primeiros dependem fundamentalmente do sistema, e não necessariamente estão associados a nenhum átomo em particular. Os coeficientes de $c_{5 A}, c_{6 A}, c_{7 A}, c_{8 A}$ e $c_{9 A}$ estão associados aos núcleos que compõem o sistema e devem ser ajustados para cada conjunto de espécie atômica (por exemplo, todos os átomos de carbono em uma molécula orgânica podem ter os mesmos parâmetros associados com correlação elétron-núcleo e correlação elétron-elétron-núcleo) ou para cada átomo individualmente presente no ambiente molecular.

Dessa forma, a função de correlação explícita para um átomo ou molécula será escrita substituindo a Equação 2.33 na Equação 2.28.

Parâmetros otimizados para átomos são encontrados na literatura e, admitindo a presença de átomos em moléculas, podem ser utilizados em ambiente molecular. ${ }^{38}$ Certamente que há perda de qualidade na energia resultante ou outra propriedade de interesse, mas são parâmetros que podem ser utilizados como ponto de partida para posterior otimização.

Ao definir a forma funcional da função de onda, ou seja, funções de base, possível combinação de determinantes e funções de correlação explícita, a etapa mais complicada do método MCV consiste no cálculo da energia cinética.

\subsection{EXPRESSÕES PARA O CÁLCULO DA ENERGIA CINÉTICA}

O cálculo da energia local expresso pela Equação 2.6 consiste na determinação da energia cinética e potencial local. A energia potencial local é normalmente calculada utilizando a definição clássica do respectivo operador de energia potencial. A energia cinética local, $T$, por sua vez, é calculada pela aplicação do laplaciano sobre a função de onda, por meio da equação:

$$
T=-\frac{1}{2} \sum_{i=1}^{N} \frac{\nabla_{i}^{2} \Psi}{\Psi}
$$

Uma vez que os elétrons com spins $\alpha$ e $\beta$ são distintos, o operador laplaciano deve caracterizar os dois conjuntos de elétrons como:

$$
\sum_{i=1}^{N} \frac{\nabla_{i}^{2} \Psi}{\Psi}=\sum_{i=1}^{N_{\alpha}} \frac{\nabla_{i}^{2} \Psi}{\Psi}+\sum_{i=1}^{N_{\beta}} \frac{\nabla_{i}^{2} \Psi}{\Psi}
$$

sendo $N$ o número total de elétrons, $N_{\alpha}$ e $N_{\beta}$ o número de elétrons com spin $\alpha$ e $\beta$, respectivamente. 
Caso a função de onda seja expressa por um único determinante de Slater multiplicado por uma função de correlação explícita, como definido pela Equação 2.20, a Equação 2.35 será escrita como:

$$
T=-\frac{1}{2} \sum_{i=1}^{N} \frac{\nabla_{i}^{2} \Psi}{\Psi}=-\frac{1}{2} \sum_{i=1}^{N_{\alpha}} \frac{\nabla_{i}^{2}\left(\Psi_{\alpha} \Psi_{c o r r}\right)}{\Psi_{\alpha} \Psi_{c o r r}}-\frac{1}{2} \sum_{i=1}^{N_{\beta}} \frac{\nabla_{i}^{2}\left(\Psi_{\beta} \Psi_{c o r r}\right)}{\Psi_{\beta} \Psi_{c o r r}}
$$

Assim, aplicando o laplaciano sobre cada produto de determinante de Slater por função de correlação explícita e somando para todos os elétrons do sistema, tem-se a seguinte expressão para a energia cinética local:

$$
\begin{aligned}
& T=-\frac{1}{2} \sum_{i=1}^{N} \frac{\nabla_{i}^{2} \Psi}{\Psi}=-\frac{1}{2}\left\{\sum_{i=1}^{N_{\alpha}} \frac{\nabla_{i}^{2} \Psi_{\alpha}}{\Psi_{\alpha}}+\sum_{i=1}^{N_{\beta}} \frac{\nabla_{i}^{2} \Psi_{\beta}}{\Psi_{\beta}}+\sum_{i=1}^{N_{\alpha}}\left[\frac{\nabla_{i}^{2} \Psi_{\text {corr }}}{\Psi_{\text {corr }}}+2\left(\frac{\nabla_{i} \Psi_{\alpha}}{\Psi_{\alpha}}\right)\left(\frac{\nabla_{i} \Psi_{\text {corr }}}{\Psi_{\text {corr }}}\right)\right]+\right. \\
& \left.+\sum_{i=1}^{N_{\beta}}\left[\frac{\nabla_{i}^{2} \Psi_{\text {corr }}}{\Psi_{\text {corr }}}+2\left(\frac{\nabla_{i} \Psi_{\beta}}{\Psi_{\beta}}\right)\left(\frac{\nabla_{i} \Psi_{\text {corr }}}{\Psi_{\text {corr }}}\right)\right]\right\}
\end{aligned}
$$

Ao considerar a forma exponencial das funções de correlação explícita, outra igualdade muito conveniente para a aplicação do laplaciano sobre essas funções é expressa por:

$$
\frac{\nabla_{i}^{2} \Psi_{c o r r}}{\Psi_{\text {corr }}}=\nabla_{i}^{2} \ln \Psi_{\text {corr }}+\left(\nabla_{i} \ln \Psi_{\text {corr }}\right)^{2}
$$

Ao substituir a Equação 2.38 na Equação 2.37, tem-se, para a expressão da energia cinética local:

$$
\begin{aligned}
& -\frac{1}{2} \sum_{i=1}^{N} \frac{\nabla_{i}^{2} \Psi}{\Psi}=-\frac{1}{2}\left\{\sum_{i=1}^{N_{\alpha}} \frac{\nabla_{i}^{2} \Psi_{\alpha}}{\Psi_{\alpha}}+\sum_{i=1}^{N_{\beta}} \frac{\nabla_{i}^{2} \Psi_{\beta}}{\Psi_{\beta}}+\sum_{i=1}^{N_{\alpha}+N_{\beta}} \nabla_{i}^{2} \ln \Psi_{\text {corr }}+\sum_{i=1}^{N_{\alpha}}\left[2\left(\frac{\nabla_{i} \Psi_{\alpha}}{\Psi_{\alpha}}\right)+\right.\right. \\
& \left.\left.+\left(\nabla_{i} \ln \Psi_{\text {corr }}\right)\right]\left(\nabla_{i} \ln \Psi_{\text {corr }}\right)+\sum_{i=1}^{N_{\beta}}\left[2\left(\frac{\nabla_{i} \Psi_{\beta}}{\Psi_{\beta}}\right)+\left(\nabla_{i} \ln \Psi_{\text {corr }}\right)\right]\left(\nabla_{i} \ln \Psi_{\text {corr }}\right)\right\}
\end{aligned}
$$

Para uma função de onda CI, a energia cinética obviamente considera diversos determinantes de Slater. Assim, a função de onda a ser empregada é representada por:

$$
\Psi_{C I}=c_{1} \Psi_{1}+c_{2} \Psi_{2}+\ldots+c_{k} \Psi_{k}=\sum_{k=1}^{n . c o n f} c_{k} \Psi_{k}
$$


sendo que cada função de onda $\Psi_{\mathrm{k}}$ representa um determinante de Slater. Como mencionado anteriormente, para uma função de onda CI representando determinado estado eletrônico, todos os determinantes de Slater possuem o mesmo número de spins $\alpha$ e $\beta$. Portanto, uma maneira conveniente de determinar propriedades locais a partir da função de onda CI é considerar que cada determinante também será representado pelo produto de um determinante de Slater contendo os elétrons com spin a por outro determinante contendo os elétrons com spin $\beta$ :

$$
\Psi_{C I}=\sum_{k=1}^{n . c o n f .} c_{k} \Psi_{k, \alpha} \Psi_{k, \beta}
$$

A energia cinética local para uma função de onda CI será obtida por meio da equação:

$$
-\frac{1}{2} \frac{\nabla_{i}^{2} \Psi}{\Psi}=-\frac{1}{2} \frac{\sum_{k=1}^{N} c_{k} \nabla_{i}^{2} \Psi_{k}}{\sum_{k=1}^{N} c_{k} \Psi_{k}}
$$

Caso o laplaciano $\nabla_{i}^{2}$ pertença a um elétron com spin $\alpha$, a Equação 2.39 será escrita como:

$$
-\frac{1}{2} \frac{\nabla_{i}^{2} \Psi}{\Psi}=-\frac{1}{2} \frac{\sum_{k=1}^{N} c_{k} \Psi_{k, \beta} \nabla_{i}^{2} \Psi_{k, \alpha}}{\sum_{k=1}^{N} c_{k} \Psi_{k}}
$$

Funções de onda constituídas como o produto de uma função de onda CI multiplicada por uma função de correlação explícita devem ser tratadas convenientemente, o que será apresentado a seguir.

Antes de detalhar o cálculo do laplaciano, deve-se chamar a atenção para uma forma alternativa de cálculo da energia cinética local expressa por:

$$
T=\sum_{i}\left(2 K_{i}-\left|\vec{F}_{i}\right|^{2}\right)
$$

sendo $K_{\mathrm{i}}$ e $F_{\mathrm{i}}$ definidos como:

$$
K_{i}=-\frac{1}{4} \nabla_{i}^{2}(\ln |\Psi|)=-\frac{1}{4} \frac{\nabla_{i}^{2} \Psi}{\Psi}+\frac{1}{4}\left(\frac{\nabla_{i} \Psi}{\Psi}\right)^{2}
$$




$$
\vec{F}_{i}=\frac{1}{\sqrt{2}} \nabla_{i}(\ln |\Psi|)=\frac{1}{\sqrt{2}} \frac{\nabla_{i} \Psi}{\Psi}
$$

Para o caso em que a função de onda seja escrita por meio da Equação 2.20 e que o laplaciano e o gradiente sejam aplicados para elétrons $\alpha$ ou $\beta$, tem-se que, para elétrons com spin $\alpha$, a componente $F_{\mathrm{i}}$ será escrita como:

$$
\begin{aligned}
& \vec{F}_{i}=\frac{1}{\sqrt{2}} \frac{\nabla_{i} \Psi}{\Psi}=\frac{1}{\sqrt{2}} \frac{\nabla_{i}\left[\Psi_{\alpha} \Psi_{\beta} \Psi_{c o r}\right]}{\Psi_{\alpha} \Psi_{\beta} \Psi_{c o r}}=\frac{1}{\sqrt{2}} \nabla_{i}\left[\ln \left(\Psi_{\alpha} \Psi_{\beta} \Psi_{c o r}\right)\right]= \\
& =\frac{1}{\sqrt{2}} \nabla_{i}\left[\ln \Psi_{\alpha}+\ln \Psi_{\beta}+\ln \Psi_{c o r r}\right]=\frac{1}{\sqrt{2}}\left[\frac{\nabla_{i} \Psi_{\alpha}}{\Psi_{\alpha}}+\nabla_{i}\left(\ln \Psi_{c o r r}\right)\right]
\end{aligned}
$$

Assim:

$$
\left|\vec{F}_{i}\right|^{2}=\vec{F}_{i} \cdot \vec{F}_{i}=\frac{1}{2}\left[\left(\frac{\nabla_{i} \Psi_{\alpha}}{\Psi_{\alpha}}\right)^{2}+2\left(\frac{\nabla_{i} \Psi_{\alpha}}{\Psi_{\alpha}}\right) \nabla_{i}\left(\ln \Psi_{c o r r}\right)+\left[\nabla_{i}\left(\ln \Psi_{c o r r}\right)\right]^{2}\right]
$$

O termo $K_{\mathrm{i}}$, por sua vez, será escrito para um elétron com spin $\alpha$ como:

$$
\begin{gathered}
-4 K_{i}=\frac{\nabla_{i}\left\{\nabla_{i}\left[\Psi_{\alpha} \Psi_{\beta} \Psi_{c o r r}\right\}\right.}{\Psi_{\alpha} \Psi_{\beta} \Psi_{c o r r}}=\nabla_{i}\left\{\nabla_{i} \ln \Psi_{\alpha}+\nabla_{i} \ln \Psi_{c o r r}\right\}= \\
=\nabla_{i}\left[\left(\frac{\nabla_{i} \Psi_{\alpha}}{\Psi_{\alpha}}\right)+\nabla_{i} \ln \Psi_{\text {corr }}\right]=\left(\frac{\Psi_{\alpha} \nabla_{i}^{2} \Psi_{\alpha}-\left(\nabla_{i} \Psi_{\alpha}\right)^{2}}{\Psi_{\alpha}^{2}}\right)+\nabla_{i}^{2} \ln \Psi_{c o r r}
\end{gathered}
$$

que, simplificando, leva à Equação 2.45:

$$
K_{i}=-\frac{1}{4}\left[\frac{\nabla_{i}^{2} \Psi_{\alpha}}{\Psi_{\alpha}}-\left(\frac{\nabla_{i} \Psi_{\alpha}}{\Psi_{\alpha}}\right)^{2}+\nabla_{i}^{2} \ln \Psi_{\text {corr }}\right]
$$

Para o caso mais geral, em que a função de onda é escrita como o produto de uma função de onda CI, por uma função de correlação explícita, tem-se que as funções $F_{i}$ e $K_{i}$ são escritas, respectivamente, como: 


$$
\left|\vec{F}_{i}\right|^{2}=\frac{1}{2}\left[\left(\frac{\nabla_{i} \Psi_{C I}}{\Psi_{C I}}\right)^{2}+2\left(\frac{\nabla_{i} \Psi_{C I}}{\Psi_{C I}}\right) \nabla_{i}\left(\ln \Psi_{\text {corr }}\right)+\left[\nabla_{i}\left(\ln \Psi_{\text {corr }}\right)\right]^{2}\right]
$$

e

$$
K_{i}=-\frac{1}{4}\left[\frac{\nabla_{i}^{2} \Psi_{C I}}{\Psi_{C I}}-\left(\frac{\nabla_{i} \Psi_{C I}}{\Psi_{C I}}\right)^{2}+\nabla_{i}^{2} \ln \Psi_{c o r r}\right]
$$

Ao substituir as equações 2.45 e 2.47 ou 2.48 e 2.49 na Equação 2.41, tem-se a energia cinética local. Resta agora determinar os gradientes e laplacianos da função de onda.

\subsection{Gradiente E 0 LapLaciano de UM Determinante de SLATER}

Independentemente da representação matemática da função de onda, o cálculo da energia cinética é dependente da determinação de gradientes e laplacianos da função de onda. Determinantes de Slater constituem a base mais utilizada para a elaboração de funções de onda. Para um conjunto de $N$ elétrons distribuídos em $N$ spin-orbitais $\varphi$, um determinante de Slater normalizado é escrito como:

$$
\Psi=\frac{1}{\sqrt{N !}}\left|\begin{array}{cccccc}
\varphi_{1}(1) & \varphi_{1}(2) & \cdots & \varphi_{1}(i) & \cdots & \varphi_{1}(i) \\
\varphi_{2}(1) & \varphi_{2}(2) & \cdots & \varphi_{2}(i) & \cdots & \varphi_{2}(i) \\
\vdots & \vdots & \ddots & \vdots & \ddots & \vdots \\
\varphi_{N}(1) & \varphi_{N}(2) & \cdots & \varphi_{N}(i) & \cdots & \varphi_{N}(N)
\end{array}\right|
$$

Portanto, o gradiente do $i$-ésimo elétron de um determinante de Slater é expresso por:

$$
\nabla_{i} \Psi=\frac{1}{\sqrt{N !}}\left|\begin{array}{llllll}
\varphi_{1}(1) & \varphi_{1}(2) & \cdots & \nabla_{i} \varphi_{1}(i) & \cdots & \varphi_{1}(i) \\
\varphi_{2}(1) & \varphi_{2}(2) & \cdots & \nabla_{i} \varphi_{2}(i) & \cdots & \varphi_{2}(i) \\
\vdots & \vdots & \ddots & \vdots & \ddots & \vdots \\
\varphi_{N}(1) & \varphi_{N}(2) & \cdots & \nabla_{i} \varphi_{N}(i) & \cdots & \varphi_{N}(N)
\end{array}\right|
$$

Uma vez que no Monte Carlo Quântico o gradiente será definido para um elétron de spin $\alpha$ ou $\beta$, o gradiente acima terá apenas orbitais com spin $\alpha$ ou $\beta$ e será a expressão utilizada para a determinação dos gradientes em cálculos de um único determinante ou de uma combinação de determinantes. 
Para o caso do uso de um único determinante de Slater combinado ou não com uma função de correlação explícita, o cálculo do gradiente é significativamente simplificado e as constantes de normalização dos determinantes são eliminadas:

$$
\begin{gathered}
\frac{\nabla_{i} \Psi}{\Psi}=\Psi^{-1} \nabla_{i} \Psi= \\
=\left|\begin{array}{cccccc}
\phi_{1}(1) & \phi_{2}(1) & \cdots & \phi_{i}(1) & \cdots & \phi_{N}(1) \\
\phi_{1}(2) & \phi_{2}(2) & \cdots & \phi_{i}(2) & \cdots & \phi_{N}(2) \\
\vdots & \vdots & \ddots & \vdots & \ddots & \vdots \\
\phi_{1}(N) & \phi_{2}(N) & \cdots & \phi_{i}(N) & \cdots & \phi_{N}(N)
\end{array}\right| \\
\left|\begin{array}{cccccc}
\phi_{1}(1) & \phi_{1}(2) & \cdots & \nabla_{i} \phi_{1}(i) & \cdots & \phi_{1}(N) \\
\phi_{2}(1) & \phi_{2}(2) & \cdots & \nabla_{i} \phi_{2}(i) & \cdots & \phi_{2}(N) \\
\vdots & \vdots & \ddots & \vdots & \ddots & \vdots \\
\phi_{N}(1) & \phi_{N}(2) & \cdots & \nabla_{i} \phi_{N}(i) & \cdots & \phi_{N}(N)
\end{array}\right|
\end{gathered}
$$

Multiplicando-se os dois determinantes, tem-se:

$$
\begin{gathered}
\frac{\nabla_{i} \Psi}{\Psi}=\Psi^{-1} \nabla_{i} \Psi= \\
=\left|\begin{array}{cccccc}
1 & 0 & \cdots & \varphi_{1}^{\prime-1}(1) \nabla_{i} \varphi_{1}(i)+\varphi_{2}^{\prime-1}(1) \nabla_{i} \varphi_{2}(i)+\cdots+\varphi_{N}^{\prime-1}(1) \nabla_{i} \varphi_{N}(i) & \cdots & 0 \\
0 & 1 & \cdots & \varphi_{1}^{\prime-1}(2) \nabla_{i} \varphi_{1}(i)+\varphi_{2}^{\prime-1}(2) \nabla_{i} \varphi_{2}(i)+\cdots+\varphi_{N}^{\prime-1}(2) \nabla_{i} \varphi_{N}(i) & \cdots & 0 \\
\vdots & \vdots & \ddots & \vdots & \ddots & \vdots \\
0 & 0 & \cdots & \varphi_{1}^{\prime-1}(i) \nabla_{i} \varphi_{1}(i)+\varphi_{2}^{\prime-1}(i) \nabla_{i} \varphi_{2}(i)+\cdots+\varphi_{N}^{\prime-1}(i) \nabla_{i} \varphi_{N}(i) & \cdots & 0 \\
\vdots & \vdots & \ddots & \vdots & \ddots & \vdots \\
0 & 0 & \cdots & \varphi_{1}^{\prime-1}(N) \nabla_{i} \varphi_{1}(i)+\varphi_{2}^{\prime-1}(N) \nabla_{i} \varphi_{2}(i)+\cdots+\varphi_{N}^{\prime-1}(N) \nabla_{i} \varphi_{N}(i) & \cdots & 1
\end{array}\right|
\end{gathered}
$$

Portanto, o único termo preservado quando o determinante for resolvido será:

$$
\frac{\nabla_{i} \Psi}{\Psi}=\sum_{j=1}^{N} \varphi_{j}^{\prime-1}(i) \nabla_{i} \varphi_{j}(i)
$$

Da mesma forma, o laplaciano de um determinante de Slater será expresso por:

$$
\frac{\nabla_{i}^{2} \Psi}{\Psi}=\sum_{j=1}^{N} \varphi_{j}^{\prime-1}(i) \nabla_{i}^{2} \varphi_{j}(i)
$$


Deve-se chamar a atenção para o fato de que a função $\varphi_{j}^{{ }^{-1}}$ corresponde ao elemento da matriz de Slater invertida, e não ao recíproco da função orbital. Como mencionado anteriormente, esse procedimento só poderá ser aplicado com a eliminação das funções de spin. No caso do MCV, o gradiente e o laplaciano devem ser aplicados sobre as respectivas funções de onda com spins $\alpha$ ou $\beta$, ou seja:

$$
\frac{\nabla_{i}^{2} \Psi_{\alpha}}{\Psi_{\alpha}}=\sum_{j=1}^{N_{\alpha}} \varphi_{j}^{\prime-1}(i) \nabla_{i}^{2} \varphi_{j}(i) \text { ou } \frac{\nabla_{i}^{2} \Psi_{\beta}}{\Psi_{\beta}}=\sum_{j=1}^{N_{\beta}} \varphi_{j}^{\prime-1}(i) \nabla_{i}^{2} \varphi_{j}(i)
$$

Embora seja aceitável recalcular os determinantes das funções espaciais quando as coordenadas de um dos elétrons são modificadas, existem algoritmos eficientes na literatura para a atualização das matrizes inversas, aumentando significativamente o desempenho computacional das atualizações dos determinantes de Slater. ${ }^{39}$

No caso de uma função CI, não há simplificação, até o momento, que permita a rápida atualização dos determinantes de Slater ou de sua função inversa com a alteração das coordenadas de um dos elétrons. Nesse caso, a receita usual de atualização de todos os determinantes deve ser feita, o que encarece o custo computacional e provavelmente seja um dos motivos pelos quais é muito comum considerar a utilização de apenas um único determinante de Slater em cálculos MCQ.

\subsection{MÉtodos de otIMIZação de PARÂMetros dAS FUnções de ONDA}

Existem vários algoritmos que podem ser utilizados para a otimização dos diferentes parâmetros de uma função de onda. Os métodos mais empregados consideram que as funções orbitais provenientes de cálculos Hartree-Fock-Roothaan permaneçam inalterados, otimizando apenas os parâmetros das funções de correlações explícitas. Os algoritmos mais recentes sugerem a possibilidade de otimização dos parâmetros de correlação explícita, dos coeficientes de combinação linear das funções CI (no caso de multideterminantes), dos coeficientes de combinação linear das funções orbitais e dos expoentes das funções de base. ${ }^{40}$ Contudo, o processo de otimização de todos esses parâmetros apresenta um custo computacional elevado e tem sido utilizado apenas em átomos e moléculas pequenas. Como mencionado anteriormente, as funções de onda mais utilizadas em cálculos MCQ são constituídas por um único determinante de Slater e uma função de correlação explícita, otimizando apenas os parâmetros desta última. Existem diferentes alternativas para otimização variacional de parâmetros ou mesmo para a construção de funções de correlações explícitas. ${ }^{41}$ Uma das alternativas mais utilizadas

39 Nukala e Kent (2009).

40 Toulouse e Umrigar $(2007,2008)$.

41 Toulouse e Umrigar (2007, 2008), Bressanini et al. (2002), Huang e Cao (1996), Lin et al. (2000), Luo et al. (2009), Neuscamman et al. (2012), Scemama e Filippi (2006), Schautz e Fahy (2002), Sorella (2005), Umrigar e Filippi (2005), Clark et al. (2011). 
é a proposta por Lin, Zhan e Rappe ${ }^{42}$ e modificada por Umrigar e Filippi ${ }^{43}$ Esse algoritmo se inicia considerando a aplicação da forma convencional do método Newton-Raphson. ${ }^{44}$

No método Newton-Raphson, expande-se a função a ser otimizada em uma série de Taylor, no caso, a energia do sistema, $E(\mathbf{C})$, em relação ao conjunto de parâmetros $\mathbf{C}^{\mathrm{T}}=\left(c_{1}, c_{2}, \ldots, c_{\mathrm{n}}\right)$ de interesse, obtendo a equação:

$$
E\left(\mathbf{C}_{a}\right)=E(\mathbf{C})+\mathbf{f}(\mathbf{C}) \cdot \Delta \mathbf{C}+\frac{1}{2} \Delta \mathbf{C}^{T} \cdot \mathbf{H}(\mathbf{C}) \cdot \Delta \mathbf{C}+\cdots
$$

sendo que $\mathbf{f}$ e $\mathbf{H}$ são matrizes contendo o gradiente e a hessiana da energia, respectivamente, e os elementos dessas matrizes são definidos como:

$$
f_{m}=\frac{\partial E(\mathbf{C})}{\partial c_{m}}
$$

$\mathrm{e}$

$$
H_{m n}=\frac{\partial^{2} E(\mathbf{C})}{\partial c_{m} \partial c_{n}}
$$

Ao truncar a série de Taylor no termo de primeira ordem, obtém-se:

$$
E(\mathbf{C}+\Delta \mathbf{C})=E(\mathbf{C})+\Delta \mathbf{C}^{T} \cdot \mathbf{f}(\mathbf{C})+\frac{1}{2} \Delta \mathbf{C}^{T} \cdot \mathbf{H}(\mathbf{C}) \cdot \Delta \mathbf{C}
$$

De maneira similar, pode-se expandir o gradiente de energia e truncar a série de potência até o termo de primeira ordem:

$$
\mathbf{f}(\mathbf{C}+\Delta \mathbf{C})=\mathbf{f}(\mathbf{C})+\mathbf{H}(\mathbf{C}) \cdot \Delta \mathbf{C}
$$

Ao considerar que uma solução de máximo ou mínimo foi atingida, tem-se que $\mathbf{f}(\mathbf{C}+\Delta \mathbf{C})=0$ e:

$$
0=\mathbf{f}(\mathbf{C})+\mathbf{H}(\mathbf{C}) \cdot \Delta \mathbf{C}
$$

Consequentemente, para determinar a variação aproximada dos parâmetros ajustáveis, basta reescrever a Equação 2.65 como: 


$$
\Delta \mathbf{C}=-\mathbf{H}^{-1}(\mathbf{C}) \mathbf{f}(\mathbf{C})
$$

Essa equação será utilizada para estimar valores dos parâmetros $\Delta \mathbf{C}$ a partir de um conjunto inicial C.

O algoritmo de Lin et al. ${ }^{45}$ considera essa aproximação e define os valores dos gradientes e hessianas a partir do cálculo das propriedades locais empregadas no método MCQ. Assim, pelo teorema do valor médio, tem-se:

$$
E=\frac{\int \Psi^{*} \hat{H} \Psi d \tau}{\int \Psi^{*} \Psi d \tau}
$$

Ao derivar a Equação 2.67 em relação a um parâmetro qualquer $c_{m}$, tem-se:

$$
\begin{aligned}
\frac{\partial E}{\partial c_{m}} & =\frac{1}{\int \Psi^{*} \Psi d \tau}\left(\int \frac{\partial \Psi^{*}}{\partial c_{m}} \hat{H} \Psi d \tau+\int \Psi^{*} \hat{H} \frac{\partial \Psi}{\partial c_{m}} d \tau\right)- \\
& -\frac{2}{\left(\int \Psi^{*} \Psi d \tau\right)^{2}}\left(\int \Psi^{*} \hat{H} \Psi d \tau \int \Psi^{*} \frac{\partial \Psi}{\partial c_{m}} d \tau\right)
\end{aligned}
$$

Ao invocar a propriedade hermitiana, pode-se considerar que:

$$
\int \frac{\partial \Psi^{*}}{\partial c_{m}} \hat{H} \Psi d \tau=\int \Psi^{*} \hat{H} \frac{\partial \Psi}{\partial c_{m}} d \tau
$$

que simplifica a Equação 2.68 para:

$$
\begin{gathered}
\frac{\partial E}{\partial c_{m}}=\frac{2}{\int \Psi^{*} \Psi d \tau}\left(\int \Psi^{*} \Psi\left(\frac{\hat{H} \Psi}{\Psi}\right)\left(\frac{1}{\Psi}\left(\frac{\partial \Psi}{\partial c_{m}}\right)\right) d \tau\right)- \\
-\frac{2}{\left(\int \Psi^{*} \Psi d \tau\right)^{2}}\left(\int \Psi^{*} \Psi\left(\frac{\hat{H} \Psi}{\Psi}\right) d \tau \int \Psi^{*} \Psi\left(\frac{1}{\Psi}\left(\frac{\partial \Psi}{\partial c_{m}}\right)\right) d \tau\right)
\end{gathered}
$$

Ao fazer a amostragem no espaço de configurações utilizando MCV, pode-se reescrever a Equação 2.70 como:

45 Lin et al. (2000). 


$$
\frac{\partial E}{\partial c_{m}}=\lim _{N \rightarrow \infty} \frac{2}{N} \sum_{\alpha=1}^{N}\left\{\left(E_{L} \cdot \Psi_{\ln , m}^{\prime}\right)_{\alpha}-E \cdot\left(\Psi_{\ln , m}^{\prime}\right)_{\alpha}\right\}
$$

sendo:

$$
\Psi_{\ln , m}^{\prime}=\frac{1}{\Psi}\left(\frac{\partial \Psi}{\partial c_{m}}\right)=\frac{\partial \ln \Psi}{\partial c_{m}}
$$

De acordo com Umrigar e Filippi, ${ }^{46}$ a Equação 2.70 também pode ser escrita considerando a propriedade hermitiana como:

$$
\begin{gathered}
\frac{\partial E}{\partial c_{m}}=\frac{2}{\int \Psi^{*} \Psi d \tau}\left(\int \Psi^{*} \Psi \frac{1}{\Psi} \frac{\partial \Psi}{\partial c_{m}} \frac{\hat{H} \Psi}{\Psi} d \tau\right)- \\
-\frac{2}{\left(\int \Psi^{*} \Psi d \tau\right)^{2}}\left(\int \Psi^{*} \hat{H} \Psi d \tau \int \Psi^{*} \Psi \frac{1}{\Psi} \frac{\partial \Psi}{\partial c_{m}} d \tau\right)
\end{gathered}
$$

ou simplesmente:

$$
\frac{\partial E}{\partial c_{m}}=\lim _{N \rightarrow \infty} 2 \sum_{\alpha=1}^{N}\left[\frac{1}{\Psi} \frac{\partial \Psi^{*}}{\partial c_{m}} \cdot E_{L}-\frac{1}{\Psi} \frac{\partial \Psi^{*}}{\partial c_{m}} \cdot \bar{E}\right]=\lim _{N \rightarrow \infty} 2 \sum_{\alpha=1}^{N}\left[\frac{1}{\Psi} \frac{\partial \Psi^{*}}{\partial c_{m}} \cdot\left(E_{L}-\bar{E}\right)\right]
$$

De maneira semelhante, os elementos da hessiana são obtidos por meio da expressão:

$$
\begin{aligned}
& \frac{\partial^{2} E}{\partial c_{m} \partial c_{\mathrm{n}}}=\lim _{N \rightarrow \infty} \frac{2}{N} \sum_{\alpha=1}^{N}\left\{\left(E_{L} \cdot \Psi_{\mathrm{ln}, m, n}^{\prime \prime}\right)_{\alpha}-E \cdot\left(\Psi_{\mathrm{ln}, m, n}^{\prime \prime}\right)_{\alpha}+\right. \\
& +2\left[\left(E_{L} \cdot \Psi_{\ln , m}^{\prime} \cdot \Psi_{\ln , n}^{\prime}\right)_{\alpha}-E \cdot\left(\Psi_{\ln , m}^{\prime} \cdot \Psi_{\ln , n}^{\prime}\right)_{\alpha}\right]-\left(\Psi_{\ln , m}^{\prime}\right)_{\alpha} \cdot \frac{\partial E}{\partial c_{n}}-\left(\Psi_{\ln , n}^{\prime}\right)_{\alpha} \cdot \frac{\partial E}{\partial c_{m}}+2.75 \\
& \left.+\left(E_{L, n}^{\prime} \cdot \Psi_{\ln , m}^{\prime}\right)_{\alpha}\right\}
\end{aligned}
$$

sendo:

$$
\Psi_{\ln , m, n}^{\prime \prime}=\frac{\partial^{2} \Psi}{\partial c_{m} \partial c_{n}}
$$

e

46 Umrigar e Filippi (2005). 


$$
\mathrm{E}_{L, n}^{\prime}=\frac{\partial^{2} \mathrm{E}_{L}}{\partial c_{n}}=\frac{\hat{H} \Psi_{n}^{\prime}}{\Psi_{n}}-E_{L} \Psi_{\mathrm{ln}, n}^{\prime}
$$

Segundo Umrigar e Filippi, ${ }^{47}$ nota-se que o último termo da Equação 2.75 não é simétrico, enquanto a verdadeira hessiana deve ser simétrica. Logo, é desejável que esse elemento seja simetrizado. Segundo os autores, essa alteração não somente modifica a eficiência do método, mas também proporciona um autossistema real. Assim, a hessiana passa a ser escrita como:

$$
\begin{aligned}
& \frac{\partial^{2} E}{\partial c_{m} \partial c_{n}}=\lim _{N \rightarrow \infty} \frac{1}{N} \sum_{\alpha=1}^{N}\left\{2\left[\left(E_{L} \cdot \Psi_{\mathrm{ln}, m, n}^{\prime \prime}\right)_{\alpha}-E \cdot\left(\Psi_{\mathrm{ln}, m, n}^{\prime \prime}\right)_{\alpha}\right]+\right. \\
& +2\left[\left(E_{L} \cdot \Psi_{\mathrm{ln}, m}^{\prime} \cdot \Psi_{\mathrm{ln}, n}^{\prime}\right)_{\alpha}-E \cdot\left(\Psi_{\mathrm{ln}, m}^{\prime} \cdot \Psi_{\mathrm{ln}, n}^{\prime}\right)_{\alpha}-\left(\Psi_{\mathrm{ln}, m}^{\prime}\right)_{\alpha} \cdot \frac{\partial E}{\partial c_{n}}-\left(\Psi_{\mathrm{ln}, n}^{\prime}\right)_{\alpha} \cdot \frac{\partial E}{\partial c_{m}}\right]+2.78 \\
& \left.+\left(E_{L, n}^{\prime} \cdot \Psi_{\mathrm{ln}, m}^{\prime}\right)_{\alpha}-\left(E_{L, n}^{\prime}\right) \cdot\left(\Psi_{\mathrm{ln}, m}^{\prime}\right)+\left(E_{L, m}^{\prime} \cdot \Psi_{\mathrm{ln}, n}^{\prime}\right)_{\alpha}-\left(E_{L, m}^{\prime}\right) \cdot\left(\Psi_{\mathrm{ln}, n}^{\prime}\right)\right\}
\end{aligned}
$$

Nessa equação, os valores entre parênteses representam valores médios e os sem parênteses representam valores de propriedades locais, com exceção de $E$, que representa o valor médio da energia.

Dessa forma, para calcular o gradiente em relação aos parâmetros $c$, devem-se utilizar as equações 2.71 e 2.72. A hessiana poderá ser calculada pela Equação 2.78 ou 2.75, com auxílio das equações $2.72,2.76$ e 2.77. Uma vez calculados os gradientes e hessianas, utiliza-se a Equação 2.66 para estimar a variação nos parâmetros a serem otimizados.

Uma vez que a otimização é realizada com o MCV e este depende de um número de passos, o esforço computacional de cada passo de otimização deve ser experimentado. Para sistemas atômicos ou moleculares pequenos, a otimização pode ser feita com cem ou duzentas configurações por simulações envolvendo em torno de trinta mil passos, nas etapas iniciais, sendo que o número de passos deve aumentar progressivamente à medida que os parâmetros estejam próximos do equilíbrio. De qualquer maneira, testes devem ser realizados para avaliar as condições ótimas de cálculo, para não tornar o processo de otimização inexequível.

\subsection{Perspectivas e aplicações do MCV}

Uma vez definida a representação matemática da função de onda e desenvolvidos os algoritmos para o cálculo da energia cinética local, da energia total local, da amostragem de Metropolis e otimização dos parâmetros variacionais, os resultados 
de aplicações do MCV podem atingir a exatidão dos melhores métodos $a b$ initio. ${ }^{48}$ Uma das grandes vantagens do MCV está na facilidade e exatidão com que o valor de uma propriedade local qualquer possa ser determinado para funções de onda consideravelmente sofisticadas, a um custo computacional usualmente dependente apenas da eficiência computacional. Apesar de sua potencialidade, grande parte das aplicações do MCV na literatura está restrita a átomos e pequenas moléculas.

As aplicações mais frequentes do MCV estão no desenvolvimento de funções de onda para a realização de cálculos envolvendo o MCD. Uma vez que o MCD proporciona energias e propriedades com precisão superior ao $\mathrm{MCV}$, as funções de onda desenvolvidas por meio deste último são constituídas geralmente de um único determinante de Slater multiplicado por funções do tipo Jastrow. Para o MCD, as aplicações vêm sendo realizadas nos mais diferentes tipos de sistemas, sendo um método de grande aplicabilidade em sólidos, sistemas periódicos, moléculas etc. ${ }^{49}$ Para o MCD, um dos algoritmos mais utilizados foi proposto por Umrigar, Nightingale e Runge, e está detalhado na referência. ${ }^{50}$

Algo que chama a atenção em relação ao $\mathrm{MCV}$ é sua pequena aplicabilidade em sistemas mais complexos. O MCD, de certa forma, reduz as potencialidades do $\mathrm{MCV}$, uma vez que este último acaba sendo visto como uma metodologia auxiliar ao MCD, que, invariavelmente, atingirá níveis de exatidão, na pior das hipóteses, iguais ao método variacional.

Outro aspecto que minimiza o impacto do MCV é que ele necessita de uma função de onda previamente elaborada, e, embora a otimização de todos os seus parâmetros seja possível, pode ser de difícil convergência ou, dependendo do tamanho do sistema, impraticável.

Se uma função de onda apresenta uma representação extremamente elaborada, sua integração tem de ser feita numericamente, e o MCV deve ser uma das poucas alternativas eficientes, se não a única, para o cálculo das propriedades desse sistema. Mas será sempre necessário definir uma forma explícita para a função de onda? Métodos importantes de solução da equação de Schrödinger ou de Kohn-Sham com base na fragmentação do espaço de coordenadas ou malhas (grids) e posterior atribuição de valores ajustáveis para a função de onda dependentes dessas coordenadas discretizadas vêm ganhando atenção de pesquisadores interessados em propriedades eletrônicas de sólidos ou moléculas. ${ }^{51}$ Em contraste com o MCV, esses métodos focam sua atenção nas propriedades das malhas de coordenadas e utilizam vantagens matemáticas ao considerar que as funções de onda possam ser obtidas a partir de combinações lineares de ondas planas ou misturas de ondas planas e funções gaussianas. ${ }^{52} \mathrm{No} \mathrm{MCV}$, a função de onda é definida e o

\footnotetext{
48 Clark et al. (2011), Zimmerman et al. (2009), Marchi et al. (2009), Tanaka (2013), Barborini e Guidoni (2012), Morales et al. (2012), Trail e Maezono (2010).

49 Lester e Hammond (1990), Foulkes et al. (2001).

50 Umrigar et al. (1993).

51 Beck (2000), Shiozaki e Hirata (2007).

52 VandeVondele et al. (2005).
} 
mapeamento do espaço de coordenadas é feito aleatoriamente por meio do Algoritmo de Metropolis. São estratégias completamente distintas que, até o momento, não se combinaram.

Para sistemas muito simples, é possível considerar o uso do princípio variacional em um espaço de coordenadas discretizado com funções de onda representadas por pontos arbitrários em cada conjunto de coordenadas discreto e posterior e ajustar variacionalmente essa função de onda discretizada. ${ }^{53}$ Nesse tipo de estratégia, a função de onda surge como um conjunto de pontos ótimos em um espaço real discretizado, e nenhuma informação, a priori, é necessária para definir a função de onda exata do sistema. Algumas das dificuldades iniciais no uso generalizado de tal tipo de estratégia estão na caracterização da antissimetria da função de onda, na necessidade de se trabalhar com funções de onda reais e no crescimento do número de pontos na malha de coordenadas, bem como em sua distribuição, para uma descrição exata do sistema. Com base nessas dificuldades iniciais, pode-se imediatamente considerar que a abordagem da função de onda não possibilita o uso generalizado desse tipo de metodologia. Para que tais metodologias possam ser usadas em sistemas moleculares grandes, deve-se lançar mão da teoria do funcional de densidade por meio de sua formulação com base na teoria de Kohn-Sham..$^{54}$ As diferentes versões da teoria do funcional de densidade são um caminho irreversível e têm sido praticamente inexploradas em termos de MCQ. As perspectivas de sua combinação com o MCQ são também raramente encontradas na literatura.

Geralmente, quando se questiona sobre a evolução desses métodos quânticos de estrutura eletrônica ou se algum deles deverá predominar nos próximos anos, deve-se responder sempre com cautela. $\mathrm{O}$ desenvolvimento dos recursos computacionais e novos algoritmos tende sempre a reduzir o custo computacional dos cálculos. Muito possivelmente, além da evolução nos equipamentos, os melhores atributos de cada método deverão ser combinados, produzindo diferentes versões do MCQ, como, por exemplo, o recém-desenvolvido FCIQMC, ${ }^{55}$ que procura combinar o ajuste de funções Full CI com o método MCQ.

É muito provável que, no futuro, a busca por funções de onda numéricas cresça significativamente, e o MCV ou adaptações dele no desenvolvimento dessas funções de onda associadas com o desenvolvimento de malhas de coordenadas ou em combinação com a teoria do funcional de densidade sejam as alternativas de cálculos rigorosos em computadores de altíssimo desempenho.

53 Custodio et al. (2012).

54 Kümmel e Kronik (2008).

55 Booth et al. (2013). 


\section{REFERÊNCIAS}

Angelotti, W. F. D.; Fonseca, A. L.; Torres, G. B.; Custodio, R. Uma abordagem simplificada do método Monte Carlo Quântico: da solução de integrais ao problema da distribuição eletrônica. Química Nova, 2008.

Austin, B. M.; Zubarev, D. Y.; Lester, W. A. Quantum Monte Carlo and related approaches. Chemical Reviews, 2012.

Bahnsen, R.; Eckstein, H.; Schattke, W.; Fitzer, N.; Redmer, R. Variational quantum Monte Carlo calculations for solid surfaces. Physical Review B, 2001.

BARborini, M.; GuIdoni, L. Reaction pathways by quantum Monte Carlo: insight on the torsion barrier of 1,3-butadiene, and the conrotatory ring opening of cyclobutene. The Journal of Chemical Physics, 2012.

BECK, T. Real-space mesh techniques in density-functional theory. Reviews of Modern Physics, 2000.

Booth, G. H.; Grüneis, A.; Kresse, G.; Alavi, A. Towards an exact description of electronic wavefunctions in real solids. Nature, 2013.

Boys, S. F.; Handy, N. C. The determination of energies and wavefunctions with full electronic correlation. Proceedings of the royal society $A$ : mathematical, physical and engineering sciences. 1969.

Bressanini, D.; Morosi, G.; Mella, M. Robust wave function optimization procedures in quantum Monte Carlo methods. The Journal of Chemical Physics, 2002.

Bressanini, D.; Reynolds, P. J. Between classical and quantum Monte Carlo methods: "variational” QMC. Advances in Chemical Physics, 1998.

Caffarel, M.; Claverie, P. Development of a pure diffusion quantum Monte Carlo method using a full generalized Feynman-Kac formula. I. Formalism. The Journal of Chemical Physics, 1988.

Ceperley, D. M. Alder, B. J. Ground state of the electron gas by a stochastic method. Physical Review Letters, 1980.

Clark, B. K.; Morales, M. A.; McMinis, J.; Kim, J.; Scuseria, G. E. Computing the energy of a water molecule using multideterminants: a simple, efficient algorithm. The Journal of Chemical Physics, 2011.

Custodio, R.; Custodio, M. R.; Creatto, E. J. Resolvendo a equação de Schrödinger utilizando procedimentos numéricos fundamentais. Quimica Nova, 35, 2076, 2012.

Dirac, P. A. M. The quantum theory of the electron. Proceedings of the royal society A: mathematical, physical and engineering sciences. 1928.

Eckstein, H.; Schattke, W. Variational quantum Monte Carlo ground state of lithium on a Slater orbital basis. Physica A: statistical mechanics and its applications. 1995.

EInstein, A. Über einen die Erzeugung und Verwandlung des Lichtes betreffenden heuristischen Gesichtspunkt. Annalen der Physik, 1905. 
FERmi, E. Un metodo statistico per la determinazione di alcune prioprietà dell'atomo. Rend. Accad. Naz. Lincei, 6, 602, 1927.

. Eine statistische Methode zur Bestimmung einiger Eigenschaften des Atoms und ihre Anwendung auf die Theorie des periodischen Systems der Elemente. Zeitschrift für Physik,1928.

FICK, A. Ueber diffusion. Annalen der Physik und Chemie, 1855.

FLAD, H.-J.; SAVIN, A. A new Jastrow factor for atoms and molecules, using two-electron systems as a guiding principle. The Journal of Chemical Physics, 1995.

Fock, V. Näherungsmethode zur Lösung des quantenmechanischen Mehrkörperproblems. Zeitschrift fur Physik, 1930.

Foulkes, W.; Mitas, L.; Needs, R.; Rajagopal, G. Quantum Monte Carlo simulations of solids. Reviews of Modern Physics, 2001.

Hartree, D. R. The wave mechanics of an atom with a non-Coulomb central field. Part II. Some results and discussion. Proceedings of Cambridge Philosophical Society, 24, 111, 1927a.

. The wave mechanics of an atom with a non-Coulomb central field. Part I. Theory and Methods. Proceedings of Cambridge Philosophical Society, 24, 89, $1927 \mathrm{~b}$.

. The calculation of atomic structures. Nova York: John Wiley \& Sons, 1957.p. 181.

Hartree, D. R.; Hartree, W.; Swirles, B. Self-consistent field, including exchange and superposition of configurations, with some results for oxygen. Philosophical Transactions of the Royal Society A: mathematical, physical and engineering sciences, 1939.

Heisenberg, W. Über quantentheoretische Umdeutung kinematischer und mechanischer Beziehungen. Zeitschrift fur Physik, 1925.

Heitler, B. Quantum theory and electron pair bond. Physical Review, 1931.

Heitler, F.; London, W. Wechselwirkung neutraler Atome und homöopolare Bindung nach der Quantenmechanik. Zeitschrift für Physik, 1927.

Helgaker, T.; Jorgensen, P.; Olsen, J. Molecular electronic-structure theory. Chichester: John Wiley \& Sons, 2012.

HuAng, H.; CaO, Z. A novel method for optimizing quantum Monte Carlo wave functions. The Journal of Chemical Physics, 1996.

Huang, S.; Sun, Z.; Lester, W. A. Optimized trial functions for quantum Monte Carlo. The Journal of Chemical Physics, 1990.

HüCKel, E. Zur Quantentheorie der Doppelbindung. Zeitschrift für Physik, 1930. . Quantentheoretische Beiträge zum Benzolproblem. Zeitschrift für Physik, 1931.

HylleraAs, E. A. Über den Grundzustand des Heliumatoms. Zeitschrift fur Physik, 1928. Jastrow, R. Many-body problem with strong forces. Physical Review, 1955.

Kato, T. On the eigenfunctions of many-particle systems in quantum mechanics. Communications on Pure and Applied Mathematics, 1957. 
KüMmel, S.; KroniK, L. Orbital-dependent density functionals: theory and applications. Reviews of Modern Physics, 2008.

Lester, W. A.; Hammond, B. L. Quantum Monte Carlo for the electronic structure of atoms and molecules. Annual Review of Physical Chemistry, 1990.

LeVIne, I. Quantum chemistry. 6. ed. Nova York: Prentice Hall, 2008. 768 p.

Lin, X.; Zhang, H.; RAppe, A. M. Optimization of quantum Monte Carlo wave functions using analytical energy derivatives. The Journal of Chemical Physics, 2000.

Luchow, A.; Anderson, J. B. Monte Carlo methods in electronic structures for large systems. Annual Review of Physical Chemistry, 2000.

Luo, H.; Hackвusch, W.; Flad, H.-J. Quantum Monte Carlo study of Jastrow perturbation theory. I. Wave function optimization. The Journal of Chemical Physics, 2009.

Manten, S.; Lüchow, A. On the accuracy of the fixed-node diffusion quantum Monte Carlo method. The Journal of Chemical Physics, 2001.

Marchi, M.; Azadi, S.; Casula, M.; Sorella, S. Resonating valence bond wave function with molecular orbitals: Application to first-row molecules. The Journal of Chemical Physics, 2009.

McQuarrie, D. A. S. D. Physical chemistry: a molecular approach. Sausalito: University Science Books, 1997. 1360 p.

Metropolis, N.; Rosenbluth, A. W.; Rosenbluth, M. N.; Teller, A. H.; Teller, E. Equation of state calculations by fast computing machines. The Journal of Chemical Physics, 1953.

Møller, C.; Plesset, M. S. Note on an approximation treatment for many-electron systems. Physical Review, 1934.

Morales, M. A.; McMinis, J.; Clark, B. K.; Kim, J.; Scuseria, G. E. Multideterminant wave functions in quantum Monte Carlo. Journal of Chemical Theory and Computation, 2012.

Moskowitz, J. W.; Kalos, M. H. A new look at correlations in atomic and molecular systems. I. Application of fermion Monte Carlo variational method. International Journal of Quantum Chemistry, 1981.

Moskowitz, J. W.; Schmidt, K. E. Correlated Monte Carlo wave functions for some cations and anions of the first row atoms. The Journal of Chemical Physics, 1992.

Mulliken, R. Electronic states and band spectrum structure in diatomic molecules. IV. Hund's theory; second positive nitrogen and swan bands; alternating intensities. Physical Review, 1927.

. The assignment of quantum numbers for electrons in molecules. I. Physical Review, 1928.

Neuscamman, E.; Umrigar, C. J.; Chan, G. K.-L. Optimizing large parameter sets in variational quantum Monte Carlo. Physical Review B, 2012. 
Nukala, P. K. V. V.; Kent, P. R. C. A fast and efficient algorithm for Slater determinant updates in quantum Monte Carlo simulations. The Journal of Chemical Physics, 2009.

O-Ohata, K.; TAketa, H.; Huzinaga, S. Gaussian expansions of atomic orbitals. Journal of the Physical Society of Japan, 1966.

Pilar, F. L. Elementary quantum chemistry. 2. ed. Nova York: Dover Publications, 2001. 640 p. Planck, M. Ueber das Gesetz der Energieverteilung im Normalspectrum. Annalen der Physik, 1901.

PRATT, L. Lower bound on the ground-state energies of atoms and molecules by variational quantum Monte Carlo methods. Physical Review A, 1989.

Press, W. H.; Flannery, B. P. T. S. A. Numerical recipes in Fortran 77: the art of scientific computing. 2. ed. Cambridge: Cambridge University Press, 1992. 933 p.

Reynolds, P. J.; Ceperley, D. M. Fixed-node quantum Monte Carlo for molecules. The Journal of Chemical Physics, 1982.

Santos Politi, J. R.; Custodio, R. Comments on the quantum Monte Carlo method and the density matrix theory. The Journal of Chemical Physics, 2003.

Scemama, A.; Filippi, C. A simple and efficient approach to the optimization of correlated wave functions. Physical Review B, 2006.

Schautz, F.; Fahy, S. Optimization of configuration interaction coefficients in multideterminant Jastrow-Slater wave functions. The Journal of Chemical Physics, 2002.

Schmidt, K. E.; Moskowitz, J. W. Correlated Monte Carlo wave functions for the atoms He through Ne. The Journal of Chemical Physics, 1990.

Schrödinger, E. An undulatory theory of the mechanics of atoms and molecules. Physical Review, 1926a.

. Quantisierung als Eigenwertproblem. Annalen der Physik, $1926 \mathrm{~b}$.

. Über die kräftefreie Bewegung in der relativistischen Quantenmechanik. Sitzber. Preuss. Akad. Wiss. Phys.-Math. Kl., 144, 1931.

Shiozaki, T.; Hirata, S. Grid-based numerical Hartree-Fock solutions of polyatomic molecules. Physical Review A, 2007.

Sorella, S. Wave function optimization in the variational Monte Carlo method. Physical Review B, 2005.

TANAKA, S. Variational quantum Monte Carlo with inclusion of orbital correlations. Journal of the Physical Society of Japan, 2013.

Thomas, L. H. The calculation of atomic fields. Mathematical Proceedings of the Cambridge Philosophical Society, 2008.

Toulouse, J.; Umrigar, C. J. Optimization of quantum Monte Carlo wave functions by energy minimization. The Journal of Chemical Physic, 2007.

. Full optimization of Jastrow-Slater wave functions with application to the first-row atoms and homonuclear diatomic molecules. The Journal of Chemical Physics, 2008. 
Trail, J. R.; MaEzono, R. Full optimization of Jastrow-Slater wave functions with application to the first-row atoms and homonuclear diatomic molecules. The Journal of Chemical Physics, 2010.

Umrigar, C. J.; Filippi, C. Energy and Variance Optimization of Many-Body Wave Functions. Physical Review Letters, 2005.

Umrigar, C. J.; Nightingale, M. P.; Runge, K. J. A diffusion Monte Carlo algorithm with very small time-step errors. The Journal of Chemical Physics, 1993.

Umrigar, C. J.; Wilson, K. G.; Wilkins, J. W. A diffusion Monte Carlo algorithm with very small time-step errors. Physical Review Letters, 1988.

VandeVondele, J.; Krack, M.; Mohamed, F.; Parrinello, M.; Chassaing, T.; Hutter, J. QuicksteP: fast and accurate density functional calculations using a mixed Gaussian and plane waves approach. Computer Physics Communications, 2005.

VogL, G. Basic principles of diffusion theory, experiment and application. Diffusion fundamentals, 2, 1, 2005.

Wigner, E. On the interaction of electrons in metals. Physical Review, 1934.

Yoshida, T.; IGUchi, K. Variational Monte Carlo method in the connected moments expansion: $\mathrm{H}, \mathrm{H}^{-}, \mathrm{Be}$, and $\mathrm{Li}_{2}$. The Journal of Chemical Physics, 1989.

Zimmerman, P. M.; Toulouse, J.; Zhang, Z.; Musgrave, C. B.; Umrigar, C. J. Excited states of methylene from quantum Monte Carlo. The Journal of Chemical Physics, 2009. 


\section{ESTUDO DE ESTRUTURA DE LÍQUIDOS PELO MÉTODO EPSR}

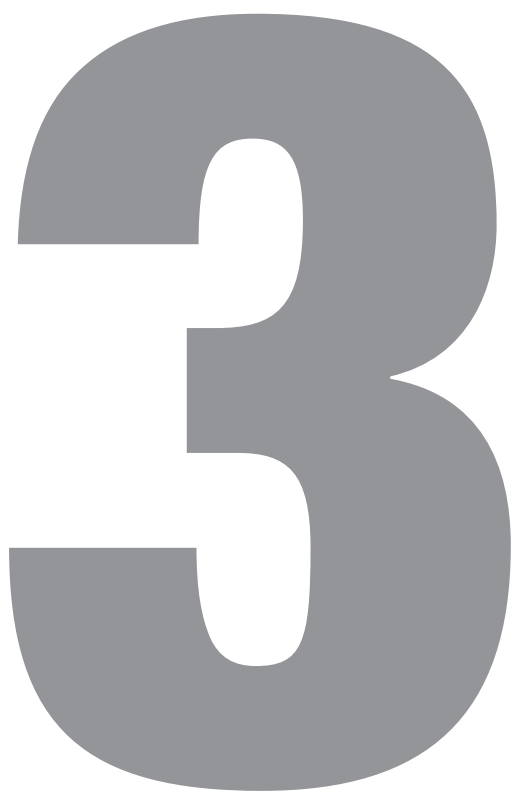

JoÃo Manuel Marques CoRDElRo ${ }^{1}$

1 Faculdade de Engenharia, Universidade Estadual Paulista "Júlio de Mesquita Filho" (UNESP), campus de Ilha Solteira-SP. E-mail: <cordeiro@dfq.feis.unesp.br>. 


\subsection{INTRODUÇÃO}

Empirical Potential Structure Refinement (EPSR) é uma técnica computacional desenvolvida para que se obtenha a estrutura tridimensional de um material amorfo, partindo da informação contida em dados de espalhamento, quer sejam nêutrons, quer sejam raios-X. Em termos gerais, utiliza-se simulação Monte Carlo de um sistema molecular e corrige-se o potencial de interação de pares entre as moléculas, a cada etapa da simulação, comparando seus resultados com os dados da difração. A técnica tem por base a metodologia do método Monte Carlo Reverso (RMC), apresentada por McGreevy e Pusztai, em 1988, ${ }^{2}$ tendo sido desenvolvida por Alan Soper a partir de $1996 .{ }^{3}$ Nesse caso, a estrutura do material é derivada, em parte, de dados disponíveis sobre ele, como densidade, entalpia de vaporização e estrutura molecular, e, em parte, dos dados de espalhamento que contêm informações sobre as funções de distribuição radial ligadas aos correspondentes fatores de estrutura parcial. Na discussão que aqui se apresenta, seguir-se-á de perto o trabalho desenvolvido por Alan Soper ${ }^{4}$ e recentemente com participação de Cordeiro. ${ }^{5}$

Como já dito, EPSR utiliza Monte Carlo para a simulação computacional, lançando mão de um potencial molecular empírico, o qual é utilizado para produzir os movimentos moleculares que serão aceitos ou rejeitados de acordo com a condição utilizada para decidir sobre essa taxa de aceitação/recusa. ${ }^{6}$ No atual estágio do método, o refinamento é feito no espaço de momento, $Q$, o que possibilita a simulação no espaço de medida do experimento e permite a comparação direta da simulação com ele. Paralelamente, evitam-se as aproximações e incertezas relacionadas à transformada de Fourier dos dados de espalhamento para o espaço r, enquanto o processo

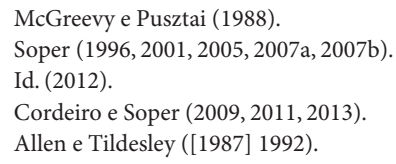


de transformadas de Fourier dos dados para o espaço Q é significativamente mais realista, em função da quase completa ausência de erros sistemáticos nas funções de distribuição radial simuladas.

Além dos erros experimentais, um experimento de espalhamento tem, também, incertezas estatísticas, mas elas são normalmente da ordem de $1 \%$ ou menos, na maioria dos laboratórios que lidam com espalhamento são geralmente conhecidas com boa precisão e governadas por uma função de distribuição normal bem comportada. Por outro lado, erros experimentais advêm de uma grande variedade de causas e são muito menos certos na prática. Dados de espalhamento são normalmente afetados por autoatenuação, múltiplo espalhamento, eficiência do detector, forma do feixe incidente e uma enorme variedade de efeitos específicos da radiação, como, por exemplo, espalhamento inelástico com nêutrons, polarização e espalhamento Compton com raios-x. Além disso, os dados estarão sujeitos a espalhamento de fundo (radiação recebida no detector que não vem da amostra) e espalhamento pela cela (a maioria dos materiais necessita ser contida em uma cela para ser submetida ao feixe de radiação). No caso de raios- $\mathrm{x}$, os dados terão de ser normalizados para os fatores de forma atômica (a fim de serem comparados com modelos atomísticos) - estes são fortemente Q dependentes e, em determinados casos particulares, não são conhecidos precisamente. É a presença desses erros nos experimentos de espalhamento que torna não trivial a questão de como interpretar adequadamente os dados, fundamentalmente porque não há uma maneira, a priori, de quantificar esses erros com algum grau de precisão. Recentemente, métodos relativamente confiáveis para realizar a necessária correção nos dados têm surgido, ${ }^{7}$ mas, ainda assim, não há consenso sobre a forma correta ou mesmo a melhor maneira de realizá-la. ${ }^{8}$

Por outro lado, funções de distribuição radial obtidas por simulação computacional podem ser calculadas com boa precisão para uma dada função de energia potencial interatômica, desde que a caixa de simulação seja suficientemente grande e se empreguem os métodos adequados. ${ }^{9}$ A questão que se coloca é: qual a qualidade do potencial usado? Um dos critérios empregados em Monte Carlo para aferir essa qualidade é calcular a energia (por exemplo, o calor de vaporização) e a densidade do material simulado e compará-los com os valores experimentais. Todavia, o teste definitivo para qualquer potencial é a precisão com que é capaz de reproduzir as funções de distribuição atomística que são responsáveis pelos fatores de estrutura observados em um experimento de espalhamento. ${ }^{10}$ É preciso ter em mente, porém, que, uma vez que para sistemas moleculares em particular a estrutura é definida essencialmente pela função de correlação de pares orientacional, e não pela de distribuição radial sítio-sítio, ${ }^{11}$ essa comparação por si só não é suficiente para creditar

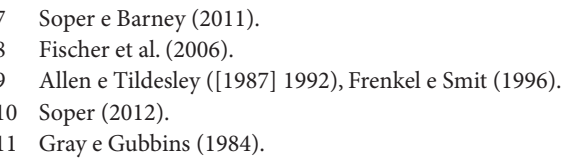


um dado potencial usado. Ainda assim, um alto nível de concordância entre a simulação e o experimento é uma condição necessária que se deve verificar, ainda que não seja suficiente para aferir completamente a estrutura molecular.

Então, o que fazer quando, a despeito de todos os esforços, não se encontra uma função de potencial que reproduza adequadamente os dados experimentais? Em resposta a essa questão, métodos como RMC e EPSR foram inventados, com o objetivo de delimitar o espaço de procura do potencial desejado. Essencialmente, a ideia é colocar átomos e moléculas em uma caixa de simulação computacional, de forma consistente com os dados de espalhamento disponíveis. Com EPSR em particular, há uma vantagem adicional, nomeadamente, que, conforme a simulação evolui, mostra o espaço de configurações de forma que, se calhar, é análoga àquela acessada pelo sistema real, de tal forma que, após muitos passos de simulação, as funções de distribuição radial têm, estatisticamente, a qualidade das funções de distribuição real, e as flutuações estatísticas nas funções se tornam cada vez menores à medida que o conjunto de variáveis termodinâmicas amostradas aumenta. ${ }^{12}$

Agora, pergunta-se: é possível obter uma distribuição molecular única dos experimentos de difração usando as técnicas de EPSR ou RMC? Esse será o foco da discussão doravante, contudo, ao fazê-la, perceber-se-á que, paralelamente, essas metodologias têm um papel subsidiário muito importante na identificação de prováveis erros no experimento e na extensão com que essas incertezas impedem a determinação de uma solução única. Em alguns casos, como a água, por exemplo, há dados suficientes para, pelo menos em princípio, uma separação completa dos dados em três fatores de estrutura parciais, $\mathrm{OO}, \mathrm{OH}$ e $\mathrm{HH}$. Em outros casos, como $\mathrm{DMSO}^{13} \mathrm{e} \mathrm{NMF}^{14}$ isto não é possível porque o contraste isotópico de carbono, oxigênio, enxofre e nitrogênio é ainda muito pequeno para prover informação isenta de ambiguidade. É claro que a maior parte dos sistemas estudados é do segundo tipo. Então, é interessante que se estabeleça a singularidade de qualquer reconstrução de dados que se faça e a extensão e natureza de qualquer ambiguidade.

\subsection{Empirical Potential Structure Refinement}

Embora desenvolvido de forma independente, EPSR é similar ao método originalmente proposto por Schommers ${ }^{15}$ no qual a diferença entre uma função de distribuição radial simulada e a função calculada dos dados de espalhamento foi usada para perturbar o potencial interatômico, e essa perturbação foi acumulada até a simulação ser capaz de reproduzir a função medida. Neuefeind et al. exploraram um método mais sofisticado desenvolvido por Levesque et al. para realizar esse re-

12 Hansen e McDonald (1986).

13 Soper (2012).

14 Cordeiro e Soper (2009).

15 Schommers (1983). 
finamento, mas depois mostraram que o método de Schommers, mais simples, dá resultados equivalentes. ${ }^{16}$ EPSR dá resultados equivalentes aos obtidos pelo método de Schommers sem a complicação de se calcularem as funções de correlação direta parcial, $c_{a b}(r)$, que não são facilmente obteníveis dos dados experimentais.

$\mathrm{Na}$ simulação EPSR, as moléculas são mantidas juntas por uma força harmônica simples, $U^{\text {(intra) }}(r)$. Cada distância intramolecular é caracterizada por uma distância média esperada, $\mathrm{d}_{\mathrm{mn}}$, e por um fator Debye-Waller, $\mathrm{w}_{\mathrm{mn}}$ :

$$
\mathrm{U}^{(\mathrm{intra})}(\mathrm{r})=\mathrm{C} \sum_{\mathrm{i}} \sum_{\mathrm{m} . \mathrm{n}>\mathrm{m}} \frac{\left(\mathrm{r}_{\mathrm{mn}}(\mathrm{i})-\mathrm{d}_{\mathrm{mn}}\right)^{2}}{\mathrm{w}_{\mathrm{mn}}^{2}}
$$

em que $\mathrm{r}_{\mathrm{mn}}$ (i) é a separação dos átomos m e $\mathrm{n}$ na molécula i e $\mathrm{w}_{\mathrm{mn}}^{2}=\mathrm{d}_{\mathrm{mn}} / \sqrt{\mu_{\mathrm{mn}}}$, com $\mu_{m n}=M_{m} M_{n} /\left(M_{m}+M_{n}\right)$, é a massa reduzida do par de átomos $m, n$. Esse termo de energia opera independentemente dos termos de energia de potencial intermolecular para evitar que o potencial empírico dissocie as moléculas. C é uma constante que é ajustada no início, para indicar a largura correta das linhas de correlação intramolecular. O uso de um fator genérico de Debye-Waller, $\mathrm{w}_{\mathrm{mn}}$, evita que se tenha de especificar esse valor para um grande número de pares de átomos.

A função de energia potencial intermolecular na simulação EPSR é representada como a soma de dois termos: o potencial de referência (RF), que permanece inalterado ao longo da simulação, e o potencial empírico (EP), que é derivado dos dados de espalhamento e que pode mudar, dependendo do grau de concordância dos dados

$$
\mathrm{U}_{\alpha \beta}^{\text {(inter) }}(\mathrm{r})=\mathrm{U}_{\alpha \beta}^{(\mathrm{RF})}(\mathrm{r})+\mathrm{U}_{\alpha \beta}^{(\mathrm{EP})}(\mathrm{r})
$$

para o par de átomos $\alpha, \beta$. Em princípio, o potencial de referência pode tomar qualquer forma, embora o que se utilize seja um potencial de combinação de Lennard-Jones e Coulomb e um termo exponencial puramente repulsivo. ${ }^{17}$ Esse termo é usado para prevenir sobreposição atômica, no caso de o potencial empírico tentar empurrar os átomos para cima uns dos outros. Isso pode ocorrer, por exemplo, se os dados contiverem erros sistemáticos, como discutido anteriormente, que não podem ser reproduzidos por distribuição de átomos que não estejam superpostos.

O potencial empírico é expandido em uma série de funções de Poisson, no espaço real:

$$
\mathrm{U}_{\alpha \beta}^{(\mathrm{EP})}=\mathrm{kT} \sum_{\mathrm{k}} \mathrm{C}_{\alpha \beta}(\mathrm{k}) \mathrm{p}_{\mathrm{k}}(\mathrm{r}, \sigma)
$$

16 Neuefeind, Fischer e Schroer (2000a, 2000b).

17 Soper (2007a). 
com:

$$
\mathrm{p}_{\mathrm{k}}(\mathrm{r}, \sigma)=\frac{1}{4 \pi \rho \sigma^{3}(\mathrm{k}+2) !}\left(\frac{\mathrm{r}}{\sigma}\right)^{\mathrm{k}} \exp \left(-\frac{\mathrm{r}}{\sigma}\right)
$$

em que $\sigma$ é uma função de largura idealmente escolhida para atingir a estrutura genuína, enquanto mascara erros sistemáticos nos dados do espalhamento. A Equação 3.4 tem uma transformada de Fourier exata no espaço $\mathrm{Q}^{18}$ tal que, na prática, os coeficientes $\mathrm{C}_{\alpha \beta}(\mathrm{k})$ são estimados no espaço de medida do experimento e, então, usados para gerar o potencial empírico no espaço $r$. Isso evita que se precise de uma transformada de Fourier numérica dos dados de espalhamento, os quais podem ter muitos artefatos associados com truncamento e ruído, mas isso não garante que tais artefatos não sejam, em alguma extensão, carregados para dentro da simulação.

Calcular o potencial empírico usando a Equação 3.3 implica conhecer experimentalmente os fatores de estrutura parciais sítio-sítio e as funções de distribuição radiais individuais. Na prática, o experimento mede uma soma ponderada de fatores de estrutura parciais, com os pesos obtidos da amplitude do espalhamento de nêutrons ou dos fatores de forma atômica dos componentes particulares presentes na amostra. Para se extrair de uma amostra com $\mathrm{N}$ pares de átomos todos os fatores de estrutura, necessitam-se $\mathrm{N}$ experimentos com pesos linearmente independentes (o número de pares de átomos está relacionado com o número de componentes J por $\mathrm{N}=\mathrm{J}(\mathrm{J}+1) / 2$ ), o que torna impossível obter todos os fatores de estrutura de uma amostra, ainda que o número de componentes seja pequeno. Para o i-ésimo componente, o fator de estrutura medido pode ser escrito como:

$$
F_{i}(Q)=\sum_{j=1}^{n} w_{i j}(Q) H_{j}(Q)
$$

em que a soma $j$ representa todos os $n$ tipos de pares de átomos no experimento. As funções de peso são expressas por

$$
\mathrm{w}_{\mathrm{ij}}(\mathrm{Q})=\left(2-\delta_{\alpha(\mathrm{j}) \beta(\mathrm{j})}\right) \mathrm{c}_{\alpha(\mathrm{j})} \mathrm{c}_{\beta(\mathrm{j})} \mathrm{b}_{\mathrm{i}, \alpha(\mathrm{j})} \mathrm{b}_{\mathrm{i}, \beta(\mathrm{j})}
$$

para nêutrons, com $\alpha(\mathrm{j}), \beta(\mathrm{j})$, o par de átomos associados com o j-ésimo termo, $\mathrm{c}_{\alpha}$, a fração atômica do componente, $\alpha, b_{i, \alpha}$, a amplitude da dispersão de nêutrons para o átomo de tipo $\alpha$, na amostra i, o fator de estrutura parcial $H_{j}(Q)$ e a transformada de Fourier da correspondente função de distribuição radial sítio-sítio $\left(g_{j}(r)-1\right)$.

Uma vez que, na maioria dos casos, o número $\mathrm{M}$ de conjuntos de dados linearmente independentes é muito menor que o número de fatores de estrutura par- 
cial disponível, $\mathrm{M}<\mathrm{N}$, o EPSR vence esses obstáculos da seguinte forma: em adição ao conjunto de dados $\mathrm{M}$, um conjunto de dados $\mathrm{N}$ fictício, derivado somente de simulação, é calculado. Esse conjunto extra de dados são os $\mathrm{N}$ fatores de estrutura parcial sítio-sítio, tal que os pesos para esses termos extras são:

$$
\mathrm{w}_{\mathrm{ij}}(\mathrm{Q})=(1-\mathrm{f}) \delta_{\mathrm{i}-\mathrm{M}, \mathrm{j}} \text { para } \quad \mathrm{M}<\mathrm{i} \leq \mathrm{M}+\mathrm{N}
$$

em que $f$ é um fator de feedback escolhido pelo usuário. Ao mesmo tempo, os pesos para o conjunto de dados experimental são multiplicados pelo fator $f$, tal que, quanto mais se escolhe um $f \rightarrow 1$, mais se está assumindo confiança nos dados, e vice-versa - ao escolher $f \rightarrow 0$, assume-se menor confiança neles. Escolher $f=1$ significa total confiança nos dados, mas isso somente levará a uma solução se o conjunto de dados experimental for completo, isto é, se $\mathrm{M} \geq \mathrm{N}$, e os pesos forem linearmente independentes. Com essas considerações, o conjunto total de $\mathrm{M}+\mathrm{N}$ pesos pode ser invertido, ${ }^{19}$ tal que os fatores de estrutura parcial individual podem ser calculados por uma combinação de dados de espalhamento e de simulação. Claro, deve-se ter sempre em mente que, enquanto esse processo resolve o problema de inverter a matriz de pesos, ele ainda sofre a desvantagem de que o conjunto de dados experimental é incompleto e, portanto, não se pode ter uma resolução da estrutura da amostra isenta de ambiguidade.

Há, ainda, outro fator que afeta o resultado de uma simulação EPSR, a amplitude do potencial empírico. Em EPSR, essa amplitude é definida como:

$$
\left|\mathrm{U}^{(\mathrm{EP})}\right|=4 \pi \rho \sum_{\mathrm{j}}\left(2-\delta_{\alpha(\mathrm{j}) \beta(\mathrm{j})}\right) \mathrm{c}_{\alpha(\mathrm{j})} \mathrm{c}_{\beta(\mathrm{j})} \int_{0}^{\infty} \mathrm{r}^{2}\left|\mathrm{U}_{\alpha(\mathrm{j}) \beta(\mathrm{j})}^{(\mathrm{EP})}(\mathrm{r})\right| \mathrm{g}_{\mathrm{j}}(\mathrm{r}) \mathrm{dr}
$$

Caso tivesse acesso a dados experimentais perfeitos, isto é, destituídos de qualquer fonte de erro, o EP cresceria em amplitude, até tal ponto que o ajuste com os dados experimentais não poderia mais ser melhorado. Nesse ponto, ele estabilizaria e não mudaria mais. Todavia, há erros inevitáveis nos dados experimentais que não podem ser reproduzidos pela simulação, independentemente do que se faça no potencial empírico, sem que se crie algum tipo de consequência irreal, como a superposição de átomos. Isso deve estar na forma de um resíduo nos dados que não pode ser reproduzido ou se deve a alguma corcova no fator de estrutura medido, sem relação com a estrutura, mas com outro aspecto das medidas, como espalhamento inelástico, interferência do contêiner etc. Nessas circunstâncias, se deixado a seu bel-prazer, o EP crescerá indefinidamente em amplitude, tentando encontrar uma distribuição de átomos que ajuste as características encontradas nos dados, mas que são irreais. Para evitar que isso aconteça, limita-se a amplitude de EP, sendo que o valor desse limite é determinado pelo usuário. 


\subsection{EPSR EM N-METILFORMAMIDA}

Os dados de espalhamento de nêutrons foram obtidos a 298 K, no difratômetro de nêutrons de baixo ângulo do Rutherford Appleton Laboratory, em Oxfordshire, Inglaterra. Os dados de difração foram coletados em ângulos de espalhamento abaixo de $40^{\circ}$. Baixos ângulos de espalhamento ajudam a reduzir os efeitos de recuo nuclear nos dados coletados. Em razão de os nêutrons se espalharem diferentemente, dependendo dos isótopos presentes no material medido, um conjunto de três amostras de $\mathrm{N}$-metilformamida, quimicamente similares, mas isotopicamente diferentes, foi submetido à difração de nêutrons para facilitar a extração das correlações estruturais intermoleculares, a saber, $\mathrm{C}_{2} \mathrm{H}_{5} \mathrm{ON}, \mathrm{C}_{2} \mathrm{D}_{5} \mathrm{ON}$ (em que átomos de hidrogênio foram substituídos pelo isótopo deutério), e uma mistura de 50\% dos dois líquidos anteriores. Para obtenção dos difratogramas, as amostras foram introduzidas em celas de uma liga $\mathrm{Ti}_{0,68} \mathrm{Zr}_{0,32}$, de dimensões internas $1 \mathrm{~mm}$ x $35 \mathrm{~mm}$ x $35 \mathrm{~mm}$ e espessura de parede de 1,1 mm. Essa liga é "transparente" aos nêutrons, não produzindo nenhum espalhamento que interfira no sinal da amostra. Os dados foram obtidos com nêutrons de comprimento de onda $\lambda$, no intervalo de 0,075 a $3,5 \AA$, sobre um correspondente intervalo de $\mathrm{Q}$ de 0,1 a $30 \AA^{-1}$. Uma vez colhidos os dados, estes foram analisados com o programa Gudrun, ${ }^{20}$ que os "depurou" considerando as contribuições das paredes da cela, background do instrumento, absorção e espalhamento múltiplo e normalizando os dados para unidades absolutas com uso do espalhamento de um padrão de vanádio.

Para a simulação, utilizou-se um potencial tipo OPLS-AA, otimizado anteriormente $^{21}$ como ponto de partida para o subsequente refinamento da estrutura. O potencial entre os átomos foi construído por uma combinação de potenciais de Coulomb e Lennard-Jones, da forma usual, ${ }^{22}$ representada por:

$$
\mathrm{U}_{\alpha \beta}(r)=4 \varepsilon_{\alpha \beta}\left[\left(\frac{\sigma_{\alpha \beta}}{r}\right)^{12}-\left(\frac{\sigma_{\alpha \beta}}{r}\right)^{6}\right]+\frac{1}{4 \pi \varepsilon_{o}} \frac{\mathrm{q}_{\alpha} \mathrm{q}_{\beta}}{r}
$$

em que $\varepsilon_{\alpha \beta}=\left(\varepsilon_{\alpha} \varepsilon_{\beta}\right)^{1 / 2}, \sigma_{\alpha \beta}=0.5\left(\sigma_{\alpha}+\sigma_{\beta}\right)$ e $\varepsilon_{o}$ é a permissividade do espaço. Os parâmetros de Lennard-Jones e as cargas parciais do modelo de potencial usado encontram-se na Tabela 3.1. A simulação foi feita apenas com moléculas do confôrmero cis (metil e oxigênio cis entre si), porque $95 \%$ das moléculas no líquido real estão nessa forma conformacional. ${ }^{23} \mathrm{~A}$ geometria molecular está detalhada em Cordeiro e Soper. ${ }^{24}$

0 Soper et al. (1989).

21 Cordeiro (1997).

22 Allen e Tildesley ([1987] 1992).

23 Luzar e Chandler (1993), McLain, Soper e Watts (2006).

24 Cordeiro e Soper (2009). 
Tabela 3.1 Parâmetros de Lennard-Jones e cargas usadas no potencial de NMF de referência. ${ }^{25}$

\begin{tabular}{cccc}
\hline Átomo & $\varepsilon(\mathbf{k J} / \mathbf{m o l})$ & $\sigma(\AA)$ & $\mathbf{q}(\mathbf{e})$ \\
\hline $\mathrm{C}$ & 0,4389 & 3,75 & 0,34 \\
$\mathrm{O}$ & 0,6688 & 2,96 & $-0,46$ \\
$\mathrm{H}(\mathrm{C})$ & 0,1520 & 2,70 & 0,12 \\
$\mathrm{~N}$ & 0,5852 & 3,25 & $-0,70$ \\
$\mathrm{H}(\mathrm{N})$ & 0,000 & 0,00 & 0,415 \\
$\mathrm{C}(\mathrm{Me})$ & 0,5016 & 3,63 & 0,285 \\
\hline $\mathrm{H}(\mathrm{Me})$ & 0,000 & 0,00 & 0,000 \\
\hline
\end{tabular}

A simulação de Monte Carlo, em si, segue o esquema tradicionalmente utilizado, ${ }^{26}$ com aplicação de condições de contorno periódicas e convenção de imagem mínima. Os potenciais de Lennard-Jones e de Coulomb são truncados, utilizando o formalismo mostrado em Cordeiro e Soper. ${ }^{27}$ A caixa de simulação é cúbica, contendo 500 moléculas, com densidade atômica de 0,09168 $\AA^{-3}$. Como o hidrogênio ligado ao nitrogênio é lábil, há uma troca isotópica de hidrogênios entre os nitrogênios na mistura isotópica $50 \%$, aspecto que é considerado no refinamento dessa mistura. Tipicamente, as simulações com o potencial de referência sofrerão mil iterações, cada qual consistindo cinco tentativas de deslocamentos e rotações de cada molécula na caixa de simulação, com um fator de aceitação de $25 \%$ tal que, após cada iteração, há uma probabilidade de $75 \%$ de cada molécula ter sido movida ou rodada pelo menos uma vez. Para as simulações em que o potencial empírico está sendo refinado, há um período adicional de equilíbrio, até que a energia, a pressão e o ajuste com os resultados experimentais se tornem estáveis. Uma vez atingido o equilíbrio, a simulação prossegue por mais aproximadamente cinco mil iterações, para acumular as funções de distribuição radial. A Figura 3.1 mostra os fatores de estrutura totais, o refinamento EPSR e os resíduos obtidos para as três amostras. ${ }^{28}$

\footnotetext{
Cordeiro (1997).

Soper e Barney (2011), Frenkel e Smit (1996).

Cordeiro e Soper (2009).

Id. ibid.
} 


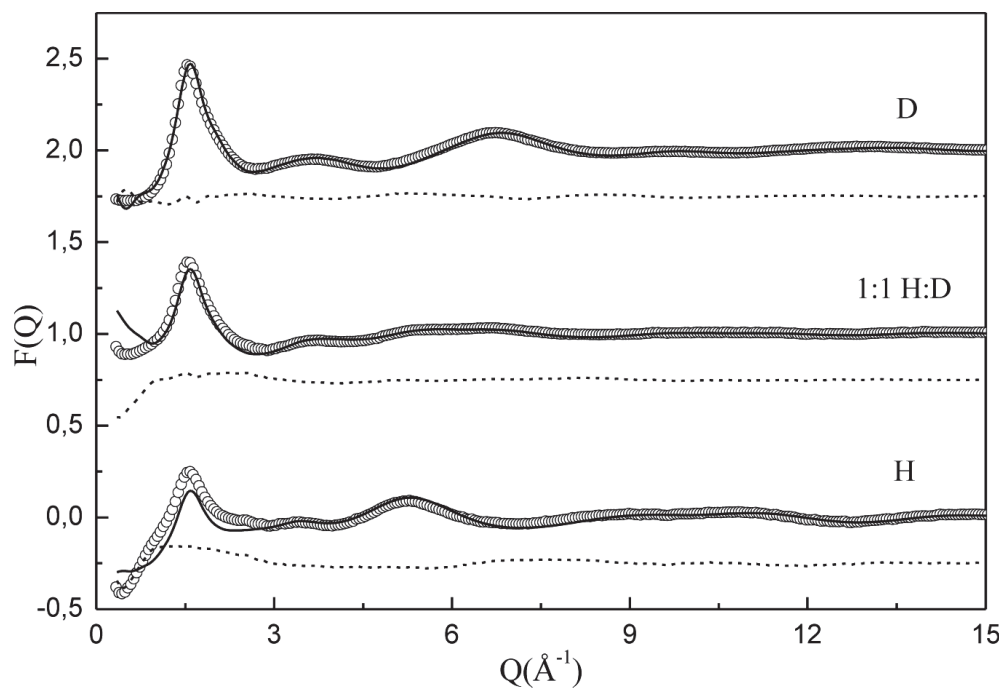

Figura 3.1 Dados de estrutura medidos experimentalmente (círculos) e refinamento EPSR (linhas) do espalhamento de nêutrons de $\mathrm{C}_{2} \mathrm{NOH}_{5}$ (no alto), $\mathrm{C}_{2} \mathrm{NOD}_{5}$ (embaixo) e da mistura de $50 \%$ desses dois líquidos (no meio). Os gráficos estão deslocados de 1 unidade para melhor visualização. Os resíduos (diferença entre o experimental e o refinamento) para cada amostra (tracejado) encontram-se deslocados de $-0,25$ unidade com relação às curvas correspondentes.

Como se observa, a qualidade do ajuste como um todo é bastante boa, embora alguma discrepância entre o modelo empírico e os dados experimentais seja notada em baixas frequências, no caso do líquido totalmente protonado e da mistura de $50 \%$. Correções de fundo e de inelasticidade são mais difíceis de serem feitas quando os isotopômeros contêm hidrogênio leve, e essas são as causas normalmente atribuídas à maior dificuldade de se conseguir um melhor ajuste nessa região de frequências.

As funções de distribuição radial total, $f(r)$, obtidas pela transformada de Fourier dos dados experimentais de fator de estrutura, $\mathrm{F}(\mathrm{Q})$, e as correspondentes funções calculadas do refinamento EPSR estão na Figura 3.2. ${ }^{29}$ 


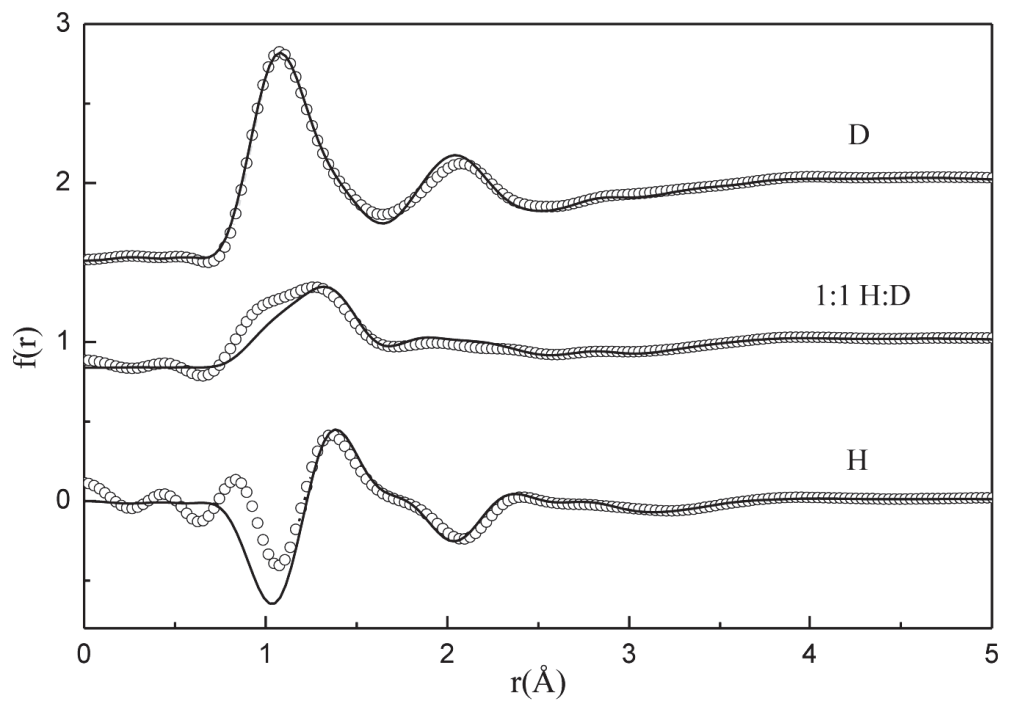

Figura 3.2 Funções de distribuição radial obtidas por transformadas de Fourier dos dados experimentais de $\mathrm{F}(\mathrm{Q})$ (círculos) e refinamento EPSR (linhas) dos dados de espalhamento de nêutrons de $\mathrm{C}_{2} \mathrm{NOH}_{5}$ (no alto), $\mathrm{C}_{2} \mathrm{NOD}_{5}$ (embaixo) e da mistura de $50 \%$ desses dois líquidos (no meio).

A despeito da discrepância entre os dados experimentais e o potencial empírico na região de $1 \AA ̊$ para a amostra protonada, no todo, o ajuste é bastante bom, indicando que as ligações atômicas no modelo (definem a forma das curvas no intervalo entre 1 e $2,5 \AA$ ) estão adequadamente definidas. ${ }^{30}$

Os resultados das figuras 3.1 e 3.2 indicam que a estrutura do líquido está adequadamente representada pela geometria molecular e pelo potencial empírico. Com esses resultados em mãos, passa-se a explorar a estrutura do líquido, com uso das ferramentas disponíveis para acessar as informações provenientes da distribuição das moléculas pelo corpo da amostra. Como exemplo, mostram-se, na Figura 3.3, algumas correlações de distribuição radial intermolecular, g(r), do líquido (para melhor compreensão das funções, consulte a estrutura molecular na Figura 3.7). Faz-se uma comparação das curvas obtidas somente com o potencial empírico e após o refinamento EPSR. ${ }^{31}$ 


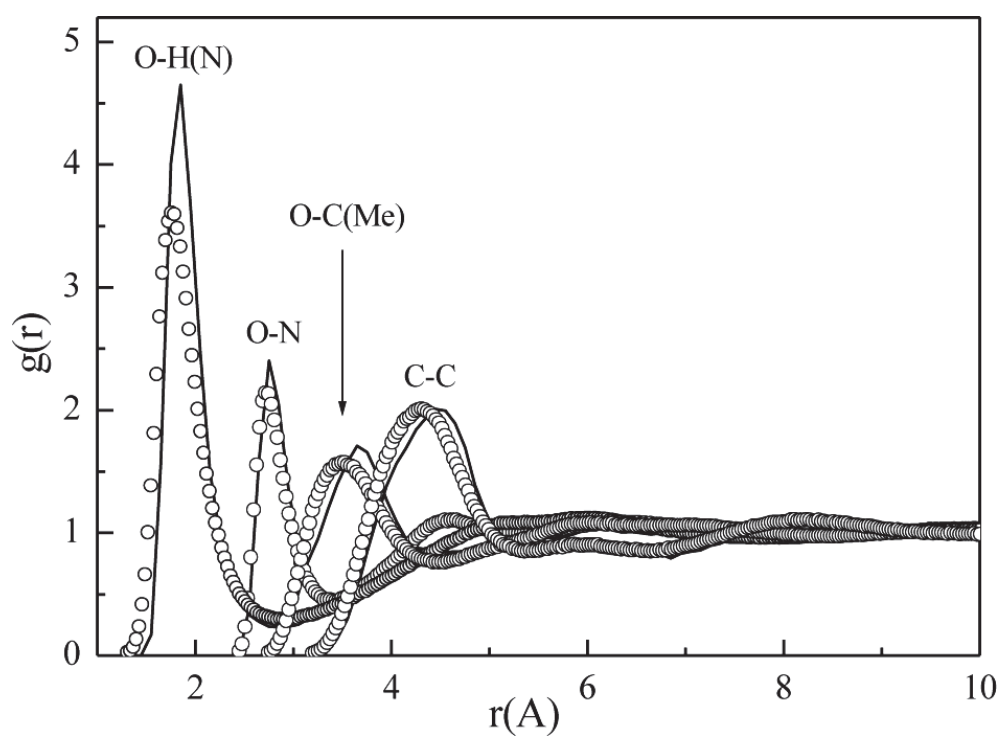

Figura 3.3 Funções de distribuição radial sítio a sítio derivadas dos cálculos EPSR (círculos) e sem refinamento de potencial (linhas). $\mathrm{H}(\mathrm{N})$ é o hidrogênio ligado ao nitrogênio e $\mathrm{C}(\mathrm{Me})$, o carbono do grupo metila.

Observa-se que a distância entre as moléculas parece ser um pouco menor no líquido, após o refinamento do potencial, sugerindo que as interações intermoleculares são um pouco mais intensas do que as representadas meramente pelo potencial empírico. Contudo, no presente caso, as diferenças não chegam a ser muito acentuadas, o que significa que o potencial empírico otimizado anteriormente ${ }^{32}$ é bastante realista. Uma análise mais extensiva da estrutura da NMF foi feita em outra oportunidade. ${ }^{33}$

\subsection{EPSR NA MISTURA N-METILFORMAMIDA-DIMETILSULFÓXIDO}

Misturas de líquidos podem ser estudadas da mesma forma que líquidos puros. ${ }^{34}$ Como exemplo, relatam-se resultados obtidos para uma mistura NMF-DMSO, 80\% em DMSO. O arcabouço experimental é o mesmo descrito no caso anterior, também sendo a mesma função de potencial intermolecular usada. No presente caso, usou-se como potencial empírico para representar o DMSO o potencial P1 otimizado por Luzar e Chandler. ${ }^{35}$ Nesse caso, pelas razões apontadas anteriormente, um conjunto de cinco amostras quimicamente similares, mas isotopicamente

\footnotetext{
Cordeiro (1997).

Cordeiro e Soper (2009).

Id. $(2011,2013)$.

35 Luzar e Chandler (1993)
} 
diferentes, foi submetido à difração de nêutrons: (1) N:H-D:H; (2) N:H-D:HD; (3) N:H-D:D; (4) N:HD-D:D; e (5) N:D-D:D. Detalhes das composições das amostras encontram-se na Tabela 3.2.

A Figura 3.4 mostra os fatores de estrutura totais e o refinamento EPSR obtidos para as cinco amostras. ${ }^{36}$ Como um todo, a qualidade do ajuste é bastante boa, com pequenas discrepâncias entre os valores experimentais e os obtidos com o refinamento em baixos valores de Q. Como já discutido anteriormente, correções de background e inelasticidade para os dados são mais difíceis de serem feitas quando os isotopômeros contêm hidrogênio leve. ${ }^{37}$

Tabela 3.2 Amostras da mistura NMF-DMSO submetidas à difratometria de nêutrons.

\begin{tabular}{ccc}
\hline Amostras & NMF & DMSO \\
\hline N:D-D:D & DCONDCD $_{3}$ & $\left(\mathrm{CD}_{3}\right)_{2} \mathrm{SO}$ \\
N:HD-D:D & $\mathrm{HCONHCH}_{3} / \mathrm{DCONDCD}_{3}^{(*)}$ & $\left(\mathrm{CD}_{3}\right)_{2} \mathrm{SO}$ \\
N:H-D:D & $\mathrm{HCONHCH}_{3}$ & $\left(\mathrm{CD}_{3}\right)_{2} \mathrm{SO}$ \\
N:H-D:HD & $\mathrm{HCONHCH}_{3}$ & $\left(\mathrm{CH}_{3}\right)_{2} \mathrm{SO} /\left(\mathrm{CD}_{3}\right)_{2} \mathrm{SO}^{(*)}$ \\
N:H-D:H & $\mathrm{HCONHCH}_{3}$ & $\left(\mathrm{CH}_{3}\right)_{2} \mathrm{SO}$ \\
\hline
\end{tabular}

Notação: N:D-D:D $\equiv$ NMF: totalmente deuterado-DMSO: totalmente deuterado. O significado para as quatro outras amostras pode ser facilmente percebido por analogia. ${ }^{*}$ O líquido é uma mistura de 50\% de NMF completamente deuterado e 50\% de NMF completamente protonado.

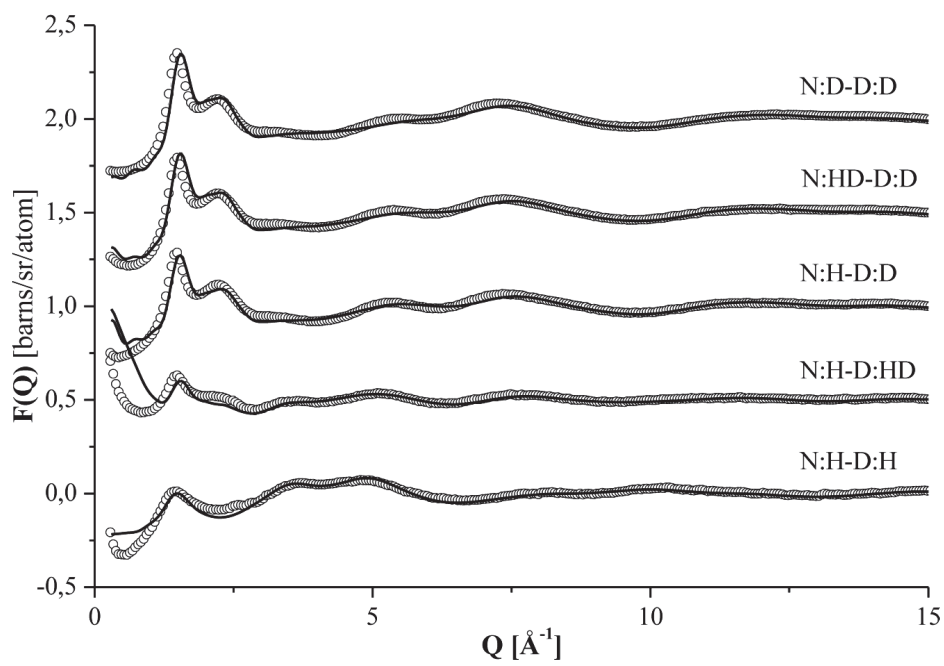

Figura 3.4 Dados de fatores de estrutura total medidos experimentalmente (círculos) e refinamento EPSR (linhas) para os dados de espalhamento de nêutrons coletados das amostras 
listadas na Tabela 3.1 (os gráficos estão deslocados verticalmente de $0,5 \mathrm{n}$, com $\mathrm{n}=0 \rightarrow 4$, para facilitar a visualização).

As funções de distribuição radial total, $f(r)$, que são obtidas por transformadas de Fourier do inverso dos fatores de estrutura experimentais, F(Q), e as correspondentes funções calculadas do refinamento EPSR são mostradas na Figura 3.5.

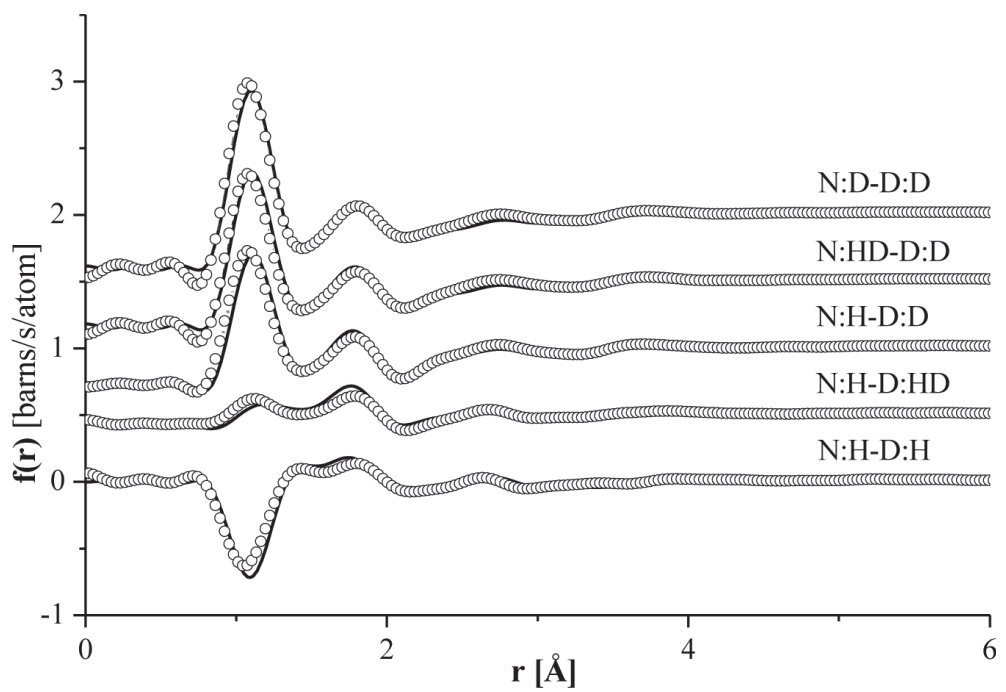

Figura 3.5 Funções de distribuição radial determinadas por transformadas de Fourier diretas dos dados experimentais (círculos) e refinamento EPSR (linhas) para os dados de espalhamento de nêutrons coletados das amostras listadas na Tabela 3.1 (os gráficos estão deslocados verticalmente de $0,5 \mathrm{n}, \mathrm{com} \mathrm{n}=0 \rightarrow 4$, para facilitar a visualização).

O ajuste é significativamente bom no intervalo entre 1 e $3 \AA$, indicando que as ligações moleculares em ambos componentes da mistura estão adequadamente representadas. Em particular, é relevante chamar a atenção para a concordância na região de $2 \AA ̊$, em função da necessidade de uma caracterização adequada da ligação de hidrogênio entre as moléculas. ${ }^{38}$

Os resultados mostrados na figura sugerem que o modelo molecular refinado está apto a mimetizar as interações intermoleculares de forma adequada. Então, como já feito no caso anterior, uma vez que se tenha atingido um modelo molecular que seja capaz de reproduzir a estrutura experimental do líquido, pode-se usar simulação computacional para explorar mais detalhadamente sua estrutura. Como sempre, um ponto de partida natural é obter as funções de distribuição radial, g(r), do sistema, calculadas a partir do modelo refinado. Algumas das funções de distribuição radial 
obtidas na mistura-exemplo são mostradas na Figura 3.6 (para entender melhor os símbolos, consulte a Figura 3.7).
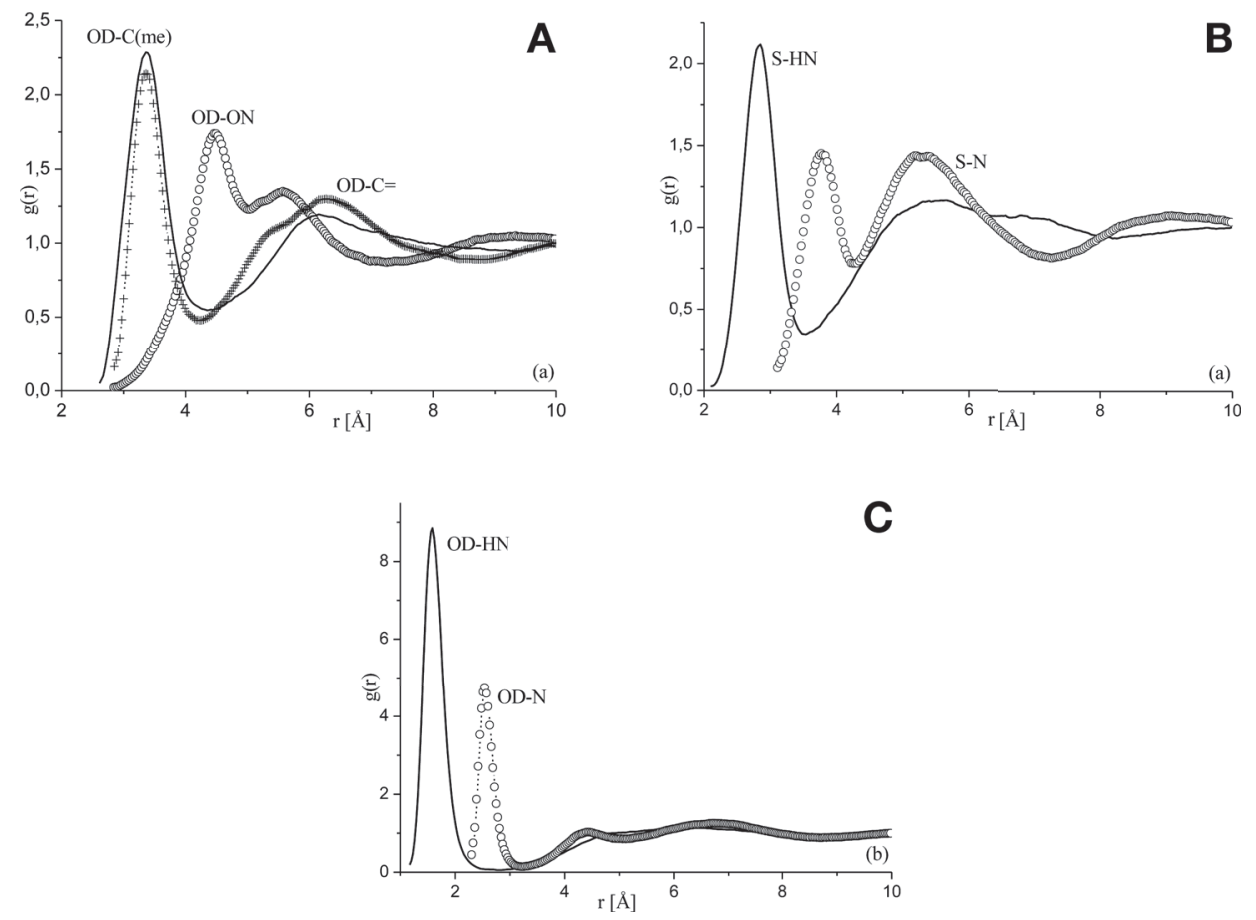

Figura 3.6 Funções de distribuição radial derivadas de EPSR para os pares de átomos indicados nas figuras. C(me) é o carbono metílico em NMF, C = é o carbono carbonílico, OD é oxigênio em DMSO, ON é oxigênio em NMF e HN é o hidrogênio ligado ao nitrogênio em NMF.
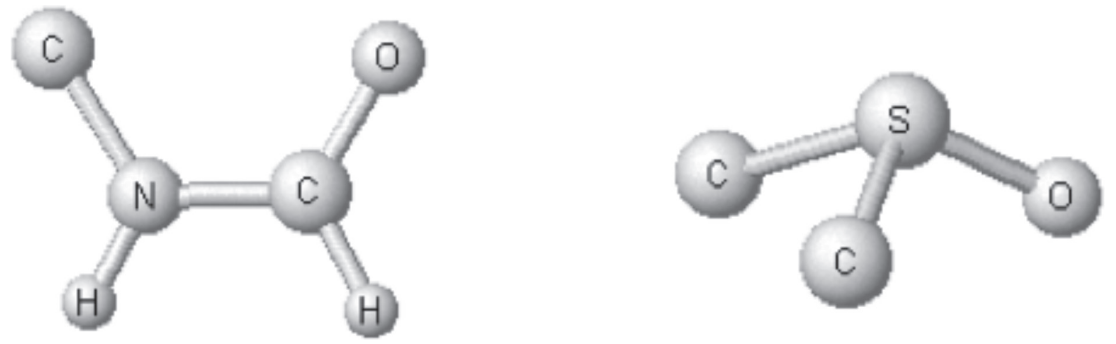

Figura 3.7 Moléculas de NMF (esquerda) e DMSO (direita). Os átomos de hidrogênio do grupo metil foram removidos para simplificar.

Uma análise mais extensiva da estrutura da mistura NMF-DMSO foi feita alhures. ${ }^{39}$

39 Cordeiro e Soper (2013). 


\subsection{CONCLUSÃo E PERSPECTIVAS}

Então, em resumo, há três aspectos que o usuário da técnica deve ter em mente antes de rodar uma simulação EPSR, especificamente: que potencial de referência adotará, que confiança tem nos dados experimentais e que amplitude máxima adotará para o potencial empírico. Em princípio, não há escolhas simples para esses valores. Na prática, porém, a escolha do fator de confiança e amplitude máxima do potencial empírico é bastante direta e tem efeito relativamente pequeno no resultado final. A escolha do potencial de referência é menos direta, em particular, quando os dados experimentais estão incompletos, o que, como discutido, acontece em função do número de experimentos que se teria de ter em um dado caso particular. Nesse caso, porém, utiliza-se um processo útil, que permite ao método EPSR identificar o potencial mais provável que é compatível com os dados. ${ }^{40}$

Vê-se, portanto, que EPSR é uma ferramenta bastante poderosa para interpretar dados de espalhamento, em termos de modelos atomísticos tridimensionais da estrutura, pois pode fornecer ao pesquisador conhecimento valioso sobre a organização local dos materiais que estão sendo investigados. Todavia, talvez sua maior virtude seja poder ser usada para explorar as ramificações estruturais de qualquer dado de espalhamento disponível: de que forma, especificamente, aqueles dados definem a estrutura, se os modelos existentes para o potencial interatômico estão corretos ou não, se os dados em si contêm falhas que têm origem nas incertezas das medidas e quão grandes são as variações na estrutura que são ainda consistentes com os dados. Ela atinge todas essas informações porque os graus de superposição atômica e a natureza das forças intermoleculares estão sob controle do pesquisador.

\section{REFERÊNCIAS}

Allen, M. P.; Tildesley, D. J. [1987]. Computer simulation of liquids. Oxford: Oxford University Press, 1992. (Oxford Science Publications).

Cordeiro, J. M. M. C-H... O and N-H...O hydrogen bonds in liquid amides investigated by Monte Carlo. Int. J. Quantum Chem., n. 65, p. 709-719, 1997.

Cordeiro, J. M. M.; Soper, A. K. Neutron diffraction study of liquid N-methylformamide using EPSR simulation. J. Phys. Chem. B, n. 113, p. 6819-6825, 2009.

. Investigation on the structure of liquid $\mathrm{N}$-methylformamide-dimethylsulfoxide mixtures. Chem. Phys., 381, p. 21-28, 2011.

. A hybrid neutron diffraction and computer simulation study on the solvation of N-methylformamide in dimethylsulfoxide. J. Chem. Phys., 138, p. 044502, 2013.

40 Soper (2012). 
Fischer, H. E.; Barnes, A. C.; Salmon, P. S. Neutron and x-ray diffraction studies of liquids and glasses. Rep. Progr. Phys., 69, p. 233-299, 2006.

Frenkel, D.; Smit, B. Understanding molecular simulation: from algorithms to applications, monographs on technical aspects. San Diego: Academic Press, 1996. v. I.

Gray, C. G.; Gubbins, K. E. Theory of molecular fluids, international series of monographs on chemistry 9. Nova York: Oxford University Press, 1984. (Fundamentals, v. I).

Hansen, J. P.; McDonald, I. R. Theory of simple liquids, international series of monographs on chemistry 9.2. ed. Londres: Academic Press, 1986.

Luzar, A.; Chandler, D. Structure and hydrogen bond dynamics of water - dimethyl sulfoxide mixtures by computer simulations. J. Chem. Phys., 98, p. 8160-8173, 1993.

McGreevy, R. L.; Pusztai, L. Reverse Monte Carlo simulation: a new technique for the determination of disordered structures. Mol. Simulation, 1, p. 359-367, 1988.

Mclain, S. E.; Soper, A. K.; Terry, A. E.; Watts, A. Structure and hydration of L-proline in aqueous solutions. J. Phys. Chem. B, 111, p. 4568, 2007.

McLain, S. E.; Soper, A. K.; Watts, A. Structural studies on the hydration of L-glutamic acid in solution. J. Phys. Chem. B, 110, p. 21251, 2006.

Neuefeind, J.; Fischer, H. E.; Schroer, W. The structure of fluid trifluoromethane and methylfluoride. J. Phys. Condens. Matter, 12, p. 8765-8776, 2000a.

. EPMC versus RMC modelling: the structure of supercritical HCF3. Physica B, 276, p. 481-482, 2000b.

Schommers, W. Pair potentials in disordered many-particle systems - a study for liquid gallium. Phys. Rev. A, 28, p. 3599-3605, 1983.

Soper, A. K. Empirical potential Monte Carlo simulation of fluid structure. Chem. Phys., 202, p. 295-306, 1996.

. Tests of the empirical potential structure refinement method and a new method of application to neutron diffraction data on water. Mol. Phys., 99, p. 1503-1516, 2001.

Partial structure factors from disordered materials diffraction data: an approach using empirical potential structure refinement. Phys. Rev. B, 72, 104204-1-104204-12, 2005.

. Joint structure refinement of x-ray and neutron diffraction data on disordered materials: application to liquid water. J. Phys. Condens. Matter, 19, 335206, 2007a.

. On the uniqueness of structure extracted from diffraction experiments on liquids and glasses. J. Phys. Condens. Matter, 19, 415108, 2007b.

. Computer simulation as a tool for the interpretation of total scattering data from glasses and liquids. Mol. Simulation, 38, p. 1171-1185, 2012.

Soper, A. K.; BARney, E. R. Extracting the pair distribution function from white-beam X-ray total scattering data. J. Appl. Cryst., 44, p. 714-726, 2011.

Soper, A. K.; Howells, W. S.; Hannon, A. C. Report no. RAL-89-046. 1989. 


\section{DESENVOLVIMENTO DE NANODISPOSITIVOS BASEADOS EM BIOMOLÉCULAS}

abordagens computacionais

Eduardo de Faria Franca ${ }^{1}$

GuedMiller Souza de Oliveria,

Jéssica Cristiane Magalhães Ierich, Ana Carolina Araúujo Vig, Caroline P. Brandin, Ariana de Souza Moraes e Fábio de Lima Lette ${ }^{2}$

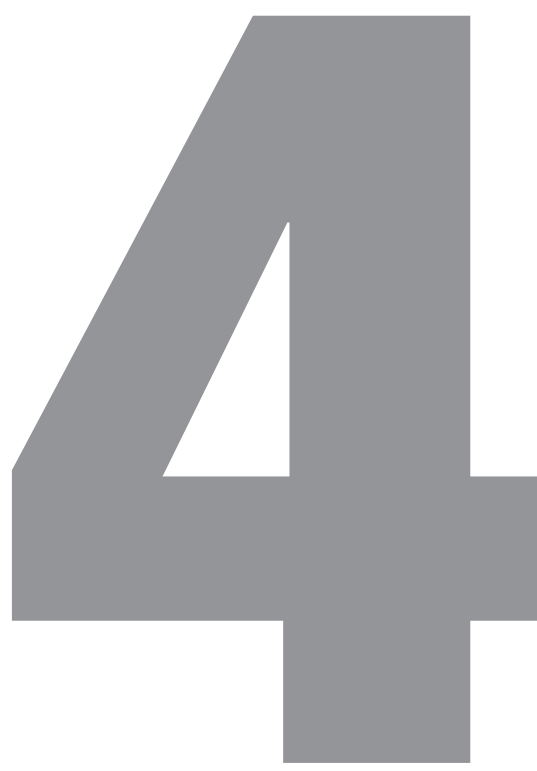

\footnotetext{
1 Instituto de Química da Universidade Federal de Uberlândia (UFU). E-mail: <eduardofranca@ufu.br>.

2 Todos os demais autores são membros do Grupo de Nanoneurobiofísica do Departamento de Física, Química e Matemática da Universidade Federal de São Carlos, campus Sorocaba-SP. E-mail: <fabioleite@ufscar.com>.
} 


\subsection{INTRODUÇÃ $0^{3}$}

A investigação de processos em escala atomística envolve a aplicação de ferramentas sofisticadas e que requerem altos investimentos. Atualmente, técnicas experimentais como a Microscopia de Força Atômica e a Microscopia Eletrônica oferecem uma boa aproximação na caracterização de processos em nível molecular. No entanto, apesar de as medidas e imagens obtidas serem muito informativas, muitas vezes o detalhamento do comportamento no tempo do sistema em estudo é dificultado, dada a escala nanométrica. Dessa forma, a Modelagem Molecular Computacional (MMC) surge como alternativa de complementação e interpretação dos resultados experimentais. A MMC se resume a um conjunto de metodologias e aproximações computacionais capazes de gerar um modelo descritivo de determinado sistema, o qual possibilita a reprodução computacional de suas propriedades reais. Nesse contexto, são inúmeras as aplicações da MMC no estudo de processos bioquímicos envolvidos no funcionamento de biomoléculas.

Em especial, é crescente o uso de nanobiotecnologias para fins de monitoramento ambiental e, por conseguinte, para a elucidação e o diagnóstico de doenças complexas, como as doenças neurodegenerativas. Inclusos nessa modalidade estão os nanobiossensores. Tais sensores específicos utilizam pontas do Microscópio de Força Atômica (AFM, do inglês Atomic Force Microscope) para a identificação precisa de determinados analitos, como, por exemplo, herbicidas inibidores enzimáticos. A aplicação da MMC no estudo de modificações químicas das pontas de AFM, durante o desenvolvimento de nanobiossensores, tem fornecido dados importantes sobre o recobrimento de superfícies por biomoléculas específicas. Um modelo capaz de descrever as propriedades de recobrimento das pontas, por exemplo, pode fornecer um direcionamento aos estudos experimentais, identificando sítios reacio-

3 Os autores agradecem a agência de fomento FAPESP sob os seguintes números de auxílio: 13/09746-5; 13/21958-8; 14/26369-3; 15/05283-6; 14/12082-4 e 13/04320-0. E também ao CNPq, processo 459768/2014-0. 
nais disponíveis para a interação com o analito que se pretende detectar. Com essa identificação, pode-se, assim, determinar o protocolo mais adequado para imobilização das biomoléculas no nanossensor biológico.

Tendo em vista o supracitado, o presente capítulo tem por objetivo elucidar os princípios que cingem a aplicação da MMC no estudo e desenvolvimento de nanobiossensores, apresentando as técnicas computacionais úteis na descrição da funcionalização de pontas de AFM e o panorama atual das pesquisas na área.

\subsection{NANOBIOSSENSORES E APLICABILIDADE}

A utilização do AFM como ferramenta de sensoriamento requisitou da comunidade científica meios para o detalhamento, em escala molecular, dos processos que descrevem a construção e aplicação desses nanodispositivos. Para o entendimento desses processos, faz-se necessária a descrição do modo de funcionamento do microscópio em questão, bem como do fundamento que rege o sensoriamento mediado pelos nanobiossensores de pontas de AFM, nos itens a seguir, para posterior elucidação dos protocolos de detalhamento molecular a partir de métodos computacionais.

\subsubsection{Microscopia de tunelamento}

A possibilidade de investigação de processos em escala nanométrica (da ordem de $10^{-9}$ ) surgiu a partir da necessidade de maior compreensão quanto ao comportamento e às propriedades elétricas de finas camadas de óxidos sobre os quais ${ }^{4}$ se questionava no final da década de 1970 . Sem um instrumento que pudesse gerar respostas para seus questionamentos, desenvolveram o microscópio de tunelamento (STM, do inglês Scanning Tunnelling Microscope), que funciona, como apresentado na Figura 4.1, a partir da varredura de uma amostra por uma ponta fina de tungstênio fixada a um piezoelétrico $\left(P_{\mathrm{x}}, P_{\mathrm{y}}\right.$ e $\left.P_{\mathrm{z}}\right)$, em velocidade e distância da amostra $(s)$ constantes; uma voltagem $\left(V_{\mathrm{z}}\right)$ é aplicada na ponta e na amostra $\left(V_{\mathrm{t}}\right)$ pelo piezo $\left(P_{\mathrm{z}}\right)$, intermediada por uma unidade controladora $(U C)$ que retorna uma imagem topográfica $(A$ e $B)$ da superfície da amostra $(C)$, pela corrente de tunelamento gerada, como um efeito da mecânica quântica. ${ }^{5}$ 


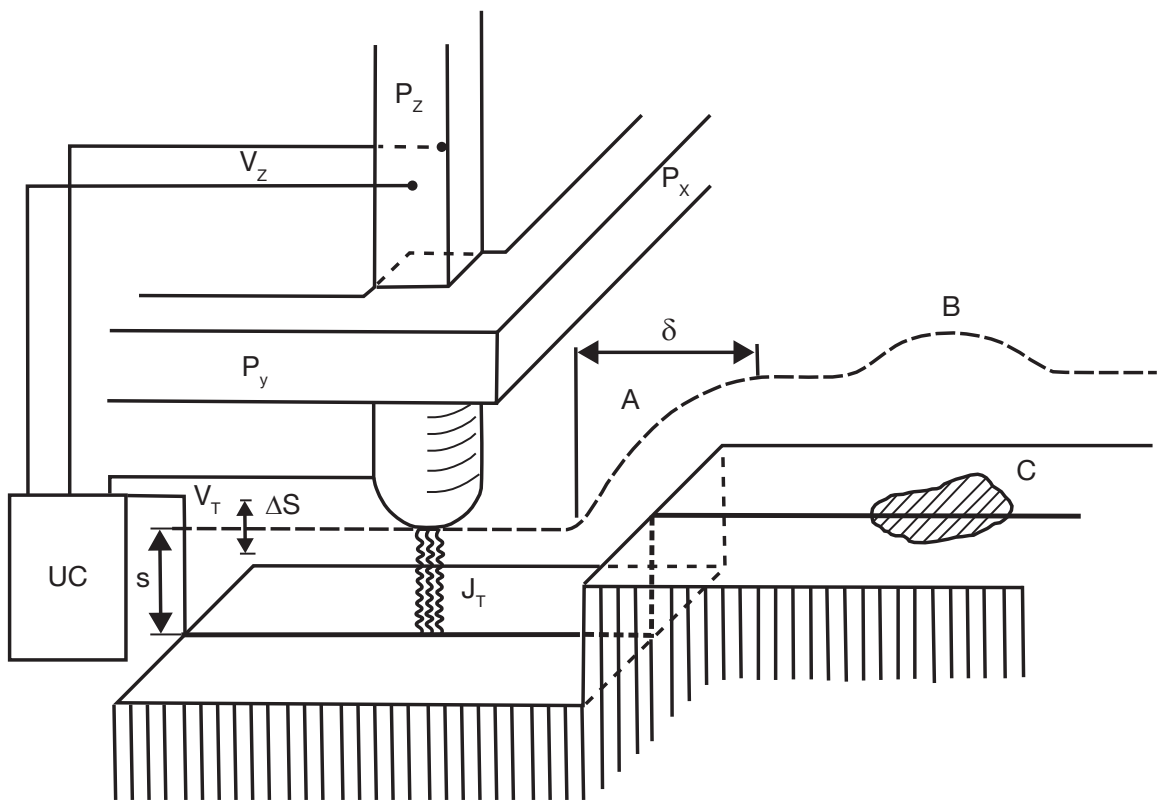

Figura 4.1 Princípio do funcionamento de um microscópio de tunelamento (STM).

Fonte: Binnig e Rohrer. ${ }^{6}$

A microscopia de tunelamento possibilitou, além da caracterização da amostra através de imagens topográficas, a modificação de superfícies como o posicionamento de átomos simples de xenônio sobre uma superfície de níquel, realizado no estudo de Eigler e Schweiser, ${ }^{7}$ pesquisadores da IBM (do inglês International Business Machines). Os cientistas moveram átomo por átomo na superfície e os organizaram com precisão atômica, como apresentado na Figura 4.2. Vislumbraram, com seus estudos, a fabricação de estruturas sobrepostas e análises de suas propriedades. $^{8}$ 

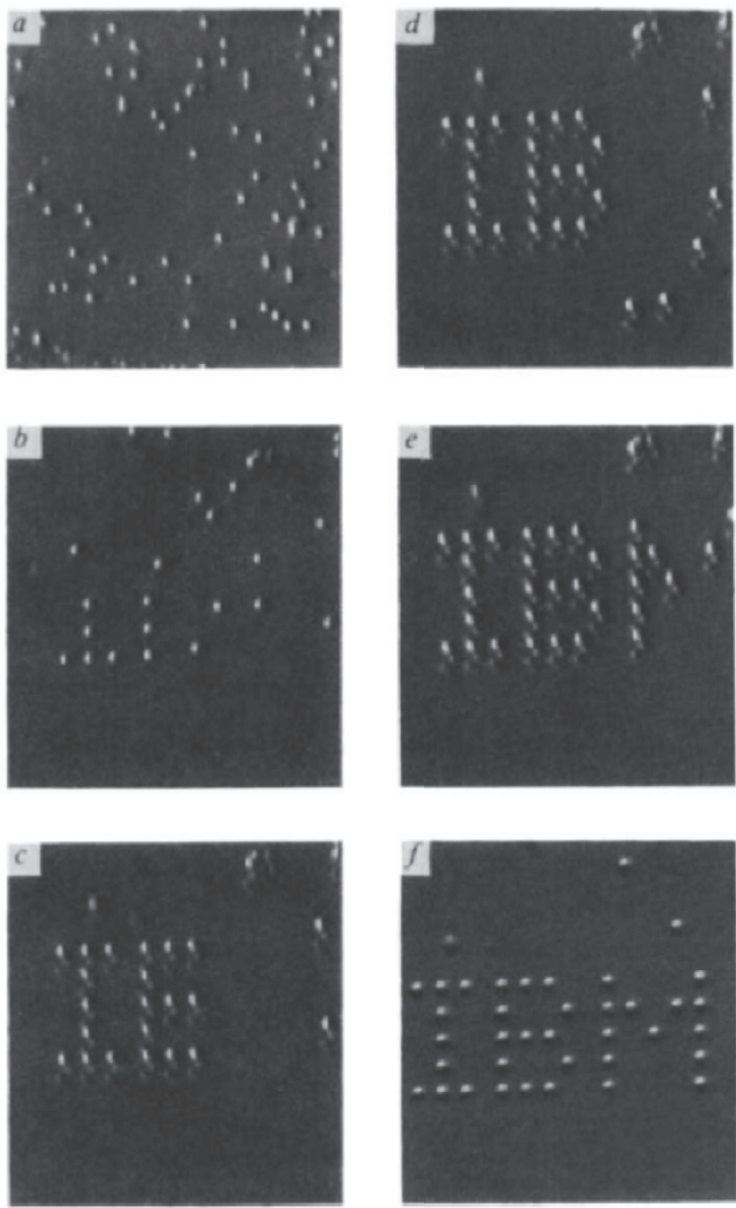

Figura 4.2 Sequência de imagens de STM mostrando o posicionamento de átomos de xenônio em uma superfície de níquel, este feito também pelo STM.

Fonte: Eigler e Schweizer. ${ }^{9}$

Atualmente, o STM tem sido utilizado para estudos de superfícies com precisões nanométricas. ${ }^{10}$

\subsubsection{Microscopia de força atômica}

Após o desenvolvimento do STM, outra ferramenta que permite estudos em escala nanométrica é o AFM, bastante semelhante ao STM, embora com algumas

9 Id. ibid.

10 Sutter et al. (2009), Tapasztó et al. (2008). 
diferenças, como a utilização de forças atômicas (Van der Waals, por exemplo) em vez de corrente de tunelamento, além de ser uma opção para análise de amostras biológicas, uma vez que pode ser feita em ar ou em meio líquido, propiciando a viabilidade das amostras. ${ }^{11}$

O princípio de funcionamento do AFM tem como base a transformação do sinal de deflexão do cantilever em imagem ou medida de força (Van der Waals, eletrostática, capilaridade, magnética, repulsão iônica e fricção). Conforme pode ser observado na Figura 4.3, um laser é incidido sobre o cantilever, que deflete, em razão da dinâmica de interação entre a ponta e a amostra. O laser é, então, refletido para um fotodetector, que recebe o sinal da oscilação do cantilever e o envia a um controlador, transformando o sinal em imagem ou medida de força no computador. A oscilação da amostra é ocasionada pelo piezoelétrico, que se movimenta nos eixos $x, y$ e $z .^{12}$

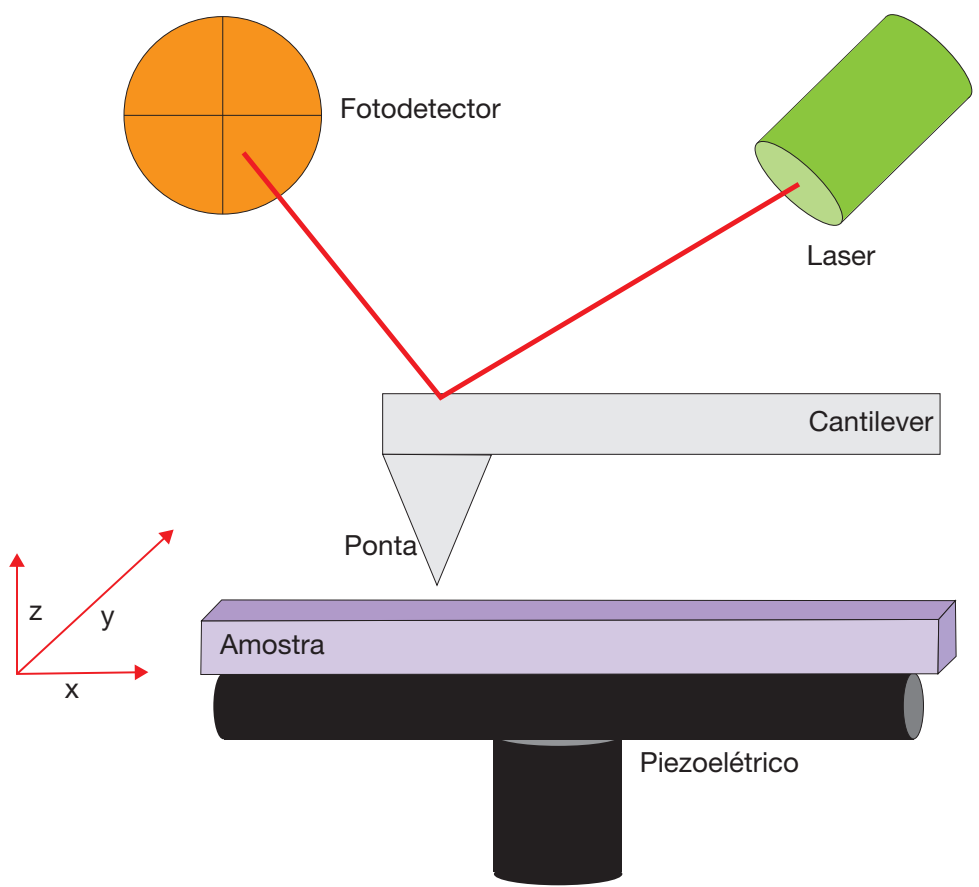

Figura 4.3 Princípio de funcionamento do AFM.

A utilização de amostras biológicas e biomoléculas para estudos morfológicos e de interações, com AFM, vem se desenvolvendo principalmente no que se refere ao estudo de interações entre enzimas ou anticorpos e seus ligantes; estudos de monitoramento ambiental com interações enzima-herbicida obtiveram resultados promissores para a aplicação do AFM também nessa área, com a imobilização

11 Binnig et al. (1986), Tamayo et al. (2001), García e Pérez (2002), Hermans (2012).

12 Meyer (1992) 
de biomoléculas em nanossuperfícies, como no cantilever do AFM e em outras superfícies. $^{13}$

\subsubsection{Desenvolvimento de nanobiossensores: imobilização de biomoléculas em nanossuperfícies}

Para estudos de interação enzima-herbicida, faz-se a imobilização das biomoléculas e seus ligantes em superfícies (superfície de deposição da amostra, por exemplo) a partir de interações químicas covalentes, como proposto pioneiramente por Butt et al. ${ }^{14}$ e também por Lyubchenko et al. ${ }^{15}$ Uma superfície de mica muscovita facilmente clivável e negativamente carregada pode ser silanizada com aminopropiltrietoxisilano (APTES), formando uma camada de funcionalização que apresenta grupos amina $\left(\mathrm{NH}_{2}\right)$ disponíveis para interação covalente com um cross-linker, podendo ser, por exemplo, o glutaraldeído, que possui grupos carboxila (-COOH), para assim interagir com biomoléculas ou seus ligantes, conforme seus grupos funcionais disponíveis para interação (Figura 4.4(a)).

O mesmo pode ser realizado com nanossuperfícies, como a ponta do AFM, geralmente fabricada de nitreto ou nitreto de silício. ${ }^{16} \mathrm{~A}$ silanização da ponta de AFM com APTES forma uma camada de recobrimento que apresenta grupos amina disponíveis para a interação com os grupos carboxila do glutaraldeído, que, por sua vez, disponibiliza terminações para interação covalente com as biomoléculas (enzimas), sendo possível sua imobilização nas pontas de AFM, resultando no desenvolvimento de um nanobiossensor, como demonstrado pela Figura 4.4(b).

\subsubsection{Técnicas computacionais aplicadas ao estudo e à representação de compostos imobilizados}

O estudo de sistemas biológicos complexos, como proteínas, enzimas e anticorpos, engloba a descrição e o entendimento dos fenômenos e mecanismos envolvidos em sua atuação. No entanto, em escala atômica, essa tarefa se torna difícil não apenas pela elevada complexidade característica dessas macromoléculas, mas também pelo fato de a ciência ainda não compreender e/ou descrever vários pontos do funcionamento global de tais sistemas. ${ }^{17}$ É nesse contexto que as técnicas de MMC tiveram seu desenvolvimento estimulado. ${ }^{18}$

3 Da Silva et al. (2013, 2014), Deda et al. (2013), Castro Bueno et al. (2014).

14 Butt et al. (1990).

15 Lyubchenko et al. (1993)

16 Etchegaray et al. (2010).

17 Wooley e Lin (2005).

18 Ramachandran et al. (2008). 


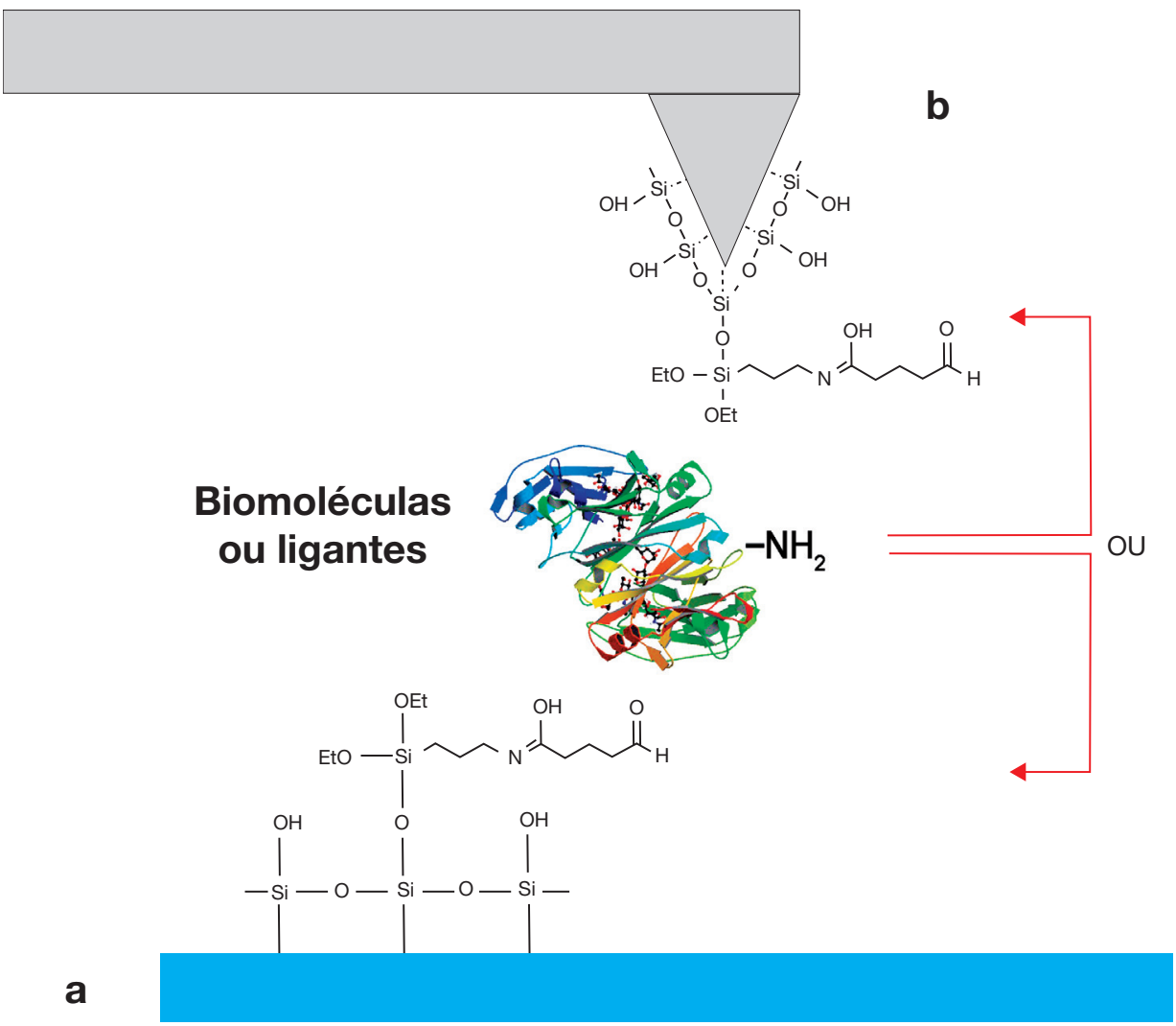

Figura 4.4 Funcionalização e imobilização de biomoléculas em superfícies ou nanossuperfícies, resultando na construção de (a) superfície de deposição da amostra ou (b) no desenvolvimento do nanobiossensor para estudo das interações enzima-ligante.

Em âmbito geral, a aplicação de ferramentas computacionais é útil para entender sobre a estrutura tridimensional e a estabilidade de macromoléculas, a caracterização do enovelamento proteico, o estudo do reconhecimento molecular e as interações intermoleculares, a descrição da catálise enzimática, entre outros conteúdos. ${ }^{19}$ Em especial, resultados promissores têm sido obtidos aplicando a MMC como ferramenta de direcionamento para o desenvolvimento de nanobiossensores de pontas de AFM. As técnicas experimentais de microscopia no estudo de materiais em escala nanométrica, conforme discutido nos itens anteriores, pertencem a um campo de fronteira transdisciplinar conhecido como Nanociência e Nanotecnologia. ${ }^{20} \mathrm{O}$ grande desafio reside em controlar as estruturas e propriedades em escala atômica, molecular e supramolecular e, assim, desenvolver e aplicar nanodispositivos. 
No contexto de desenvolvimento de nanobiossensores, foco deste capítulo, a modificação química das pontas, descrita no item 4.2.3, é um meio de facilitar interações moleculares específicas. Dependendo da biomolécula em estudo, podem ser definidos diferentes tipos de modificações químicas da ponta do AFM, a fim de melhor se adequar aos grupos reativos presentes ao longo da estrutura molecular. Computacionalmente, a modificação química é realizada a partir de um programa para desenho de estrutura molecular. ${ }^{21}$ Em contrapartida, as reações experimentais dependem de uma molécula ligante que estabeleça uma ponte adequada para que a interação entre a ponta metálica do AFM e a biomolécula seja viável; isto requer um estudo aprofundado das condições termodinâmicas favoráveis que se adéquem à imobilização de biomoléculas. ${ }^{22}$ Desta forma, simulações computacionais podem reduzir o tempo de procura por um reagente adequado para este fim, bem como o custo.

Em condições ambientes normais, as pontas de AFM podem sofrer oxidação, formando grupos $\mathrm{SiO}_{2}$ na superfície. Quando há oxidação parcial, $\mathrm{SiOH}$ é formado na camada mais externa da ponta. Estes grupos reagem fortemente com grupos silanos que são utilizados para funcionalização de pontas de AFM. O composto APTES é um reagente comum para este fim, pois o grupo amino em uma de suas extremidades é muito reativo e pode ser utilizado para reação com outras moléculas, como, por exemplo, o glutaraldeído, que se liga aos constituintes biomoleculares com facilidade. ${ }^{23}$

Além do glutaraldeído, outros grupos podem ser utilizados para a imobilização de biomoléculas, dependendo da estrutura específica que se deseja imobilizar. Pesquisas computacionais podem trabalhar na proposição de grupos reativos para serem utilizados nesse processo, já que a atividade computacional é mais favorável com relação ao custo-benefício, quando comparada com a rotina laboratorial. A Figura 4.5 ilustra uma simulação computacional, por Dinâmica Molecular (DM), da imobilização da enzima AcetilCoA carboxilase (ACCase), em uma superfície funcionalizada com o composto APTES, quimicamente ligado ao glutaraldeído para o desenvolvimento de um biossensor em nanoescala. ${ }^{24}$ Essas simulações são de fundamental importância para a compreensão do experimento atomisticamente, dada a dificuldade de prever, por métodos experimentais, a posição favorável em que a biomolécula será imobilizada e também as regiões de maior interação com seus substratos e/ou inibidores.

Nesse contexto, as técnicas computacionais que podem ser utilizadas para complementar os resultados experimentais são: (i) Modelagem por Homologia; (ii) Docking Molecular; (iii) DM; (iv) Mecânica Quântica e os cálculos híbridos de QM/ MM (Mecânica Quântica e Mecânica Molecular); e (v) Dinâmica Molecular Direcionada (SMD, do inglês Steered Molecular Dynamics).

21 Amarante et al. (2014), Oliveira et al. (2013).

22 Amarante et al. (2014).

23 Etchegaray et al. (2010).

24 Oliveira et al. (2013). 


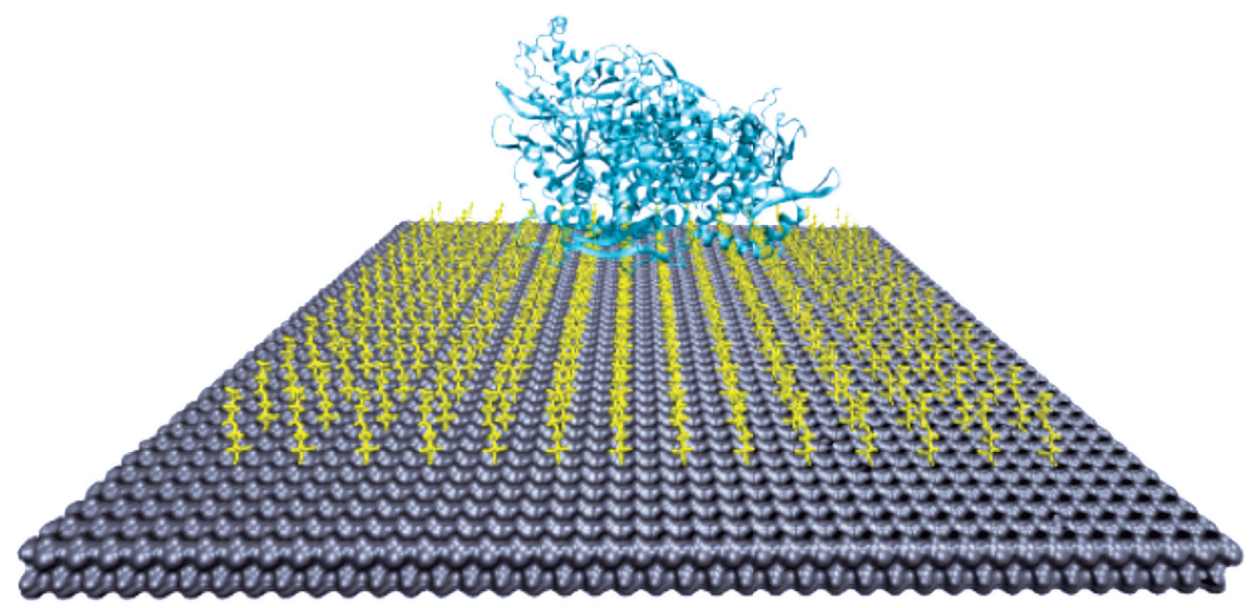

Figura 4.5 Representação esquemática de uma superfície funcionalizada com APTES + glutaraldeído (linker), com a finalidade de imobilização biomolecular. Em cinza é representada uma superfície de nitreto de silício ligada ao linker em amarelo. Em azul ciano está representada a enzima.

\subsubsection{Modelagem por homologia}

As biomoléculas são descritas por estruturas altamente específicas e complexas, as quais podem possuir vários níveis de organização estrutural. ${ }^{25}$ Dessa forma, sua descrição engloba a aplicação de técnicas experimentais refinadas de estudo e descrição estrutural, em especial a Difração de Raios-X (DRX), técnicas essas que funcionam como fontes primárias de dados estruturais. ${ }^{26}$ Em DRX, os cristais da biomolécula são irradiados por um feixe de raios- $\mathrm{X}$, de forma que os eventos de interferência gerem um padrão de difração crucial para a descrição da estrutura tridimensional. ${ }^{27}$ A determinação da primeira estrutura tridimensional de proteína ocorreu na década de 1950, quando Kendrew et al. ${ }^{28}$ descreveram por DRX a mioglobina. A partir daí, várias outras proteínas foram sendo investigadas e determinadas. Com o avanço tecnológico nas últimas décadas, marcado pela inserção de novos componentes de software e hardware, as técnicas experimentais de determinação estrutural foram aprimoradas, de forma a gerar um notável crescimento no número de proteínas com estrutura tridimensional, descritas com base no maior repositório de estruturas tridimensionais, o Protein Data Bank (PDB), ${ }^{29}$ que conta com mais de 139.000 estruturas

\footnotetext{
Kessel e Ben-Tal (2011), Nelson e Cox (2008), Voet e Voet (2011).

Rhodes (2006).

Giorgetti et al. (2005).

Kendrew et al. (1958).

29 Berman et al. (2000).
} 
depositadas atualmente. As informações disponíveis nesse banco de dados advêm das coordenadas atômicas obtidas pela comunidade científica.

No entanto, algumas dificuldades na aplicação de tais técnicas podem comprometer a determinação estrutural, impedindo a descrição de algumas macromoléculas, ou mesmo gerando uma descrição que pode ser aprimorada, dadas algumas incertezas com relação à identidade e à posição de átomos derivados de dados de densidade eletrônica. ${ }^{30}$ Tais incertezas no modelo atômico podem ter consequências significativas em estudos subsequentes, principalmente aqueles envolvendo docking e DM. ${ }^{31}$ Assim, a MMC surge como alternativa na solução de vários problemas básicos recorrentes na aplicação de métodos experimentais, assumindo um papel complementar às técnicas experimentais na obtenção e no refinamento de modelos tridimensionais de biomoléculas. ${ }^{32}$

Algumas proteínas compartilham graus de similaridade significativos da sequência de aminoácidos e da estrutura tridimensional e, por isso, são denominadas proteínas homólogas. ${ }^{33}$ Geralmente, proteínas que realizam funções similares em organismos diferentes compartilham certo grau de identidade. ${ }^{34}$ De acordo com a teoria evolutiva, espécies relacionadas evoluíram de um ancestral comum, o que sugere que cada proteína, da mesma forma, deve ter evoluído a partir de uma correspondente do mesmo ancestral. ${ }^{35}$ Dessa forma, proteínas de uma mesma família evolutiva compartilham várias similaridades, no que se fundamenta a técnica de modelagem por homologia estrutural. ${ }^{36}$

De forma geral, a modelagem por homologia aplica ferramentas computacionais de forma a predizer a estrutura tridimensional de uma proteína-alvo a partir de estruturas homólogas conhecidas no PDB. ${ }^{37}$ A aplicação de tal técnica envolve as seguintes etapas: (i) identificação e seleção das proteínas que servirão como molde; (ii) alinhamento das sequências de resíduos da proteína-alvo com os moldes; (iii) construção das coordenadas do modelo; e (iv) validação e otimização do modelo (Figura 4.6). ${ }^{38}$

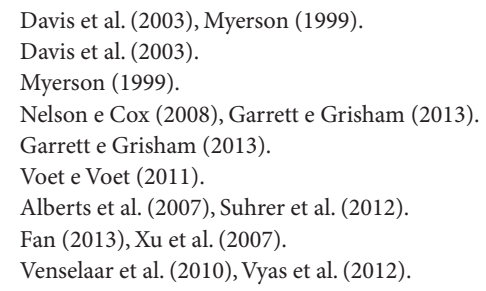




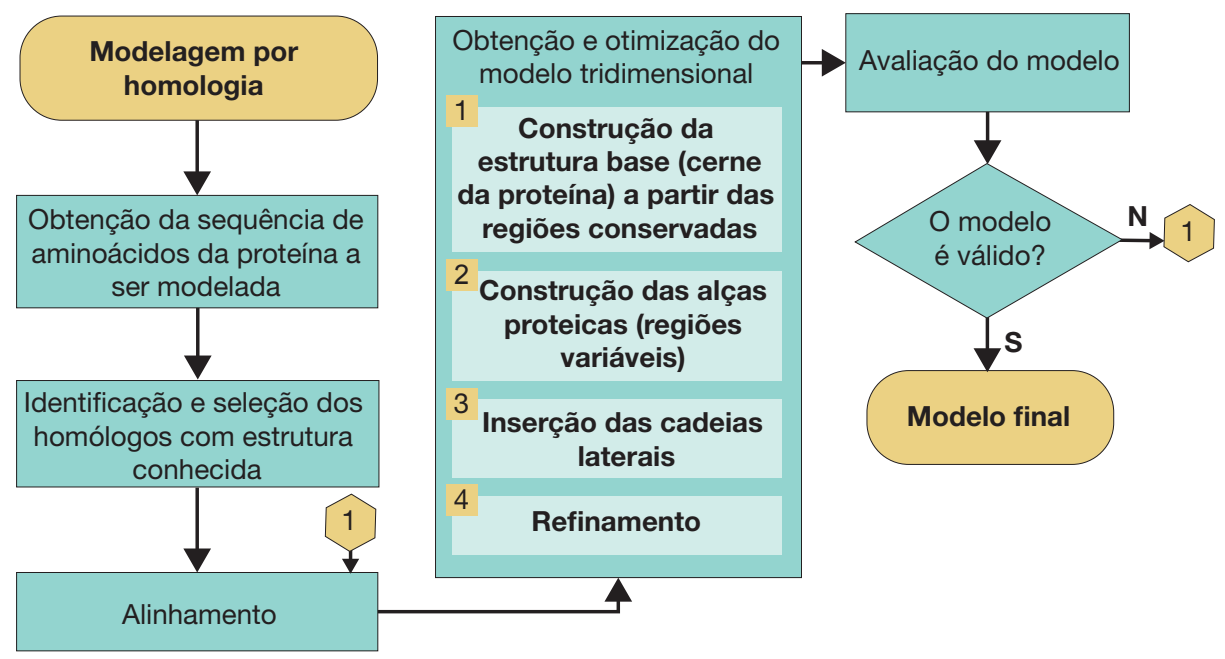

Figura 4.6 Fluxograma de aplicação da modelagem por homologia.

Previamente à aplicação da técnica de modelagem comparativa propriamente dita, o usuário deve obter os dados sobre a estrutura primária da proteína/enzima a ser modelada, ou seja, sua sequência de aminoácidos, a qual servirá de guia para os passos subsequentes. A sequência de aminoácidos pode ser obtida em bancos de dados específicos, como o Protein-NCBI, ${ }^{39}$ que disponibiliza sequências proteicas e é mantido pelo National Center for Biotechnology Information (NCBI), e o UniProt Knowledgebase (UniProtKB), ${ }^{40}$ que fornece informações sobre sequência, função e propriedades de proteínas.

A sequência de aminoácidos da proteína-alvo é essencial para a primeira etapa da aplicação da modelagem por homologia: identificação e seleção dos moldes a serem utilizados para construção do modelo. Os moldes são encontrados por similaridade com a sequência-alvo ou também por demais critérios, como informação estrutural. ${ }^{41}$ A existência de estruturas homólogas no repositório PDB é a principal condição para a realização da modelagem comparativa. ${ }^{42}$ Alguns algoritmos específicos auxiliam na identificação dos moldes, buscando por similaridades entre a sequência de aminoácidos da proteína-alvo e as sequências disponíveis em bancos de dados e calculando a significância estatística das similaridades. ${ }^{43}$ É o caso do software Protein Similarity Search (FASTA <www.ebi.ac.uk/Tools/sss/fasta/>) ${ }^{44}$ e do Basic Local Alignment Search Tool (BLAST <http://blast.ncbi.nlm.nih.gov/Blast.cgi>). ${ }^{45} \mathrm{Um}$ ou mais moldes podem ser designados para a modelagem. As proteínas com maior

39 Pruitt et al. (2007).

40 Magrane e Consortium (2011).

41 Contreras-Moreira et al. (2002).

42 Alberts et al. (2007), Kumar e Filipski (2007).

43 Contreras-Moreira et al. (2002).

44 Lipman e Pearson (1985), Pearson e Lipman (1988).

45 Altschul et al. (1990). 
grau de similaridade são, geralmente, as mais indicadas para servirem de molde. ${ }^{46}$ Quando a identidade entre as sequências for inferior a $30 \%$, a construção do modelo é dificultada, havendo a necessidade de aplicação de estratégias específicas. ${ }^{47}$

A etapa subsequente é o alinhamento das sequências de aminoácidos da proteína-alvo e dos moldes. No alinhamento, a similaridade entre as sequências é medida por comparação entre elas, realizada de forma a evidenciar as regiões conservadas e as regiões variáveis. ${ }^{48}$ Ao longo da evolução das proteínas, mutações podem ocorrer de forma a remover, substituir e inserir determinado aminoácido na cadeia polipeptídica. ${ }^{49}$ Essas mutações podem modificar o comprimento da sequência, sendo necessária a inserção de espaços vazios, as lacunas ou gaps, posicionados da melhor forma pelo software de alinhamento, a fim de igualar as sequências para comparação..$^{50} \mathrm{O}$ alinhamento das sequências funciona como guia para a construção do modelo, sendo uma das etapas mais críticas e intimamente relacionadas à qualidade da estrutura final. ${ }^{51}$

Após o alinhamento, é iniciada a etapa de construção do modelo da proteína-alvo. Primeiramente, a estrutura-base da proteína é construída a partir das regiões conservadas, identificadas pelo alinhamento. ${ }^{52}$ Em seguida, as regiões de dobramento, as alças ou loops que conectam elementos de estrutura secundária e apresentam elevada flexibilidade, são modeladas. ${ }^{53} \mathrm{~A}$ precisão da modelagem de tais regiões é fator determinante na utilidade dos modelos construídos em estudos das interações proteína-ligante. ${ }^{54} \mathrm{~A}$ construção das alças pode ocorrer de duas formas: (i) com base em bancos de dados estruturais internos dos programas de modelagem, com referência em estruturas disponíveis no PDB; e (ii) a partir da modelagem ab initio, que toma como base a sequência de aminoácidos da região para gerar a estrutura tridimensional. ${ }^{55}$ Por fim, são adicionadas as cadeias laterais à cadeia principal, tarefa que, em geral, é fundamentada em bancos de dados específicos advindos de estruturas cristalográficas conhecidas e bem refinadas. ${ }^{56}$

Obtido o modelo tridimensional, ele deve passar por uma etapa de refinamento, a qual visa corrigir possíveis erros e distorções na geometria que possam ter ocorrido durante o processo de modelagem, principalmente com relação às alças e cadeias laterais. ${ }^{57}$ De forma geral, o refinamento aproxima a resolução do modelo àquela apresentada por estruturas experimentais. ${ }^{58}$ Essa etapa se fundamenta na

\footnotetext{
46 Santos-Filho e Alencastro (2003).

47 Contreras-Moreira et al. (2002), Zhang (2008), Venclovas (2012), Xiang (2006).

48 Altschul (1991), Santos-Filho e Alencastro (2003).

49 Alberts et al. (2007), Kumar e Filipski (2007).

50 Venclovas (2012), Kumar e Filipski (2007), Kinch e Grishin (2002).

51 Peitsch (2002).

52 Daga et al. (2010), Schwede et al. (2003).

53 Nelson e Cox (2008), Santos-Filho e Alencastro (2003).

54 Fiser e Šali (2003).

55 Arnautova et al. (2011), Fiser e Šali (2003).

56 Daga et al. (2010), Bower et al. (1997).

57 Xiang (2006), Schwede et al. (2003).

58 Zhang (2009).
} 
minimização de energia, por meio da movimentação dos átomos, de forma a liberar energia local presa e aproximar-se da estrutura nativa da proteína. ${ }^{59} \mathrm{~A}$ minimização de energia pode ser realizada pela aplicação de ferramentas de DM, permitindo o relaxamento da estrutura global em água, além de corrigir contatos atômicos muito próximos. ${ }^{60}$ Após o refinamento estrutural, segue a etapa final da modelagem por homologia, a validação, que envolve a avaliação das características do modelo gerado. A aplicação específica de um modelo tridimensional está estritamente relacionada à sua qualidade. ${ }^{61}$ Entre os principais fatores com influência na qualidade do modelo final estão: (i) a identidade entre as sequências-alvo e molde (dependente da relação evolutiva entre as proteínas, assim como da similaridade das sequências); (ii) a escolha dos moldes e precisão no alinhamento realizado durante a modelagem; e (iii) precisão da modelagem, principalmente das regiões variáveis, como as alças. ${ }^{62}$ Em geral, os erros abrangem o empacotamento das cadeias laterais, os desvios ou as distorções de regiões centrais da cadeia principal, assim como as regiões de alças, em que os erros maiores podem ocorrer, dada a dificuldade de modelá-las. ${ }^{63}$

A validação do modelo tridimensional envolve a estimativa dos erros presentes na estrutura tridimensional, que pode ser realizada englobando duas abordagens principais: (i) cálculo da energia do modelo com base em um campo de força, cálculo este que avalia os comprimentos e ângulos de ligações químicas, assim como desacordos atômicos e impedimentos estéricos; e (ii) determinação dos índices de normalidade, envolvendo a comparação das características apresentadas pelo modelo com aquelas apresentadas por estruturas refinadas, ou seja, essa abordagem define o quão normal ou incomum é determinada característica do modelo quando comparada com estruturas experimentais conhecidas. ${ }^{64} \mathrm{~A}$ validação pode guiar algumas melhorias necessárias, as quais resultarão na obtenção do modelo tridimensional final para a proteína-alvo.

Cada uma das etapas supracitadas está fundamentada na utilização de uma série de programas, servidores e/ou bancos de dados. A maioria deles é de acesso gratuito, sendo os principais listados na Tabela 4.1.

\footnotetext{
Xiang (2006), Schwede et al. (2003).

Fan e Mark (2004).

Ginalski (2006).

Ginalski (2006), Baker e Šali (2001), Tress et al. (2005).

Baker e Šali (2001).

Venselaar et al. (2009).
} 
Tabela 4.1 Programas, servidores e bancos de dados úteis na modelagem por homologia estrutural.

\begin{tabular}{|c|c|c|c|}
\hline Ferramenta & Descrição & Endereço & Referência \\
\hline UniProt & $\begin{array}{l}\text { Banco de dados de informações } \\
\text { sobre sequência, função e proprie- } \\
\text { dades de proteínas. }\end{array}$ & $\begin{array}{l}<\text { www.uniprot. } \\
\text { org/> }\end{array}$ & $\begin{array}{c}\text { Bairoch e Apweiler (1997), } \\
\text { Bairoch e Boeckmann } \\
\text { (1994), } \\
\text { Magrane e Consortium } \\
\text { (2011) }\end{array}$ \\
\hline Protein NCBI & $\begin{array}{l}\text { Banco de dados de sequências } \\
\text { proteicas. }\end{array}$ & $\begin{array}{l}<\text { www.ncbi.nlm.nih. } \\
\text { gov/protein }>\end{array}$ & Pruitt et al. (2007) \\
\hline BRENDA & $\begin{array}{l}\text { Banco de dados para caracterização } \\
\text { enzimática, contendo informações } \\
\text { sobre a reação catalisada, assim } \\
\text { como parâmetros funcionais e } \\
\text { propriedades moleculares. }\end{array}$ & $\begin{array}{l}<\text { www.brenda- } \\
\text {-enzymes.org }>\end{array}$ & $\begin{array}{c}\text { Pharkya et al. (2003), Schom- } \\
\text { burg et al. }(2000,2013)\end{array}$ \\
\hline PDB & $\begin{array}{l}\text { Banco de dados de estruturas tri- } \\
\text { dimensionais de macromoléculas } \\
\text { advindas da aplicação de métodos } \\
\text { experimentais, como DRX. }\end{array}$ & $\begin{array}{l}<\text { www.rcsb.org/ } \\
\text { pdb }>\end{array}$ & $\begin{array}{l}\text { Berman et al. (2000), Berns- } \\
\text { tein et al. (1977) }\end{array}$ \\
\hline NCBI-BLAST & $\begin{array}{l}\text { Pacote disponível para identifi- } \\
\text { cação e seleção de moldes, assim } \\
\text { como alinhamento entre as sequ- } \\
\text { ências. }\end{array}$ & $\begin{array}{l}\text { <http://blast.ncbi. } \\
\text { nlm.nih.gov/Blast. } \\
\text { cgi> }\end{array}$ & Altschul et al. (1990) \\
\hline $\begin{array}{c}\text { FASTA } \\
\text { (ProteinData- } \\
\text { bases) }\end{array}$ & $\begin{array}{l}\text { Servidor para identificação e } \\
\text { seleção dos moldes, assim como } \\
\text { alinhamento entre as sequências. }\end{array}$ & $\begin{array}{l}<\text { www.ebi.ac.uk/ } \\
\text { Tools/sss/fasta/> }\end{array}$ & $\begin{array}{l}\text { Lipman e Pearson (1985), } \\
\text { Pearson }(1990,1991)\end{array}$ \\
\hline Clustal & $\begin{array}{l}\text { Servidor para alinhamento múl- } \\
\text { tiplo de sequências proteicas e de } \\
\text { ácidos nucleicos. }\end{array}$ & $<$ www.clustal.org/> & $\begin{array}{c}\text { Chenna et al. (2003), Higgins } \\
\text { e Sharp (1988), Larkin et } \\
\text { al. (2007), Thompson et al. } \\
\text { (1994) }\end{array}$ \\
\hline MultAlin & $\begin{array}{l}\text { Servidor para alinhamento múl- } \\
\text { tiplo de sequências proteicas e de } \\
\text { ácidos nucleicos. }\end{array}$ & $\begin{array}{l}<\text { http://multalin. } \\
\text { toulouse.inra.fr/ } \\
\text { multalin/> }\end{array}$ & Corpet (1988) \\
\hline MODELLER & $\begin{array}{l}\text { Software para construção de mo- } \\
\text { delos tridimensionais de proteínas } \\
\text { a partir de dados provenientes do } \\
\text { alinhamento. }\end{array}$ & $\begin{array}{l}<\mathrm{http}: / / \text { salilab.org/ } \\
\text { modeller }>\end{array}$ & $\begin{array}{l}\text { Eswar et al. (2007), } \\
\text { Šali e Blundell (1993) }\end{array}$ \\
\hline $\begin{array}{l}\text { Swiss-PDB } \\
\text { viewer } \\
(\mathrm{SPDBv})\end{array}$ & $\begin{array}{l}\text { Aplicação voltada para a modela- } \\
\text { gem de proteínas, desde a identi- } \\
\text { ficação e seleção dos moldes até a } \\
\text { validação do modelo. }\end{array}$ & $\begin{array}{l}<\text { www.expasy.org/ } \\
\text { spdbv/> }\end{array}$ & $\begin{array}{l}\text { Guex et al. }(1999,2009) \\
\text { Guex e Peitsch }(1997)\end{array}$ \\
\hline $\begin{array}{l}\text { SWISS- } \\
\text {-MODEL }\end{array}$ & $\begin{array}{l}\text { Servidor para modelagem de pro- } \\
\text { teínas por homologia. }\end{array}$ & $\begin{array}{l}<\text { http://swissmodel. } \\
\text { expasy.org/works- } \\
\text { pace }>\end{array}$ & $\begin{array}{l}\text { Arnold et al. (2006), Schwede } \\
\text { et al. (2003), Guex et al. } \\
\text { (2009), Peitsch (1995) }\end{array}$ \\
\hline PROCHECK & $\begin{array}{l}\text { Software voltado para a avaliação } \\
\text { da qualidade estereoquímica de } \\
\text { estruturas proteicas. }\end{array}$ & $\begin{array}{c}<\text { www.ebi.ac.uk/ } \\
\text { thornton-srv/ } \\
\text { software/PROCHE- } \\
\text { CK/> }\end{array}$ & $\begin{array}{l}\text { Laskowski et al. (1993), } \\
\text { Morris et al. (1992) }\end{array}$ \\
\hline
\end{tabular}


Tabela 4.1 Continuação...

\begin{tabular}{|c|c|c|c|}
\hline Ferramenta & Descrição & Endereço & Referência \\
\hline Whatcheck & $\begin{array}{l}\text { Software útil na avaliação do mo- } \\
\text { delo, principalmente com relação } \\
\text { às características da cadeia princi- } \\
\text { pal, do empacotamento global, da } \\
\text { geometria e simetria. }\end{array}$ & $\begin{array}{c}\text { <http://swift.cmbi. } \\
\text { ru.nl/gv/whatche- } \\
\text { ck/> }\end{array}$ & Hooft et al. (1996) \\
\hline Verify3D & $\begin{array}{l}\text { Servidor para avaliação da quali- } \\
\text { dade estrutural por meio da análise } \\
\text { da compatibilidade do modelo } \\
\text { tridimensional com a estrutura } \\
\text { primária da proteína. }\end{array}$ & $\begin{array}{c}<\text { http://nihserver. } \\
\text { mbi.ucla.edu/ } \\
\text { Verify_3D/> }\end{array}$ & Eisenberg et al. (1997) \\
\hline
\end{tabular}

Bancos de dados $\quad$ Seleção dos moldes e alinhamento _ Construção do modelo _ Validação

Os modelos gerados pela técnica de modelagem comparativa possuem amplas aplicações, dependendo da qualidade apresentada, como já mencionado ${ }^{65} \mathrm{Co}-$ mumente, são aplicados em: (i) estudos de mutagênese sítio-direcionada para gerar mutantes úteis no teste de hipóteses funcionais; (ii) identificação de sítio ativo e sítios de ligação de cofatores em enzimas; (iii) estudo e desenvolvimento de ligantes de um dado sítio de ligação; (iv) modelagem da especificidade do substrato; (v) simulações de docking molecular enzima-ligante; (vi) interpretação de resultados experimentais; e (vii) refinamento de estruturas cristalográficas. ${ }^{66}$

No âmbito da descrição de estruturas tridimensionais de macromoléculas, uma importante aplicação dos modelos preditos por homologia estrutural é no refinamento de estruturas cristalográficas. ${ }^{67} \mathrm{O}$ padrão de difração é definido pela densidade eletrônica da macromolécula, a qual, por sua vez, depende da soma de todas as amplitudes e fases advindas das reflexões. ${ }^{68}$ No entanto, durante a detecção dos eventos de difração em uma análise por DRX, as informações sobre as fases são perdidas, originando o problema das fases. ${ }^{69}$ Neste contexto, os modelos preditos são aplicados de forma a auxiliar na solução deste problema em cristalografia, em que a modelagem por homologia pode ser utilizada como guia na determinação das fases. ${ }^{70} \mathrm{~A}$ utilização em conjunto da DRX e das técnicas de modelagem por homologia contribui grandemente para a descrição estrutural de macromoléculas, de forma a potencializar e acelerar a obtenção de estruturas tridimensionais de enzimas e demais biomoléculas com elevada precisão. ${ }^{71}$

Além do refinamento estrutural, a modelagem por homologia pode ser útil na geração de uma estrutura tridimensional aprimorada de enzimas e demais macromoléculas. Na estrutura descrita por DRX, alguns dados sobre resíduos específicos

65 Baker e Šali (2001), Ginalski (2006).

66 Baker e Šali (2001), Sánchez e Šali (2000).

67 Giorgetti et al. (2005), DiMaio et al. (2011), Qian et al. (2007).

68 Rhodes (2006), Giorgetti et al. (2005).

69 Rhodes (2006).

70 Zhang (2009), Qian et al. (2007), Claude et al. (2004).

71 Giorgetti et al. (2005), Claude et al. (2004), Jones (2001). 
podem ser perdidos, visto que algumas regiões apresentam desordens vibracionais e de ocupação, como as alças. ${ }^{72}$ Em particular, no caso das enzimas, as regiões das alças geralmente determinam a especificidade da macromolécula, já que fazem parte do sítio ativo e dos sítios de ligação. ${ }^{73}$ Nesse contexto, a modelagem por homologia pode ser aplicada na predição de regiões proteicas específicas: as alças e as cadeias laterais. ${ }^{74}$ Assim, modelos aprimorados de macromoléculas são gerados, nos quais estão contidos também os resíduos perdidos na estrutura cristalográfica. Um exemplo desse procedimento foi observado no estudo envolvendo a enzima ACCase no desenvolvimento de nanobiossensores, em que, durante a construção do sistema molecular para simulação, a estrutura tridimensional da ACCase foi obtida do repositório $\mathrm{PDB}$, e o software $\mathrm{SPDBv}$ foi utilizado para adicionar os resíduos não descritos na estrutura, obtendo um sistema mais aprimorado para estudos de DM e docking molecular. ${ }^{75}$

\subsubsection{Docking molecular}

A partir da descrição das coordenadas atômicas da biomolécula, ou seja, da obtenção do modelo tridimensional completo, parte-se para o estudo das interações intermoleculares, as quais podem descrever mecanismos-chave em processos biológicos. ${ }^{76}$ Essa tarefa pode ser realizada pela aplicação do docking molecular, uma estratégia computacional capaz de prever o modo de ligação entre moléculas em um complexo bioquímico, geralmente envolvendo uma designada como receptora (macromolécula) e outra menor designada como ligante. ${ }^{77}$ A definição da conformação possibilita, assim, a identificação do sítio de interação, bem como a quantificação da afinidade de ligação entre ambas. ${ }^{78} \mathrm{~A}$ técnica de docking é frequentemente aplicada para predizer a orientação de ligação de moléculas pequenas candidatas a fármacos em suas proteínas-alvo, a fim de estudar a afinidade e atividade de pequenas moléculas. ${ }^{79}$ Assim, o docking cumpre um papel importante no design racional de fármacos. ${ }^{80}$

A importância de se detalhar o modo pelo qual as moléculas e ligantes interagem entre si, para a medicina, consiste no entendimento dos mecanismos que regem o funcionamento normal do organismo, assim como o desenvolvimento de doenças.$^{81} \mathrm{~A}$ descrição do processo de reconhecimento molecular envolve a caracterização do grande número de interações intermoleculares entre o ligante, a mo-

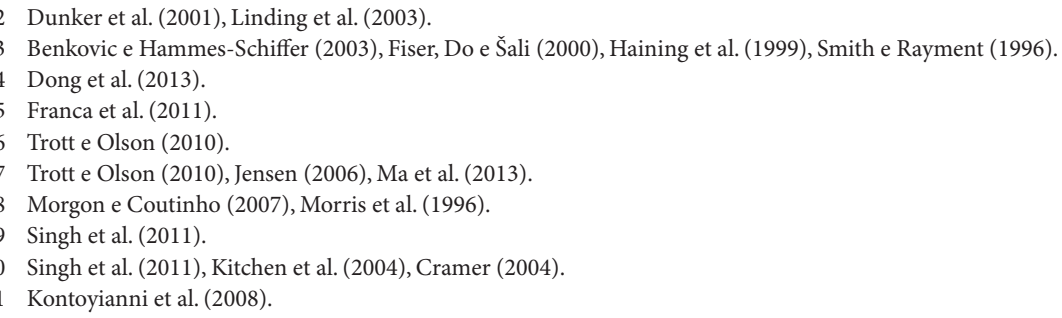


lécula receptora e o solvente.$^{82}$ Resumidamente, o problema de docking, dada sua elevada complexidade, pode ser dividido em dois subproblemas: (i) definição da orientação assumida pela molécula ligante no sítio de ligação do receptor, com base na aplicação de um algoritmo que promova buscas conformacionais guiadas por uma grade de energia em uma área delimitada da macromolécula; e (ii) utilizando a função scoring (por exemplo, aproximação da energia de ligação entre o receptor e o ligante), identificar a conformação do ligante com a mínima energia de ligação, a qual seja viável computacionalmente. ${ }^{83}$

As proteínas possuem estruturas que podem ser consideradas rígidas, e o ligante pode explorar livremente seu espaço conformacional. ${ }^{84}$ As conformações são geradas a partir dos cálculos de docking, em que o ligante é, então, acoplado sucessivamente na estrutura proteica. ${ }^{85}$ Nesses cálculos, a obtenção das energias de ligação é chave para a determinação das conformações. A descrição das energias de ligação é feita com base na energia livre de ligação de Gibbs $\left(\Delta G_{\text {lig }}\right)$, expressa pela Equação 4.1:86

$$
\Delta \mathrm{G}_{\text {lig }}=\Delta \mathrm{H}-\mathrm{T} \Delta \mathrm{S}=\mathrm{RT} \ln \mathrm{K}_{\mathrm{i}}
$$

em que $\Delta \mathrm{H}$ é a variação de entalpia, $T$ é a temperatura absoluta, $\Delta \mathrm{S}$ é a variação de entropia, $\mathrm{R}$ é a constante universal dos gases e $\mathrm{K}_{\mathrm{i}}$ é a constante de inibição (medida experimentalmente).

A obtenção dos valores de $\Delta \mathrm{G}_{\text {lig }}$ pode ser realizada pela aplicação de diversos métodos, desde aqueles com maior custo computacional e precisão, que empregam simulações de DM, aplicando um campo de força molecular clássico, ${ }^{87}$ tal como as metodologias que reduzem o custo computacional, calculando a energia com base em simulações de DM nos estados inicial, envolvendo o ligante em solução, e final, envolvendo o complexo receptor-ligante. ${ }^{88}$

Uma série de conformações aceitáveis que descrevem o complexo receptor-ligante é, assim, computada. Esse conjunto de orientações é submetido a funções de avaliação (scoring) para a determinação da pose mais favorável, ou seja, com a energia de ligação mínima. As funções de avaliação realizam aproximações e simplificações computacionais a fim de atingir um equilíbrio entre tempo gasto e precisão dos resultados durante o procedimento de avaliação das conformações aceitáveis. ${ }^{89}$ Existem três classes principais de funções de avaliação usadas em programas de docking: (i) com base em campos de força, os quais utilizam uma série de termos de interação derivados de fenômenos físico-químicos para avaliar a energia do sistema; (ii) empíricas, que consistem na soma de um conjunto de funções parametrizadas

82 Morgon e Coutinho (2007).

83 Trott e Olson (2010), Ma et al. (2013), Morgon e Coutinho (2007), Coupez e Lewis (2006), Halperin et al. (2002).

84 Trott e Olson (2010).

85 Trott e Olson (2010), Zsoldos et al. (2006).

86 Morgon e Coutinho (2007).

87 Morgon e Coutinho (2007), Kollman (1993), Van Gunsteren et al. (1994).

88 Morgon e Coutinho (2007).

89 Jensen (2006), Zsoldos et al. (2006). 
que reproduzem dados experimentais (por exemplo, energias de ligação ou conformações); e (iii) com base em conhecimentos que utilizam dados estatísticos derivados de informações experimentais de complexos proteína-ligante para a definição de interações favoráveis e, assim, classificar o conjunto de conformações. ${ }^{90} \mathrm{Em}$ suma, a Figura 4.7 sintetiza os passos de aplicação da técnica de docking.

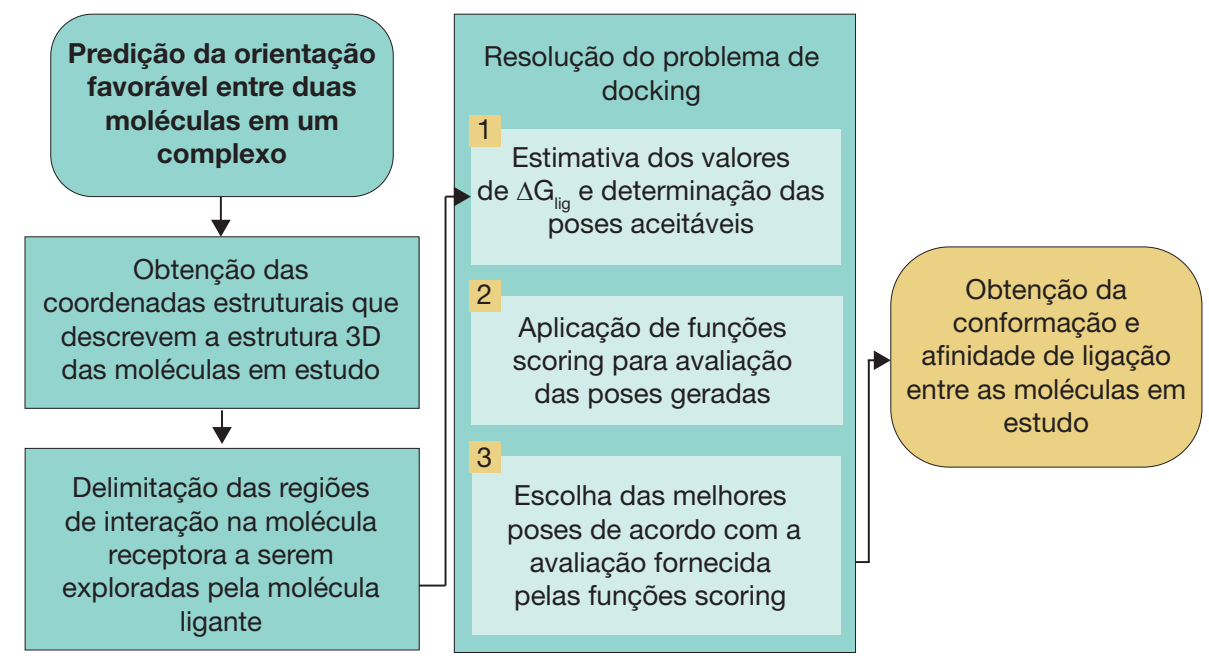

Figura 4.7 Fluxograma de aplicação do docking molecular.

O blind docking, outra modalidade de docking de grande relevância, foi introduzido para detecção de modos sítios de ligação de ligantes peptídicos por meio do escaneamento completo das proteínas-alvo. ${ }^{91}$ Algumas partes da proteína, dependendo do sequenciamento de aminoácidos, podem ser tão reativas quanto o sítio de ligação, e, com isso, a investigação de regiões catalíticas não específicas é importante, já que a orientação espacial da enzima nem sempre é favorável para interação com o sítio ativo, havendo casos em que o substrato interage com regiões não funcionais da enzima. Portanto, o blind docking se mostra importante para a investigação dessas regiões enzimáticas. ${ }^{92}$ Ademais, um método que tem sido bastante usado no meio científico é o essencial de dinâmica com distância restrita, em inglês Distance Constrained Essential Dynamics Method (DCED), o qual tem sido aplicado na geração de múltiplas estruturas de encaixe, denominadas autoestruturas. Essa abordagem evita a maioria dos cálculos por dinâmica molecular de alto custo e pode captar os movimentos essenciais envolvidos em um receptor flexível, representado por uma dinâmica de coarse-grained. ${ }^{93}$

\footnotetext{
90 Morgon e Coutinho (2007), Zsoldos et al. (2006).

91 Aita et al. (2010), Davis et al. (2009), Gueto et al. (2009), Hetényi e Van der Spoel (2011), Ferrara et al. ([2007] 2014).

92 Gueto et al. (2009), Davis et al. (2009), Hetényi e Van der Spoel (2011), Ferrara et al. ([2007] 2014).

93 Corpet (1988), Mustard e Ritchie (2005). Técnica que faz uso de modelos reduzidos, os quais não englobam detalhes atômicos na análise estrutural; todavia, dada a simplicidade, a velocidade de cálculo das avaliações de energia do sistema é expandida.
} 


\subsubsection{Dinâmica molecular}

As simulações de DM têm como base as leis clássicas da Mecânica e têm sido aplicadas em larga escala nos problemas encontrados em Física, Química, Ciência dos Materiais, Biologia e, recentemente, em campos da Nanociência. ${ }^{94}$ A metodologia de DM está fundamentada na resolução da equação de movimento de Newton para um sistema de $\mathrm{N}$ átomos, os quais são considerados partículas que podem interagir entre si (Equação 4.2): ${ }^{95}$

$$
F_{i}=m_{i} \frac{\partial^{2} r_{i}}{\partial t^{2}}, i=1,2, \ldots, N
$$

sendo $F_{i}$ a força, $m_{i}$ a massa, $r_{i}$ a posição de uma dada partícula i e $t$, o tempo.

As forças podem ser descritas pela derivada negativa de uma função potencial $\mathrm{V}\left(\mathrm{r}_{1}, \mathrm{r}_{2}, \ldots, \mathrm{r}_{\mathrm{N}}\right)$, conforme mostrado na Equação $4.3:{ }^{96}$

$$
F_{i}=-\frac{\partial \mathrm{V}}{\partial r_{i}}
$$

A descrição das forças envolvidas em um sistema molecular é realizada com base na energia potencial $\mathrm{V}$, ou seja, previamente à obtenção das forças deve-se calcular a energia potencial do sistema em questão. $\mathrm{O}$ cálculo da energia potencial é realizado com base em um campo de força, o qual é definido por um conjunto de potenciais de interação que descrevem a dinâmica do sistema. ${ }^{97} \mathrm{~A}$ equação de campo de força leva em conta as contribuições devidas às interações ligadas (ligação, angular e torção), bem como as interações não ligadas (Van der Waals e eletrostáticas). Tais contribuições são determinadas de energia por um conjunto de parâmetros empíricos usados pelo campo de força para calcular a contribuição de energia para cada tipo de interação para os tipos de átomos que são definidos no sistema molecular considerado. ${ }^{98}$

As equações são resolvidas simultaneamente, em pequenos passos de tempo da ordem de fentossegundos ( $1 \mathrm{fs}=10^{-15}$ segundos). Em uma típica simulação de DM, as coordenadas iniciais dos átomos são obtidas experimentalmente, ou, então, derivadas da modelagem estrutural, conforme descrito no item 4.2.1. Dessa maneira, por meio da integração da equação de Newton, a simulação de DM pode converter

94 Czajka et al. (1998).

95 Jensen (2006).

96 Id. ibid.

97 Jensen (2006), MacKerell et al. (1998), Adcock e McCammon (2006), Sotomayor e Schulten (2007), Daggett e Levitt (1993), Karplus e Petsko (1990).

98 Leach (2001). 
dados estáticos dessas técnicas em informações dinâmicas. ${ }^{99}$ Os quadros das coordenadas atômicas (obtidos a cada passo de tempo), combinados sequencialmente em conjuntos, são denominados trajetórias, resultando em detalhados filmes de como as moléculas se comportam no tempo, sob certas condições predefinidas. ${ }^{100}$

As etapas para uma simulação de DM, geralmente, podem ser descritas por: (i) geração das conformações iniciais do sistema, em que as coordenadas atômicas (provenientes de dados experimentais, de métodos de modelagem por homologia ou mesmo de informações de um complexo preditas pela aplicação de docking molecular) são utilizadas para a construção do ambiente inicial de simulação; (ii) minimização de energia, em que os átomos são reacomodados na caixa de simulação, de modo que os contatos atômicos próximos e as geometrias distorcidas são corrigidos; (iii) equilíbrio do sistema, em que o sistema é levado a valores específicos de temperatura, pressão e pH; (iv) cálculo da energia potencial, o qual é realizado em uma série de termos de interação (campo de força); (v) obtenção das forças pela diferenciação dos valores de energia potencial em relação à posição das partículas no sistema; (vi) atualização das posições e velocidades dos componentes do sistema a cada passo de tempo; (vii) repetição das etapas iv, v e vi, até completar o tempo total de simulação; e, por fim, (viii) obtenção da trajetória do sistema (isto é, conjunto de posições e velocidades dos átomos no tempo de simulação). ${ }^{101}$

As limitações da DM se relacionam ao tamanho da biomolécula simulada e ao limite de tempo da metodologia. Essas dificuldades não permitiriam uma simulação realística da maioria dos processos celulares, já que eles geralmente envolvem centenas de milhares de átomos e ocorrem em uma escala de tempo de milissegundos a segundos. ${ }^{102}$ Nesse contexto, para contornar as limitações de tamanho e tempo, a DM tem sido simplificada por meio dos métodos de coarse-grained, ${ }^{103} \mathrm{e}$ os processos biomoleculares têm sido acelerados pela aplicação de forças direcionadas, por métodos de SMD. ${ }^{104}$

\subsubsection{Cálculos híbridos de mecânica quântica e mecânica molecular}

A investigação de sistemas moleculares grandes é um ponto limitante para a aplicação de abordagens quânticas. Apesar de a DM fornecer uma boa aproximação sobre o comportamento de biomoléculas e complexos moleculares no tempo, a Física Clássica é limitada quanto à descrição de um sistema atômico com relação às suas propriedades eletrônicas. No entanto, a abordagem eletrônica é crucial para

\footnotetext{
99 MacKerell et al. (1998), Adcock e McCammon (2006), Sotomayor e Schulten (2007), Daggett e Levitt (1993), Karplus e Petsko (1990), Lee et al. (2009).

100 Lee et al. (2009).

101 Rapaport (2004), Friedman et al. (2013), Gonçalves (2012).

102 Griebel et al. (2007).

103 Shih et al. (2006), Arkhipov et al. (2006), Klein e Shinoda (2008).

104 Kosztin et al. (1999), Isralewitz et al. (2001), Park e Schulten (2004), Parravicini et al. (2010).
} 
detalhar as interações envolvidas na dinâmica de processos celulares (por exemplo, enzima-substrato, antígeno-anticorpo, proteína-ligante, entre outros). ${ }^{105}$ Nesse contexto, com o intuito de aprimorar a descrição computacional de sistemas moleculares, a aplicação concomitante de abordagens advindas da mecânica molecular e da mecânica quântica vem sendo feita com êxito na descrição de fenômenos de grande relevância na interface entre Química e Biologia. ${ }^{106}$

Basicamente, o emprego de cálculos híbridos de QM/MM envolve a divisão do sistema em duas regiões principais ${ }^{107}$ (Figura 4.8). A região menor, designada como região de QM, é tratada por Química Quântica (isto é, empregando um método que descreva a estrutura eletrônica das moléculas), e a outra, maior, designada por região de MM, é tratada por mecânica molecular (isto é, método que descreve as interações interatômicas com base em uma função de energia potencial, determinada por um campo de força). ${ }^{108} \mathrm{Em}$ razão do tratamento do sistema com base em abordagens diferentes, a energia total é, então, descrita pela Equação 4.4: ${ }^{109}$

$$
\mathrm{E}_{\mathrm{Tot}}=\mathrm{E}_{\mathrm{QM}}+\mathrm{E}_{\mathrm{MM}}+\mathrm{E}_{\mathrm{QM}, \mathrm{MM}}
$$

sendo $\mathrm{E}_{\mathrm{QM}}$ a energia na região de $\mathrm{QM}, \mathrm{E}_{\mathrm{MM}}$ a energia na região de $\mathrm{MM}$ e $\mathrm{E}_{\mathrm{QM}, \mathrm{MM}}$ a energia na interface entre ambas.

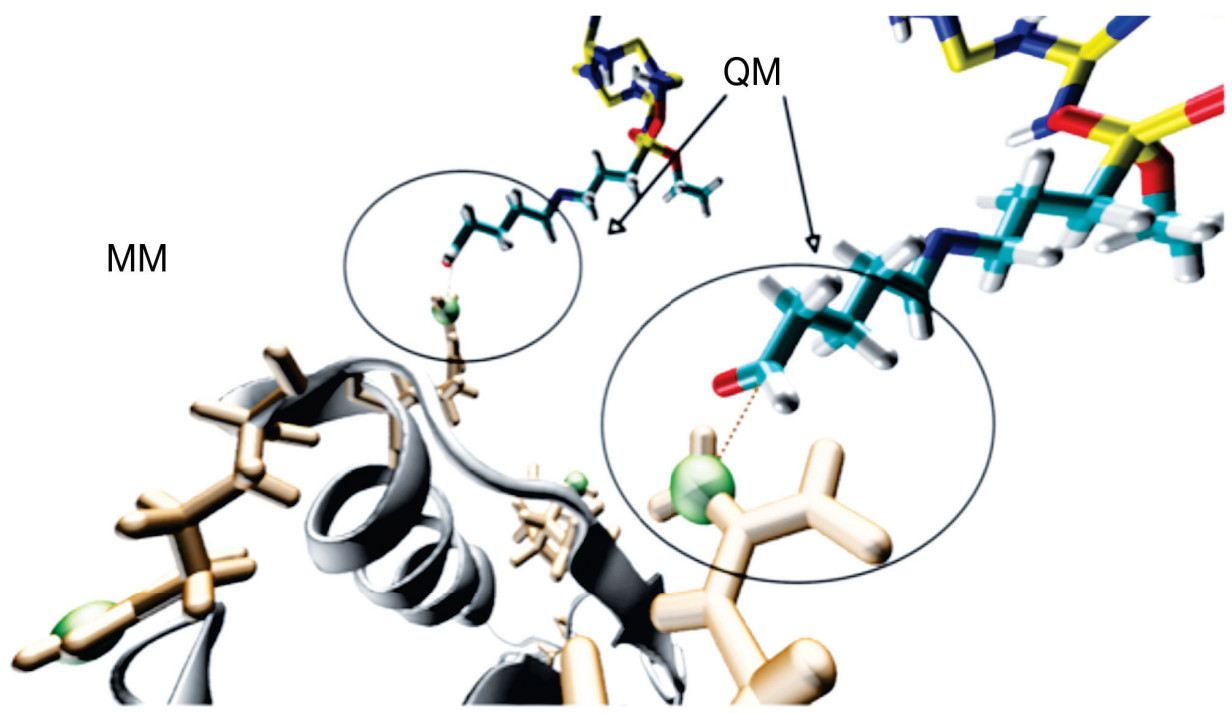

Figura 4.8 Descrição do sistema molecular com as interfaces das regiões QM e MM.

105 Menikarachchi e Gascon (2010)

106 Id. ibid.

107 Menikarachchi e Gascon (2010), Kang et al. (2012), Vreven et al. (2006).

108 Menikarachchi e Gascon (2010), Kang et al. (2012), Van der Kamp e Mulholland (2013).

109 Kang et al. (2012). 
A aplicação da abordagem QM/MM em um dado sistema depende das seguintes etapas: (i) seleção do método de QM empregado (dependente do processo molecular a ser caracterizado); (ii) seleção do campo de força utilizado nas análises de MM; (iii) divisão do sistema em regiões a serem tratadas por QM e MM (considerando as especificidades para a descrição computacional das regiões de interface entre elas); (iv) geração da estrutura tridimensional inicial para a descrição do sistema; e (v) definição do perfil de simulação (por exemplo, seleção de parâmetros, tempo de simulação, taxa de amostragem conformacional). ${ }^{110}$

Um dos pontos críticos na aplicação da metodologia de QM/MM é a definição da região a ser tratada por QM. Em razão da maior precisão desse método, supõe-se que quanto maior a região selecionada, melhor a qualidade dos resultados. No entanto, devem ser consideradas as limitações computacionais atuais, as quais restringem o tamanho da área de QM para o menor possível. ${ }^{111}$ Além disso, a precisa definição da fronteira entre os subsistemas e o modo como a energia é calculada é outro fator crucial no sucesso da aplicação dos cálculos híbridos, visto que as interações eletrostáticas, assim como os possíveis cortes de ligações químicas, devem ser consideradas. ${ }^{112}$

A interface pode ser fixada em uma região definida ou permitir seu movimento durante o curso da simulação, a fim de descrever processos como mudanças no sítio ativo e/ou movimento de íons solvatados. ${ }^{113} \mathrm{~A}$ escolha da região QM considera a precisão e confiabilidade versus o desprendimento computacional. Os métodos semiempíricos são os mais significativos e usados, porém o custo computacional ainda é alto. ${ }^{114}$ Em contrapartida, o método que usa a Teoria Funcional de Densidade (DFT) é uma alternativa em muitos estudos contemporâneos, fornecendo resultados com alta precisão em tempo menor, comparado com os métodos semiempíricos. ${ }^{115}$ $\mathrm{Na}$ região MM existem campos de força disponíveis para aplicações em biomoléculas, como, por exemplo, CHARMM, ${ }^{116}$ AMBER, ${ }^{117}$ GROMOS ${ }^{118}$ e OPLS, ${ }^{119}$ e para o tratamento de solventes explícitos, tais como TIP3 $\mathrm{P}^{120}$ ou SPC, ${ }^{121}$ no caso da água.

\subsubsection{Steered Molecular Dynamics (SMD)}

No estudo de certas propriedades de ligação e respostas biomoleculares a perturbações externas, é crescente o uso de metodologias fundamentadas na

\footnotetext{
110 Van der Kamp e Mulholland (2013), Senn e Thiel (2009).

111 Morgon e Coutinho (2007).

112 Senn e Thiel (2009).

113 Heyden et al. (2007).

114 Senn e Thiel (2009).

115 Id. ibid.

116 Brooks et al. (2009).

117 Christen et al. (2005).

118 Id. ibid.

119 Jorgensen et al. (1996).

120 Id. (1983).

121 Berendsen et al. (1981).
} 
aplicação de forças mecânicas em complexos biológicos, como a microscopia de força atômica. ${ }^{122}$ Nesse contexto, técnicas computacionais que reproduzem as forças envolvidas na remoção de uma dada molécula de um complexo estável são úteis na complementação e interpretação de resultados experimentais. ${ }^{123}$ Uma abordagem computacional muito utilizada para esse fim é a Dinâmica Molecular Direcionada (SMD, do inglês Steered Molecular Dynamics).

Uma simulação de SMD envolve a aplicação de uma força externa $F$ em um complexo macromolécula-ligante, induzindo a remoção deste último (Figura 4.9). De forma geral, a força $F$ é aplicada a um átomo (ou conjunto de átomos) de um sistema mecânico clássico regido pelo hamiltoniano $\mathrm{H}(\mathbf{r}, \mathrm{t})$, em que $\mathbf{r}$ especifica a configuração de todo o sistema e $t$ é o tempo. ${ }^{124} \mathrm{Na}$ formulação cv-SMD ("constant velocity SMD"), a força $F$ produz uma alteração concreta do sistema em um intervalo de tempo definido (isto é, com velocidade $v$ constante), conduzindo-o ao longo de uma coordenada generalizada $(\xi)$. No instante $t, F$ é expressa por: ${ }^{125}$

$$
\mathrm{F}(\mathrm{t})=\mathrm{k}\left(\xi_{0}+\mathrm{vt}-\xi^{\prime}\right)
$$

em que $k$ é constante de força, $\xi_{0}$ é o valor da coordenada generalizada em $\mathrm{t}=0$, $v$ é a velocidade e $\xi^{\prime}$ é o valor de $\xi$ no instante $t$. A integração de $\mathrm{F}(\mathrm{t})$ em relação a t resulta na computação do trabalho $\mathrm{W}(\mathrm{t})$, que, por sua vez, pode ser utilizado para calcular a diferença entre as energias livres dos estados $A$ e $B\left(G_{A}\right.$ e $G_{B}$, respectivamente) por meio da igualdade de Jarzynski, ${ }^{126}$

$$
\exp \left(-\frac{\Delta G}{k_{B} T}\right)=\left\langle\exp \left(\frac{W}{k_{B} T}\right)\right\rangle_{A}
$$

sendo $T$ a temperatura, $k_{\mathrm{B}}$ a constante de Boltzmann e $\Delta \mathrm{G}=\mathrm{G}_{\mathrm{B}}-\mathrm{G}_{\mathrm{A}}$; a expressão $\left\langle\exp \left(\frac{\mathrm{W}}{\mathrm{k}_{\mathrm{B}} \mathrm{T}}\right)\right\rangle_{\mathrm{A}}$ implica a média da quantidade entre parênteses angulares, realizada no estado inicial $A$. Identificando o estado A com $\xi_{0}(\xi$ em $t=0)$ e o estado B com $\xi$ no instante t, é possível reconstruir o perfil de $\Delta \mathrm{G}$ ao longo da coordenada generalizada $\xi$, isto é, o Potencial Médio de Força, $\mathrm{PMF} \equiv \Delta \mathrm{G}(\xi){ }^{127}$

De acordo com a Equação 4.6, o PMF, que é uma propriedade de sistemas em equilíbrio, pode ser extraído de simulações em regime de não equilíbrio, embora seja necessário um elevado número de réplicas, uma vez que está envolvida uma média exponencial. Contudo, o PMF pode ser satisfatoriamente reconstruído 
a partir da expansão cumulativa de segunda ordem da média exponencial, cujos acumuladores (ou armazenadores) são calculáveis com elevada exatidão, a partir de poucas réplicas, fornecendo, geralmente, um limite superior para o PMF. ${ }^{128}$

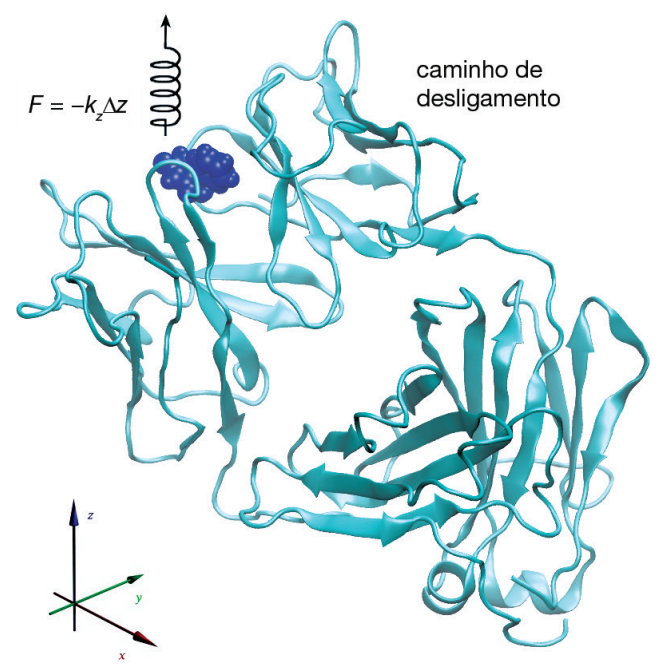

Figura 4.9 Representação da simulação utilizando SMD para retirada de uma molécula de antígeno do sítio de ligação do anticorpo. PDB ID: 1IGY.

Fonte: Franca et al. ${ }^{129}$

\subsection{APLICAÇÃO DAS TÉCNICAS COMPUTACIONAIS NOS ESTUDOS DE MICROSCOPIA DE FORÇA ATÔMICA E PANORAMA ATUAL DAS PESQUISAS}

O escopo das pesquisas do Grupo de Nanoneurobiofísica (GNN ${ }^{130}$ envolve o emprego da nanotecnologia no desenvolvimento de nanobiossensores, com base em pontas de AFM. A aplicabilidade desses nanodispositivos se expande desde o monitoramento de resíduos químicos provenientes da agricultura até o estudo do mecanismo de doenças complexas, tais como câncer, Alzheimer e Esclerose Múltipla (EM). Nesse contexto, as técnicas computacionais para a descrição do recobrimento de superfícies têm se mostrado cruciais para o melhor entendimento do mecanismo envolvido no sensoriamento mediado por esses nanodispositivos. Resultados promissores têm sido obtidos pela aplicação concomitante de metodologias experimentais com o AFM e abordagens computacionais. Alguns dos principais trabalhos serão detalhados nos parágrafos seguintes. 
Franca et al., ${ }^{131} \mathrm{em}$ 2011, utilizaram protocolos de modelagem por homologia, docking molecular e simulações de DM para assistir ao desenvolvimento de nanobiossensores empregando a enzima AcetilCoA carboxilase (ACCase). Foi observado que o dímero é a forma mais estável da enzima em solução aquosa, sendo a estrutura escolhida para a funcionalização. A partir dos cálculos computacionais, foram possibilitadas a identificação da área de imobilização da ACCase, na ponta do AFM, e a descrição da funcionalização. Ademais, a estratégia de docking caracterizou a interação entre o dímero da ACCase e as moléculas de herbicida (atrazina e diclofop). Em conjunto com simulações de DM e cálculos quânticos semiempíricos, foi observado que a ACCase interage preferencialmente com o diclofop, direcionando, assim, a construção do nanobiossensor. ${ }^{132}$

Em 2013, Deda et al. ${ }^{133}$ utilizaram a MMC na predição da orientação apropriada de biomoléculas sobre a ponta de AFM, a qual foi capaz de caracterizar a posição dos sítios ativos da enzima ALS, evidenciando presença de dois sítios ativos da enzima Acetolactato sintase (ALS) acessíveis para a interação com o inibidor (herbicida metsulfuron-methyl). Além disso, as técnicas de modelagem molecular apresentaram alta potencialidade para fornecer informações relacionadas à energia envolvida na interação enzima-herbicida, a predição do número de biomoléculas presentes na superfície da ponta, assim como informações extras, como quantas moléculas de herbicida interagem quando a ponta se aproxima do substrato. Os resultados preliminares indicaram a presença de, no máximo, nove biomoléculas na superfície de uma ponta com um raio de $20 \mathrm{~nm}$ (equivalente ao raio das pontas utilizadas nas experiências) livres para interação com as moléculas de herbicida. ${ }^{134}$ No entanto, estudos adicionais são necessários para corroborar esta hipótese.

Ainda em 2013, Oliveira et al. ${ }^{135}$ utilizaram simulações de DM para mimetizar a ponta do AFM funcionalizada, interagindo com a enzima, inicialmente modelada por Franca et al., ${ }^{136}$ em solução aquosa. Com os resultados de potencial eletrostático, foram propostas três possíveis orientações da enzima ACCase sobre a ponta do AFM. Os cálculos finais de DM revelaram que, após 50 ns de tempo de simulação, a geometria proteica preservou os sítios ativos da enzima ACCase para interagir com as moléculas de herbicidas no substrato. A análise do potencial eletrostático das interações enzima-ponta do AFM foi de grande importância na quantificação desse tipo de interação. As ligações de hidrogênio, que são interações fortes, puderam ser monitoradas em função do tempo. Outro parâmetro que pôde ser monitorado em razão da interação da enzima com a superfície recoberta pelo agente espaçador foi a integridade da enzima em termos de desnaturação. O gráfico de Ramachandran foi

131 Franca et al. (2011).

132 Id. ibid.

133 Deda et al. (2013).

134 Id. ibid.

135 Oliveira et al. (2013).

136 Franca et al. (2011). 
capaz de mostrar que, depois de uma simulação por DM extensa, a superfície não exerce influência suficiente para desnaturar a enzima.

Em 2014 foi publicado por Bueno et al. ${ }^{137}$ um estudo detalhando o processo de funcionalização em escala atômica com base em ferramentas computacionais. Enquanto, experimentalmente, estudos de AFM proporcionaram o desenvolvimento de um nanobiossensor para a detecção do diclofop, foi verificada computacionalmente a influência do processo de funcionalização na integridade das moléculas. Nesse processo, sendo as moléculas de herbicida ligadas ao APTES em conjunto com glutaraldeído para imobilização no substrato, foi estudada a possível influência desse sistema na capacidade do herbicida de inibir a ACCase. A interação entre o sistema herbicida+glutaraldeído+APTES e a enzima ACCase foi representada com base nas coordenadas cristalográficas disponíveis online, e as simulações computacionais mostraram que, com base nos resultados de energia de interação, o diclofop mantém suas características de inibição enzimática após imobilização. ${ }^{138}$

Ainda nessa linha de pesquisa, em 2014, Amarante et al. ${ }^{139}$ propuseram um modelo para descrição do recobrimento da superfície da ponta de AFM no nanobiossensor desenvolvido por Bueno et al., ${ }^{140}$ tal como obtiveram teoricamente os valores da força de interação ACCase-diclofop. O modelo para descrição do recobrimento da ponta de AFM envolveu uma abordagem estocástica, em que as moléculas de enzima foram representadas por poliedros rígidos. Foi estimado, por esse modelo, o número de enzimas adsorvidas na ponta de AFM, de acordo com seu raio. Por essa estimativa, também foi possível quantificar os sítios ativos disponíveis para interação com o herbicida, após a imobilização da ACCase na superfície. Ademais, a aplicação da metodologia de SMD permitiu mensurar as forças teóricas de interação enzima-herbicida, as quais se equipararam àquelas medidas experimentalmente por Bueno et al. ${ }^{141}$

As técnicas computacionais também foram úteis na descrição dos eventos moleculares relevantes na interação entre a enzima 4-hidroxifenil piruvato (HPPD) e o herbicida mesotriona, no qual as energias de interação entre tais moléculas foram mensuradas a partir do sítio de interação computado para esse sistema. Esses dados foram úteis na caracterização da interação HPPD-mesotriona, durante o desenvolvimento de nanobiossensor de ponta de AFM específico por Garcia et al. ${ }^{142}$

A MMC, além das aplicações supracitadas, tem sido utilizada com sucesso para a descrição de eventos específicos, como o reconhecimento molecular e a interação antígeno-anticorpo. ${ }^{143} \mathrm{~A}$ modelagem da especificidade das regiões variáveis de anticorpos também tem sido reportada na literatura, assim como o estabelecimento de protocolos computacionais para estudo de estruturas de tais macromo-

\footnotetext{
137 Bueno et al. (2014).

138 Id. ibid.

139 Amarante et al. (2014).

140 Bueno et al. (2014).

141 Id. ibid.

142 Garcia et al. (2015).

143 Yuan et al. (2012), Mulyanto (2011), Hanasaki et al. (2008), Carreño et al. (2008), Mikulska et al. (2011).
} 
léculas. ${ }^{144}$ Nesse panorama, considerando a elevada especificidade dos anticorpos e também seu papel como biomarcador de determinadas doenças, como a neuromielite óptica, ${ }^{145}$ a construção de nanossensores com base em anticorpos mostra-se promissora para o desenvolvimento de técnicas de diagnóstico mais precisas. Com os nanobiossensores envolvendo outras biomoléculas, como no caso dos anticorpos, a MMC deve, concomitantemente, descrever o recobrimento de pontas de AFM, considerando essas novas biomoléculas nos modelos, e, assim, futuramente, desenvolver novos protocolos de caracterização de superfícies.

\subsection{CONSIDERAÇõES FINAIS}

Neste capítulo foram mostradas algumas das principais metodologias computacionais aplicadas na descrição dos processos bioquímicos envolvidos no desenvolvimento de nanobiossensores. Tais metodologias, em conjunto, constituem protocolos específicos que são capazes de reproduzir, em escala atomística, os eventos contidos no processo de funcionalização de pontas de AFM. As abordagens computacionais são capazes de auxiliar de forma crucial na interpretação e no refinamento dos resultados obtidos experimentalmente, de forma a direcionar o desenvolvimento de nanobiossensores.

$\mathrm{O}$ uso de nanobiossensores tem mostrado grande potencialidade na área ambiental, conforme estudos publicados pelo GNN da UFSCar do campus de Sorocaba. Tais estudos abrem novas perspectivas para a aplicação desses dispositivos para fins biomédicos, por exemplo, a descrição de mecanismos moleculares e novas técnicas de diagnóstico e tratamento de doenças. Nesse contexto, várias aplicações das técnicas computacionais vêm sendo descritas na literatura, conforme também revisado no capítulo, o que faz das técnicas computacionais ferramentas importantes para as investigações de processos biológicos envolvidos no desenvolvimento de doenças.

O maior problema em reproduzir experimentos de AFM computacionalmente se refere ao tempo limitado de simulação, já que abrange um espaço temporal muito menor do que aquele envolvido na interação entre as moléculas funcionalizadas e o substrato. De forma geral, à medida que os computadores vão se aprimorando, tempos maiores de simulação vão se tornando possíveis, e os resultados dos cálculos teóricos vão se aproximando cada vez mais dos resultados experimentais. Com isso, o custo de funcionalização de pontas de AFM por meio de conhecimento prévio pelos computadores é reduzido.

144 Sircar (2012), Burkovitz et al. (2013), Almagro et al. (2011), Kurella e Gali (2014), Zhang et al. (2013)

145 Bennett et al. (2009), Graber et al. (2008). 


\section{REFERÊNCIAS}

Adcock, S. A.; McCammon, J. A. Molecular dynamics: survey of methods for simulating the activity of proteins. Chemical Reviews, v. 106, n. 5, p. 1589-1615, maio 2006.

Aita, T.; Nishigaki, K.; Husimi, Y. Toward the fast blind docking of a peptide to a target protein by using a four-body statistical pseudo-potential. Computational Biology and Chemistry, v. 34, n. 1, p. 53-62, fev. 2010.

Alberts, B. et al. Molecular biology of the cell. 5. ed. Nova York: Garland Science, 2007.

Almagro, J. C. et al. Antibody modeling assessment. Proteins, v. 79, n. 11, p. 3050-3066, nov. 2011.

Altschul, S. F. Amino acid substitution matrices from an information theoretic perspective. J Mol Biol, v. 219, p. 555-565, jun. 1991.

Altschul, S. F. et al. Basic local alignment search tool. J Mol Biol, v. 215, 403410, out. 1990.

Amarante, A. M. et al. Modeling the coverage of an AFM tip by enzyme and its application in nanobiosensors. Journal of Molecular Graphics \& Modelling, 2014.

AмAтo, I. Nanotechnology: shaping the world atom by atom. NTSC Report. 1999. Disponível em: <http://itri.loyola.edu/nano/IWGN.Public.Brochure/>. Acesso em: 23 jul. 2016.

Arkhipov, A. et al. Coarse-grained molecular dynamics simulations of a rotating bacterial flagellum. Biophysical Journal, v. 91, n. 12, p. 4589-4597, 15 dez. 2006.

Arnautova, Y. A.; Abagyan, R. A.; Totrov, M. Development of a new physics-based internal coordinate mechanics force field and its application to protein loop modeling. Proteins, v. 79, p. 477-498, fev. 2011.

ARNOLD, K. et al. The SWISS-MODEL workspace: a web-based environment for protein structure homology modelling. Bioinformatics, v. 22, p. 195-201, jan. 2006.

BAIroch, A.; ApweIler, R. The SWISS-PROT protein sequence database: its relevance to human molecular medical research. J Mol Med, Berlim, v. 75, p. 312-316, maio 1997.

Bairoch, A.; Boeckmann, B. The SWISS-PROT protein sequence data bank: current status. Nucleic Acids Res, v. 22, p. 3578-3580, set. 1994.

BAKER, D.; ŠAlI, A. Protein structure prediction and structural genomics. Science, v. 294, p. 93-96, out. 2001.

Benkovic, S. J.; Hammes-Schiffer, S. A perspective on enzyme catalysis. Science, v. 301, p. 1196-1202, ago. 2003.

BennetT, J. L. et al. Intrathecal pathogenic anti-aquaporin-4 antibodies in early neuromyelitis optica. Annals of Neurology, v. 66, n. 5, p. 617-629, nov. 2009.

Berendsen, H. J. C. et al. Interaction models for water in relation to protein hydration. In: Pullman, B. (Ed.). Intermolecular forces: the Jerusalem Symposia on Quantum Chemistry and Biochemistry. [S.1.]: Springer Netherlands, 1981. p. 331-342.

Berman, H. M. et al. The protein data bank. Nucleic Acids Res, v. 28, p. 235-242, jan. 2000. 
BERnSTEIN, F. C. et al. The protein data bank: a computer-based archival file for macromolecular structures. J Mol Biol, v. 112, p. 535-542, maio 1977.

Binnig, G.; Quate, C. F.; Gerber, C. Atomic force microscope. Physical Review Letters, v. 56, n. 9, p. 930-933, 03 mar. 1986.

Binnig, G.; Rohrer, H. Scanning tunneling microscopy. Surface Science, v. 126, n. 1-3, p. 236-244, 02 mar. 1983.

Bower, M. J.; Cohen, F. E.; Dunbrack, R. L. Prediction of protein side-chain rotamers from a backbone-dependent rotamer library: a new homology modeling tool. J Mol Biol, v. 267, p. 1268-1282, abr. 1997.

Brooks, B. R. et al. CHARMM: the biomolecular simulation program. Journal of Computational Chemistry, v. 30, n. 10, p. 1545-1614, 30 jul. 2009.

Bueno, C. C. et al. Nanobiosensor for diclofop detection based on chemically modified AFM probes. IEEE Sensor Journal, 2014.

Burkovitz, A. et al. Computational identification of antigen-binding antibody fragments. Journal of Immunology, Baltimore, v. 190, n. 5, p. 2327-2334, 01 mar. 2013.

Butt, H. J.; Downing, K. H.; Hansma, P. K. Imaging the membrane protein bacteriorhodopsin with the atomic force microscope. Biophysical Journal, v. 58, n. 6, p. 1473-1480, dez. 1990.

CARreño, R. et al. A mechanism for antibody-mediated outside-in activation of LFA-1. The Journal of Biological Chemistry, v. 283, n. 16, p. 10642-10648, 18 abr. 2008.

CAse, D. A et al. AMBER. São Francisco: University of California, 2008.

CAstro Bueno, C. et al. Nanobiosensor for diclofop detection based on chemically modified AFM probes. IEEE Sensors Journal, v. 14, n. 5, p. 1467-1475, maio 2014.

Chenna, R. et al. Multiple sequence alignment with the Clustal series of programs. Nucleic Acids Res, v. 31, p. 3497-3500, jul. 2003.

Сhipot, C.; Pohorille, A. Free energy calculations: theory and applications in chemistry and biology. Nova York: Springer, 2007.

Christen, M. et al. The GROMOS software for biomolecular simulation: GROMOS05. Journal of Computational Chemistry, v. 26, n. 16, p. 1719-1751, dez. 2005.

Claude, J. B. et al. CaspR: a web server for automated molecular replacement using homology modelling. Nucleic Acids Res, v. 32, p. W606-W609, jul. 2004.

Contreras-Moreira, B.; Fitzjohn, P. W.; Bates, P. A. Comparative modelling: an essential methodology for protein structure prediction in the post-genomic era. Appl Bioinformatics, v. 1, p. 177-190, 2002.

CORPET, F. Multiple sequence alignment with hierarchical clustering. Nucleic Acids Res, v. 16, p. 10881-10890, nov. 1988.

Coupez, B.; LewIs, R. A. Docking and scoring: theoretically easy, practically impossible? Current Medicinal Chemistry, v. 13, n. 25, p. 2995-3003, 2006. 
Cramer, C. J. Essentials of computational chemistry: theories and models. 2. ed. Chichester: John Wiley \& Sons, 2004.

Czajka, R.; Jurczyszyn, L.; RafiI-TABar, H. Surface physics at the nano-scale via scanning probe microscopy and molecular dynamics simulations. Progress in Surface Science, v. 59, n. 1-4, p. 13-23, 1998.

DA Silva, A. C. N. et al. Nanobiosensors based on chemically modified AFM probes: a useful tool for metsulfuron-methyl detection. Sensors, Basileia, v. 13, n. 2, p. 1477-1489, 24 jan. 2013.

. Nanobiosensors exploiting specific interactions between an enzyme and herbicides in atomic force spectroscopy. Journal of Nanoscience and Nanotechnology, v. 14, n. 9, p. 6678-6684, 01 set. 2014.

Daga, P. R.; Patel, R. Y.; Doerksen, R. J. Template-based protein modeling: recent methodological advances. Curr Top Med Chem, v. 10, p. 84-94, 2010.

Daggett, V.; Levitt, M. Realistic simulations of native-protein dynamics in solution and beyond. Annual Review of Biophysics and Biomolecular Structure, v. 22, n. 1, p. 353-380, 1993.

Davis, A. M.; Teague, S. J.; Kleywegt, G. J. Application and limitations of X-ray crystallographic data in structure-based ligand and drug design. Angew Chem Int Ed Engl, v. 42, p. 2718-2736, jun. 2003.

DAvis, I. W. et al. Blind docking of pharmaceutically relevant compounds using RosettaLigand. Protein Science: a publication of the Protein Society, v. 18, n. 9, p. 1998-2002, set. 2009.

DEDA, D. K. et al. The use of functionalized AFM tips as molecular sensors in the detection of pesticides. Materials Research, São Carlos, v. 16, n. 3, p. 683-687, jun. 2013.

DiMAio, F. et al. Improved molecular replacement by density-and energy-guided protein structure optimization. Nature, v. 473, p. 540-543, maio 2011.

Dong, G. Q. et al. Optimized atomic statistical potentials: assessment of protein interfaces and loops. Bioinformatics, set. 2013.

Dunker, A. K. et al. Intrinsically disordered protein. J Mol Graph Model, v. 19, p. 26-59, 2001.

EIgler, D. M.; Schweizer, E. K. Positioning single atoms with a scanning tunnelling microscope. Nature, v. 344, n. 6266, p. 524-526, 05 abr. 1990.

EIsenberg, D.; Luthy, R.; Bowie, J. U. VERIFY3D: assessment of protein models with three-dimensional profiles. Methods Enzymol, v. 277, p. 396-404, 1997.

Eswar, N. et al. Comparative protein structure modeling using MODELLER. Curr Protoc Protein Sci, nov. 2007. (v. chapter 2, p. unit 2 9).

Etchegaray, A.; Bueno, C. C.; Teschke, O. Identification of microcistin LR at the molecular level using atomic force microscopy. Química Nova, v. 33, n. 9, p. 1843-1848, jan. 2010.

FAN, H. Virtual ligand screening against comparative models of proteins. In: Ruso, J. M.; Piñero, A. (Ed.). Proteins in solution and at interfaces: methods and applications in biotechnology and materials science. 1. ed. Hoboken: John Wiley \& Sons, 2013. p. 179-192. 
FAn, H.; Mark, A. E. Refinement of homology-based protein structures by molecular dynamics simulation techniques. Protein Sci, v. 13, p. 211-220, jan. 2004.

Ferrara, J. T.; Rosales, M. C.; Basurto, J. C. Homology modeling and blind docking approach studies of pig heart fumarase. 2007. Disponível em: <http://www.redalyc.org/ resumen.oa?id=47551305>. Acesso em: 12 ago. 2014.

FISER, A.; Do, R. K.; ŠALI, A. Modeling of loops in protein structures. Protein Sci, v. 9, p. 1753-1773, set. 2000.

FISER, A.; ŠALI, A. ModLoop: automated modeling of loops in protein structures. Bioinformatics, v. 19, p. 2500-2501, dez. 2003.

Franca, E. F.; Amarante, A. M.; Leite, F. L. Introduction to atomic force microscopy simulation. In: MÉndez-Vilas, A.; Díaz, J. Microscopy: science, technology, applications and education. 1. ed. Badajoz: Formatex Research Center, 2010. v. 2, p. 1338-1349.

FrancA, E. F. et al. Designing an enzyme-based nanobiosensor using molecular modeling techniques. Phys Chem Chem Phys, v. 13, p. 8894-8899, maio 2011.

Friedman, R.; Boye, K.; Flatmark, K. Molecular modelling and simulations in cancer research. Biochim Biophys Acta, v. 1836, n. 1, p. 1-14, ago. 2013.

GARCiA, P. S. et al. A nanobiosensor based on 4-hydroxyphenylpyruvate dioxygenase enzyme for mesotrione detection. IEEE Sensors Journal, v. 15, n. 4, p. 2106-2113, abr. 2015.

García, R.; PÉrez, R. Dynamic atomic force microscopy methods. Surface Science Reports, v. 47, n. 6-8, p. 197-301, set. 2002.

Garrett, R. H.; Grisham, C. M. Biochemistry. 5. ed. Belmont: Cengage Learning, 2013.

GinAlski, K. Comparative modeling for protein structure prediction. Curr Opin Struct Biol, v. 16, p. 172-177, abr. 2006.

Giorgetti, A. et al. Evaluating the usefulness of protein structure models for molecular replacement. Bioinformatics, v. 21, supl. 2, p. ii72-ii76, set. 2005.

GonçAlves, R. B. Modelagem teórica e computacional de dendrímeros para o transporte de tuberculostáticos. Tese de Doutorado. Pontifícia Universidade Católica do Rio de Janeiro, Rio de Janeiro, 2012.

Graber, D. J. et al. Neuromyelitis optica pathogenesis and aquaporin 4. Journal of Neuroinflammation, v. 5, p. 22, 2008.

Griebel, M.; KnAPeK, S.; Zumbusch, G. Numerical simulation in molecular dynamics: numerics, algorithms, parallelization, applications. Heidelberg: Springer, 2007. v. 5.

Gueto, C.; Torres, J.; Vivas-Reyes, R. CoMFA, LeapFrog and blind docking studies on sulfonanilide derivatives acting as selective aromatase expression regulators. European Journal of Medicinal Chemistry, v. 44, n. 9, p. 3445-3451, set. 2009.

Guex, N.; Diemand, A.; Peitsch, M. C. Protein modelling for all. Trends in Biochemical Sciences, v. 24, p. 364-367, 1999. 
Guex, N.; Peitsch, M. C. SWISS-MODEL and the Swiss-PdbViewer: an environment for comparative protein modeling. Electrophoresis, v. 18, p. 2714-2723, dez. 1997.

Guex, N.; Peitsch, M. C.; Schwede, T. Automated comparative protein structure modeling with SWISS-MODEL and Swiss-PdbViewer: a historical perspective. Electrophoresis, v. 30, supl. 1, p. S162-S173, jun. 2009.

HAINING, R. L. et al. Enzymatic determinants of the substrate specificity of CYP2C9: role of B'-C loop residues in providing the pi-stacking anchor site for warfarin binding. Biochemistry, v. 38, p. 3285-3292, mar. 1999.

Halperin, I. et al. Principles of docking: an overview of search algorithms and a guide to scoring functions. Proteins: Structure, Function, and Bioinformatics, v. 47, n. 4, p. 409-443, 01 jun. 2002.

Hanasaki, I.; Haga, T.; Kawano, S. The antigen-antibody unbinding process through steered molecular dynamics of a complex of an Fv fragment and lysozyme. Journal of Physics: Condensed Matter, v. 20, n. 25, 255-238, 25 jun. 2008.

Hermans, R. I. Atomic force microscopy in liquid. In: Bar, A. M.; Reifenberger, R. G. (Ed.). Atomic force microscopy in liquid. [S.l.]: Wiley-VCH, 2012. p. 157-184.

Hetényi, C.; VAn der Spoel, D. Toward prediction of functional protein pockets using blind docking and pocket search algorithms. Protein Science: a Publication of the Protein Society, v. 20, n. 5, p. 880-893, maio 2011.

Heyden, A.; Lin, H.; Truhlar, D. G. Adaptive partitioning in combined quantum mechanical and molecular mechanical calculations of potential energy functions for multiscale simulations. The Journal of Physical Chemistry, B, v. 111, n. 9, p. 2231-2241, 08 mar. 2007.

Higgins, D. G.; SHARP, P. M. CLUSTAL: a package for performing multiple sequence alignment on a microcomputer. Gene, v. 73, p. 237-244, dez. 1988.

Hooft, R. et al. Errors in protein structures. Nature, v. 381, p. 272, 1996.

Hummer, G.; Szabo, A. Free energy reconstruction from nonequilibrium single-molecule pulling experiments. Proceedings of the National Academy of Sciences of the United States of America, v. 98, n. 7, p. 3658-3661, 27 mar. 2001.

Kinetics from nonequilibrium single-molecule pulling experiments. Biophysical Journal, v. 85, n. 1, p. 5-15, jul. 2003.

IsRalewitz, B.; GAO, M.; SCHUlten, K. Steered molecular dynamics and mechanical functions of proteins. Current Opinion in Structural Biology, v. 11, n. 2, p. 224-230, abr. 2001.

Izrailev, S. et al. Steered molecular dynamics. In: Deuflhard, P. et al. (Ed.). Computational molecular dynamics: challenges, methods, ideas. Lecture notes in computational science and engineering. [S.1.]: Springer Berlin Heidelberg, 1999. p. 39-65.

JARZynski, C. Nonequilibrium equality for free energy differences. Phys. Rev. Lett., v. 78, n. 14, p. 2690-2693, 1997a.

. Equilibrium free-energy differences from nonequilibrium measurements: A master-equation approach. Phys. Rev. E, v. 56, n. 5, p. 5018-5035, 1997 b. 
JENSEN, F. Introduction to computational chemistry. 2. ed. [S.l.]: Wiley, 2006.

Jensen, M. O. et al. Energetics of glycerol conduction through aquaglyceroporin GlpF. Proceedings of the National Academy of Sciences of the United States of America, v. 99, n. 10, p. 6731-6736, 14 maio 2002.

JonEs, D. T. Evaluating the potential of using fold-recognition models for molecular replacement. Acta Crystallogr D Biol Crystallogr, v. 57, p. 1428-1434, out. 2001.

Jorgensen, W.; Maxwell, D.; Tiradorives, J. Development and testing of the OPLS all-atom force field on conformational energetics and properties of organic liquids. Journal of the American Chemical Society, v. 118, n. 45, p. 11225-11236, 1996.

Jorgensen, W. L. et al. Comparison of simple potential functions for simulating liquid water. The Journal of Chemical Physics, v. 79, n. 2, p. 926-935, 1983.

Kang, J.; Hagiwara, Y.; Tateno, M. Biological applications of hybrid quantum mechanics/molecular mechanics calculation. BioMed Research International, v. 2012, p. 1-11, 28 mar. 2012.

Karplus, M.; Petsko, G. A. Molecular dynamics simulations in biology. Nature, v. 347, n. 6294, p. 631-639, 18 out. 1990.

Kendrew, J. C. et al. A three-dimensional model of the myoglobin molecule obtained by x-ray analysis. Nature, v. 181, p. 662-668, mar. 1958.

Kessel, A.; Ben-TAL, N. Introduction to proteins: structure, function, and motion. 1. ed. Boca Raton: CRC Press, 2011.

Kinch, L. N.; Grishin, N. V. Evolution of protein structures and functions. Curr Opin Struct Biol, v. 12, p. 400-408, jun. 2002.

Kitchen, D. B. et al. Docking and scoring in virtual screening for drug discovery: methods and applications. Nature reviews. Drug Discovery, v. 3, n. 11, p. 935-949, nov. 2004.

KLein, M. L.; ShinodA, W. Large-scale molecular dynamics simulations of self-assembling systems. Science, v. 321, n. 5890, p. 798-800, 08 ago. 2008.

Kollman, P. Free energy calculations: applications to chemical and biochemical phenomena. Chemical Reviews, v. 93, n. 7, p. 2395-2417, 01 nov. 1993.

Kontoyianni, M. et al. Theoretical and practical considerations in virtual screening: a beaten field? Current Medicinal Chemistry, v. 15, n. 2, p. 107-116, 2008.

Kosztin, D.; Izrailev, S.; Schulten, K. Unbinding of retinoic acid from its receptor studied by steered molecular dynamics. Biophysical Journal, v. 76, p. 188-197, 1999.

Kumar, S.; Filipski, A. Multiple sequence alignment: in pursuit of homologous DNA positions. Genome Res, v. 17, p. 127-135, fev. 2007.

KuRELla, V. B.; Gali, R. Structure guided homology model based design and engineering of mouse antibodies for humanization. Bioinformation, v. 10, n. 4, p. 180-186, 2014.

LARKIN, M. A. et al. Clustal W and clustal X version 2.0. Bioinformatics, v. 23, p. 2947-2948, nov. 2007. 
LAsKOWsKI, R. et al. PROCHECK: a program to check the stereochemical quality of protein structures. Journal of Applied Crystallography, v. 26, p. 283-291, abr. 1993.

LEACH, A. Molecular modelling: principles and applications. 2. ed. [S.1.]: Prentice Hall, 2001. LEE, E. H. et al. Discovery through the computational microscope. Structure, Londres, v. 17, n. 10 , p. $1295-1306,14$ out. 2009.

Leite, F. L.; Hausen, M.; Oliveira, G. S.; Brum, D. G.; Oliveira, O. N. Nanoneurobiophysics: new challenges for diagnosis and therapy of neurologic disorders. Nanomedicine, Londres, v. 10, n. 23, p. 3417-3419, 2015.

Linding, R. et al. Protein disorder prediction: implications for structural proteomics. Structure, v. 11, p. 1453-1459, nov. 2003.

Lipman, D. J.; Pearson, W. R. Rapid and sensitive protein similarity searches. Science, v. 227, p. 1435-1441, mar. 1985.

Lyubchenko, Y. L. et al. Atomic force microscopy of DNA and bacteriophage in air, water and propanol: the role of adhesion forces. Nucleic Acids Research, v. 21, n. 5, p. 1117-1123, 11 mar. 1993.

MA, R. et al. Mutual artificial bee colony algorithm for molecular docking. International Journal of Biomathematics, v. 6, n. 6, p. 1350038-11, set. 2013.

MacKerell, A. D. et al. All-atom empirical potential for molecular modeling and dynamics studies of proteins. Journal of Physical Chemistry, B, v. 102, n. 18, p. 3586-3616, 1998.

Magrane, M.; Consortium, U. UniProt knowledgebase: a hub of integrated protein data. Database, Oxford, v. 2011, p. 1-11, 2011.

MenikarachCHI, L.; GAsCON, J. QM/MM Approaches in medicinal chemistry research. Current Topics in Medicinal Chemistry, v. 10, n. 1, p. 46-54, 01 jan. 2010.

Meyer, E. Atomic force microscopy. Progress in Surface Science, v. 41, n. 1, p. 3-49, set. 1992. Mikulska, K.; PepŁowski, L.; Nowak, W. Nanomechanics of Ig-like domains of human contactin (BIG-2). Journal of Molecular Modeling, v. 17, n. 9, p. 2313-2323, set. 2011.

Morgon, N.; Coutinho, K. Métodos de química teórica e modelagem molecular. 1. ed. São Paulo: Livraria da Física, 2007.

Morris, A. L. et al. Stereochemical quality of protein structure coordinates. Proteins, v. 12, p. 345-364, abr. 1992.

Morris, G. M. et al. Distributed automated docking of flexible ligands to proteins: Parallel applications of AutoDock 2.4. Journal of Computer-Aided Molecular Design, v. 10, n. 4, p. 293-304, 01 ago. 1996.

Mulyanto, C. C. Prediction of a neutralizing epitope of a H5N1 virus hemagglutinin complexed with an antibody variable fragment using molecular dynamics simulation. Journal of Biophysical Chemistry, v. 2, n. 3, p. 258-267, 2011.

Mustard, D.; Ritchie, D. W. Docking essential dynamics eigenstructures. Proteins, v. 60, n. 2, p. 269-274, 01 ago. 2005. 
Myerson, A. S. Molecular modeling applications in crystallization. 1. ed. Nova York: Cambridge University Press, 1999.

Nelson, D. L.; Cox, M. M. Lehninger principles of biochemistry. 5. ed. Nova York: W. H. Freeman and Company, 2008.

Oliveira, G. S. et al. Molecular modeling of enzyme attachment on AFM probes. Journal of Molecular Graphics and Modelling, v. 45, p. 128-136, 2013.

PARK, S. et al. Free energy calculation from steered molecular dynamics simulations using Jarzynski's equality. J. Chem. Phys., v. 119, n. 6, p. 3559-3566, 2003.

PARK, S.; Schulten, K. Calculating potentials of mean force from steered molecular dynamics simulations. The Journal of Chemical Physics, v. 120, n. 13, p. 5946-5961, 01 abr. 2004. Parravicini, C. et al. Forced unbinding of GPR17 ligands from wild type and R255I mutant receptor models through a computational approach. BMC Structural Biology, v. 10, n. 1, p. 8, 16 mar. 2010.

Pearson, W. R. Rapid and sensitive sequence comparison with FASTP and FASTA. Methods Enzymol, v. 183, p. 63-98, 1990.

Searching protein sequence libraries: comparison of the sensitivity and selectivity of the Smith-Waterman and FASTA algorithms. Genomics, v. 11, p. 635-650, nov. 1991.

Pearson, W. R.; Lipman, D. J. Improved tools for biological sequence comparison. Proc Natl Acad Sci USA, v. 85, p. 2444-2448, abr. 1988.

Peitsch, M. C. Protein modeling by e-mail. Nat Biotech, v. 13, p. 658-660, 1995.

. About the use of protein models. Bioinformatics, v. 18, p. 934-938, jul. 2002.

Pharkya, P.; Nikolaev, E. V.; Maranas, C. D. Review of the BRENDA Database. Metab Eng, v. 5, p. 71-73, abr. 2003.

Pruitt, K. D.; TAtusova, T.; Maglott, D. R. NCBI reference sequences (RefSeq): a curated non-redundant sequence database of genomes, transcripts and proteins. Nucleic Acids Res, v. 35, p. D61-D65, jan. 2007.

QIAN, B. et al. High-resolution structure prediction and the crystallographic phase problem. Nature, v. 450, p. 259-264, nov. 2007.

Ramachandran, K. I.; Deepa, G.; Namboori, K. Computational chemistry and molecular modelling: principles and applications. 1. ed. Heidelberg: Springer, 2008.

RAPAPORT, D. C. The art of molecular dynamics simulation. 2. ed. Cambridge: Cambridge University Press, 2004.

RHodes, G. Crystallography made crystal clear: a guide for users of macromolecular models. 3. ed. San Diego: Elsevier, 2006.

ŠAli, A.; Blundell, T. L. Comparative protein modelling by satisfaction of spatial restraints. J Mol Biol, v. 234, p. 779-815, dez. 1993.

SÁNCHEZ, R.; ŠAli, A. Comparative protein structure modeling. In: Webster, D. M. (Ed.). Protein structure prediction: methods and protocols. Nova York: Kluwer, 2000. p. 97-130. 
Santos-Filho, O. A.; Alencastro, R. B. Modelagem de proteínas por homologia. Quím. Nova, v. 26, p. 1-14, mar. 2003.

Schomburg, I. et al. Enzyme data and metabolic information: BRENDA, a resource for research in biology, biochemistry, and medicine. Gene Function \& Disease, v. 1, p. 109-118, out. 2000 .

. BRENDA in 2013: integrated reactions, kinetic data, enzyme function data, improved disease classification: new options and contents in BRENDA. Nucleic Acids Res, v. 41, p. D764-D772, jan. 2013.

Schwede, T. et al. SWISS-MODEL: an automated protein homology-modeling server. Nucleic Acids Res, v. 31, p. 3381-3385, jul. 2003.

SEnN, H. M.; ThIEL, W. QM/MM methods for biomolecular systems. Angewandte Chemie (International ed. in English), v. 48, n. 7, p. 1198-1229, 2009.

$\mathrm{SHIH}$, A. Y. et al. Coarse grained protein-lipid model with application to lipoprotein particles. The Journal of Physical Chemistry, B, v. 110, n. 8, p. 3674-3684, 02 mar. 2006.

SINGH, S. et al. Identification and characterization of novel small-molecule inhibitors against hepatitis delta virus replication by using docking strategies. Hepatitis Monthly, v. 11, n. 10, p. 803-809, 01 out. 2011.

SirCAR, A. Methods for the homology modeling of antibody variable regions. Methods in Molecular Biology, Clifton, v. 857, p. 301-311, 2012.

Smith, C. A.; Rayment, I. Active site comparisons highlight structural similarities between myosin and other P-loop proteins. Biophys J, v. 70, p. 1590-1602, abr. 1996.

Sotomayor, M.; Schulten, K. Single-molecule experiments in vitro and in silico. Science, v. 316, n. 5828, p. 1144-1148, maio 2007.

Suhrer, S. J. et al. Effective techniques for protein structure mining. In: OrRY, A. J. W; Abagyan, R. (Ed.). Homology modeling: methods and protocols. 1. ed. Nova York: Springer, 2012. p. 33-54.

Sutter, E. et al. Scanning tunneling microscopy on epitaxial bilayer graphene on ruthenium (0001). Applied Physics Letters, v. 94, n. 13, p. 133101-1-133101-3, 30 mar. 2009.

TAmayo, J. et al. High-Q dynamic force microscopy in liquid and its application to living cells. Biophysical Journal, v. 81, n. 1, p. 526-537, jul. 2001.

TAPAszTó, L. et al. Tailoring the atomic structure of graphene nanoribbons by scanning tunnelling microscope lithography. Nature Nanotechnology, v. 3, n. 7, p. 397-401, jul. 2008.

Thompson, J. D.; Higgins, D. G.; Gibson, T. J. CLUSTAL W: improving the sensitivity of progressive multiple sequence alignment through sequence weighting, position-specific gap penalties and weight matrix choice. Nucleic Acids Res, v. 22, p. 4673-4680, nov. 1994.

Tress, M. et al. Assessment of predictions submitted for the CASP6 comparative modeling category. Proteins, v. 61, supl. 7, p. 27-45, 2005. 
Trotт, O.; Olson, A. J. Software news and update AutoDock Vina: improving the speed and accuracy of docking with a new scoring function, efficient optimization, and multithreading. Journal of Computational Chemistry, v. 31, n. 2, p. 455-461, 30 jan. 2010.

VAN der Kamp, M. W.; Mulholland, A. J. Combined quantum mechanics/molecular mechanics (QM/MM) methods in computational enzymology. Biochemistry, v. 52, p. 27082728, abr. 2013.

Van Gunsteren, W. F.; King, P. M.; Mark, A. E. Fundamentals of drug design from a biophysical viewpoint. Quarterly Reviews of Biophysics, v. 27, n. 4, p. 435-481, 1994.

Venclovas, C. Methods for sequence-structure alignment. In: Orry, A. J. W.; Abagyan, R. (Ed.). Homology modeling: methods and protocols. 1. ed. Nova York: Springer, 2012. p. 55-82.

Venselaar, H.; Krieger, E.; Vriend, G. Homology modeling. In: Gu, J.; Bourne, P. E. (Ed.). Structural bioinformatics. 2. ed. Hoboken: John Wiley \& Sons, 2009. p. 715-732.

VenselaAR, H. et al. Homology modelling and spectroscopy, a never-ending love story. Eur Biophys J, v. 39, p. 551-563, mar. 2010.

Voet, D.; Voet, J. G. Biochemistry. 4. ed. Kendallville: Wiley, 2011.

Vreven, T. et al. Combining quantum mechanics methods with molecular mechanics methods in ONIOM. Journal of Chemical Theory and Computation, v. 2, n. 3, p. 815-826, maio 2006.

Vyas, V. K. et al. Homology modeling a fast tool for drug discovery: current perspectives. Indian J Pharm Sci, v. 74, p. 1-17, jan. 2012.

Wooley, J. C.; Lin, H. S. Catalyzing inquiry at the interface of computing and biology. 1. ed. Washington, D.C.: The National Academies Press, 2005.

XIANG, Z. Advances in homology protein structure modeling. Curr Protein Pept Sci, v. 7, p. 217-27, jun. 2006.

Xu, Y.; Xu, D.; LIANG, J. Computational methods for protein structure prediction and modeling. 1. ed. Nova York: Springer, 2007. v. 2.

YUAN, M. et al. Computer-aided molecular modeling study on antibody recognition of small molecules: an immunoassay for triazine herbicides. Journal of Agricultural and Food Chemistry, v. 60, n. 42, p. 10486-10493, out. 2012.

ZHANG, D. et al. A novel antibody humanization method based on epitopes scanning and molecular dynamics simulation. PLoS ONE, v. 8, n. 11, p. 1-10, 21 nov. 2013.

ZHANG, Y. Progress and challenges in protein structure prediction. Curr Opin Struct Biol, v. 18, p. 342-348, jun. 2008.

Protein structure prediction: when is it useful? Curr Opin Struct Biol, v. 19, p. 145155, abr. 2009.

Zsoldos, Z. et al. eHiTS: an innovative approach to the docking and scoring function problems. Current Protein \& Peptide Science, v. 7, n. 5, p. 421-435, out. 2006. 


\section{MODELAGEM COMPUTACIONAL DE LÍQUIDOS IÔNICOS}
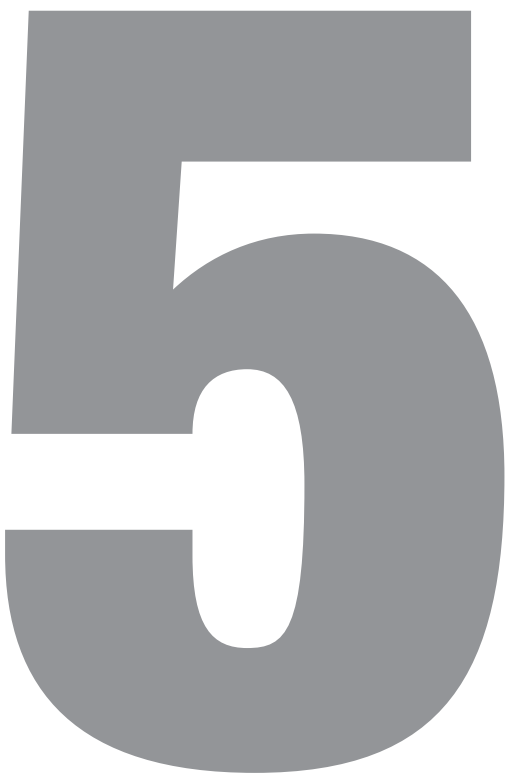

Luciano T. Costa $^{1}$ e Eudes Eterno Fileti ${ }^{2}$

1 Instituto de Química do Departamento de Físico-Química da Universidade Federal Fluminense (UFF), Niterói-RJ. E-mail: $<$ ltcosta@id.uff.br>.

2 Instituto de Ciência e Tecnologia da Universidade Federal de São Paulo (Unifesp), São José dos Campos-SP. E-mail: $<$ fileti@iq.usp>. 


\subsection{INTRODUÇã̃ $0^{3}$}

Líquidos iônicos (LIs) consistem em uma classe de solventes com propriedades ajustáveis e têm sido amplamente utilizados como substituto "verde" para solventes orgânicos tóxicos, perigosos, inflamáveis e altamente voláteis. ${ }^{4}$ De fato, as potenciais aplicações técnicas e comerciais de LIs estão principalmente ligadas às suas propriedades físico-químicas únicas, como baixa pressão de vapor, múltiplas interações de solvatação com compostos orgânicos e inorgânicos, ${ }^{5}$ excelente estabilidade química e térmica, ${ }^{6}$ relativa condutividade iônica e ampla janela eletroquímica. ${ }^{7}$ Além disso, propriedades como viscosidade, hidrofobicidade, densidade e solubilidade podem ser ajustadas, escolhendo diferentes combinações de cátions e ânions, para adequar o LI a exigências específicas. Tais características conferem aos LIs a capacidade de serem moldáveis, com potenciais aplicações científicas e tecnológicas. ${ }^{8}$

Ao longo da última década, os LIs apresentaram enorme potencial como (co) solventes e/ou reagentes em uma ampla gama de aplicações, incluindo a Engenharia Química (separação, extração e membranas), ${ }^{9}$ Química (síntese orgânica, reações catalíticas, síntese de nanomateriais e reações de polimerização), ${ }^{10}$ conversão de energia (baterias, células de combustível e armazenamento de calor), ${ }^{11}$ biotecnologia

Os autores agradecem ao suporte das agências de amparo à pesquisa CNPq e FAPESP. Brooks (2014), Mohammad e Inamuddin (2014), Weingärtner (2008), Reichardt (2005), Feng et al. (2010).

Weingärtner (2008), Reichardt (2005), Feng et al. (2010).

Weingärtner (2008), Reichardt (2005), Feng et al. (2010).

Brooks (2014), Mohammad e Inamuddin (2014), Weingärtner (2008), Reichardt (2005), Feng et al. (2010).

Hywel et al. (2014), Vishal Govind et al. (2013), McCrary et al. (2013), Azevedo et al. (2013).

Rao et al. (2013).

0 Brooks (2014), Mohammad e Inamuddin (2014).

11 Brooks (2014), Mohammad e Inamuddin (2014). 
(biocatálise, purificação de biomoléculas e produção de biocombustíveis) ${ }^{12}$ e ciências farmacêuticas (pró-drogas, transporte de drogas e solubilização). ${ }^{13}$

Do ponto de vista molecular e estrutural, os líquidos iônicos são compostos de cátions orgânicos de baixa simetria e ânions orgânicos ou inorgânicos de alta simetria. A primeira geração de líquidos iônicos, proposta no início da década de 1970 e meados de 1980, apresenta uma gama de possíveis compostos constituídos, em geral, por um cátion orgânico e um ânion inorgânico, tendo aplicações industriais relevantes: dispositivos eletroquímicos, como capacitores, solventes em síntese orgânica, aditivos em lubrificantes, entre outros. Propriedades físicas, como viscosidade, condutividade e densidade, têm sido alvo de investigação para esses compostos. ${ }^{14}$ Uma segunda geração permitiu o modelamento de propriedades químicas e físicas por meio da substituição de um ânion inorgânico por uma classe de ânions orgânicos funcionais ou pela substituição do cátion, promovendo características diferenciadas quanto à solvatação, à hidrofobicidade e à indução quiral. ${ }^{15}$ Recentemente, uma terceira geração de líquidos iônicos tem sido proposta, em que propriedades de interesse biológico podem ser modeladas com a proposição de novos cátions e ânions biocompatíveis, bioativos e não tóxicos, sendo compostas de líquidos iônicos com funcionalidade específica. ${ }^{16} \mathrm{~A}$ evolução dessas gerações revela a capacidade de racionalizar e planejar novos líquidos iônicos com base no conhecimento estrutural, termodinâmico e dinâmico desses compostos. ${ }^{17}$

Como exemplo, a forma e o tamanho do cátion, bem como sua assimetria, são responsáveis pela redução da temperatura de fusão dos líquidos iônicos, que é, por definição, abaixo de $100^{\circ} \mathrm{C}$. Além disso, cátions de baixa simetria possuem um empacotamento íon-íon menos eficiente, diminuindo a energia de rede e, portanto, o ponto de fusão. Um exemplo típico de cátions com essa característica são os do tipo alquilimidazólio. O tamanho e a forma dos cátions também são relevantes na determinação do ponto de fusão de líquidos iônicos; em geral, íons grandes provocam redução no ponto de fusão. Por outro lado, ânions são estruturas orgânicas ou inorgânicas menores que os cátions e geralmente são responsáveis pelas propriedades físicas do líquido. Esses ânions possuem carga negativa difusa, como o $\left[\mathrm{BF}_{4}\right]^{-} \mathrm{e}$ $\mathrm{o}\left[\mathrm{PF}_{6}\right]^{-}$, por exemplo. Com o aumento do tamanho do ânion, em geral, observa-se uma redução no ponto de fusão. Na Figura 5.1 apresenta-se a estrutura de alguns pares iônicos que constituem os líquidos iônicos mais convencionais.

Por outro lado, constata-se o uso da simulação computacional no auxílio a técnicas experimentais, a técnica preditiva, capaz de prever comportamentos, bem como propriedades físico-químicas. De fato, estudos revelam que a funcionalização de líquidos iônicos promove uma modulação de suas propriedades, derivadas dos

2 Rao et al. (2013), Huiyong et al. (2013).

13 Cojocaru et al. (2013), Suruchi et al. (2012), Stoimenovski et al. (2012), Bica et al. (2012).

14 Pádua et al. (2007), Greaves et al. (2006).

15 Welton (1999), Huddleston et al. (1998).

16 Hough et al. (2007).

17 Id. ibid. 
grupos funcionais substituintes, como éter, éster, álcool, amina etc. Como exemplo, recente estudo mostra que o grupo éter inserido na cadeia do cátion imidazólio diminui a viscosidade do líquido e aumenta a condutividade iônica dos eletrólitos. ${ }^{18}$

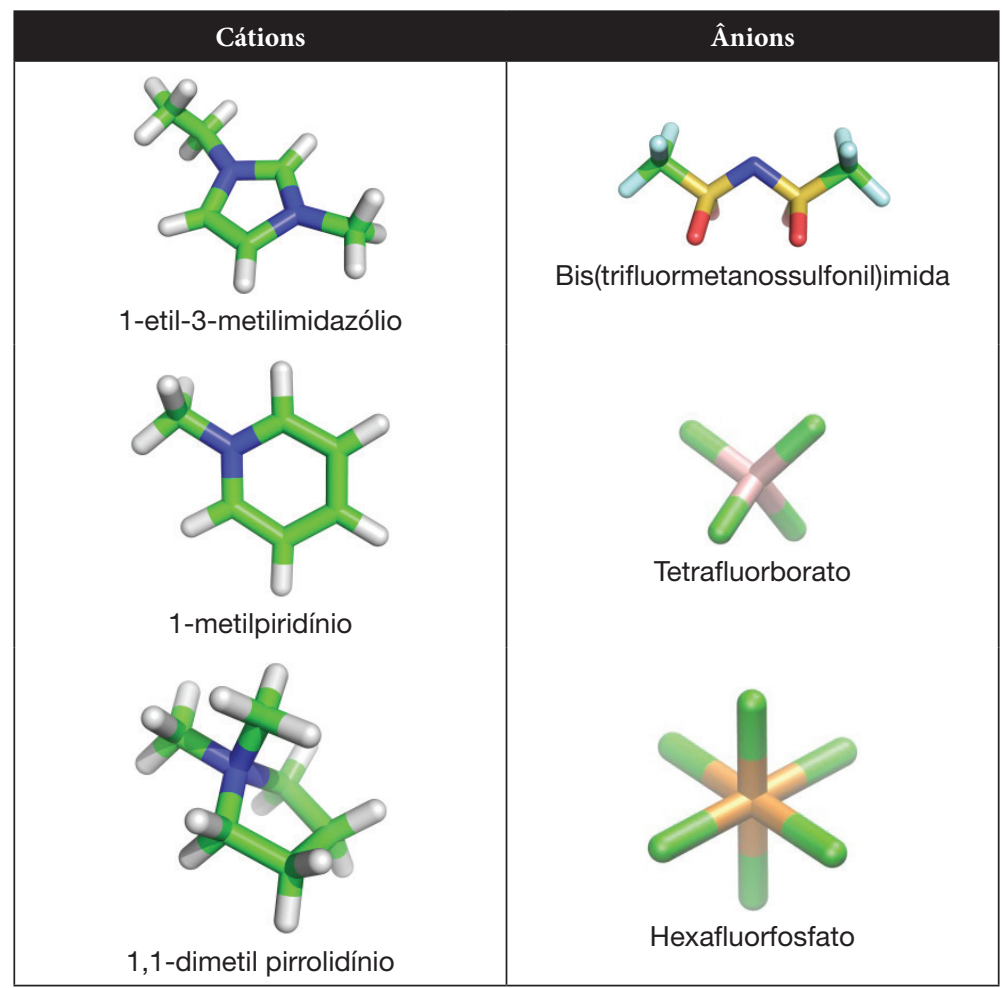

Figura 5.1 Modelos moleculares para alguns cátions e ânions mais empregados em simulação computacional de líquidos iônicos.

\subsection{Metodologias computacionais}

Nesta seção apresentar-se-á uma visão geral sobre duas das mais importantes abordagens computacionais para o estudo da matéria desordenada, em especial dos líquidos iônicos: a dinâmica molecular atomística e a dinâmica molecular coarse-grained. 


\subsection{DinÂMICA MOLECULAR ATOMÍSTICA}

Simulações computacionais têm sido, nas últimas décadas, ferramenta poderosa para tal estudo, especialmente quando se consideram escalas de tempo e de tamanho dos múltiplos processos associados à química supramolecular. ${ }^{19} \mathrm{~A}$ produção de configurações moleculares via dinâmica molecular é obtida por meio da solução das equações de Newton para cada uma das moléculas do sistema, a partir das posições e velocidades iniciais e do conhecimento da força que atua em cada molécula, em um determinado instante. ${ }^{20}$ Calculam-se, assim, as posições e velocidades de cada molécula ao fim de intervalos de tempo sucessivos, ou seja, obtém-se a evolução temporal do sistema. As forças que atuam na molécula i podem ser obtidas por meio de: ${ }^{21}$

$$
\mathrm{F}=-\frac{\mathrm{dU}(\mathrm{r})}{\mathrm{dr}}=-\mathrm{m}_{\mathrm{i}} \frac{\mathrm{d}^{2} \mathrm{r}_{\mathrm{i}}}{\mathrm{dt}^{2}}
$$

em que $U(\boldsymbol{r})$ é a energia potencial total das interações entre as moléculas de massa mi e que depende apenas do módulo $r$ da distância entre elas. Frequentemente, basta escolher uma forma simples de $U(\boldsymbol{r})$.

A energia potencial é considerada o fator mais importante da simulação, pois a modelagem das interações entre as moléculas depende necessariamente da escolha de um modelo adequado para a descrição da energia potencial. A forma analítica da energia potencial consiste em um conjunto de parâmetros que são característicos do sistema atômico-molecular que está sendo simulado e que são denominados campos de força empíricos. ${ }^{22}$

Campos de força descrevem a energia total de um sistema em função das contribuições das interações intramoleculares (interações ligadas) e intermoleculares (interações não ligadas). As interações intramoleculares compreendem, basicamente, o estiramento de ligações químicas, as deformações angulares e os termos torcionais, enquanto as interações intermoleculares são interações de Van der Waals e coulombianas. ${ }^{23}$ No caso das interações ligadas, são utilizadas aproximações de potencial de interação harmônico. Para a escolha do método clássico, é possível

19 Srivastava e Voth (2013), Voth (2012), Barone (2011), Schmid (2010), Sansom et al. (2010), Shim e Kim (2009), Senn e Thiel (2009), Hwang et al. (2006, 2009), Ekkabut et al. (2008), Wang et al. (2007), Marrink et al. (2007), Lyynden-Bell et al. (2007), Ariga e Kunitake (2006).

20 Allen e Tildesley (1987), Leach (2001), Rapaport (1995).

21 Allen e Tildesley (1987), Leach (2001), Rapaport (1995).

22 Allen e Tildesley (1987), Leach (2001), Rapaport (1995).

23 Allen e Tildesley (1987), Leach (2001), Rapaport (1995). 
considerar uma série de campos de força disponíveis. Entre os exemplos mais populares estão os campos AMBER, ${ }^{24} \mathrm{CHARMM}^{25} \mathrm{GROMOS}^{26}$ e OPLS-AA. ${ }^{27}$

Tabela 5.1 Formas analíticas do campo de força para descrição das interações ligadas e não ligadas.

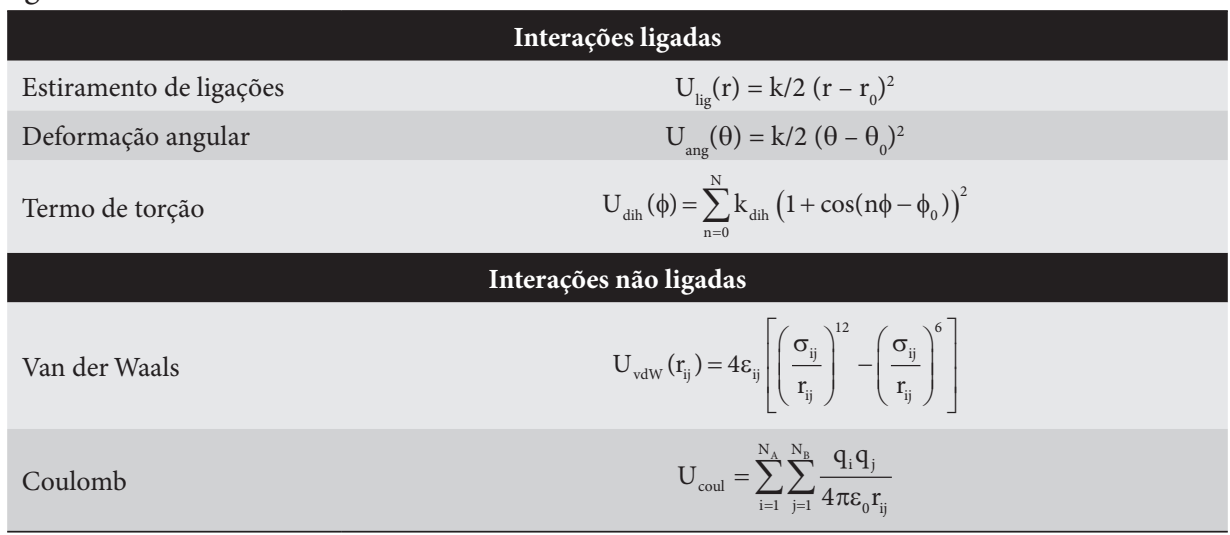

\subsection{CÁLCULO DE PROPRIEDADES}

Em geral, com exceção das fontes originais de livros altamente especializados, não é comum o leitor se deparar com o estado da arte sobre o cálculo de propriedades em dinâmica molecular. A proposta aqui é apresentar ao leitor uma descrição sumarizada da teoria que está por trás dos cálculos, cujos detalhes poderão ser acompanhados na literatura da área. ${ }^{28}$

\subsubsection{Estruturais}

A estrutura de líquidos pode ser analisada pela função de distribuição de pares de partículas i-j (átomos, moléculas ou íons) do sistema, $g(r):^{29}$

$$
g(r)=\rho^{-2}\left\langle\sum_{i} \sum_{i \neq j} \delta\left(r_{i}\right) \delta\left(r_{j}-r\right)\right\rangle=\frac{V}{N^{2}}\left\langle\sum_{i} \sum_{i \neq j} \delta\left(r-r_{i j}\right)\right\rangle
$$

\footnotetext{
Case et al. (2008).

MacKerell et al. (1998).

Soares et al. (2005).

Jorgensen et al. (1996).

Soares et al. (2005), Jorgensen et al. (1996), March e Tosi (1976).

Allen e Tildesley (1987), Sadus (1999), Hansen e McDonald (1990).
} 
em que $\mathrm{V}$ é o volume da caixa de simulação e $\mathrm{N}$ e $\mathbf{r}$ são o número e a posição das partículas, respectivamente. $O$ símbolo $\delta$ define a função delta de Dirac. ${ }^{30} \mathrm{~A}$ função $\mathrm{g}(\mathbf{r})$ contabiliza a densidade local de ocorrência de vizinhos $\mathrm{j}$ em torno de uma partícula i, normalizada pela densidade bulk do sistema. A Figura 5.2(A) ilustra a estrutura de um líquido monoatômico. Pode-se representar essa probabilidade por meio de um gráfico de ocorrências em que a partícula i está localizada na origem (em vermelho, na Figura 5.2), em que o eixo x define a distância $r$ entre uma dada partícula j de sua vizinha i, como mostra a figura. É importante lembrar que a função de distribuição radial de pares pode ser obtida de experimentos de difração de raio-X e espalhamento de nêutrons. ${ }^{31}$
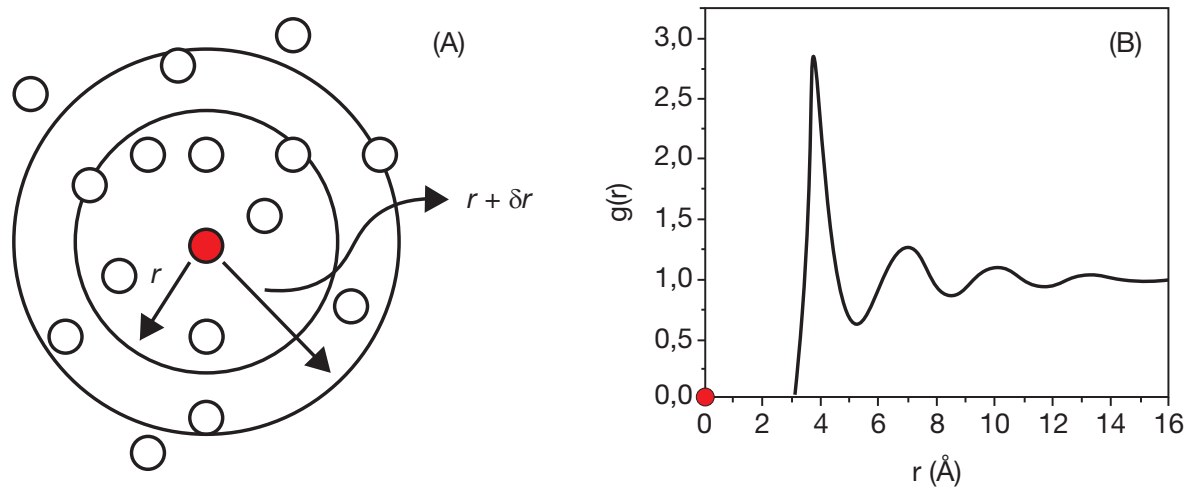

Figura 5.2 Representação de um líquido atômico, em que as esferas ilustram as partículas ou átomos do sistema e os círculos, as camadas (A). A distância $r$ define o raio da primeira camada de vizinhos, enquanto $\delta$ r é definido pela distância entre duas camadas consecutivas. A esfera no centro representa uma partícula i, e todas as outras, a vizinhança j. Ao lado, a g(r) correspondente (B).

Na Figura 5.2(B), o primeiro pico revela a distância de primeiros vizinhos j em torno da partícula i, como ilustrado na Figura 5.2(A). Outra ferramenta usada na caracterização estrutural e que ajuda a construir uma imagem da vizinhança local em torno de determinada espécie é o mapa de densidade de probabilidade. ${ }^{32}$ Essa análise é definida pela probabilidade de ocorrência de determinada espécie em torno de uma molécula de referência. Faz-se uma seleção de vizinhos em torno da molécula de referência, para a distância de primeiros vizinhos na $\mathrm{g}(\mathbf{r})$, salvando suas coordenadas $(\mathrm{x}, \mathrm{y}, \mathrm{z})$ e, dessa forma, construindo um mapa de densidade ao redor de uma dada partícula $\mathrm{i}$.

30 Hansen e McDonald (1990).

31 Hansen e McDonald (1990), Elliott (1952), March e Tosi (1976).

32 Urahata e Ribeiro (2004). 
A função $g(\mathbf{r})$ expressa a correlação de densidade local de equilíbrio. A densidade local em um ponto $r$ no espaço é expressa por: ${ }^{33}$

$$
\rho(r)=\sum_{i=1}^{N} \delta\left(r-r_{i j}\right)
$$

em que $\mathbf{r}$ é o vetor posição da partícula. Experimentalmente, obtém-se o fator de estrutura estático, $S(k)$, por espectroscopia de espalhamento de nêutrons e, a partir de sua transformada de Fourier, calcula-se a $g(\mathbf{r})$. Portanto, a densidade em termos do vetor de onda $\mathbf{k}$ é a transformada de Fourier da equação anterior: ${ }^{34}$

$$
\rho_{k}=\sum_{i=1}^{N} e^{-i k \cdot r_{i}}
$$

e a correlação de densidades no espaço recíproco, o fator de estrutura estático, a transformada de Fourier espacial da $g(\mathbf{r}):^{35}$

$$
\mathrm{S}(\mathrm{k})=\frac{1}{\mathrm{~N}}\left\langle\rho_{\mathrm{k}} \rho_{-\mathrm{k}}\right\rangle=\frac{1}{\mathrm{~N}}\left\langle\sum_{\mathrm{i}} \sum_{\mathrm{j}} \mathrm{e}^{-\mathrm{ik} \cdot\left(\mathrm{r}_{\mathrm{i}}-\mathrm{r}_{\mathrm{j}}\right)}\right\rangle
$$

em que $\boldsymbol{k}$ define o vetor de onda no espaço recíproco. O fator de estrutura estático é importante por facilitar a observação de correlação entre partículas em uma escala espacial mais estendida ou intermediária (intermediate range order, IRO), sendo expresso por um pré-pico em vetor de onda pequeno. A função $S(\boldsymbol{k})$ parcial pode ser definida pela equação: ${ }^{36}$

$$
\mathrm{S}(\mathrm{k})=\frac{1}{\sqrt{\mathrm{N}_{\alpha} \mathrm{N}_{\beta}}}\left\langle\sum_{\mathrm{i} \in \alpha}^{\mathrm{N}_{\alpha}} \sum_{\mathrm{i} \in \beta}^{\mathrm{N}_{\alpha}} \mathrm{e}^{-\mathrm{ik} \cdot\left(\mathrm{r}_{\mathrm{i}}-\mathrm{r}_{\mathrm{j}}\right)}\right\rangle
$$

em que $\alpha$ e $\beta$ representam espécies diferentes.

\subsubsection{Dinâmicas}

O avanço da mecânica estatística de não equilíbrio, na década de 1950, com os trabalhos realizados por Green e Kubo sobre fenômenos de transporte, deu início à formulação de funções de correlação na descrição de muitos processos dependentes do tempo. ${ }^{37}$ Assim, um microestado do sistema no espaço de fase pode ser definido

33 Hansen e McDonald (1990).

34 Id. ibid.

35 Id. ibid.

36 Id. ibid.

37 McQuarrie (2000). 
pela coordenada $\mathbf{r}$ e momentum p. Pode-se escrever, portanto, que a evolução no tempo se torna: ${ }^{38}$

$$
\begin{aligned}
& \mathrm{p}(\mathrm{t})=\mathrm{p}(\mathrm{p}, \mathrm{r} ; \mathrm{t}) \\
& \mathrm{r}(\mathrm{t})=\mathrm{r}(\mathrm{p}, \mathrm{r} ; \mathrm{t})
\end{aligned}
$$

Se for considerado que $\mathrm{A}\{\mathrm{p}(\mathrm{t}), \mathrm{r}(\mathrm{t})\}$ é função das coordenadas no espaço de fase, pode-se definir que: ${ }^{39}$

$$
\mathrm{A}\{\mathrm{p}(\mathrm{t}), \mathrm{r}(\mathrm{t})\}=\mathrm{A}\{\mathrm{p}, \mathrm{r} ; \mathrm{t}\}=\mathrm{A}(\mathrm{t})
$$

em que $A(t)$ define qualquer propriedade dependente do tempo para um dado sistema. Dessa forma, a função de correlação no tempo clássica de $A(t)$ pode ser definida por: ${ }^{40}$

$$
\mathrm{C}_{\mathrm{A}}(\mathrm{t})=\left\langle\sum_{\mathrm{i}=1}^{\mathrm{N}} \mathrm{A}_{\mathrm{i}}(\mathrm{t}) \mathrm{A}_{\mathrm{i}}(0)\right\rangle
$$

em que $\langle\ldots\rangle$ significa a média; $A_{\mathrm{i}}(t)$, o valor da propriedade $A$ em determinado tempo $t ; A_{\mathrm{i}}(0)$, o valor de $A$ em diferentes origens de tempo. Se $A(t)$ é uma função vetorial, a equação anterior se torna: ${ }^{41}$

$$
C_{A}(t)=\left\langle\sum_{i=1}^{N} A_{i}(t) \cdot A_{i}(0)\right\rangle
$$

Para sistemas como líquidos iônicos, está-se interessado em funções de correlação no tempo de propriedades, como velocidade das partículas i do sistema, orientação de vetores no espaço (função de correlação reorientacional), transições de ângulos diedros, entre outras. Por exemplo, a equação acima, em termos da velocidade de uma dada partícula $i$ do sistema, pode ser escrita como: ${ }^{42}$

$$
\mathrm{C}_{\mathrm{v}}(\mathrm{t})=\left\langle\mathrm{v}_{\mathrm{i}}(\mathrm{t}) \cdot \mathrm{v}_{\mathrm{i}}(0)\right\rangle
$$

em que, nesse caso, $C_{\mathrm{v}}(t)$ é conhecida como função de autocorrelação (ACF) da velocidade. A partir dessa função, é possível calcular o coeficiente de difusão, $D$, para uma dada partícula i, por meio da relação de Green-Kubo, em que: ${ }^{43}$

43 Hansen e McDonald (1990), McQuarrie (2000).
} 


$$
\mathrm{D}=\frac{1}{3} \int_{0}^{\infty}\left\langle\mathrm{v}_{\mathrm{i}}(\mathrm{t}) \cdot \mathrm{v}_{\mathrm{i}}(0)\right\rangle \mathrm{dt}
$$

O coeficiente de difusão pode ser obtido a partir da relação de Einstein, em que o deslocamento quadrático médio das partículas é definido por: ${ }^{44}$

$$
6 \mathrm{tD}=\left\langle\left|\mathrm{r}_{\mathrm{i}}(\mathrm{t})-\mathrm{r}_{\mathrm{i}}(0)\right|^{2}\right\rangle
$$

Essa função contém o autotermo do deslocamento de cada partícula $i$ do sistema em um dado tempo $t$. Os brackets denotam uma média no conjunto, que, em MD, significa uma média sobre todas as partículas $i$ e origens no tempo. Outra propriedade de transporte que pode ser calculada é a condutividade, também propriedade dos deslocamentos dos íons no sistema. Contudo, é uma propriedade coletiva de todos os íons, e, portanto, os termos cruzados devem ser contabilizados: ${ }^{45}$

$$
\kappa=\lim _{t \rightarrow \infty} \frac{e^{2}}{6 \mathrm{tVk}_{\mathrm{B}} \mathrm{T}}\left\langle\sum_{\mathrm{i}} \sum_{\mathrm{j}} \mathrm{z}_{\mathrm{i}} \mathrm{z}_{\mathrm{j}}\left[\mathrm{r}_{\mathrm{i}}(\mathrm{t})-\mathrm{r}_{\mathrm{i}}(0)\right]\left[\mathrm{r}_{\mathrm{j}}(\mathrm{t})-\mathrm{r}_{\mathrm{j}}(0)\right]\right\rangle
$$

em que $V$ é o volume; $k_{\mathrm{b}}$, a constante de Boltzmann; $T$, a temperatura; $e$, a carga do elétron; $z_{\mathrm{i}}$, a carga formal do íon $i$. Pode-se também, pela relação de Nernst-Einstein, estimar a condutividade do sistema por meio do coeficiente de difusão calculado pela equação acima:

$$
\mathrm{k}^{\mathrm{NE}}=\frac{\mathrm{e}^{2}}{\mathrm{k}_{\mathrm{B}} \mathrm{T}}\left(\rho_{-} \mathrm{z}_{-}^{2} \mathrm{D}_{-}+\rho_{+} \mathrm{z}_{+}^{2} \mathrm{D}_{+}\right)
$$

em que $\rho_{-}$e $p_{+}$são definidos como a densidade dos ânions e cátions na caixa de simulação; $z_{-}$e $z_{+}$, a carga formal dessas espécies; e $D_{-}$e $D_{+}$, os coeficientes de difusão de ânions e cátions, respectivamente. A razão $\kappa / \kappa_{\mathrm{NE}}$ é indicativa da formação de par iônico, revelando a importância da correlação de termos cruzados na dinâmica iônica.

Para ilustrar essas propriedades dinâmicas em sistemas contendo líquido iônico, têm sido aplicadas simulações MD em eletrólitos poliméricos derivados de líquidos iônicos com base no polímero polioxietileno (POE) ou poli(óxido de etileno), PEO, e ILs derivados do cátion imidazólio. ${ }^{46}$ De forma geral, simulações MD com potenciais não polarizáveis para ILs reportam propriedades dinâmicas, uma ordem de grandeza menor que dados experimentais. Por exemplo, a condutividade calculada do LI puro é de $3.2 \times 10^{-3}{\mathrm{~S} . \mathrm{cm}^{-1}}^{\text {, a }} 400 \mathrm{~K}$, enquanto o valor experimental é de $1.7 \times 10^{-2} \mathrm{~S} \mathrm{~cm}^{-1}$, a 373 K. Outras simulações MD reportam a mesma diferença entre condutividades calculada

44 McQuarrie (2000).

45 Hansen e McDonald (1990).

46 Siqueira e Ribeiro (2006), Costa e Ribeiro (2006). 
e experimental, ${ }^{47}$ por exemplo, em POE- $\mathrm{LiClO}_{4}$, cuja condutividade é uma ordem de grandeza menor em relação aos dados experimentais, comportamento similar ao encontrado em simulações MD para o sistema POE-LiI. Ainda assim, pode-se afirmar que esses resultados mostram modelos coerentes e transferíveis, já que foram utilizados em trabalhos anteriores realizados por Urahata e Siqueira. ${ }^{48}$

De forma a sintetizar a dinâmica de LIs em diferentes escalas de tempo, a Figura 5.3 mostra uma perspectiva em escala temporal das várias dinâmicas que ocorrem no sistema, evidenciando uma hierarquia dos processos dinâmicos do LI inserido na matriz polimérica. A rápida relaxação do grupo butil e oscilações na $\mathrm{C}_{\mathrm{v}}(\mathrm{t})$ ocorrem em escala de subpicossegundos, enquanto MSD e a $\mathrm{Cr}(\mathrm{t})$ ainda estão em um primeiro estágio de relaxação, dado por movimentos do tipo rattling e libracionais. O resultado mostrado na Figura 5.2 está em concordância com resultados anteriormente previstos na dinâmica de líquidos iônicos ${ }^{49} \mathrm{e}$ em correlação com a proposição de que, em transições de fase a partir da fase cristalina de LI, distintos graus de liberdade são ativados durante o processo de relaxação estrutural. Uma descrição em detalhe desses processos dinâmicos em líquidos iônicos derivados do cátion imidazólio pode ser vista na literatura. ${ }^{50}$
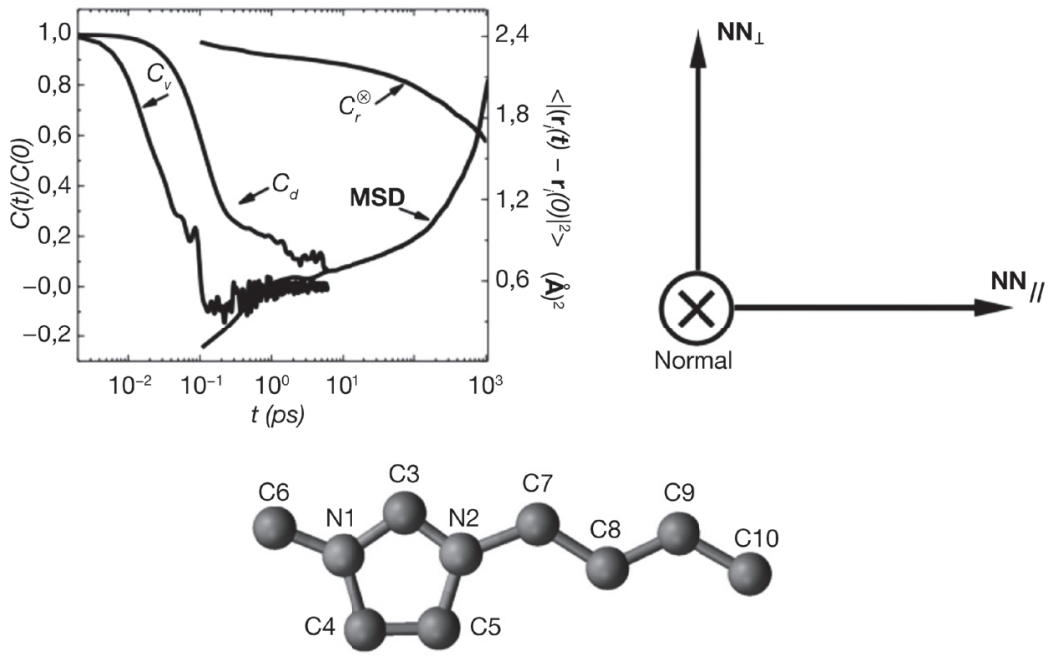

Figura 5.3 Comparação de algumas funções de correlação no tempo do cátion [bmim $]^{+}$no $\mathrm{P}(\mathrm{OE})_{8}$ - $[\mathrm{bmim}] \mathrm{PF}_{6}$. A figura mostra as ACFs de velocidade do centro de massa do cátion, $C_{\mathrm{v}}(t)$, do ângulo diedro da cadeia 1-butil, $C_{\mathrm{d}}(t)$, a projeção reorientacional normal ao plano do anel, $\mathrm{C}_{r}^{\otimes}$, e o MSD do centro de massa do cátion. Note que a escala do MSD está à direita, na figura.

\footnotetext{
Siqueira e Ribeiro (2006), Duan et al. (2005), Borodin e Smith (2006a, 2006b, 2006c).

Urahata e Ribeiro (2004, 2005), Siqueira e Ribeiro (2006).

Urahata e Ribeiro (2005, figura 11).

Id. $(2005,2006)$.
} 


\subsection{DINÂMICA MOLECULAR COARSE-GRAINED}

Apesar dos avanços computacionais, as simulações atomísticas ainda são limitadas a sistemas de tamanho reduzido em escala de tempo reduzida. Os processos celulares, no entanto, cobrem escalas de tempo de nanossegundos a segundos e envolvem centenas de diferentes moléculas que interagem em diferentes escalas de tamanho. Muitos fenômenos biologicamente interessantes, incluindo fusão de vesículas, formação de complexos de proteína de ordem mais elevada, enovelamento de proteínas e transdução de sinal, estão além da capacidade das simulações atomísticas. Para simular esses processos é necessária uma simplificação do modelo.

A utilização de modelos coarse-grained (CG) representa uma alternativa atraente comparada com modelos atomísticos, permitindo que simulações sejam executadas para sistemas maiores, em escalas de tempo mais longas, e ainda fornece detalhes estruturais realísticos. ${ }^{51}$ As funções analíticas para o campo de força atomístico e coarse-grained são exatamente as mesmas. O que difere nos dois campos são os parâmetros do potencial. Dinâmica molecular coarse-grained (DCG) é uma técnica de simulação relativamente recente e foi desenvolvida especificamente para modelar sistemas orgânicos de grande porte, na escala de tempo experimental. ${ }^{52} \mathrm{O}$ foco principal na DCG está nas interações que envolvem grandes deformações ou rearranjos de sistemas supramoleculares. Na DCG, agrupamentos de átomos são substituídos por um sítio interagente que tem a dimensão aproximada de quatro átomos pesados e interage com os sítios vizinhos ligados por interações tipo massa-mola, com constantes de força brandas que imitam o movimento da estrutura molecular. O uso dos sítios CG diminui os graus de liberdade do sistema, minimizando drasticamente, assim, o tempo computacional, em comparação com a dinâmica atomística. ${ }^{53}$ Além de diminuir o tempo por meio da redução do número de sítios de interação, conforme Figura 5.4, a DCG também permite aumentar o time step por uma ordem de grandeza, de forma que, no total, a DCG alcança duas ordens de grandeza a mais que a dinâmica atomística, permitindo, assim, que a DCG possa ser aplicada na investigação de problemas mais realísticos envolvendo materiais supramoleculares de amplo interesse biomédico e biotecnológico, como, por exemplo, problemas envolvendo membranas biomoleculares. ${ }^{54}$

Apesar da vasta aplicabilidade da dinâmica molecular, alguns fenômenos físico-químicos importantes não podem ser tratados diretamente por essa técnica. Entre esses fenômenos estão a quebra e a formação de ligações químicas, o que inviabiliza qualquer tentativa de estudo de reações químicas e efeitos quânticos de tunelamento.

51 Srivastava e Voth (2013), Voth (2012), Wang et al. (2007), Marrink et al. (2007), Barnoud et al. (2014).

52 Marrink et al. (2007).

53 Id. ibid.

54 Voth (2012), Hwang et al. (2009), Barnoud et al. (2014). 

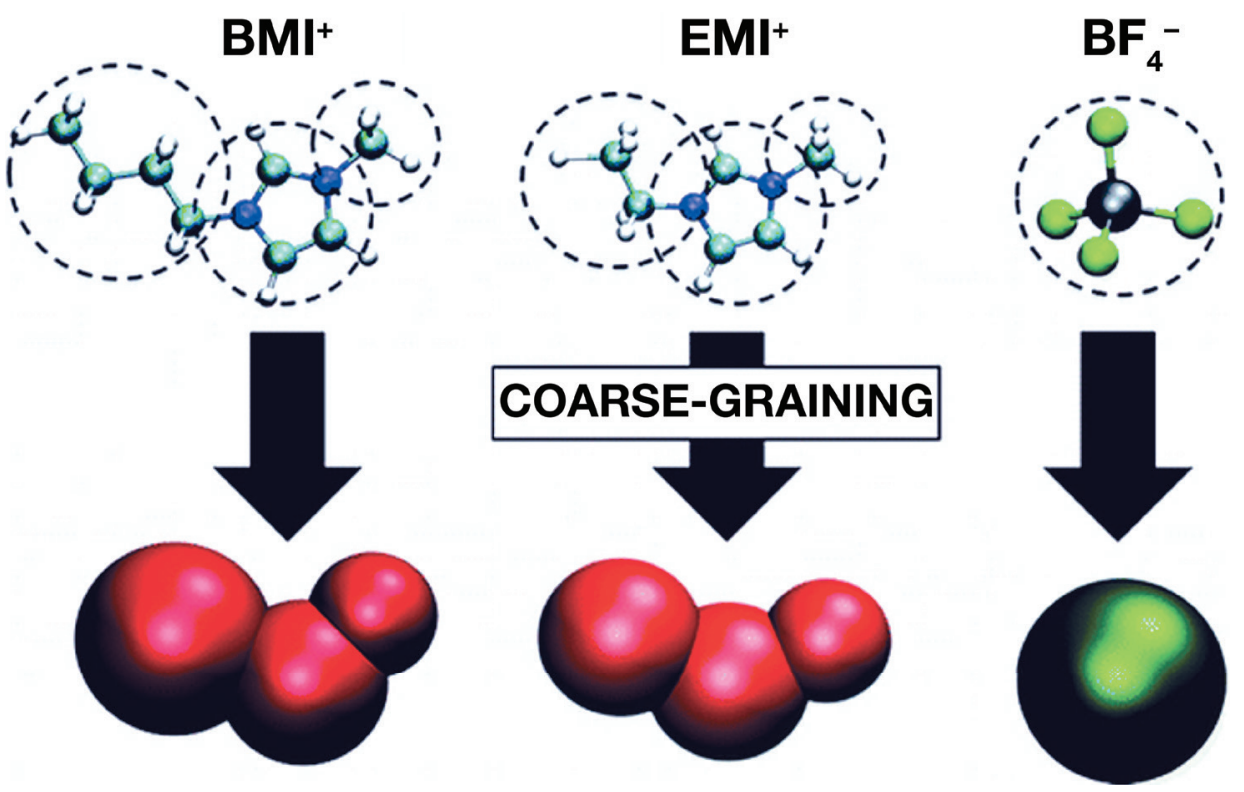

Figura 5.4 Representação da abordagem coarse-graining (embaixo) e atomística (em cima). Os 25 átomos do cátion $\mathrm{BMI}^{+}$são representados por três sítios no modelo $\mathrm{CG}$, o que reduz drasticamente o custo computacional da simulação. Reproduzida de Merlet et al. ${ }^{55}$

\subsection{MODELAGEM DE LÍQUIDOS IÔNICOS: APLICAÇÕES}

\subsubsection{Solvatação em líquidos iônicos}

Como mencionado, LIs podem dissolver muitos compostos orgânicos e inorgânicos que são insolúveis ou fracamente solúveis em água, bem como na maioria dos solventes orgânicos. De fato, na fase líquida, cátions e ânions formam uma complexa rede polar de ligações, em razão de suas intensas interações eletrostáticas, enquanto os grupos apolares formam domínios governados por interações de Van der Waals de curto alcance. ${ }^{56} \mathrm{~A}$ formação de domínios polares e apolares nos líquidos iônicos tem estabelecido uma nova maneira de analisar o processo de solvatação nesses ambientes. ${ }^{57}$ Nesse contexto, estudos computacionais recentes têm fornecido importantes análises das propriedades de solvatação em líquidos iônicos de nanoestruturas de carbono. Uma aplicação recente se refere ao problema da dissolução do fulereno $\mathrm{C}_{60} \mathrm{em}$ líquidos iônicos. Dissolver fulerenos de maneira eficiente é uma questão importante para numerosas aplicações. Uma enorme variedade de solventes (mais de 150) e de

55 Merlet et al. (2011).

56 Pádua et al. (2007), Lopes e Pádua (2006), Wang e Voth (2005).

57 Pádua et al. (2007), Wang e Voth (2005), Lopes e Pádua (2006), Lynden-Bell et al. (2007), Leach (2001). 
suas misturas tem sido aplicada para obtenção de soluções reais de fulerenos $\mathrm{C}_{60}, \mathrm{C}_{70} \mathrm{e}$ outros ainda maiores ${ }^{58}$ Os dados disponíveis na literatura ainda são, no entanto, pouco animadores. Na maioria dos solventes polares, como a água, soluções fulerênicas são extremamente diluídas ou são coloidais. Soluções relativamente concentradas são alcançadas apenas em alguns solventes de baixa polaridade, como os de hidrocarbonetos aromáticos e seus derivados halogenados. Por exemplo, a solubilidade do $\mathrm{C}_{60}$ em benzeno, tolueno e etilbenzeno é de $1,50 \mathrm{~g} \mathrm{~L}^{-1},{ }^{59} 2,40 \mathrm{~g} \mathrm{~L}^{-1},{ }^{60} 2,60 \mathrm{~g} \mathrm{~L}^{-1},{ }^{61}$ respectivamente, à temperatura de $298 \mathrm{~K}$. De forma geral, essas solubilidades ainda são muito baixas para a maioria das aplicações industriais relevantes e, dessa forma, líquidos iônicos surgem com uma possibilidade atrativa para contornar a alta hidrofobicidade do $\mathrm{C}_{60^{\circ}}$

A solvatação do $\mathrm{C}_{60}$ tem sido investigada computacionalmente, com o objetivo de se quantificar a complexa energética entre soluto e solvente, por meio da análise de sua energia potencial e energia livre. Além disso, o processo de dissolução do $\mathrm{C}_{60} \mathrm{em}$ líquidos iônicos tem sido analisado em termos da solubilidade. Simulações extensivas de dinâmica molecular para um aglomerado sólido de fulerenos $\mathrm{C}_{60}$, em bmimBF4, foram realizadas para tal investigação.
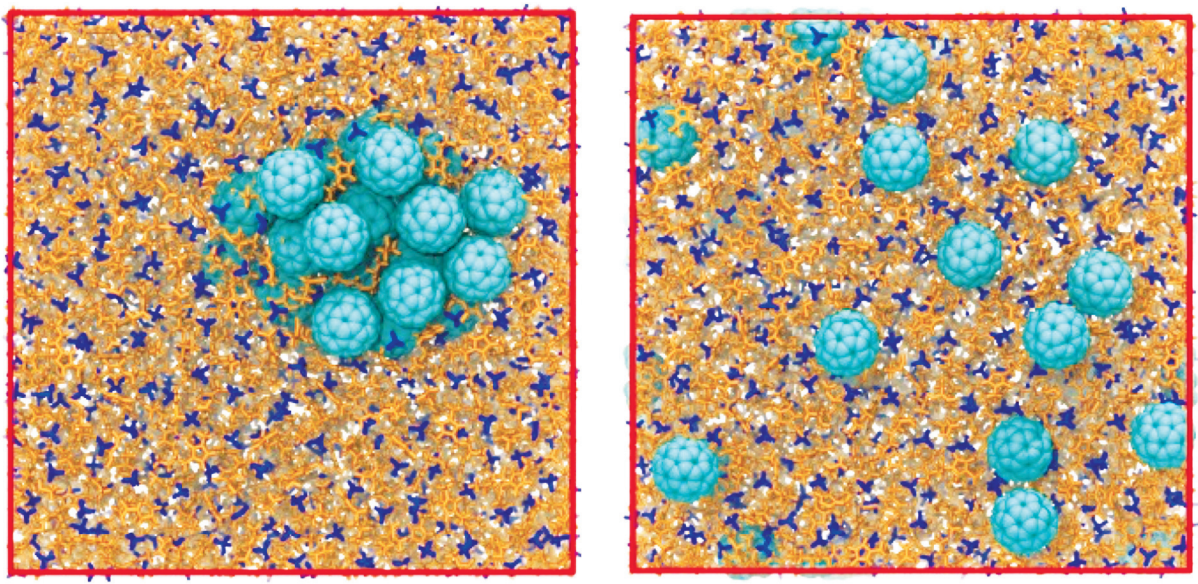

Figura 5.5 Imagens de configurações representativas do $\mathrm{C}_{60}$ em estado sólido (esquerda) e dissolvido (direita).

Embora a estrutura periódica bem ordenada do $\mathrm{C}_{60}$ em fase sólida se converta para um agregado em líquido iônico (semelhante ao da Figura 5.5), nenhuma molécula de fulereno é encontrada completamente dissolvida por um tempo significativo, durante $300 \mathrm{~ns}$ de evolução espontânea do sistema. Esse resultado está em excelente concordância com as recentes observações experimentais da solvatação do fulereno

58 Mchedlov-Petrossyan (2011), Semenov e Charykov (2010), Semenov et al. (2010).
59 Scrivens e Tour (1993).
60 Talukdar et al. (1997).
61 Scrivens e Tour (1993). 
$\mathrm{C}_{70}$ em líquidos iônicos comumente utilizados. ${ }^{62}$ Apesar do baixo poder de dissolução do líquido bmimBF4 em condições ambientes, esse solvente se torna excepcionalmente bem-sucedido, a partir de pequenos aumentos de temperatura da solução, sendo que cerca de $20 \mathrm{~K}$ já são suficientes para observar esse fenômeno. Para as temperaturas de 310,320 e $333 \mathrm{~K}$, as solubilidades obtidas são, respectivamente, 5, 49 e maiores que $66 \mathrm{~g} \mathrm{~L}^{-1}$. Uma vez que os fatores entálpicos não mudam significativamente entre 300 e $320 \mathrm{~K}$, a dissolução é impulsionada em razão do aumento do fator entrópico. Não é possível identificar com os modelos simulados a solubilidade máxima do $\mathrm{C}_{60}$ em temperaturas maiores, já que esses sistemas originalmente continham apenas 30 moléculas de fulereno, correspondendo a um máximo para a solubilidade de $66 \mathrm{~g} \mathrm{~L}^{-1}$. Esse valor-limite foi alcançado e excedido em $333 \mathrm{~K}$ e pode ser comparado à solubilidade em solventes "reativos", 63 embora nenhuma reação entre $\mathrm{o}_{60} \mathrm{e}$ o líquido iônico seja prevista.
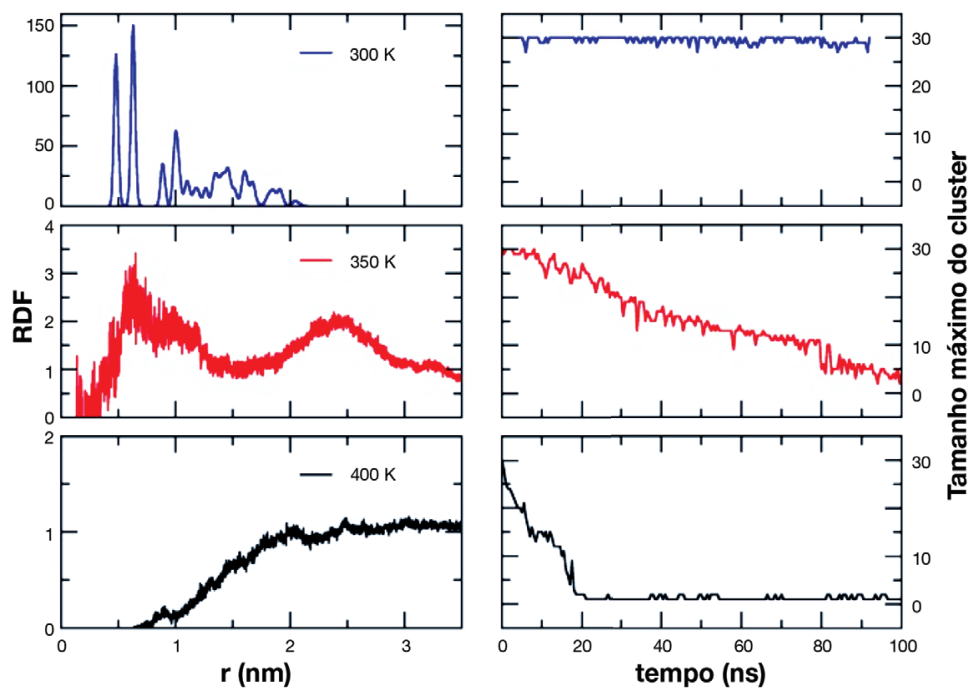

Figura 5.6 Função de distribuição radial em relação ao centro de massa do $\mathrm{C}_{60}$ (esquerda) e evolução do tamanho dos agregados em função do tempo de simulação (direita). Os picos pronunciados e bem ordenados da RDF em $300 \mathrm{~K}$, cujo arranjo é similarmente observado em baixas temperaturas (menores que $260 \mathrm{~K}$ ), deixam clara a existência de agregados moleculares não dissolvidos.

Esses resultados são bastante encorajadores e podem chamar atenção aos representantes de outras famílias de líquidos iônicos à temperatura ambiente, a fim de promover a solubilidade para valores cada vez maiores. A polarização mútua do bmimBF4 e do $\mathrm{C}_{60}$ desempenha um papel fundamental em dissoluções bem- 
-sucedidas. A natureza iônica do líquido bmimBF4 e a carga deslocalizada do cátion são importantes pré-requisitos para sua polarizabilidade eletrônica. Vale notar que essa aproximação é possível mesmo com líquidos iônicos à temperatura ambiente, mas impossível com soluções de íons em líquidos moleculares polares. Nesse último caso, íons são fortemente solvatados pelas moléculas de solvente e não conseguem se aproximar do fulereno. O fulereno é coordenado predominantemente por partículas neutras, as quais, na maioria dos casos, exibem de insignificante (álcoois, por exemplo) a negligenciável (nitrilas, por exemplo) potencial de polarização.

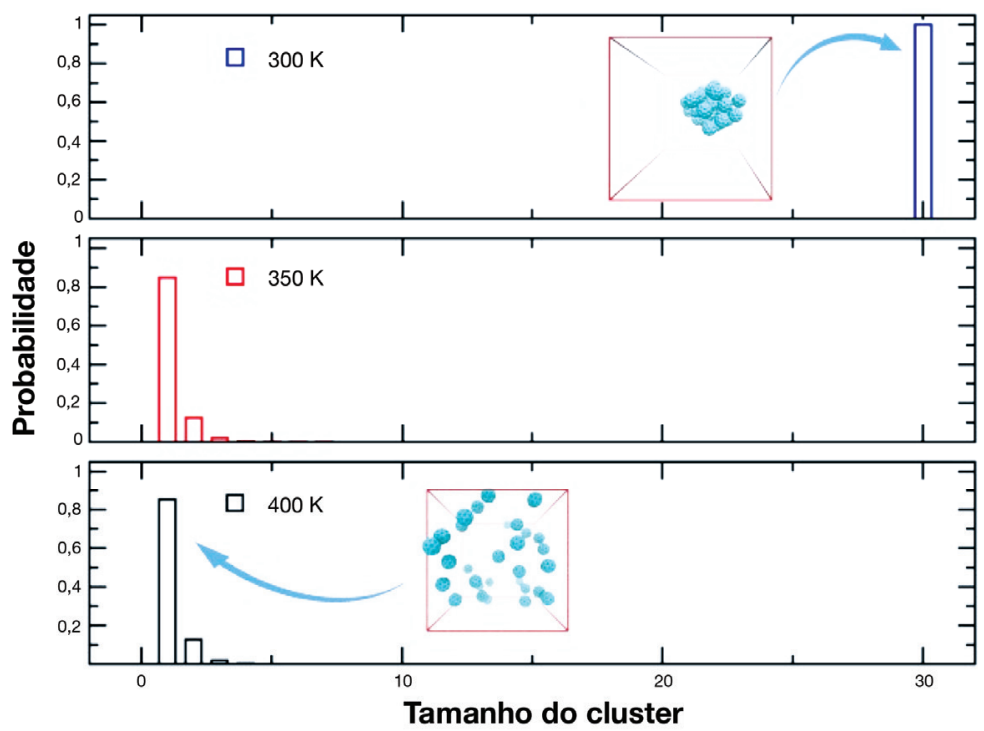

Figura 5.7 Monômeros, dímeros e trímeros do $\mathrm{C}_{60}$ em bmimBF4.

\subsubsection{Captura e separação de gases}

A concentração de dióxido de carbono na atmosfera continua a aumentar, já ultrapassando os níveis de 400 ppm, resultado da ação antropogênica, cujas principais fontes são a acelerada produção industrial, emissões por veículos automotivos e a queima de reservas florestais. Scott et al., ${ }^{64} \mathrm{em}$ recente trabalho de revisão, notaram a necessidade de uma política agressiva para a implementação de tecnologias de captura de carbono. De fato, como constatado por Zhang et al., novas tecnologias para captura de $\mathrm{CO}_{2}$ são necessárias, já que as atuais, com base em solventes orgânicos convencionais, como as soluções aquosas de metanolamina (MEA), possuem limitações e elevado custo energético ao fim do processo de captura ${ }^{65}$ Além

64 Scott et al. (2012).

65 Zhang, Lin e Wang (2008). 
disso, o $\mathrm{CO}_{2}$ não apenas contribui para a mudança climática como, não sendo ele utilizado na geração de compostos químicos por meio de sua conversão, abre, assim, um debate sustentável quanto ao seu real aproveitamento energético. Portanto, processos não apenas de captura, mas aliados com a conversão de $\mathrm{CO}_{2}$, tornam-se um atrativo do ponto de vista tecnológico.

Nesse ponto, torna-se importante salientar que os processos devem possuir tecnologia suficiente para não apenas capturar o $\mathrm{CO}_{2}$, mas o fazer de forma seletiva e específica, já que outros gases presentes são considerados interferentes no processo de captura, como $\mathrm{H}_{2} \mathrm{~S}$ e $\mathrm{SO}_{2}$, entre outros. As tecnologias emergentes de pós-combustão incluem sistemas com base em carbonato, amônia aquosa, membranas, adsorventes sólidos para captura, MOFs (Metal Organic Frameworks) e líquidos iônicos. ${ }^{66}$

Blanchard et al. publicaram um dos primeiros trabalhos sobre o assunto, no qual reportaram a alta solubilidade de $\mathrm{CO}_{2} \mathrm{em}$ [bmim][PF6], com fração molar de 0,6 em $8 \mathrm{MPa}$. A solubilidade de [bmim][PF6] em $\mathrm{CO}_{2}$ é da ordem de 10-5, a 13,8 $\mathrm{MPa}$ e $40{ }^{\circ} \mathrm{C}$. Após a aplicação de $8 \mathrm{MPa}$ de $\mathrm{CO}_{2}$, observou-se que a fase líquida aumenta em volume em apenas 10-20\%, comportamento esse diferente de solventes orgânicos, os quais possuem elevado aumento do volume quando é adicionado gás. A mudança de volume do líquido é medida pela seguinte relação:

$$
\frac{\Delta \mathrm{V}}{\mathrm{V}_{0}}(\%)=100 \frac{\mathrm{v}_{\mathrm{m}}(\mathrm{T}, \mathrm{p}, \mathrm{x})-\mathrm{V}_{\mathrm{IL}}\left(\mathrm{T}, \mathrm{p}_{0}\right)}{\mathrm{V}_{\mathrm{IL}}\left(\mathrm{T}, \mathrm{p}_{0}\right)}
$$

em que $\mathrm{V}_{\mathrm{m}}(\mathrm{T}, \mathrm{p}, \mathrm{x})$ é o volume molar na mistura de concentração $x$ de $\mathrm{CO}_{2}, \mathrm{eV}_{\mathrm{IL}}(\mathrm{T}$, $\mathrm{p}_{0}$ ) é o volume molar do líquido iônico puro. Shiflett e Yokozeki têm obtido resultados para a solubilidade de $\mathrm{CO}_{2}$ em $[\mathrm{bmim}]\left[\mathrm{PF}_{6}\right]$ e $[\mathrm{bmim}]\left[\mathrm{BF}_{4}\right]$ aplicando uma equação cúbica de estado em ajuste aos dados experimentais de absorção em diferentes temperaturas e pressões. ${ }^{67}$ Cálculos de dinâmica molecular de equilíbrio, usando o pacote GROMACS e condições termodinâmicas semelhantes ao trabalho de Shiflett e Yokozeki, variando a concentração de $\mathrm{CO}_{2}$ em líquido iônico [emim] [Tf2N], foram realizados. ${ }^{68} \mathrm{~A}$ Tabela 5.2 mostra um resumo das características dos sistemas simulados a $313 \mathrm{~K}$, e a Figura 5.8 revela que a variação de volume molar da mistura segue a mesma tendência encontrada pelos autores, validando não apenas o modelo computacional usado, mas predizendo o comportamento da solubilidade de $\mathrm{CO}_{2}$ nesse sistema.

66 Blanchard et al. (1999), Cadena et al. (2004), Li et al. (2011).

67 Shiflett e Yokozeki (2005).

68 Lourenço et al. (2013). 
Tabela 5.2 Dados de expansão do volume e variação do volume molar para o sistema $\operatorname{emim}[\mathrm{Tf} 2 \mathrm{~N}] / \mathrm{CO}_{2}$.

\begin{tabular}{cccccc}
$\begin{array}{c}\mathbf{x} \text { (fração } \\
\text { molar) } \mathbf{C O}_{\mathbf{2}}\end{array}$ & $\begin{array}{c}\mathbf{N} \\
\text { \#CO }\end{array}$ & $\begin{array}{c}\text { Volume molar } \\
\left(\mathbf{c m}^{3} / \mathbf{m o l}\right)\end{array}$ & $\mathbf{\Delta V / \mathbf { V } _ { \mathbf { 0 } }}$ & $\begin{array}{c}\text { Expansão do } \\
\text { volume }(\%)\end{array}$ & $\begin{array}{c}\text { Densidade } \\
\left(\mathbf{k g} / \mathbf{m}^{3}\right)\end{array}$ \\
\hline 0 & 0 & $127,3(0,06)$ & 0 & 0 & $1537(1)$ \\
0,03 & 10 & $124,5(0,11)$ & $-2,1$ & 0,9 & $1534(2)$ \\
0,059 & 20 & $122,1(0,09)$ & $-4,1$ & 1,9 & $1530(1)$ \\
0,099 & 35 & $118,4(0,03)$ & $-7,0$ & 3,2 & $1526(1)$ \\
0,135 & 50 & $115,2(0,07)$ & $-9,5$ & 4,6 & $1521(1)$ \\
0,206 & 83 & $108,9(0,03)$ & $-14,5$ & 7,7 & $1510(2)$ \\
0,286 & 128 & $101,8(0,03)$ & $-20,1$ & 11,9 & $1497(1)$ \\
0,351 & 173 & $95,9(0,01)$ & $-24,6$ & 16,1 & $1485(1)$ \\
0,389 & 204 & $92,4(0,02)$ & $-27,4$ & 18,9 & $1478(1)$ \\
\hline
\end{tabular}

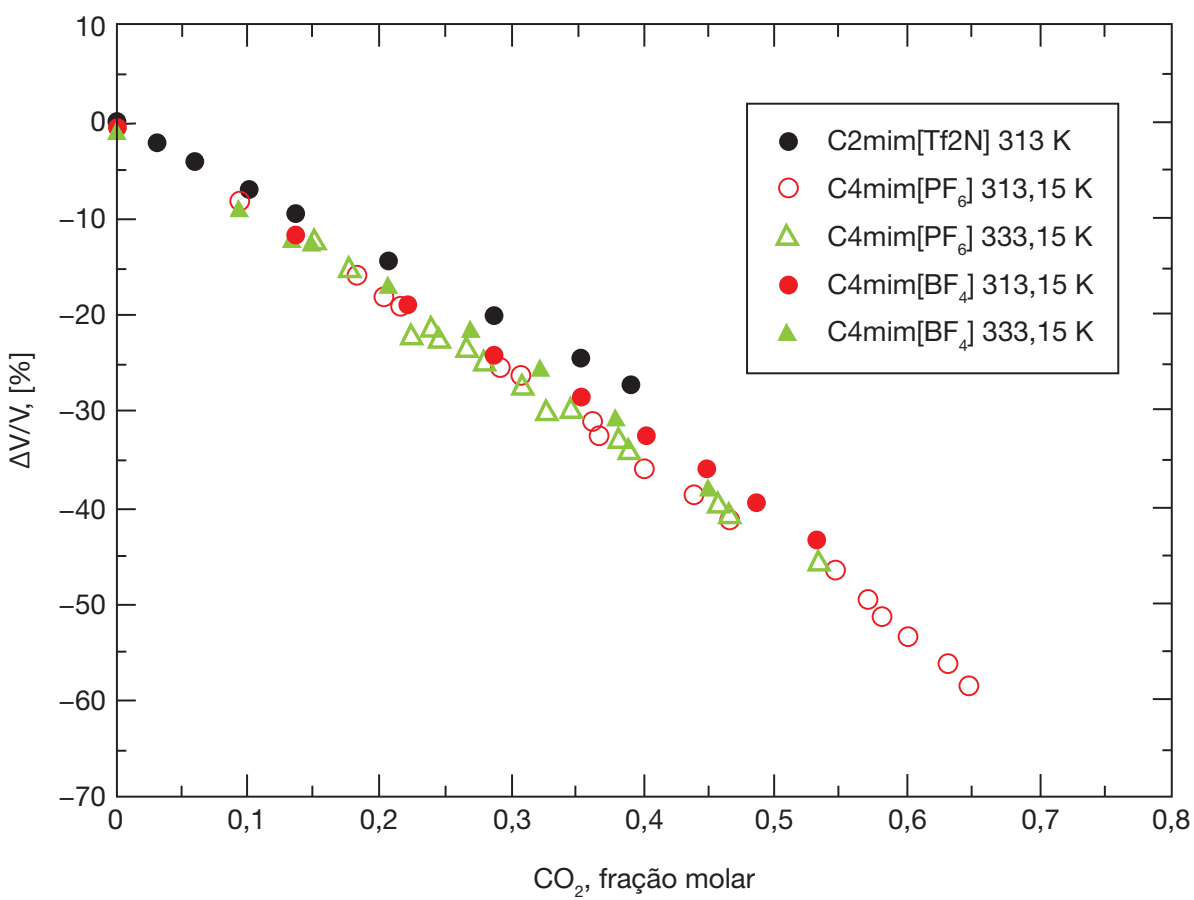

Figura 5.8 Expansão do volume molar $\left(\Delta \mathrm{V} / \mathrm{V} \_0\right)$ do sistema emim[Tf2N] (círculo preto) a $313 \mathrm{~K}$, a partir de cálculos de dinâmica molecular (MD), comparada com dados experimentais de Shiflett et al. para os sistemas bmim[BF4] e bmim[PF6]. ${ }^{69}$ 
$\mathrm{O}$ volume livre e o volume livre fracional (FFV, do inglês Fractional Free Volume) aumentam monotonicamente com a concentração de $\mathrm{CO}_{2}$. Lin e Freeman reportam que, para líquidos, os valores de volume livre fracional são tipicamente maiores que $21 \%$, enquanto para polímeros tendem a ser menores que esse valor. ${ }^{70}$ Como visualizado na Tabela 5.3, os valores de FFV se tornam mais próximos aos polímeros que aos líquidos regulares, podendo ser justificado pelas fortes interações de Coulomb e pela alta densidade. Mais detalhes acerca desse estudo podem ser encontrados na literatura. ${ }^{71}$

Tabela 5.3 Volume livre (FV, \%), volume fracional livre (FFV, \%) e desvios padrões entre parênteses.

\begin{tabular}{cccc|} 
Fração molar (x) & \#CO $_{2}$ & FV & FFV \\
\hline 0 & 0 & $37,4(0,3)$ & $18,6(0,2)$ \\
0,030 & 10 & $37,4(0,3)$ & $18,7(0,2)$ \\
0,059 & 20 & $37,6(0,3)$ & $18,9(0,2)$ \\
0,099 & 35 & $37,7(0,3)$ & $19,0(0,2)$ \\
0,135 & 50 & $37,8(0,3)$ & $19,1(0,1)$ \\
0,206 & 83 & $38,1(0,3)$ & $19,6(0,2)$ \\
0,286 & 128 & $38,5(0,3)$ & $20,0(0,2)$ \\
0,351 & 173 & $38,8(0,3)$ & $20,4(0,2)$ \\
0,389 & 204 & $39,0(0,3)$ & $20,6(0,2)$ \\
\hline
\end{tabular}

Medidas de solubilidade realizadas por Yim e Lim, em cinco líquidos iônicos, ${ }^{72}$ permitiram estabelecer a seguinte ordem: $[\mathrm{hmim}][\mathrm{Tf} 2 \mathrm{~N}]>[\mathrm{hmim}][$ triflato $]>$ $[\mathrm{hmim}]\left[\mathrm{PF}_{6}\right]>[\mathrm{hmim}]\left[\mathrm{BF}_{4}\right]>[\mathrm{hmim}]\left[\mathrm{MeSO}_{4}\right]$ a $333,15 \mathrm{~K}$. De acordo com os autores, a maior solubilidade associada ao $[\mathrm{hmim}][\mathrm{Tf} 2 \mathrm{~N}]$ se deve ao maior número de átomos de flúor, o que não ocorre com a espécie $\mathrm{MeSO}_{4}$. A molécula de $\mathrm{CO}_{2}$ apresenta momento de quadrupolo, interage com ânions por meio de interações do tipo ácido-base de Lewis e tem alta afinidade por flúor, com a formação espontânea de $\mathrm{F}^{-\mathrm{CO}_{2}}$.

Anthony et al. mediram a solubilidade de uma série de gases em $[\mathrm{bmim}]\left[\mathrm{BF}_{4}\right]$, $[\mathrm{bmim}][\mathrm{Tf} 2 \mathrm{~N}]$ e $[\mathrm{bmim}]\left[\mathrm{PF}_{6}\right] .{ }^{73} \mathrm{CO}_{2}$ e $\mathrm{NO}_{2}$ apresentaram as maiores solubilidades e interações mais fortes com os líquidos iônicos. A $25^{\circ} \mathrm{C}$, a constante de Henry para $\mathrm{CO}_{2}$ em $[\mathrm{bmim}]\left[\mathrm{PF}_{6}\right]$ é de $53,4 \pm 0,3$ bar, $[\mathrm{bmim}]\left[\mathrm{BF}_{4}\right]$ de $59,0 \pm 2,6$ bar e [bmim] [Tf2N] de 33,0 $\pm 0,3$ bar, com $\Delta \mathrm{H}$ de $(-14,3 ;-13,96 ;-12,5) \mathrm{kJ} / \mathrm{mol}$, respectivamente.

Lee et al. investigaram a influência de ânions halogenetos sobre a solubilidade de $\mathrm{SO}_{2}{ }^{74} \mathrm{~A}$ ordem determinada é $[\mathrm{emim}] \mathrm{Br}>[\mathrm{emim}] \mathrm{Cl}>[\mathrm{emim}] \mathrm{I}$, com razão mo$\operatorname{lar}\left(\mathrm{mol} \mathrm{SO}_{2} / \mathrm{mol} \mathrm{LI}\right)$ de 2,06, 2,11 e 1,91, respectivamente. A solubilidade determi-

\footnotetext{
70 Lin e Freeman (2005).

71 Lourenço et al. (2013).

72 Id. ibid.

73 Anthony et al. (2005).

74 Lee et al. (2010).
} 
nada para [emim] Cl (2,03 $\mathrm{mol} / \mathrm{mol}), \mathrm{hmimCl}(2,19 \mathrm{~mol} / \mathrm{mol})$ e omimCl $(2,19 \mathrm{~mol} /$ mol) indica o papel secundário do cátion sobre a solubilidade, enquanto o ânion exerce um papel primordial.

Estudos de Shiflett e Yokozeki mostraram, no entanto, que o $[\mathrm{bmim}]\left[\mathrm{PF}_{6}\right]$ não é necessariamente a melhor escolha para separação gasosa ou captura de $\mathrm{H}_{2} \mathrm{~S}$ e $\mathrm{CO}_{2}$, já que o LI pode afetar a seletividade do gás. ${ }^{75}$

Uma descrição em nível molecular das interações de LI com $\mathrm{SO}_{2}, \mathrm{CO}_{2}$ e $\mathrm{N}_{2}$ foi apresentada por Prasad e Senapati e suas implicações à solubilidade de gases. ${ }^{76}$ Resultados indicaram a importância da interação ânion-gás na solubilidade de gases em LI. A ordem de solubilidade encontrada é de $\mathrm{SO}_{2}>\mathrm{CO}_{2}>\mathrm{N}_{2}$. A interação ânion-gás segue a mesma ordem, sendo mais fortes as interações ânion- $\mathrm{SO}_{2}$, com cálculos realizados em nível de teoria MP2 e função de base 6-311+G*. Como exemplo, $\mathrm{PF}_{6}-\mathrm{SO}_{2}$ tem energia de interação de $-32,78 \mathrm{~kJ} / \mathrm{mol}, \mathrm{PF}_{6}-\mathrm{CO}_{2}$ é de $-11,08 \mathrm{~kJ} / \mathrm{mol}$ e $\mathrm{PF}_{6}-\mathrm{N}_{2}$ é de $-4,67 \mathrm{~kJ} / \mathrm{mol}$. Outros ânions estudados foram F-, Cl-, Br- e NO3-.

Em 2013, Haghbakhsh et al. propuseram uma correlação com base no método de regressão múltipla para predizer a solubilidade de $\mathrm{CO}_{2}$ em 27 líquidos iônicos comuns, a partir de 3.073 dados da literatura sobre o tema. ${ }^{77}$ Como exemplo, para o ânion triflato, foi obtida a seguinte ordem de solubilidade: [omim][TFA] $>$ [hmim] $[$ TFA $]>[$ bmim $][$ TFA $]>[$ emim $][$ TFA $]$. Ainda foram estudados líquidos iônicos com base em ânions $\mathrm{PF}_{6}^{-}, \mathrm{BF}_{4}^{-}$e cátions com base em piridínio, fosfônio, entre outros.

A densidade molar, que segue a ordem $[\mathrm{emim}][\mathrm{Tf} 2 \mathrm{~N}]>[$ bmim $][\mathrm{Tf} 2 \mathrm{~N}]>$ $[\mathrm{hmim}][\mathrm{Tf} 2 \mathrm{~N}]>[\mathrm{omim}][\mathrm{Tf} 2 \mathrm{~N}]$, pode ser associada à solubilidade, cujo comportamento é inverso. A explicação está no enfraquecimento da interação cátion-ânion de emim para omim, gerando um aumento de volumes livres no LI, com o consequente aumento do espaço livre disponível aos gases. ${ }^{78}$ De acordo com Cadena et al. ${ }^{79}$ a densidade menor de $[\mathrm{bmmim}]\left[\mathrm{PF}_{6}\right]$ em relação a $[\mathrm{bmim}]\left[\mathrm{PF}_{6}\right]$ sugere que o grupo metila reduz a eficiência de empacotamento. Resultados de dinâmica molecular indicam que o $\mathrm{CO}_{2}$ tem efeito desprezível para a organização de $\mathrm{PF}_{6}$ sobre o carbono $\mathrm{C} 2$, o que se deve às interações coulômbicas fortes responsáveis pela organização do líquido, forçando o gás a ocupar os interstícios, causando aumento da densidade molar do líquido iônico, já que não há expansão de volume.

De forma a evidenciar a localização do $\mathrm{CO}_{2}$ nos espaços vazios deixados pelo líquido iônico, mostra-se, na Figura 5.9, a função de distribuição espacial (SDF) de cátions e $\mathrm{CO}_{2}$ em torno do ânion (A) e ânion e $\mathrm{CO}_{2}$ em torno do cátion (B), obtidos de simulações MD a $313 \mathrm{~K}$.

5 Shiflett e Yokozeki (2010).

76 Prasad e Senapati (2009).

77 Haghbakhsh et al. (2013).

78 Hong et al. (2011).

79 Cadena et al. (2004). 

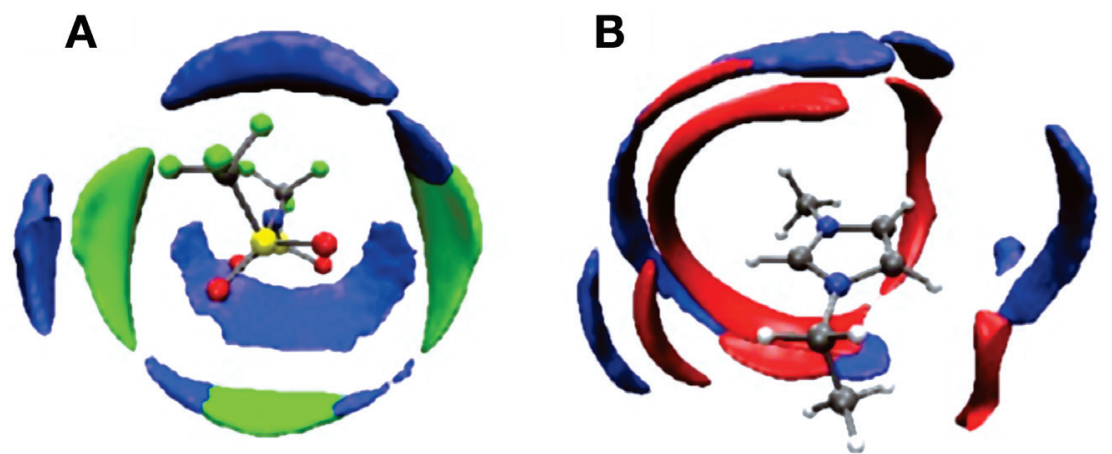

Figura 5.9 Função de distribuição espacial (SDF) de cátion (verde) e $\mathrm{CO}_{2}$ (azul) em torno do ânion (A) e de ânion (vermelho) e $\mathrm{CO}_{2}$ (azul) em torno do cátion (B).

A Figura 5.9 mostra a SDF para o sistema emim[Tf2N $] / \mathrm{CO}_{2}$, contendo 50 moléculas de $\mathrm{CO}_{2}$. Em recente trabalho também de simulação $\mathrm{MD}$, Yue et al. mostraram a SDF de $\mathrm{CO}_{2}$ em torno de cátion e ânion para os sistemas emim [Tf2 $\left.\mathrm{N}\right] / \mathrm{CO}_{2}$, emim $\left[\mathrm{PF}_{6}\right] / \mathrm{CO}_{2}$ e $\mathrm{PC}_{666,14}\left[\mathrm{PF}_{6}\right] / \mathrm{CO}_{2}$, porém não estabelecendo a correlação entre a baixa expansão do volume e o rearranjo dos líquidos iônicos para acomodarem o $\mathrm{CO}_{2}{ }^{80} \mathrm{~A}$ Figura 5.9A mostra que $\mathrm{CO}_{2}$ (azul) coordena os ânions em regiões em que não há cátions (verde), revelando, do ponto de vista microscópico, que o $\mathrm{CO}_{2}$ ocupa os vazios deixados pelos cátions. A Figura 5.9B mostra as ocorrências de ânions e $\mathrm{CO}_{2}$ em torno do cátion. Os ânions coordenam o cátion pelos sítios de interação de hidrogênio, mas isso evidencia que a interação mais favorável e de maior probabilidade ocorre com o H mais ácido do anel imidazólio. Nesse estudo, mostrou-se, conforme já destacado anteriormente por Lin e Freeman, ${ }^{81}$ que as cavidades existentes nos LIs são decorrências das interações mais fracas entre cátion-ânion e, portanto, reguladas pela termodinâmica dessas interações. Ou seja, quanto mais fraca a interação cátion-ânion, maior será a ocorrência de cavidades, permitindo, assim, a captura de gases como $\mathrm{CO}_{2}$. Esse mecanismo é de suma importância na modulação de líquidos iônicos capazes de atuar na captura e separação de gases.

\subsection{CONSIDERAÇõeS FINAIS}

Simulações de dinâmica molecular consistem em um método fundamental para compreender as observações experimentais e prever as propriedades de líquidos iônicos. Neste capítulo, apresentou-se uma visão geral sobre duas das mais importantes abordagens computacionais para a modelagem desses líquidos, em especial dos líquidos iônicos: a dinâmica molecular atomística e a dinâmica molecular

80 Yue et al. (2011).

81 Lin e Freeman (2005). 
coarse-grained. Por meio das aplicações apresentadas, mostrou-se o quanto tais técnicas são versáteis e eficientes. Nos modelos computacionais de líquidos iônicos, as estruturas, a dinâmica e a energética do líquido podem ser simuladas em resolução atomística e/ou em escalas espacial e temporal superiores. Esses modelos permitem compreender a origem e o comportamento molecular desses líquidos, além de prever suas propriedades macroscópicas.

\section{REFERÊNCIAS}

Allen, M. P.; Tildesley, D. J. Computer simulations of liquids. Oxford: Clarendon Press, 1987.

Anthony, J. L.; Anderson, J. L.; Maginn, E. J.; Brennecke, J. F. Anion effects on gas solubility in ionic liquids. J Phys Chem B, 109, p. 6366-6374, 2005.

ARIga, K.; Kunitake, T. Supramolecular chemistry. Fundamentals and applications: advanced textbook. 1. ed. Nova York: Springer, 2006.

Azevedo, A. M. O.; Ribeiro, D. M. G.; Pinto, P. C. A. G.; Lúcio, M.; Reis, S.; Saraiva, M. L. M. F. S. Imidazolium ionic liquids as solvents of pharmaceuticals: influence on hsa binding and partition coefficient of nimesulide. International Journal of Pharmaceutics, 443, 2013.

Barnoud, J.; Rossi, G.; Monticelli, L. Lipid membranes as solvents for carbon nanoparticles. Physical Review Letters, 112, 2014.

BARONE, V. (Ed.). Computational strategies for spectroscopy: from small molecules to nano systems. 1. ed. Londres: Wiley, 2011.

Bica, K.; Rodríguez, H.; Gurau, G.; Cojocaru, O. A.; Rissager, A.; Fehrmann, R.; Rogers, R. D. Pharmaceutically active ionic liquids with solids handling, enhanced thermal stability, and fast release. Chemical Communications, 48, p. 5422-5424, 2012.

Blanchard, L. A.; Hancu, D.; Beckman, E. J.; Brennecke, J. F. Green processing using ionic liquids and Co2. Nature, 399, p. 28-29, 1999.

Borodin, O.; SмIтH, G. D. Mechanism of ion transport in amorphous poly(ethylene oxide)/litfsi from molecular dynamics simulations. Macromolecules, 39, p. 1620-1629, $2006 \mathrm{a}$. . Development of many-body polarizable force fields for li-battery components: 1. ether, alkane, and carbonate-based solvents. J Phys Chem B, 110, p. 6279-6292, 2006b.

. Development of many-body polarizable force fields for li-battery applications: 2 . litfsi-doped oligoether, polyether, and carbonate-based electrolytes. J Phys Chem B, 110, p. 6293-6299, 2006c.

Brooks, A. Ionic liquids: synthesis, characterization and applications. Nova York: Nova Science Pub Inc., 2014. 
Cadena, C.; Anthony, J. L.; Shah, J. K.; Morrow, T. I.; Brennecke, J. F.; Maginn, E. J. Why is CO2 so soluble in imidazolium-based ionic liquids? J Am Chem Soc., 126, p. 53005308, 2004.

Canongia Lopes, J. N.; PÁdua, A. A. H. Molecular force field for ionic liquids iii: imidazolium, pyridinium, and phosphonium cations; chloride, bromide, and dicyanamide anions. Journal of Physical Chemistry B, 110, p. 19586-19592, 2006.

Case, D. A.; Darden, T. A.; Cheatham, T. E.; Simmerling, C. L.; Wang, Y.; Duke, R. E.; Luo, R.; Crowley, M.; Walker, R. C.; Zhang, W.; Merz, K. M.; Wang, B.; Hayik, S.; Roitberg, A.; Seabra, G.; Kolossváry, I.; Wong, K. F.; Paesani, F.; Vanicek, J.; Wu, X.; Brozell, S. R.; Steinbrecher, T.; Gohlke, H.; Yang, L.; Tan, C.; Mongan, J.; Hornak, V.; Cui, G.; Mathews, D. H.; Seetin, M. G.; Sagui, C.; Babin, V.; Kollman, P. A. Amber 10 user's manual. São Francisco: University of California, 2008.

Cojocaru, O. A.; Bica, K.; Gurau, G.; Narita, A.; McCrary, P. D.; Shamshina, J. L.; BArber, P. S.; Rogers, R. D. Prodrug ionic liquids: functionalizing neutral active pharmaceutical ingredients to take advantage of the ionic liquid form. MedChemComm, 4, p. 559-563, 2013.

Costa, L. T.; Ribeiro, M. C. Molecular dynamics simulation of polymer electrolytes based on poly(ethylene oxide) and ionic liquids. i. structural properties. J Chem Phys, 124, p. 184902-184908, 2006.

Duan, Y.; Halley, J. W.; Curtiss, L.; Redfern, P. Mechanisms of lithium transport in amorphous polyethylene oxide. J Chem Phys, 122, p. 54702-54708, 2005.

Ekkabut, J. W.; Baoukina, S.; Triampo, W.; Tang, I. M.; Tieleman, D. P.; Monticelli, L. Computer simulation study of fullerene translocation through lipid membranes. Nature Nanotechnology, 3, p. 363-368, 2008.

Elliott, S. R. Physics of amorphous materials. Nova York: Longman Scientific and Technical, 1952.

Feng, R.; ZhaO, D.; Guo, Y. Revisiting characteristics of ionic liquids: a review for further application development. J. Env. Protec., 1, 1, 95, p. 95-104, 2010.

Greaves, T. L.; Weerawardena, A.; Fong, C.; Krodkiewska, I.; Drummond, C. J. Protic ionic liquids: solvents with tunable phase behavior and physicochemical properties. J. Phys. Chem. B, 110, p. 22479-22487, 2006.

Haghbakhsh, R.; Soleymani, H.; Raeissi, S. A simple correlation to predict high pressure solubility of carbon dioxide in 27 commonly used ionic liquids. The Journal of Supercritical Fluids, 77, p. 158-166, 2013.

Hansen, J. P.; McDonald, I. R. Theory of simple liquids. Nova York: Academic Press, 1990. Hong, S. Y.; Im, J.; Palgunadi, J.; Lee, S. D.; Lee, J. S.; Kim, H. S.; Cheong, M.; Jung, K.-D. Ether-functionalized ionic liquids as highly efficient So2 absorbents. Energy \& Environmental Science, 4, p. 1802-1806, 2011. 
Hough, W. L.; Smiglak, M.; Rodríguez, H.; Swatloski, R. P.; Spear, S. K.; Daly, D. T.; Pernak, J.; Grisel, J. E.; Carliss, R. D.; Soutullo, M. D.; Davis, J. J. H.; Rogers, R. D. The third evolution of ionic liquids: active pharmaceutical ingredients. New Journal of Chemistry, 31, p. 1429-1436, 2007.

Huddleston, J. G.; Willauer, H. D.; Swatloski, R. P.; Visser, A. E.; Rogers, R. D. Room temperature ionic liquids as novel media for "clean" liquid-liquid extraction. Chemical Communications, 16, p. 1765-1766, 1998.

Huiyong, W.; Lamei, Z.; Jianji, W.; Zhiyong, L.; Suojiang, Z. The first evidence for unilamellar vesicle formation of ionic liquids in aqueous solutions. Chemical Communications, 49, 2013.

Hwang, H.; Schatz, G. C.; Ratner, M. A. Steered molecular dynamics studies of the potential of mean force of a na+ or $\mathrm{k}+$ ion in a cyclic peptide nanotube. J. Phys. Chem. B, 110, p. 26448-26460, 2006.

. Coarse-grained molecular dynamics study of cyclic peptide nanotube insertion into a lipid bilayer. J. Phys. Chem. A, 113, p. 4780-4787, 2009.

Hywel, D. W.; Yasemin, S.; Leigh, F.; Tri-Hung, N.; Peter, J. S.; Christopher, J. H. P. Ionic liquids provide unique opportunities for oral drug delivery: structure optimization and in vivo evidence of utility. Chemical Communications, 50, 2014.

Jorgensen, W. L.; Maxwell, D. S.; Tirado-Rives, J. Development and testing of the opls all-atom force field on conformational energetics and properties of organic liquids. Journal of the American Chemical Society, 118, p. 11225-11236, 1996.

LEACH, A. Molecular modelling: principles and applications. 2. ed. Nova York: Prentice Hall, 2001.

Lee, K.-Y.; Kim, C.-S.; Kim, H.-G.; Cheong, M.-S.; MukherJee, D. K.; Jung, K.-D. Effects of halide anions to absorb SO2 in ionic liquids. Bulletin of the Korean Chemical Society, 31, p. 1937-1940, 2010.

Li, J.-R.; Ma, Y.; McCarthy, M. C.; Sculley, J.; Yu, J.; Jeong, H.-K.; Balbuena, P. B.; Zhou, H.-C. Carbon dioxide capture-related gas adsorption and separation in metal-organic frameworks. Coordination Chemistry Reviews, 255, p. 1791-1823, 2011.

Lin, H.; Freeman, B. D. Materials selection guidelines for membranes that remove CO2 from gas mixtures. Journal of Molecular Structure, 739, p. 57-74, 2005.

Lopes, J.; PÁduA, A. A. H. Nanostructural organization in ionic liquids. Journal of Physical Chemistry B, 110, p. 3330-3335, 2006.

Lourenço, T. C.; Coelho, M. F.; Ramalho, T. C.; Van der Spoel, D.; Costa, L. T. Insights on the solubility of CO2 in 1-Ethyl-3-Methylimidazolium bis(trifluoromethylsulfonyl) imide from the microscopic point of view. Environ Sci Technol, 47, p. 7421-7429, 2013.

Lynden-Bell, R. M.; Del Popolo, M. G.; Youngs, T. G. A.; Kohanoff, J.; Hanke, C. G.; Harper, J. B.; Pinilla, C. C. Simulations of ionic liquids, solutions, and surfaces. Accounts of Chemical Research, 40, p. 1138-1145, 2007. 
MacKerell, A. D.; Bashford, D.; Bellott, M.; Dunbrack, R. L.; Evanseck, J. D.; Field, M. J.; Fischer, S.; GaO, J.; Guo, H.; Ha, S.; Joseph-McCarthy, D.; Kuchnir, L.; Kuczera, K.; Lau, F. T. K.; Mattos, C.; Michnick, S.; Ngo, T.; Nguyen, D. T.; Prodhom, B.; Reiher, W. E.; Roux, B.; Schlenkrich, M.; Smith, J. C.; Stote, R.; Straub, J.; WataNABE, M.; Wiórkiewicz-Kuczera, J.; Yin, D.; KARPlus, M. All-atom empirical potential for molecular modeling and dynamics studies of proteins. J. Phys. Chem. B, 102, 1998.

March, N. H.; Tosi, M. P. Atomic dynamics in liquids. Nova York: Dover Publications, 1976. Marrink, S. J.; Risselada, H. J.; Yefimov, S.; Tieleman, D. P.; Vries, A. H. The MARTINI force field: coarse grained model for biomolecular simulations. J. Phys. Chem. B, 111, p. 7812-7824, 2007.

Martins, S.; Fedorov, A.; Afonso, C. A. M.; Baleizao, C.; Berberan-Santos, M. N. Fluorescence of fullerene $\mathrm{C}_{70}$ in ionic liquids. Chemical Physics Letters, 497, p. 43-47, 2010. McCrary, P. D.; Beasley, P. A.; Gurau, G.; Narita, A.; Barber, P. S.; Cojocaru, O. A.; Rogers, R. D. Drug specific, tuning of an ionic liquid's hydrophilic-lipophilic balance to improve water solubility of poorly soluble active pharmaceutical ingredients. New Journal of Chemistry, 37, p. 2196-2202, 2013.

Mchedlov-Petrossyan, N. O. Fullerenes in molecular liquids. Solutions in "good" solvents: another view. Journal of Molecular Liquids, 161, p. 1-12, 2011.

McQuarrie, D. A. Statistical mechanics. Sausalito: University Science Book, 2000.

Merlet, C.; Salanne, M.; Rotenberg, B.; Madden, P. A. Imidazolium ionic liquid interfaces with vapor and graphite: interfacial tension and capacitance from coarse-grained molecular simulations. Journal of Physical Chemistry C, 115, p. 16613-16618, 2011.

Mohammad, A.; Inamuddin, D. Green solvents I: properties and applications in Chemistry. Nova York: Springer, 2014.

Pádua, A. G. H.; Gomes, M. F. C.; Canongia Lopes, J. N. A. Molecular solutes in ionic liquids: a structural perspective. Accounts of Chemical Research, 40, p. 1087-1096, 2007.

Prasad, B. R.; Senapati, S. Explaining the differential solubility of flue gas components in ionic liquids from first-principle calculations. J Phys Chem B, 113, p. 4739-4743, 2009.

Rao, K. S.; Soonyong, S.; Arvind, K. Vesicles and reverse vesicles of an ionic liquid in ionic liquids. Chemical Communications, 49, 2013.

RAPAPORT, R. C. The art of molecular dynamics simulation. Cambridge: Cambridge University Press, 1995.

Reichardt, C. Polarity of ionic liquids determined empirically by means of solvatochromic pyridinium N-phenolate betaine dyes. Green Chemistry, 7, p. 339-351, 2005.

SAdus, R. J. Molecular simulations of fluids: theory, algorithms, and object-orientation. Nova York: Elsevier, 1999.

Sansom, M. S. P.; Biggin, P. C.; Neidle, S. Molecular simulations and biomembranes: from biophysics to function. Cambridge: Royal Society of Chemistry, 2010.

Schmid, G. Nanoparticles: from theory to application. 2. ed. Nova York: Wiley-VCH, 2010. 
Scott, V.; Gilfillan, S.; Markusson, N.; Chalmers, H.; Haszeldine, R. S. Last chance for carbon capture and storage. Nature Climate Change, 3, p. 105-111, 2012.

Scrivens, W. A.; Tour, J. M. Potent solvents for $\mathrm{C}_{60}$ and their utility for the rapid acquisition of C-13 NMR data for fullerenes. J. Chem. Soc. Chem. Comm., p. 1207-1109, 1993.

Semenov, K. N.; Charykov, N. A. Temperature dependence of solubility of individual light fullerenes and industrial fullerene mixture in 1-chloronaphthalene and 1-bromonaphthalene. J. Chem. Eng. Data, 55, p. 2373-2378, 2010.

Semenov, K. N.; Charykov, N. A.; Keskinov, V. A.; Piartman, A. K.; Blokhin, A. A.; Kopyrin, A. A. Solubility of light fullerenes in organic solvents. J. Chem. Eng. Data, 55, p. 13-36, 2010.

Senn, H. M.; Thiel, W. QM/MM methods for biomolecular systems. Angew. Chem. Int. Ed. Engl., 48, p. 1198-1229, 2009.

Shiflett, M. B.; Yokozeki, A. Solubilities and diffusivities of carbon dioxide in ionic liquids: [bmim][Pf6] and [bmim][Bf4]. Industrial \& Engineering Chemistry Research, 44, p. 4453-4464, 2005.

. Separation of $\mathrm{CO} 2$ and $\mathrm{H} 2 \mathrm{~S}$ using room-temperature ionic liquid [bmim][Pf6]. Fluid Phase Equilibria, 294, p. 105-113, 2010.

SHIM, Y.; KIM, H. J. Solvation of carbon nanotubes in a room-temperature ionic liquid. Acs Nano, 3, p. 1693-1702, 2009.

Siqueira, L. J.; Ribeiro, M. C. Molecular dynamics simulation of the polymer electrolyte poly(ethylene oxide)/liclo(4). ii. dynamical properties. J Chem Phys, 125, p. 214903214908, 2006.

- Molecular dynamics simulation of the ionic liquid n-ethyl-n,n-dimethyl-n-(2-methoxyethyl)ammonium bis(trifluoromethanesulfonyl)imide. J Phys Chem B, 111, p. 11776-11785, 2007.

Soares, T. A.; Hunenberger, P. H.; Kastenholz, M. A.; Krautler, V.; Lenz, T.; Lins, R. D.; Oostenbrink, C.; Van Gunsteren, W. F. An improved nucleic acid parameter set for the gromos force field. J Comput Chem, 26, p. 725-737, 2005.

Srivastava, A.; Voth, G. A. Hybrid approach for highly coarse-grained lipid bilayer models. J. Chem. Theory Comput., 9, p. 750-765, 2013.

Stoimenovski, J.; Dean, P. M.; Izgorodina, E. I.; MacFarlane, D. R. Protic pharmaceutical ionic liquids and solids: aspects of protonics. Faraday Discussions, 154, p. 439-464, 2012.

Suruchi, M.; Rabia, S.; Rakesh Kumar, M. An investigation of drug binding ability of a surface active ionic liquid: micellization, electrochemical, and spectroscopic studies. Langmuir, 28, 2012.

Talukdar, S.; Pradhan, P.; BanerJi, A. Electron donor-acceptor interactions of $\mathrm{C}_{60}$ with $\mathrm{N}$ - and P-donors: a rational approach towards its solubility. Fullerene Sci. Techn., 5, p. 547557, 1997. 
Urahata, S. M.; Ribeiro, M. C. Structure of ionic liquids of 1-alkyl-3-methylimidazolium cations: a systematic computer simulation study. J Chem Phys, 120, p. 1855-1863, 2004.

. Single particle dynamics in ionic liquids of 1-alkyl-3-methylimidazolium cations. J Chem Phys, 122, p. 024511-024519, 2005.

. Collective excitations in an ionic liquid. J Chem Phys, 124, p. 74513-74518, 2006.

Vishal Govind, R.; Chiranjib, B.; Surajit, G.; Sarthak, M.; Jagannath, K.; NilmoNI, S. A step toward the development of high-temperature stable ionic liquid-in-oil microemulsions containing double-chain anionic surface active ionic liquid. The Journal of Physical Chemistry B, 117, 2013.

Voth, G. A. E. Coarse-graining of condensed phase and biomolecular systems. [S.1.]: CRC Press, 2012.

WANG, Y.; JiAng, W.; YAn, T.; Voth, G. A. Understanding ionic liquids through atomistic and coarse-grained molecular dynamics simulations. Acc. Chem. Res., 40, p. 1193-1199, 2007.

WANG, Y.; Voth, G. A. Unique spatial heterogeneity in ionic liquids. Journal of the American Chemical Society, 127, p. 12192-12193, 2005.

WeINGäRTnER, H. Understanding ionic liquids at the molecular level: facts, problems, and controversies. Angew. Chem. Int. Ed., 47, p. 654-670, 2008.

Welton, T. Room-temperature ionic liquids: solvents for synthesis and catalysis. Chemical Reviews, 99, p. 2071-2083, 1999.

Yue, Z.-G.; Liu, X.-M.; ZhaO, Y.-L.; Zhang, X.-C.; Lu, X.-M.; Zhang, S.-J. Molecular simulation on microstructure of ionic liquids in capture of CO2. Chin. J. Proc. Eng., 11, p. $652-659,2011$.

ZHANG, X.; LIU, Z.; WANG, W. Screening of ionic liquids to capture CO2 by Cosmo-Rs and experiments. AIChE Journal, 54, p. 2717-2728, 2008. 


\section{ESTUDO COMPUTACIONAL DE NANOTUBOS $\mathrm{DE}\left[\left(\mathrm{SnO}_{2}\right)_{\mathrm{n}}\right]_{\mathrm{m}}$}

José Divino SAntos ${ }^{1}$ e Júnio César Fonseca Silvą ${ }^{2}$

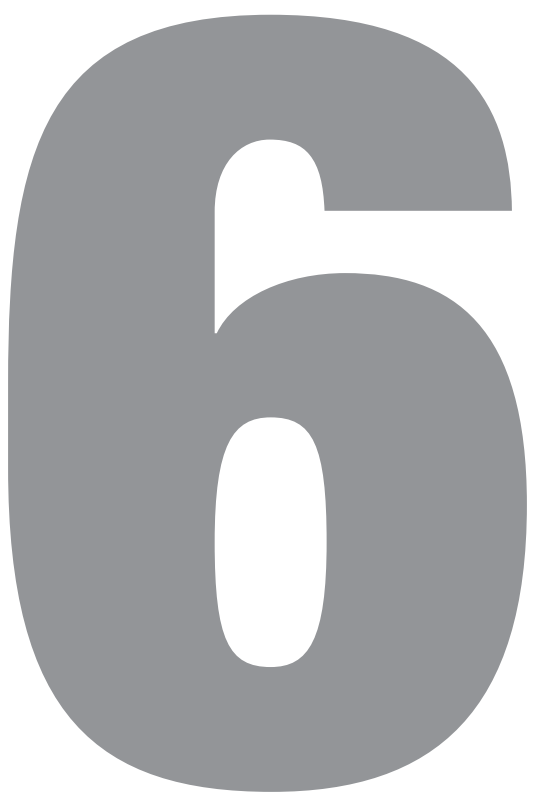

2 Universidade Estadual de Goiás (UEG), Anápolis-GO. E-mail: <juniocesar_1@hotmail.com>. 


\subsection{INTRODUÇ̃̃̃}

Com o desenvolvimento da nanociência e da nanotecnologia, um vasto número de literaturas sobre materiais nanoestruturais está sendo publicado todos os anos, ${ }^{3}$ apresentando diversas aplicações, tais como nanodispositivos, nanocircuitos e nanossistemas. ${ }^{4}$ Em particular, os nanotubos de carbono (CNTs) têm recebido consideráveis interesses por apresentarem propriedades para aplicação em nanotecnologia, ${ }^{5}$ tornando-se importante para a aplicação industrial em nanoeletrônicos e nanodispositivos, conforme inúmeros estudos teóricos e experimentais relatados na literatura. ${ }^{6}$

Pesquisas intensas vêm sendo realizadas sobre sínteses de nanotubos, principalmente os nanotubos de óxidos (oxides nanotubes). Entre esses óxidos inorgânicos, são citados $\mathrm{TiO}_{2}, \mathrm{MnO}_{2}, \mathrm{CoO}_{3}, \mathrm{~V}_{2} \mathrm{O}_{5}, \mathrm{ZrO}_{2}, \mathrm{SnO}_{2}$ e $\mathrm{SiO}_{4}{ }^{7}$ Remskar cita seis famílias de nanotubos inorgânicos: metal de transição calcogênio, NTs óxido (óxidos de metais de transição), NTs de metais de transição halogênios $\left(\mathrm{NiCl}_{2}\right)$, NTs com fases misturadas e metais dopantes, NTs baseados em boro e silício, nanotubos metálicos, sintetizados por diferentes rotas: oxidação de metais tri e tetravalentes, ${ }^{8}$ síntese solvotérmica, pirólise hidrotérmica, reação de transporte químico, pulverização, deposição de vapor químico, processos de pulverização química reativa, eletrodeposição, oxidação térmica. ${ }^{9}$

Dentre esses compostos, destaca-se o cristal do óxido de estanho $\left(\mathrm{SnO}_{2}\right)$, apresentando-se como um importante semicondutor do tipo n (n-type) com band

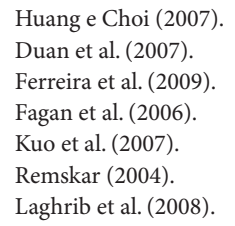


gap $(\mathrm{Eg}=3,6 \mathrm{eV}$ a $300 \mathrm{~K}),{ }^{10}$ destacando-se por suas aplicações em sensores de gás, ${ }^{11}$ por exemplo, $\mathrm{C}_{2} \mathrm{H}_{5} \mathrm{OH},{ }^{12} \mathrm{H}_{2}, \mathrm{SO}_{2}, \mathrm{H}_{2} \mathrm{~S}, \mathrm{CO}, \mathrm{NO}_{\mathrm{x}^{\prime}}$, hidrocarbonetos etc., ${ }^{13}$ transistores, células solares, catalisadores para aplicação em oxidação orgânica, cristal líquido (liquid crystal displays) ${ }^{14}$ fotocatálise, ${ }^{15}$ varistores, refratários, filmes protetores para eletrodos de baterias. ${ }^{16}$ Entretanto, várias nanoestruturas de $\mathrm{SnO}_{2}$, tais como nanobastões, nanofios, nanotubos, ${ }^{17}$ filmes finos foram sintetizados ${ }^{18}$ por diversos métodos, por exemplo: método de transporte da fase de vapor, ${ }^{19}$ evaporação térmica, sínteses solvotérmicas. ${ }^{20}$ Podem ser citados os filmes de nanocestas sintetizadas e caracterizados por difração de raios X (R-X), espectroscopia de raios X, espectroscopia Raman. ${ }^{21}$

De acordo com a estrutura do plano do cristal do rutilo na direção [110], ${ }^{22}$ foi construído um modelo para os nanotubos de $\mathrm{SnO}_{2}$. Esse modelo é formado por n número de unidades de $\mathrm{SnO}_{2}$, em que o átomo de estanho $(\mathrm{Sn})$ tem número de coordenação igual a $6(\mathrm{NC}=6){ }^{23}$

\subsection{Metodologia e métodos}

Os nanotubos de dióxido de estanho estão incluídos no grupo estequiométrico $\mathrm{XY}_{2}$ e podem estar combinados de várias formas e com distintas conformações. Nesses modelos, partiu-se de informações iniciais da forma cristalográfica conhecida para o óxido de estanho, que é encontrado na forma de rutilo, tendo-se, assim, várias aplicações tecnológicas, como sensores, varistores, catalisadores de uma série de substâncias. Observa-se que o plano cristalino do $\mathrm{SnO}_{2}$ mais listado tem a direção [110], em que se encontram estruturas de $\mathrm{SnO}_{2}$ combinadas, de formas alternadas, com ângulos de 90 graus entre eles, conforme a Figura 6.1:

10 Duan et al. (2007), Kim et al. (2006), Zhang et al. (2006).

11 Kim e Shin (2006).

12 Antunes et al. (1995).

13 Maziarz e Pisarkiewicz (2008).

14 Dong et al. (2008).

15 Firroz et al. (2008).

16 Kupchak et al. (2005).

17 Duan et al. (2007), Kim et al. (2006), Dong et al. (2008).

18 Dong et al. (2008).

19 Zhang et al. (2006).

20 Wang et al. (2009).

21 Johnson e Teeters (2006).

22 Camargo et al. (1996), Rantala et al. (1999), Antunes et al. (1995), Xue e Tang (2009), Whang et al. (2006), Vlcek et al. (2007), Prades et al. (2007a, 2007b), Zhu et al. (2009).

23 Ferreira et al. (2009). 


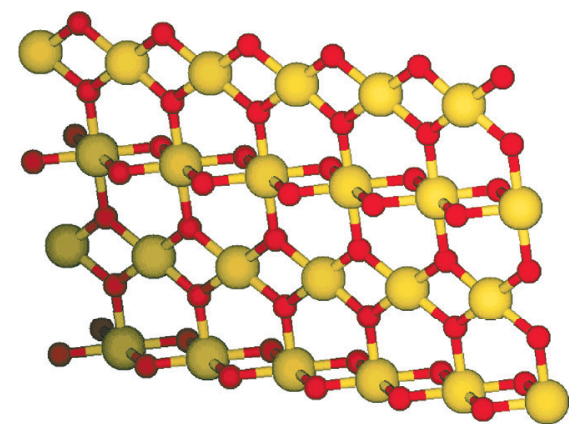

Figura 6.1 Parte do plano [110] do cristal do $\mathrm{SnO}_{2}$ na forma de rutilo.

As estruturas que são geradas na forma de nanotubos têm sido utilizadas como critério para a repetição de unidades de $\left(\mathrm{XY}_{2}\right)_{\mathrm{n}}$, cujos nanotubos são ordenados em linhas fechadas, como círculos, elipses etc.

Em um primeiro momento, construiu-se uma lógica para a geração de linhas nas formas de circunferências, com simetrias em todas as direções, ao longo desse círculo.

Encontraram-se relações entre o tamanho do perímetro das formas fechadas e o número de unidades das espécies $\mathrm{XY}_{2}$, conforme Figura 6.2:

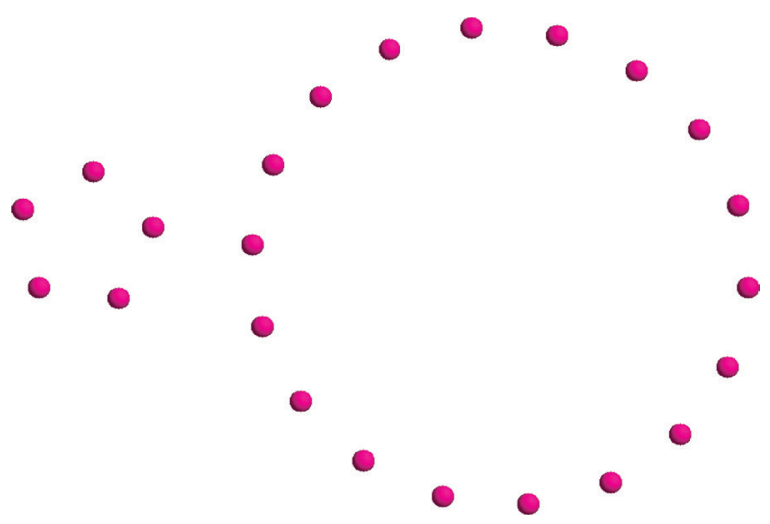
a) 5 estanhos
b) 18 estanhos.

Figura 6.2 Distribuição dos átomos $\mathrm{X}$ das espécies $\left(\mathrm{XY}_{2}\right) \mathrm{n}$ ao longo de círculos com os números de unidades diferentes, a) $\mathrm{n}=5$; b) $\mathrm{n}=18$.

As grandes quantidades de unidades de espécies $\mathrm{XY}_{2}$ ao longo do perímetro fazem com que seus raios sejam proporcionais, ou seja, há aumento dos diâmetros entre os modelos com número de unidades grandes, e as distâncias médias entre eles vão aumentando de acordo com o aumento das quantidades de espécies $\mathrm{XY}_{2}$, pois tamanho e comprimento entre as unidades básicas de $\mathrm{SnO}_{2}$ têm valores fixos. Assim:

Perímetro (nanotubo- $\left.\mathrm{XY}_{2}\right) \sim$ Número-de-unidades $\left(\mathrm{XY}_{2}\right)$ 
Dessa forma, obtém-se também a informação sobre a curvatura da superfície em questão, lembrando que ela é inversamente proporcional ao raio do nanotubo, com o número de unidades n, como mostrado na Figura 6.2. Assim, a espécie de menor número de unidades $\mathrm{XY}_{2}$ tem maior curvatura comparada com o item (b), em que os modelos com mais unidades de $\mathrm{XY}_{2}$ teriam curvaturas menores, tendendo a um valor muito pequeno ou zero, se o número de unidades $\mathrm{XY}_{2}$ fosse muito grande,

$$
\text { Curvatura (nanotubo- } \left.\mathrm{XY}_{2}\right) \rightarrow \text { zero se } \mathrm{n}\left(\mathrm{XY}_{2}\right) \rightarrow \text { muito grande }
$$

aproximando-se, assim, de um plano.

Como representado na Figura 6.1, observa-se que o diâmetro do nanotubo $\mathrm{XY}_{2}$ varia também segundo os valores das distâncias dos átomos constituintes do modelo do nanotubo. Tais distâncias seriam $\mathrm{d}_{\mathrm{XX}}, \mathrm{d}_{\mathrm{YY}}$ e $\mathrm{d}_{\mathrm{XY}}$. Pode-se escrever uma equação para o diâmetro em função dos valores dessas distâncias como:

$$
f_{D}=f_{D}\left(n X Y_{2}, d_{X X}, d_{Y Y}, d_{X Y}\right)
$$

Na Figura 6.3 são mostradas as posições em que estariam dispostas tais distâncias ao longo do modelo do nanotubo $\mathrm{XY}_{2}$.

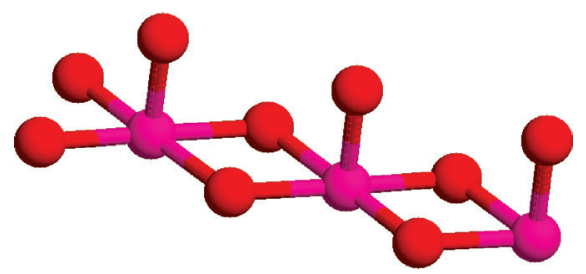

Figura 6.3 Disposição das distâncias $\mathrm{d}_{\mathrm{XX}}, \mathrm{d}_{\mathrm{YY}}$ e $\mathrm{d}_{\mathrm{XY}}$ ao longo do modelo do nanotubo $\mathrm{XY}_{2}$.

Os valores das distâncias entre o Sn-O no modelo têm maior contribuição na altura final dessa estrutura que foi construída, pois foi escolhido um crescimento ao longo do eixo z que tem a mesma direção dessa ligação no nanotubo. O plano é feito em xy, e vão ocorrendo repetições de unidades $\mathrm{XY}_{2}$, associadas às distâncias $\mathrm{d}_{\mathrm{xx}} \mathrm{e}$ $\mathrm{d}_{\mathrm{YY}}$. Deve-se salientar que os planos das unidades verticais influenciam as partes horizontais e vice-versa, sabendo que existem interações entre essas regiões ao longo da estrutura.

A construção dos modelos de $\mathrm{SnO}_{2}$ foi feita utilizando a estrutura do plano [110] do rutilo para um primeiro nível, em que se têm as unidades de $\mathrm{SnO}_{2}$ ligadas formando um círculo, conforme a Figura 6.4: 


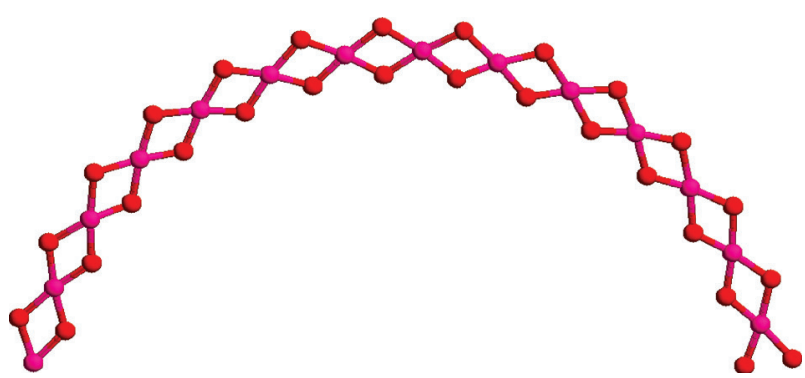

Figura 6.4 Representação de parte horizontal do modelo do nanotubo de $\mathrm{SnO}_{2}$.

Consideram-se as distâncias entre os átomos de $\mathrm{Sn}$-Sn ao longo do perímetro para se calcular o diâmetro da circunferência associada a esse número de unidades. Em seguida, são colocadas outras unidades de $\mathrm{SnO}_{2}$, perpendicularmente às últimas unidades, para formar um conjunto com simetria horizontal/vertical, conforme ilustra a Figura 6.5.

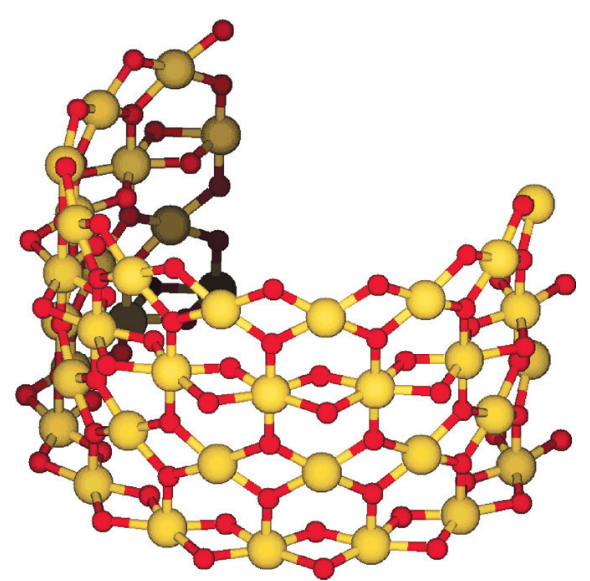

Figura 6.5 Representação entre unidades de $\mathrm{SnO}_{2}$ pertencentes aos planos perpendiculares.

Tais níveis nos nanotubos podem crescer indefinidamente na direção positiva ou negativa do eixo $z$.

Para obter o tamanho de diâmetro, coloca-se um átomo de Sn no eixo X a uma distância qualquer positiva da origem, faz-se a escolha de um segundo átomo, que pertencerá a uma circunferência, estando a uma distância $\mathrm{d}_{\mathrm{SnSn}}$, estanho-estanho, associada ao parâmetro de rede do plano [110] do rutilo. Dessa forma, obtém-se o valor de ângulo teta, associado a essa distância Sn-Sn. Contudo, mesmo assim, existiriam vários ângulos teta, pois são funções do raio da circunferência em questão; por isso, faz-se uma segunda escolha, que seria a quantidade de unidades de espécies de $\mathrm{SnO}_{2}$ ao longo de perímetro, de forma que o raio varie conforme a quantidade de unidades $\mathrm{SnO}_{2}$ ao longo desse caminho, uma vez que as distâncias $\mathrm{Sn}-\mathrm{Sn}$ seriam 
constantes e, dessa forma, haveria uma correlação diretamente proporcional entre o diâmetro, o raio, o número de unidades e a distância $S n-S n$. Tem-se uma função escrita como:

$$
\text { raio = raio (n (unidades), distância }(S n-S n))
$$

Desse modo, o raio é calculado como mostrado na Figura 6.6, com vetores posições $\overrightarrow{\mathrm{u}}, \overrightarrow{\mathrm{v}}$, que representam as coordenadas dos átomos $S n_{\mathrm{i}}, \mathrm{Sn}_{\mathrm{j}}$, separados por uma distância $|\overrightarrow{\mathrm{v}}-\overrightarrow{\mathrm{u}}|=\mathrm{d}_{\mathrm{Sn}-\mathrm{Sn}}$, a qual é igual à distância de ligação entre os átomos de estanho ao longo do caminho na circunferência.
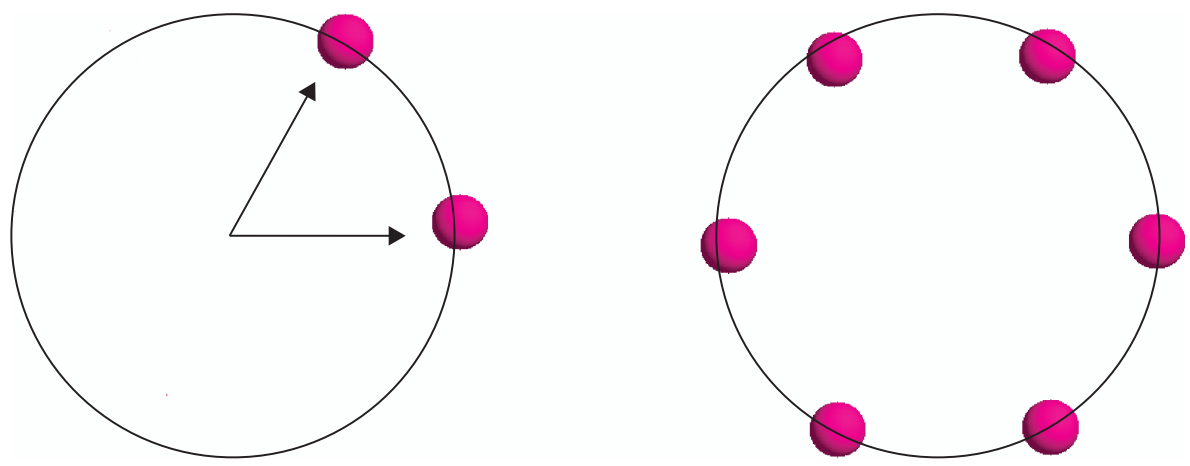

Figura 6.6 Representação dos vetores posições $\overrightarrow{\mathrm{u}}, \overrightarrow{\mathrm{v}}$ para os átomos de estanho $S n_{\mathrm{i}}, S n_{\mathrm{j}}$, separados por uma distância $\mathrm{d}_{\mathrm{Sn}-\mathrm{Sn}}=|\overrightarrow{\mathrm{v}}-\overrightarrow{\mathrm{u}}|$.

Escolhe-se a quantidade de unidades $\mathrm{nSnO}_{2}$ no nível em questão, que está associado à coordenada em que o valor de z é nulo no início. Assim, utilizam-se somente os vetores posições para as coordenadas x, y. Então, os valores dos ângulos teta são:

$$
\theta=\frac{2 \pi}{\mathrm{n}}
$$

o que representa uma distribuição simétrica de átomos de estanho que formarão sempre ângulos iguais, passando pela origem da circunferência, conforme demonstra a Figura 6.6.

As coordenadas dos vetores posições $\mathrm{u}, \mathrm{v}$ são:

$\vec{u}=r_{\hat{i}}$

$$
\overrightarrow{\mathrm{v}}=r \cos \theta \hat{\mathrm{i}}+\mathrm{rsen} \theta \hat{\mathrm{j}}
$$

e podem ser escritas como:

$$
\vec{u}=r_{\hat{\imath}}
$$




$$
\overrightarrow{\mathrm{v}}=r \cos \frac{2 \pi}{\mathrm{n}} \hat{\mathrm{i}}+\mathrm{rsen} \frac{2 \pi}{\mathrm{n}} \hat{\mathrm{j}}
$$

Faz-se a diferença $|\overrightarrow{\mathrm{v}}-\overrightarrow{\mathrm{u}}|$ como o módulo $\mathrm{d}_{\text {SnSn }}$, que é escrito como:

$$
\overrightarrow{\mathrm{v}}-\overrightarrow{\mathrm{u}}=\mathrm{r} \cos \frac{2 \pi}{\mathrm{n}} \hat{\mathrm{i}}-1+\mathrm{rsen} \frac{2 \pi}{\mathrm{n}} \hat{\mathrm{j}}
$$

obtendo-se:

$$
|\vec{v}-\vec{u}|=d_{S n S n}=r \sqrt{2-2 \cos \frac{2 \pi}{n}}
$$

Assim, o raio da circunferência associada ao número de unidades de $\mathrm{SnO}_{2}$ e à distância $\mathrm{d}_{\mathrm{Sn}-\mathrm{Sn}}$ é:

$$
\mathrm{r}=\text { raio }=\frac{\mathrm{d}_{\mathrm{SnSn}}}{\sqrt{2-2 \cos \frac{2 \pi}{\mathrm{n}}}}
$$

Substituindo esse valor no vetor v, que tem uma representação mais genérica, e renomeando-o para um vetor $\mathrm{f}$, tem-se:

$$
\begin{gathered}
\vec{f}=f_{x} \vec{i}+f_{y} j+f_{z} \vec{k} \\
\vec{f}=\frac{d_{\text {SnSn }} \cos \frac{2 \pi}{n}}{\sqrt{2-2 \cos \frac{2 \pi}{n}}} \vec{i}+\frac{d_{\text {SnSn }} \operatorname{sen} \frac{2 \pi}{n}}{\sqrt{2-2 \cos \frac{2 \pi}{n}}} \vec{j}+f_{z} \vec{k}
\end{gathered}
$$

em que of é zero, referente à coordenada $\mathrm{z}$ inicial no plano XY, considerada como nula.

$\mathrm{Na}$ obtenção do próximo nível, as ligações das espécies $\mathrm{SnO}_{2}$ ficam perpendiculares ao conjunto anterior, mas seguem a geometria do plano [110] da forma do rutilo. Começa-se pela coordenada do átomo de oxigênio, que estará a uma distância $\mathrm{d}_{\text {Sn-O }}$ do plano XY inicial, e tem-se, assim, a coordenada do vetor de formação associado a um outro ângulo alfa, conforme a Figura 6.7. 


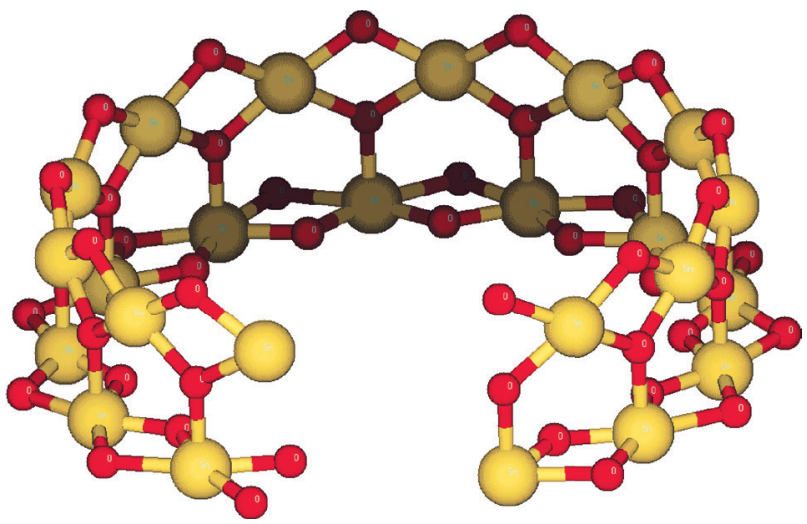

Figura 6.7 Disposições dos átomos no plano de primeiro nível, horizontal e outro vertical.

Conseguem-se as coordenadas do vetor de formação completo, que estariam, dessa forma, condicionadas a mais uma distância, $\mathrm{d}_{\mathrm{SnO}}$, podendo a função geradora ser escrita como:

$$
f_{D}=f_{D}\left(n n n O_{2}, d_{S n S n}, d_{S n O}\right)
$$

escrevendo o nanotubo com repetições simétricas e alternadas a quantidades de níveis $m$ escolhidas para fazer o cálculo teórico para a simulação.

A obtenção das coordenadas dos átomos diferentes do estanho no primeiro nível, no caso, os átomos de oxigênio, é feita por aplicações de pequenas translações no plano XY, em que esses incrementos estejam associados aos ângulos formados entre $\mathrm{O}-\mathrm{Sn}-\mathrm{O}$ ou à distância $\mathrm{O}-\mathrm{O}$, no nível em questão. Da mesma forma, no segundo nível, obtêm-se as coordenadas dos átomos de $\mathrm{Sn}$ por meio de pequenas translações simétricas ao longo de um cilindro que se forma conforme o número de níveis $\mathrm{m}$ vai aumentando no modelo de nanotubo de $\mathrm{SnO}_{2}$.

A função geradora fica com mais duas variáveis e pode ser escrita como:

$$
\mathrm{f}_{\mathrm{D}}=\mathrm{f}_{\mathrm{D}}\left(\mathrm{nSnO}_{2}, \mathrm{~m}, \mathrm{~d}_{\mathrm{SnSn}}, \mathrm{d}_{\mathrm{OO}}, \mathrm{d}_{\mathrm{SnO}}\right)
$$

Os métodos utilizados para obtenção das energias desses clusters têm como resolução a equação de Schröedinger, com aproximação em semiempírico MNDO e ab initio com métodos DFT, HF utilizando bases do tipo Huzinaga. Foi feita a análise segundo as variações das energias obtidas nesses métodos, conforme as modificações das coordenadas do conjunto de unidades de $\mathrm{SnO}_{2}$ ao longo do modelo do nanotubo. A estabilidade desses nanotubos foi estudada com as variações de $\mathrm{nSnO}_{2}$, $\mathrm{m}, \mathrm{d}_{\mathrm{SnSn}}, \mathrm{d}_{\mathrm{OO}}$ e $\mathrm{d}_{\mathrm{SnO}}$. Os valores iniciais para essas distâncias foram os mesmos encontrados como parâmetros de rede no plano [110] do cristal rutilo do dióxido de estanho, quais sejam, $\mathrm{d}_{\mathrm{SnSn}}=3,30-4,31 \AA \mathrm{d}_{\mathrm{SnO}}=2,13-2,63 \AA$, $\mathrm{d}_{\mathrm{OO}}=1,94-2,40 \AA$. 
As conformações foram sofrendo pequenas variações, e calculadas as energias totais dessas estruturas, procurando, assim, as geometrias mais estáveis com diferentes diâmetros e números de unidades de $\mathrm{SnO}_{2}$ e níveis $\mathrm{m}$, referentes ao crescimento dos modelos ao longo da direção do eixo z.

Para entendimento dos modelos, adotou-se uma simbologia para os nanotubos de $\mathrm{SnO}_{2}$ :

$$
(\mathrm{n}, \mathrm{m})=\left\{\left[\left(\mathrm{SnO}_{2}\right)_{2}\right]_{\mathrm{n}}\right\}_{\mathrm{m}}
$$

Assim, todos os modelos calculados podem ser escritos conforme a Tabela 6.1, tendo 30 modelos com a quantidade de átomos de Sn, O, variando de 36 até 540, sabendo-se que se utilizou o método DFT/B3LYP com base de Huzinaga para as otimizações, a fim de diminuir os tempos computacionais necessários para as convergências das estruturas. Mesmo com os métodos com aproximações em semiempírico MNDO com software mopac2009, alguns dos resultados levaram alguns dias rodando em computadores com mais de 40 gigabytes de memória RAM.

Tabela 6.1 Unidades $\mathrm{n}$ de $\mathrm{SnO}_{2}$, o número de níveis $\mathrm{m}$ em $\left\{\left[\left(\mathrm{SnO}_{2}\right)_{2}\right]_{\mathrm{n}}\right\}_{\mathrm{m}}$ e o respectivo número de átomos em cada modelo.

\begin{tabular}{ccc}
$\mathbf{n}$ unidades & Níveis m $=\mathbf{1}, \mathbf{2 , 3}$ & $\boldsymbol{(} \mathbf{n}, \mathbf{m})=$ número de átomos \\
\hline 6 & $\left\{\left[\left(\mathrm{SnO}_{2}\right)_{2}\right]_{6}\right\}_{\mathrm{m}}$ & $(6,1)=36,(6,2)=72,(6,3)=108$ \\
8 & $\left\{\left[\left(\mathrm{SnO}_{2}\right)_{2}\right]_{8}\right\}_{\mathrm{m}}$ & $(8,1)=48,(8,2)=96,(8,3)=144$ \\
10 & $\left\{\left[\left(\mathrm{SnO}_{2}\right)_{2}\right]_{10}\right\}_{\mathrm{m}}$ & $(10,1)=60,(10,2)=120,(10,3)=180$ \\
12 & $\left\{\left[\left(\mathrm{SnO}_{2}\right)_{2}\right]_{12}\right\}_{\mathrm{m}}$ & $(12,1)=72,(12,2)=144,(12,3)=216$ \\
14 & $\left\{\left[\left(\mathrm{SnO}_{2}\right)_{2}\right]_{14}\right\}_{\mathrm{m}}$ & $(14,1)=84,(14,2)=168,(14,3)=252$ \\
16 & $\left\{\left[\left(\mathrm{SnO}_{2}\right)_{2}\right]_{16}\right\}_{\mathrm{m}}$ & $(16,1)=96,(16,2)=192,(16,3)=288$ \\
18 & $\left\{\left[\left(\mathrm{SnO}_{2}\right)_{2}\right]_{18}\right\}_{\mathrm{m}}$ & $(18,1)=108,(18,2)=216,(18,3)=324$ \\
20 & $\left\{\left[\left(\mathrm{SnO}_{2}\right)_{2}\right]_{20}\right\}_{\mathrm{m}}$ & $(20,1)=120,(20,2)=240,(20,3)=360$ \\
30 & $\left\{\left[\left(\mathrm{SnO}_{2}\right)_{2}\right]_{30}\right\}_{\mathrm{m}}$ & $(30,1)=180,(30,2)=360,(30,3)=540$ \\
40 & $\left\{\left[\left(\mathrm{SnO}_{2}\right)_{2}\right]_{40}\right\}_{\mathrm{m}}$ & $(40,1)=240,(40,2)=480$ \\
50 & $\left\{\left[\left(\mathrm{SnO}_{2}\right)_{2}\right]_{50}\right\}_{\mathrm{m}}$ & $(50,1)=300$ \\
\hline
\end{tabular}

Tem-se, em seguida, na Figura 6.8, um grupo de nanotubos de $\mathrm{SnO}_{2}$, com números de unidades em um nível iguais a $\mathrm{n}=8,12,16,20,30$. 


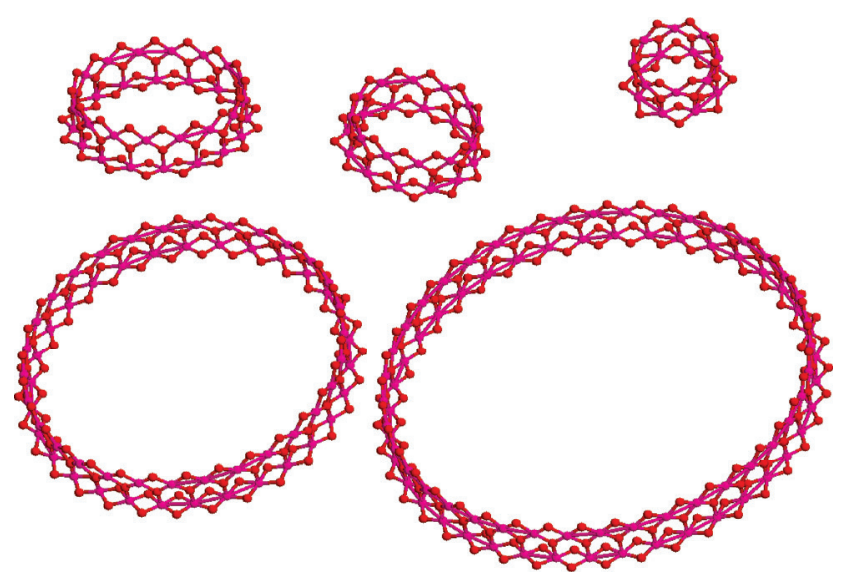

Figura 6.8 Representações de modelos dos nanotubos de $\mathrm{SnO}_{2}$ com vistas frontais e números de unidades: $(8,1) ;(12,1) ;(16,1) ;(20,1) ;(30,1)$.

Observa-se na Figura 6.8 que os raios aumentam com números de unidades e as curvaturas desses modelos vão diminuindo, isto é, estas são inversamente proporcionais ao raio. Se for interpretado, fazendo um paralelo com o plano [110] do $\mathrm{SnO}_{2}$, seria como se o plano dessa estrutura fosse sendo enrolado, dependendo desse raio de enrolamento, e essa nova conformação ficaria mais instável ou estável segundo a taxa de curvatura do modelo.

Neste estudo, faz-se uma análise das variações das energias de uma estrutura inicial preestabelecida, tendo como base os parâmetros de rede do material $\mathrm{SnO}_{2}$ cristalizado, em que é possível obter várias combinações para essas variações de energias, pois elas podem ser modificadas conforme os tamanhos das estruturas; no caso, o diâmetro é vinculado ao número de unidades de $\mathrm{SnO}_{2}$; a altura do modelo, no caso, é vinculada à quantidade de níveis que são colocados ao longo do eixo $\mathrm{z}$ e também às pequenas variações das distâncias $\mathrm{d}_{\mathrm{Snnn}}, \mathrm{d}_{\mathrm{OO}}$ e $\mathrm{d}_{\mathrm{SnO}}$, que são escolhidas como valores iniciais para as primeiras coordenadas que são geradas para as conformações desses nanotubos de $\mathrm{SnO}_{2}$.

É necessário o estudo de modelos que contenham uma quantidade maior de átomos, encontrando, assim, a dependência da estabilidade dos clusters com essas quantidades de espécies de $\mathrm{SnO}_{2}$ nas estruturas, podendo analisar uma diversidade de isômeros/alótropos que são gerados com os crescimentos para as várias direções, sempre considerando uma proximidade com a geometria do plano [110] da estrutura do rutilo do $\mathrm{SnO}_{2}$. 


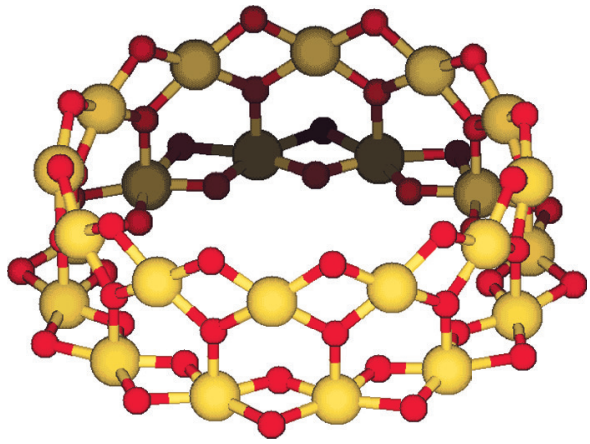

a) $(12,1)$

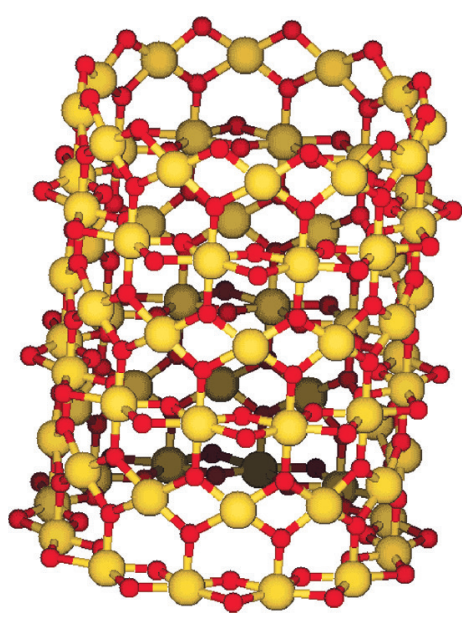

b) $(12,3)$

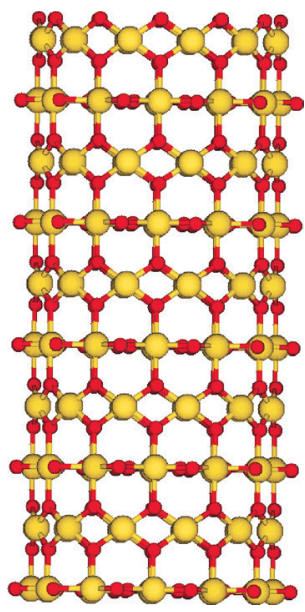

c) $(12,5)$

Figura 6.9 Modelos de nanotubos $\mathrm{SnO}_{2},\left\{\left[\left(\mathrm{SnO}_{2}\right)_{2}\right]_{12}\right\}_{1},\left\{\left[\left(\mathrm{SnO}_{2}\right)_{2}\right]_{12}\right\}_{3},\left\{\left[\left(\mathrm{SnO}_{2}\right)_{2}\right]_{12}\right\}_{5} ; \mathrm{m}=1,3,5$.

$\mathrm{Na}$ Figura 6.9, têm-se modelos de nanotubos de $\mathrm{SnO}_{2}$ com números de unidades iguais e com níveis diferentes.

Foram feitas as análises de variações das energias ao longo das variações de distâncias, ângulos, torções, cargas ao longo dos níveis, dipolos, Homo-Lumo, DOS, diferença entre os vários modelos que foram trabalhados, com diâmetros e alturas diferentes. 


\subsection{ANÁLISES DE RESULTADOS E DISCUSSÕES}

As variações das energias como funções das distâncias Sn-Sn, O-O, Sn-O, o número de unidades de $\mathrm{SnO}_{2}$ ao longo dos diâmetros e o número de níveis levam a comprimentos ou alturas diferentes para as estruturas dos nanotubos de $\mathrm{SnO}_{2}$.

As otimizações dos clusters foram feitas conforme as distâncias entre os átomos, as quais foram sendo modificadas com o objetivo de encontrar as estruturas com maiores estabilidades para os modelos de nanotubo.

Ao utilizar um algoritmo para o desenvolvimento de modelos com a linguagem em shell bash para o sistema operacional Linux, faz-se uma entrada de dados associados aos parâmetros iniciais, como as distâncias entre os átomos, o número de unidades no plano XY, a quantidade de níveis que são utilizados no sentido positivo do eixo $\mathrm{z}$, a carga do sistema, a multiplicidade necessária, o método quântico semiempírico ou ab initio escolhido, bem como o range das variações para as distâncias entre os SnSn, OO e SnO.

A evolução nas otimizações foi sendo feita em etapas, pois uma total liberdade do cluster faz com que este se instabilize, e, em seguida, o sistema perderia a simetria e convergiria para situações totalmente não previstas, perdendo, assim, a geometria ou conformação do nanotubo. Dessa forma, foi utilizada uma forma semelhante às otimizações de modelos cristalinos, partindo sempre de informações associadas aos parâmetros de rede cristalinos do plano de trabalho [110] da forma rutilo para o dióxido de estanho.

Escreve-se a forma d(n, m), que representa as distâncias que são as menores energias para todos os modelos que estariam associados às geometrias que levam a uma maior estabilização dos clusters estudados, e a $\Delta \mathrm{E}(\mathrm{n}, \mathrm{m})$, variações de energias respectivas, conforme mostrado nas tabelas 6.2, 6.3 e 6.4.

A obtenção das estruturas com maiores estabilidades confere oportunidades para comparar uma gama de nanotubos que têm os mesmos números de átomos, diferenciando-os pelas conformações ou pelos números de unidades e níveis. Assim, obteve-se um conjunto de pares com as energias semelhantes, mas com um diferencial entre eles, em razão das conformações escolhidas entre os átomos de estanho e oxigênio. As energias de isômeros geométricos são escritas conforme a Tabela 6.2.

Tabela 6.2 Comparações das estabilidades entre polímeros de nanotubo de $\mathrm{SnO}_{2}$.

\begin{tabular}{|cccc|}
\hline Isômero I & Energia/eV & Isômero II & Energia/eV \\
\hline$(6,2)$ & -17593.875 & $(12,1)$ & -17632.389 \\
$(8,2)$ & -23485.797 & $(16,1)$ & -23517.571 \\
\hline$(10,2)$ & -29374.352 & $(20,1)$ & -29401.134 \\
\hline$(12,2)$ & -35250.000 & $(8,3)$ & -35228.098 \\
$(6,3)$ & -26390.809 & $(18,1)$ & -26459.475 \\
\hline$(10,3)$ & -44060.749 & $(30,1)$ & -44107.992 \\
\hline
\end{tabular}


Tabela 6.2 Continuação...

\begin{tabular}{cccc}
\hline Isômero I & Energia/eV & Isômero II & Energia/eV \\
\hline$(12,3)$ & -52888.305 & $(18,2)$ & -52911.839 \\
$(20,2)$ & -58794.479 & $(6,2)$ & -58813.723 \\
$(20,3)$ & -88188.489 & $(30,2)$ & -88203.929 \\
\hline
\end{tabular}

A partir desses resultados, observa-se que as estruturas com menores curvaturas, diâmetros maiores e quantidade de unidades de $\mathrm{SnO}_{2}$ maiores têm maiores estabilidades ou energias menores, em comparação com as espécies com grande curvatura, diâmetros pequenos ou quantidades menores de unidades de $\mathrm{SnO}_{2}$. Assim, no conjunto anterior, mostram-se essas tendências, bem como as tendências de que as estruturas químicas dos nanotubos de $\mathrm{SnO}_{2}$ vão crescendo ou aparecendo com os diâmetros maiores que os apresentados, mostrando uma concordância com os experimentos, em que foi observada uma série de materiais que têm suas funcionalidades específicas e uma gama de aplicações tecnológicas.

A Tabela 6.3 mostra os valores das energias para os nanotubos de $\mathrm{SnO}_{2}$, calculados utilizando métodos $a b$ initio e método funcional de densidades com bases de Huzinaga, B3LYP/Huzinaga, em que os comportamentos entre os valores das energias dos modelos para as várias unidades e distintos níveis calculados são semelhantes aos obtidos pelo método semiempírico MNDO, o que indica maiores estabilidades associadas às estruturas que têm maiores diâmetros e maiores alturas.

Os resultados nas tabelas podem ser comparados entre si, para os modelos que têm as mesmas quantidades de átomos de estanho e oxigênio, como foi feito na Tabela 6.2. Assim, os valores das energias para tais estruturas indicam as mesmas tendências que foram encontradas com o método MNDO, no qual, se forem comparados dois a dois os modelos de mesmo número de átomos, ter-se-á uma série de pares que, no caso dos resultados com o método B3LYP-Huzinaga, se mostram mais estáveis para as geometrias com quantidade maior de unidades de $\mathrm{SnO}_{2}$, ao longo do diâmetro, em comparação com as estruturas com menores diâmetros e maiores níveis. Dessa forma, o comportamento para as estruturas com maiores diâmetros é beneficiado do ponto de vista da estabilidade desses clusters e métodos mecânicos quânticos escolhidos para fazer tais verificações.

Tabela 6.3 Valores das energias ab initio B3LYP/Huzinaga de nanotubos $\left\{\left[\left(\mathrm{SnO}_{2}\right)_{2}\right]_{\mathrm{n}}\right\}_{\mathrm{m}}$.

\begin{tabular}{|ccc|}
\hline$(\mathbf{n}, \mathbf{1})$ & $\mathbf{d S n S n - d O O - d S n O / a n g s t r o n s}$ & B3LYP-Huzinaga/eV \\
\hline$(6,1)$ & $3.465-2.325-2.125-\mathrm{SnSn}$ & -2014826.240 \\
$(8,1)$ & $3.319-2.386-2.125-\mathrm{OO}$ & -2686447.076 \\
$(10,1)$ & $3.319-2.386-2.125-\mathrm{OO}$ & -3358068.032 \\
$(12,1)$ & $3.319-2.386-2.125-\mathrm{OO}$ & -4029687.053 \\
$(14,1)$ & $3.319-2.344-2.125-\mathrm{OO}$ & -4701302.105 \\
$(16,1)$ & $3.319-2.344-2.125-\mathrm{OO}$ & -5372919.186 \\
\hline
\end{tabular}


Tabela 6.3 Continuação...

\begin{tabular}{|ccc|}
\hline$(\mathbf{n}, \mathbf{1})$ & $\mathbf{d} \mathbf{S n S n - d O O}-\mathbf{d S n O} / \mathbf{a n g s t r o n s}$ & B3LYP-Huzinaga/eV \\
\hline$(18,1)$ & $3.319-2.344-2.125-\mathrm{OO}$ & -6044535.932 \\
\hline$(20,1)^{*}$ & $3.319-2.344-2.125-\mathrm{OO}$ & -6716152.386 \\
\hline$(30,1)$ & $3.319-2.344-2.125-\mathrm{OO}$ & -10074233.544 \\
\hline$(6,2)$ & $3.525-2.325-2.125-\mathrm{SnSn}$ & -4029669.949 \\
\hline$(8,2)$ & $3.319-2.386-2.125-\mathrm{OO}$ & -5372908.163 \\
\hline$(10,2)^{*}$ & $3.319-2.386-2.125-\mathrm{OO}$ & -6716153.347 \\
\hline$(12,2)$ & $3.319-2.386-2.125-\mathrm{OO}$ & -8059394.173 \\
\hline$(14,2)$ & $3.319-2.386-2.125-\mathrm{OO}$ & -9402633.154 \\
\hline$(6,3)$ & $3.585-2.325-2.125-\mathrm{SnSn}$ & -6044511.468 \\
\hline$(8,3)$ & $3.406-2.325-2.125-\mathrm{SnSn}$ & -8059374.628 \\
\hline$(10,3)$ & $3.286-2.325-2.125-\mathrm{SnSn}$ & -10074223.762 \\
\hline
\end{tabular}

Da mesma forma, foi utilizado o método ab initio HF/Huzinaga para todas as estruturas indicadas na Tabela 6.4, que têm os valores das energias associados aos modelos de nanotubos de $\mathrm{SnO}_{2}$. Foram escolhidas as distâncias entre $\mathrm{SnSn}$, OO e $\mathrm{SnO}$ que levassem a uma maior estabilidade das estruturas. Assim, tem-se que as estruturas isoméricas são comparadas entre si e com menores energias relacionadas àquelas com maiores diâmetros. Pode-se, assim, observar os valores das energias dos conjuntos $(6,2)$ e $(12,1),(8,2)$ e $(16,1)$, e assim por diante, como no conjunto de comparações da Tabela 6.2.

Tabela 6.4 Valores das energias ab initio HF/Huzinaga de nanotubos $\left\{\left[\left(\mathrm{SnO}_{2}\right)_{2}\right]_{\mathrm{n}}\right\}_{\mathrm{m}}$.

\begin{tabular}{|ccc|}
\hline$(\mathbf{n}, \mathbf{1})$ & dSnSn-dOO-dSnO/angstrons & HF-Huzinaga/eV \\
\hline$(6,1)$ & $3.525-2.325-2.125-\mathrm{SnSn}$ & -2013736.824 \\
\hline$(8,1)$ & $3.319-2.386-2.125-\mathrm{OO}$ & -2685000.261 \\
\hline$(10,1)$ & $3.319-2.386-2.125-\mathrm{OO}$ & -3356263.052 \\
\hline$(12,1)$ & $3.319-2.386-2.125-\mathrm{OO}$ & -4027522.811 \\
\hline$(14,1)$ & $3.319-2.344-2.125-\mathrm{OO}$ & -4698779.310 \\
\hline$(16,1)$ & $3.226-2.325-2.125-\mathrm{SnSn}$ & -5370037.252 \\
\hline$(18,1)$ & $3.226-2.325-2.125-\mathrm{SnSn}$ & -6041294.972 \\
\hline$(20,1)$ & $3.226-2.325-2.125-\mathrm{SnSn}$ & -6712552.345 \\
\hline$(30,1)$ & $3.166-2.325-2.125-\mathrm{SnSn}$ & -10068835.432 \\
\hline$(40,1)$ & $3.166-2.325-2.125-\mathrm{SnSn}$ & -13425118.167 \\
\hline$(50,1)$ & $3.166-2.325-2.125-\mathrm{SnSn}$ & -16781400.142 \\
\hline$(6,2)$ & $3.525-2.325-2.125-\mathrm{SnSn}$ & -4027484.932 \\
\hline$(8,2)$ & $3.319-2.386-2.125-\mathrm{OO}$ & -5370012.073 \\
\hline$(10,2)$ & $3.319-2.386-2.125-\mathrm{OO}$ & -6712540.183 \\
\hline
\end{tabular}


Tabela 6.4 Continuação...

\begin{tabular}{ccc}
\hline$(\mathbf{n}, \mathbf{1})$ & $\mathbf{d S n S n - d O O - d S n O / a n g s t r o n s}$ & HF-Huzinaga/eV \\
\hline$(12,2)$ & $3.319-2.386-2.125-\mathrm{OO}$ & -8055062.848 \\
$(14,2)$ & $3.319-2.386-2.125-\mathrm{OO}$ & -9397582.784 \\
$(16,2)$ & $3.319-2.386-2.125-\mathrm{OO}$ & -10740101.223 \\
$(18,2)$ & $3.319-2.386-2.125-\mathrm{OO}$ & -12082618.784 \\
\hline
\end{tabular}

Pode-se também analisar uma série de modelos com as variações das distâncias associadas aos átomos de $\mathrm{SnSn}, \mathrm{OO}, \mathrm{SnO}$, sabendo que há mais recobrimento de orbitais somente entre as ligações $\mathrm{SnO}$, que são de natureza química.

A análise da Tabela 6.5 informa que as distâncias entre os átomos de oxigênio que passaram por uma otimização ficaram entre 2.344 e 2.427 angstrons nos modelos dos nanotubos de $\mathrm{SnO}_{2}$, sabendo-se que esses átomos estão ligados quimicamente aos átomos de estanho desse cluster. Observa-se que as variações das energias dos sistemas vão diminuindo conforme vai aumentando o tamanho dos diâmetros dos sistemas (número de unidades de $\mathrm{SnO}_{2}$ ), bem como a estabilização vai aumentando, representada pela variação da energia, com o aumento do número de níveis (a altura ou o comprimento) dos nanotubos. Na mesma tabela, podem ser calculadas as taxas de variações de energias conforme os valores de $\mathrm{n}$ e $\mathrm{m}$ vão variando nos modelos. Há uma indicação de linearidade para essas taxas de variações versus o aumento de níveis com o aumento de unidades constantes no modelo em questão e em relação às variações das distâncias entre os átomos de oxigênio.

Escreve-se a equação química correspondente às variações dessas energias como:

$$
2\left\{\left[\left(\mathrm{SnO}_{2}\right)_{2}\right]_{\mathrm{n}}\right\}_{1} \rightarrow\left\{\left[\left(\mathrm{SnO}_{2}\right)_{2}\right]_{\mathrm{n}}\right\}_{2}
$$

escrita como: $2(\mathrm{n}, 1) \rightarrow(\mathrm{n}, 2)$

$$
2\left\{\left[\left(\mathrm{SnO}_{2}\right)_{2}\right]_{\mathrm{n}}\right\}_{1}+\left\{\left[\left(\mathrm{SnO}_{2}\right)_{2}\right]_{\mathrm{n}}\right\}_{1} \rightarrow\left\{\left[\left(\mathrm{SnO}_{2}\right)_{2}\right]_{\mathrm{n}}\right\}_{3}
$$

escrita como: $2(\mathrm{n}, 1)+(\mathrm{n}, 1) \rightarrow(\mathrm{n}, 3)$.

Faz-se a análise das estabilidades desses clusters em termos das energias, como funções entre as distâncias $\mathrm{SnSn}, \mathrm{OO}$ e $\mathrm{SnO}$, com uma variação em um intervalo entre essas distâncias, utilizando as energias relacionadas às menores distâncias com parâmetros de comparação entre as várias outras distâncias. Assim, foram construídos vários tipos de variações e taxas que são comparados.

Nas tabelas 6.5, 6.6, 6.7, observam-se as variações de energias em relação às menores distâncias, bem como uma análise posterior entre essas variações de energias, como funções dos números de unidades, $\frac{\partial \Delta \mathrm{E}}{\partial \mathrm{m}_{\mathrm{n}}}$, de $\mathrm{SnO}_{2}$ constantes.

Ao fazer esse tipo de análise, pode-se escrever um esquema de todas as taxas a serem obtidas a partir das estruturas com as menores energias, em função dos 
valores de n e m nas regiões de mínimos para distâncias $\mathrm{SnSn}$, OO e $\mathrm{SnO}$, como escrito no organograma a seguir:

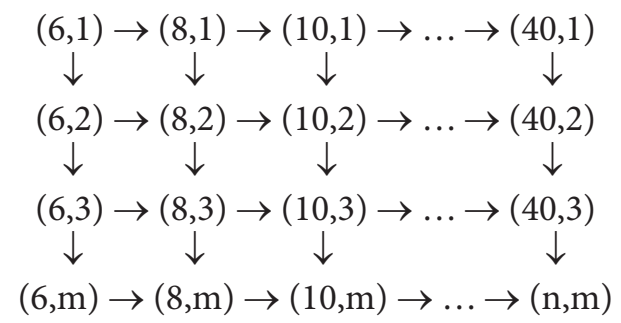

Na linha horizontal, no esquema anterior, representam-se as estruturas com as mesmas alturas e os diâmetros diferentes, enquanto na vertical estão as estruturas com os mesmos diâmetros e alturas diferentes. A partir dos resultados obtidos das energias, observa-se que a estabilização se move da esquerda para a direita e de cima para baixo, ou seja, para estruturas com alturas e diâmetros maiores, mas com maiores pesos nessas modificações associadas aos diferentes diâmetros que estão ligados aos números de unidade de $\mathrm{SnO}_{2}$. As taxas relacionadas à razão $\frac{\partial \Delta \mathrm{E}}{\partial \mathrm{n}_{\mathrm{m}}}$ seriam representadas em todos os nanotubos com número de $\mathrm{SnO}_{2}$ constante e vários níveis na direção $\mathrm{z}$ do crescimento.

Nas tabelas 6.5, 6.6 e 6.7 são realizadas comparações com otimizações das distâncias entre $\mathrm{SnSn}$, OO e $\mathrm{SnO}$ nos modelos, bem como comparações de todas as variações de energias ao longo dos vários valores escolhidos para os números de unidades de $\mathrm{SnO}_{2}$ e níveis calculados para esse nanotubos.

Tabela 6.5 Valores de $\mathrm{n}$ e m utilizados em $\left\{\left[\left(\mathrm{SnO}_{2}\right)_{2}\right]_{\mathrm{n}}\right\}_{\mathrm{m}}$; distâncias entre os oxigênios nos mínimos de energia; menores variações das energias; taxa das variações das energias em função das alturas e dos diâmetros dos nanotubos.

\begin{tabular}{|c|c|c|c|c|}
\hline$(\mathbf{n}, \mathbf{m})$ & $\begin{array}{c}\mathrm{d}_{\mathrm{O}-\mathrm{o}} \\
\text { (angstrons) }\end{array}$ & $\begin{array}{c}\Delta \mathrm{E}(\mathbf{n}, \mathbf{m}) \\
(\mathbf{e V})\end{array}$ & $\begin{array}{l}\Delta(\Delta E) / \Delta \mathrm{m} \\
\left(\mathrm{eV} / \text { nível}^{\prime}\right)\end{array}$ & $\begin{array}{c}\Delta(\Delta \mathrm{E}) / \Delta \mathrm{n} \\
(\mathrm{eV} / \mathrm{unidades})\end{array}$ \\
\hline$(6,1)$ & 2.386 & -8.248 & - & - \\
\hline$(6,2)$ & 2.427 & -18.848 & $\sim-10,0$ & - \\
\hline$(6,3)$ & 2.427 & -29.571 & $\sim-10,0$ & - \\
\hline$(8,1)$ & 2.386 & -9.844 & - & $\sim-1,6$ \\
\hline$(8,2)$ & 2.386 & -22.410 & $\sim-12,0$ & $\sim-3,6$ \\
\hline$(8,3)$ & 2.427 & -35.023 & $\sim-12,0$ & $\sim-5,5$ \\
\hline$(10,1)$ & 2.386 & -12.269 & - & $\sim-2,2$ \\
\hline$(10,2)$ & 2.386 & -26.260 & $\sim-14,0$ & $\sim-3,8$ \\
\hline$(10,3)$ & 2.427 & -40.725 & $\sim-14,0$ & $\sim-5,70$ \\
\hline$(12,1)$ & 2.386 & -14.499 & - & $\sim-2,2$ \\
\hline
\end{tabular}


Tabela 6.5 Continuação...

\begin{tabular}{|c|c|c|c|c|}
\hline$(\mathbf{n}, \mathbf{m})$ & $\begin{array}{c}\mathrm{d}_{\mathrm{O}-\mathrm{o}} \\
\text { (angstrons) }\end{array}$ & $\begin{array}{c}\Delta \mathbf{E}(\mathbf{n}, \mathbf{m}) \\
(\mathbf{e V})\end{array}$ & $\begin{array}{l}\Delta(\Delta \mathrm{E}) / \Delta \mathrm{m} \\
\left(\mathrm{eV} / \text { nível }^{\prime}\right)\end{array}$ & $\begin{array}{c}\Delta(\Delta E) / \Delta n \\
(e V / u n i d a d e s)\end{array}$ \\
\hline$(12,2)$ & 2.386 & -31.041 & $\sim-16,0$ & $\sim-4,7$ \\
\hline$(12,3)$ & 2.386 & -47.513 & $\sim-16,0$ & $\sim-6,8$ \\
\hline$(14,1)$ & 2.344 & -16.729 & - & $\sim-2,2$ \\
\hline$(14,2)$ & 2.386 & -35.760 & $\sim-19,0$ & $\sim-4,7$ \\
\hline$(14,3)$ & 2.386 & -54.740 & $\sim-19,0$ & $\sim-7,2$ \\
\hline$(16,1)$ & 2.344 & -18.970 & - & $\sim-2,2$ \\
\hline$(16,2)$ & 2.386 & -40.488 & $\sim-21,0$ & $\sim-4,7$ \\
\hline$(16,3)$ & 2.386 & -61.980 & $\sim-21,0$ & $\sim-7,2$ \\
\hline$(18,1)$ & 2.344 & -21.218 & - & $\sim-2,2$ \\
\hline$(18,2)$ & 2.386 & -45.235 & $\sim-24,0$ & $\sim-4,7$ \\
\hline$(18,3)$ & 2.386 & -69.248 & $\sim-24,0$ & $\sim-7,2$ \\
\hline$(20,1)$ & 2.344 & -23.476 & - & $\sim-2,2$ \\
\hline$(20,2)$ & 2.386 & -50.003 & $\sim-26,0$ & $\sim-4,7$ \\
\hline$(20,3)$ & 2.386 & -76.550 & $\sim-26,0$ & $\sim-7,3$ \\
\hline$(30,1)$ & 2.344 & -34.476 & - & $\sim-2,2$ \\
\hline$(30,2)$ & 2.386 & -74.050 & $\sim-39,0$ & $\sim-4,8$ \\
\hline$(30,3)$ & 2.386 & -113.373 & $\sim-39,3$ & $\sim-7,3$ \\
\hline$(40,1)$ & 2.344 & -46.276 & - & $\sim-2,3$ \\
\hline$(40,2)$ & 2.386 & -98.282 & $\sim-52,0$ & $\sim-4,8$ \\
\hline$(50,1)$ & 2.344 & -57.740 & - & $\sim-2,2$ \\
\hline
\end{tabular}

As taxas das variações de energias seriam as diferenças entre os valores da coluna três, na Tabela 6.5, divididos pela variação do número de níveis, $\frac{\partial \Delta \mathrm{E}}{\partial \mathrm{m}_{\mathrm{n}}}$ ou $\frac{\partial \Delta \mathrm{E}}{\partial \mathrm{n}_{\mathrm{m}}}$. Observa-se que tais taxas têm valores muito próximos e pode-se considerar que o comportamento delas seja linear. Essa é uma tendência que se repete ao longo das variações do número de unidades dos diâmetros entre os nanotubos. Afirma-se, assim, que, se a curvatura da estrutura se mantiver constante, a variação das energias desses clusters vai mudando segundo constantes que independerão do número de níveis, mas dependerão das quantidades de unidades de $\mathrm{SnO}_{2}$ em cada nível.

Da mesma maneira, têm-se as tabelas 6.6 e 6.7, referentes às distâncias entre os átomos de $\mathrm{Sn}-\mathrm{O}$ e $\mathrm{Sn}-\mathrm{Sn}$ nos modelos de nanotubos de $\mathrm{SnO}_{2}$. Na Tabela 6.6, as distâncias $\mathrm{SnO}$ associadas às menores energias dos modelos dos nanotubos de $\mathrm{SnO}_{2}$ têm variações em torno de 2,14 a 2,21 angstrons. Nota-se que as taxas das variações das menores energias ficam em torno de um mesmo valor, independendo da quantidade de níveis que os clusters têm, mas ficam em função da quantidade de unidades em cada cluster em questão, como na discussão da tabela anterior. Assim, 
quanto maior o diâmetro do nanotubo de $\mathrm{SnO}_{2}$, maior fica a estabilização do cluster, mostrando que as estruturas com comprimentos e larguras maiores tendem a uma maior probabilidade de ocorrência, como vem sendo mostrado experimentalmente.

Os valores das taxas de variações das energias em relação ao aumento dos níveis dos nanotubos são diferentes quando se fazem comparações entre as distâncias oxigênio-oxigênio e as distâncias estanho-oxigênio, nas tabelas 6.5 e 6.6. As taxas são decrescentes, mas com valores mais acentuados em razão das vibrações das distâncias entre os átomos de oxigênio na estrutura do nanotubo de $\mathrm{SnO}_{2}$.

Quanto maior o número de níveis em todos os diâmetros calculados, mais estáveis as estruturas relacionadas a essas quantidades de átomos. Se a comparação for feita entre os modelos com o mesmo número de níveis e com quantidades de unidades de $\mathrm{SnO}_{2}$ diferentes, como escrito na equação química apresentada a seguir, ter-se-á como exemplo:

$$
\left\{\left[\left(\mathrm{SnO}_{2}\right)_{2}\right]_{8}\right\}_{1}+2\left(\mathrm{SnO}_{2}\right)_{2} \rightarrow\left\{\left[\left(\mathrm{SnO}_{2}\right)_{2}\right]_{10}\right\}_{1}+2\left(\mathrm{SnO}_{2}\right)_{2} \rightarrow \ldots \rightarrow\left\{\left[\left(\mathrm{SnO}_{2}\right)_{2}\right]_{50}\right\}_{1} .
$$

Nota-se que as variações de energias vão diminuindo conforme o aumento dos números de unidades de $\mathrm{SnO}_{2}$ na horizontal e na vertical, indicando que tais estruturas vão se estabilizando para regiões de maiores diâmetros e maiores comprimentos, conforme as figuras de 6.10 a 6.22 .

Tabela 6.6 Valores de n e $\mathrm{m}$ utilizados em $\left\{\left[\left(\mathrm{SnO}_{2}\right)_{2}\right]_{\mathrm{n}}\right\}_{\mathrm{m}}$; distâncias entre os átomos de estanho e oxigênio nos mínimos de energias; menores variações das energias; taxa das variações das energias em função das alturas e dos diâmetros dos nanotubos.

\begin{tabular}{|c|c|c|c|c|}
\hline$(\mathbf{n}, \mathrm{m})$ & $\begin{array}{c}\text { dSn-O } \\
\text { (angstrons) }\end{array}$ & $\begin{array}{c}\Delta \mathrm{E}(\mathrm{n}, \mathrm{m}) \\
(\mathrm{eV})\end{array}$ & $\begin{array}{l}\Delta(\Delta \mathrm{E}) / \Delta \mathrm{m} \\
(\mathrm{eV} / \text { nível) }\end{array}$ & $\begin{array}{c}\Delta(\Delta \mathrm{E}) / \Delta \mathrm{n} \\
(\mathrm{eV} / \text { unidades })\end{array}$ \\
\hline$(6,1)$ & 2.142 & -2.699 & - & - \\
\hline$(6,2)$ & 2.180 & -9.457 & $\sim-6,7$ & - \\
\hline$(6,3)$ & 2.218 & -16.109 & $\sim-6,7$ & - \\
\hline$(8,1)$ & 2.180 & -3.845 & - & $\sim-1,1$ \\
\hline$(8,2)$ & 2.180 & -13.681 & $\sim-9,7$ & $\sim-4,2$ \\
\hline$(8,3)$ & 2.180 & -20.909 & $\sim-7,2$ & $\sim-4,8$ \\
\hline$(10,1)$ & 2.180 & -4.419 & - & $\sim-0,5$ \\
\hline$(10,2)$ & 2.218 & -15.607 & $\sim-11,2$ & $\sim-1,9$ \\
\hline$(10,3)$ & 2.218 & -26.879 & $\sim-11,2$ & $\sim-5,9$ \\
\hline$(12,1)$ & 2.142 & -5.068 & - & $\sim-0,6$ \\
\hline$(12,2)$ & 2.180 & -18.050 & $\sim-13,0$ & $\sim-2,4$ \\
\hline$(12,3)$ & 2.218 & -31.060 & $\sim-13,0$ & $\sim-4,1$ \\
\hline$(14,1)$ & 2.142 & -5.750 & - & $\sim-0,6$ \\
\hline$(14,2)$ & 2.180 & -20.586 & $\sim-14,8$ & $\sim-2,5$ \\
\hline$(14,3)$ & 2180 & -35.442 & $\sim-14,8$ & $\sim-4,3$ \\
\hline
\end{tabular}


Tabela 6.6 Continuação...

\begin{tabular}{ccccc}
$(\mathbf{n}, \mathbf{m})$ & $\begin{array}{c}\text { dSn-O } \\
\text { (angstrons) }\end{array}$ & $\begin{array}{c}\Delta \mathbf{E}(\mathbf{n}, \mathbf{m}) \\
(\mathbf{e V})\end{array}$ & $\begin{array}{c}\Delta(\mathbf{\Delta E}) / \mathbf{\Delta} \mathbf{m} \\
(\mathbf{e V} / \mathbf{n} \mathbf{v} \mathbf{})\end{array}$ & $\begin{array}{c}\Delta(\mathbf{\Delta E}) / \mathbf{\Delta} \mathbf{n} \\
(\mathbf{e V} / \mathbf{u n i d a d e s})\end{array}$ \\
\hline$(16,1)$ & 2.142 & -6.440 & - & $\sim-0,6$ \\
$(16,2)$ & 2.180 & -23.172 & $\sim-16,7$ & $\sim-2,5$ \\
$(16,3)$ & 2.180 & -39.953 & $\sim-16,8$ & $\sim-4,5$ \\
$(18,1)$ & 2.142 & -7.159 & - & $\sim-0,7$ \\
$(18,2)$ & 2.180 & -25.791 & $\sim-18,6$ & $\sim-2,6$ \\
$(18,3)$ & 2.180 & -44.483 & $\sim-18,6$ & $\sim-4,5$ \\
$(20,1)$ & 2.142 & -7.878 & - & $\sim-0,7$ \\
\hline$(20,2)$ & 2.180 & -28.435 & $\sim-20,6$ & $\sim-2,6$ \\
$(20,3)$ & 2.180 & -49.071 & $\sim-20,6$ & $\sim-4,5$ \\
$(30,1)$ & 2.142 & -11.542 & - & $\sim-0,7$ \\
\hline$(30,2)$ & 2.180 & -41.855 & $\sim-30,0$ & $\sim-2,6$ \\
$(30,3)$ & 2180 & -72.337 & $\sim-30,0$ & $\sim-4,6$ \\
\hline$(40,1)$ & 2.142 & -15.259 & - & $\sim-0,7$ \\
$(40,2)$ & 2.142 & -55.432 & $\sim-40,0$ & $\sim-2,7$ \\
$(50,1)$ & 2.180 & -18.998 & - & $\sim-0,7$ \\
\hline
\end{tabular}

Variação de energias $\mathrm{x}$ distância 0-0; níveis = 1; MNDO Distância 0-0/angstrons

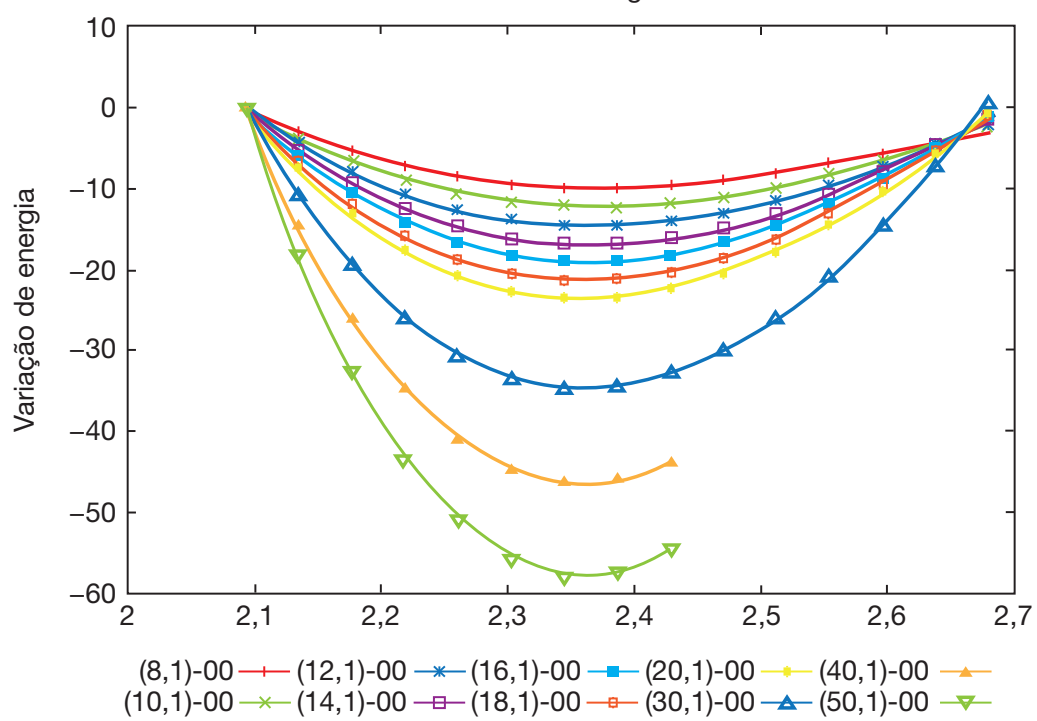

Figura 6.10 Variações das energias dos nanotubos de $\mathrm{SnO}_{2}$ conforme as distâncias entre os oxigênios em $\left\{\left[\left(\mathrm{SnO}_{2}\right)_{2}\right]_{\mathrm{n}}\right\} 1 ; \mathrm{n}=8,10, \ldots, 50 ; \mathrm{m}=1$ (um nível horizontal e um nível vertical). 
Variação de energias $\mathrm{x}$ distância 0-0; níveis = 2; MNDO Distância 0-0/angstrons

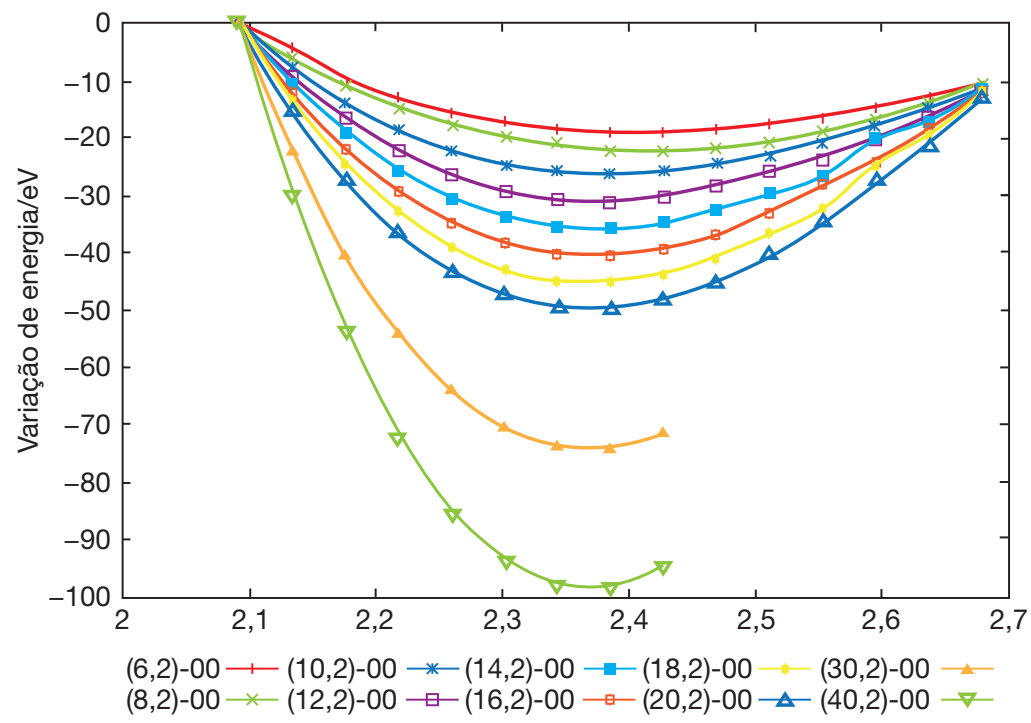

Figura 6.11 Variações das energias dos nanotubos de $\mathrm{SnO}_{2}$ conforme as distâncias entre os oxigênios em $\left\{\left[\left(\mathrm{SnO}_{2}\right)_{2}\right]_{\mathrm{n}}\right\}_{2} ; \mathrm{n}=8,10, \ldots, 40 ; \mathrm{m}=2$ (dois níveis horizontais e dois níveis verticais).

Variação de energias $\mathrm{x}$ distância 0-0; níveis = 3; MNDO Distância 0-0/angstrons

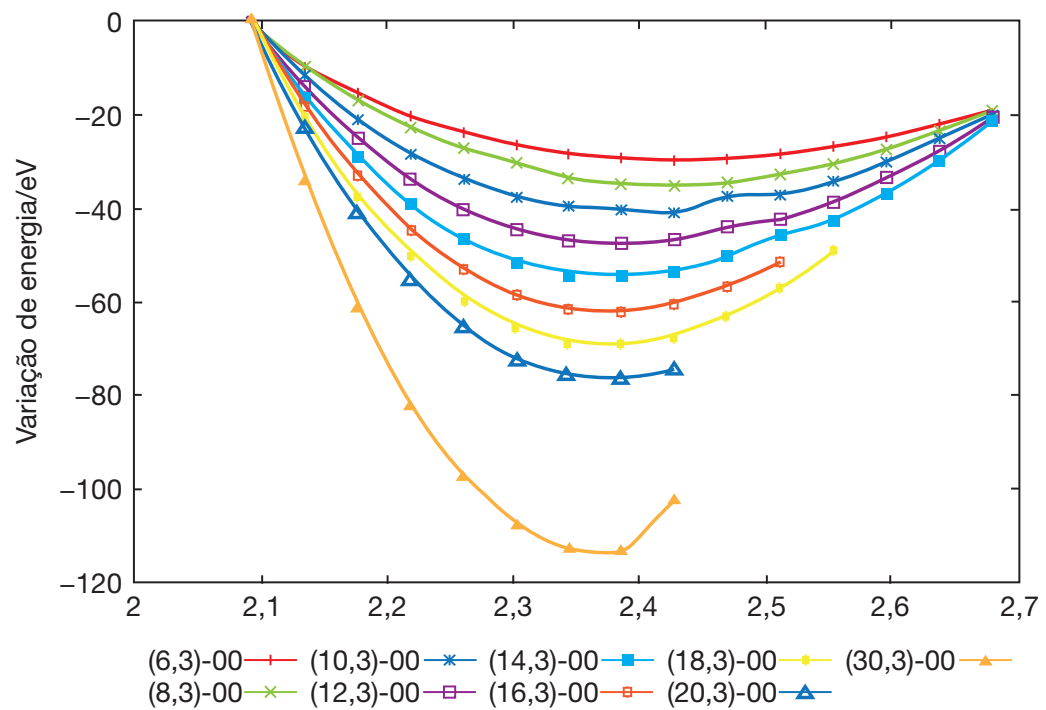

Figura 6.12 Variações das energias dos nanotubos de $\mathrm{SnO}_{2}$ conforme as distâncias entre o oxigênio em $\left\{\left[\left(\mathrm{SnO}_{2}\right)_{2}\right]_{\mathrm{n}}\right\}_{3} ; \mathrm{n}=8,10, \ldots, 30 ; \mathrm{m}=3$ (três níveis horizontais e três níveis verticais). 
Variação de energias $\mathrm{x}$ distância Sn-O; níveis = 1; MNDO Distância Sn-O/angstrons

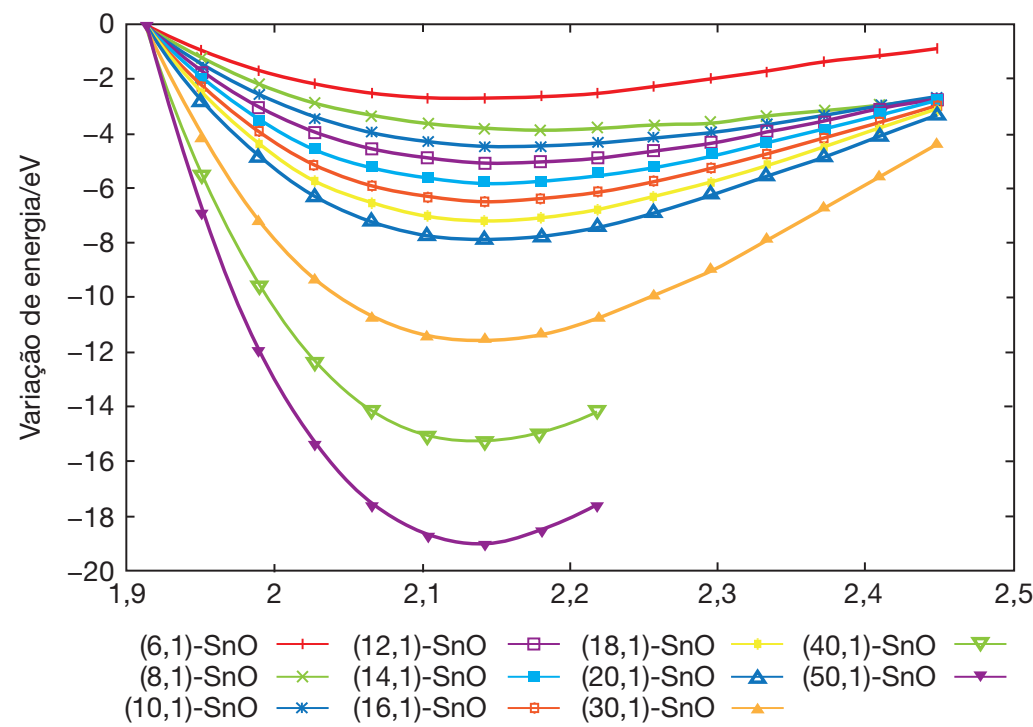

Figura 6.13 Variações das energias dos nanotubos de $\mathrm{SnO}_{2}$ conforme as distâncias entre estanho e oxigênio em $\left\{\left[\left(\mathrm{SnO}_{2}\right)_{2}\right]_{\mathrm{n}}\right\}_{1} ; \mathrm{n}=8,10, \ldots, 30 ; \mathrm{m}=1$ (um nível horizontal e um nível vertical).

Variação de energias $\mathrm{x}$ distância Sn-O; níveis = 2; MNDO

Distância Sn-O/angstrons

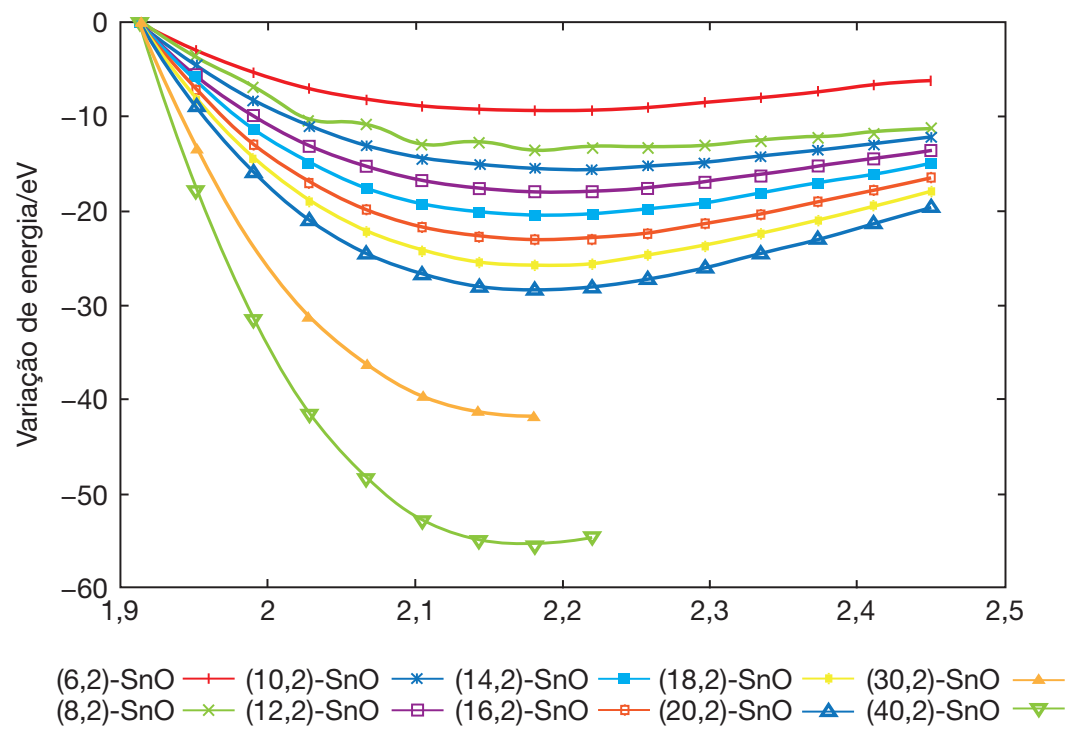

Figura 6.14 Variações das energias dos nanotubos de $\mathrm{SnO}_{2}$ conforme as distâncias entre estanho e oxigênio em $\left\{\left[\left(\mathrm{SnO}_{2}\right)_{2}\right]_{\mathrm{n}}\right\}_{2} ; \mathrm{n}=8,10, \ldots, 40 ; \mathrm{m}=2$ (dois níveis horizontais e dois níveis verticais). 
Variação de energias $x$ distância Sn-O; níveis = 3; MNDO Distância Sn-O/angstrons

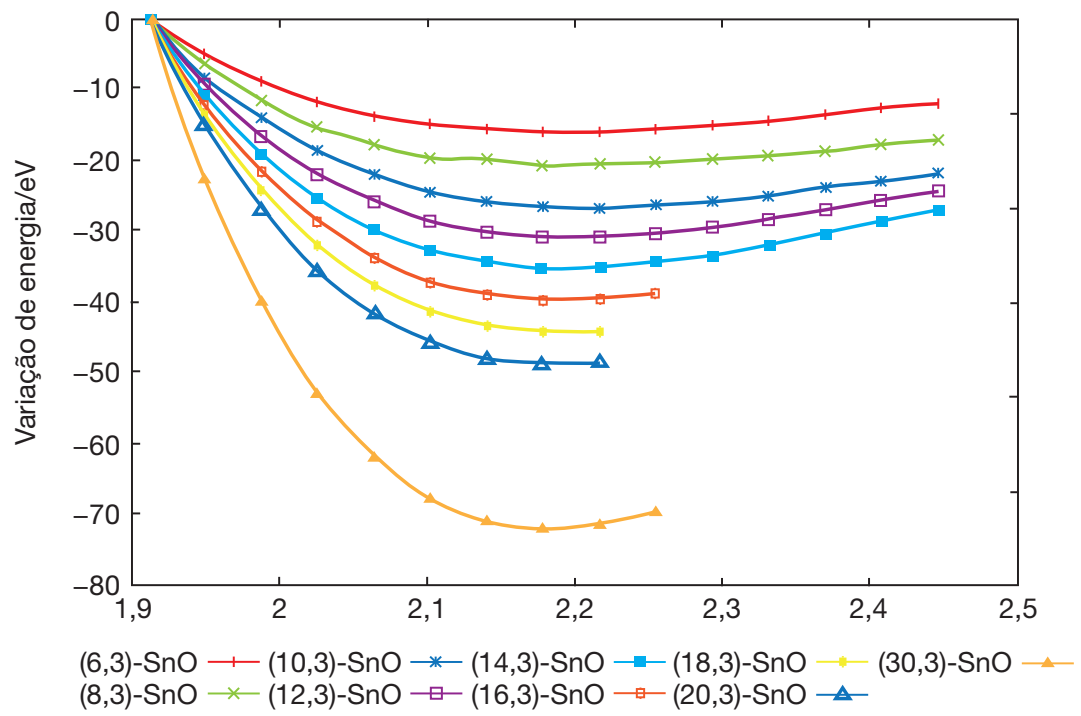

Figura 6.15 Variações das energias dos nanotubos de $\mathrm{SnO}_{2}$ conforme as distâncias entre estanho e oxigênio em $\left\{\left[\left(\mathrm{SnO}_{2}\right)_{2}\right]_{\mathrm{n}}\right\}_{3} ; \mathrm{n}=8,10, \ldots, 30 ; \mathrm{m}=3$ (três níveis horizontais e três níveis verticais).

Diferença de energia $\times\left[\left(\mathrm{SnO}_{2}\right)_{2}\right] \mathrm{n} \times \mathrm{d}(\mathrm{O}-\mathrm{O})$

"superfície-delta-energias-MNDO-nanoSnO ${ }_{2}-\mathrm{utn}_{1}-\mathrm{OO}$ "

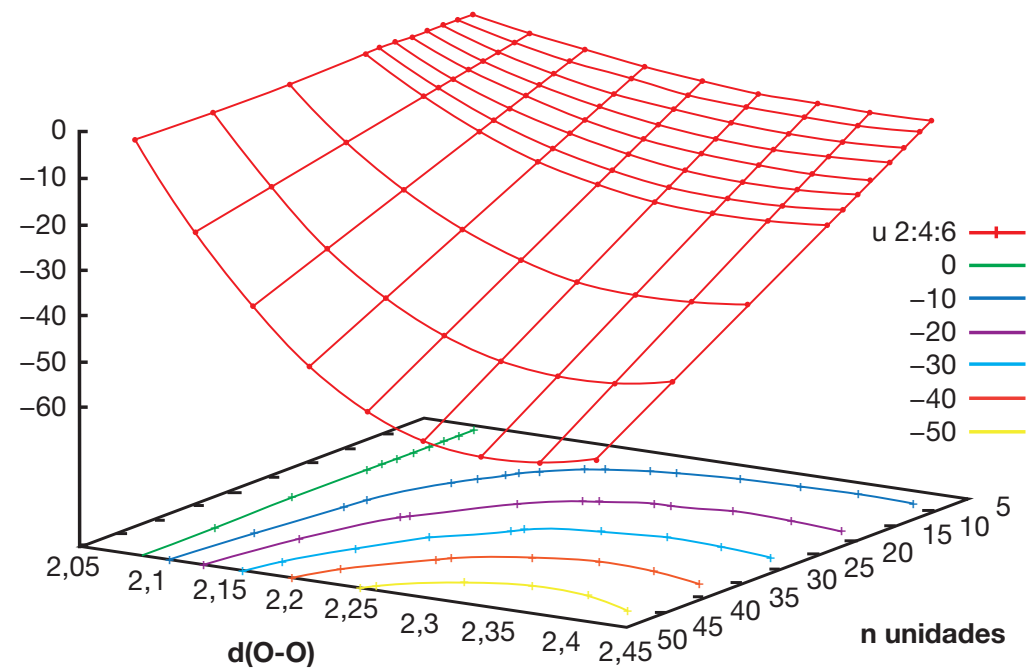

Figura 6.16 Superfície das variações das energias dos nanotubos de $\mathrm{SnO}_{2}$ como função das distâncias entre os átomos de oxigênio e as quantidades de unidades de $\mathrm{SnO}_{2}$, nos planos horizontal e vertical, no modelo $\left\{\left[\left(\mathrm{SnO}_{2}\right)_{2}\right]_{\mathrm{n}}\right\}_{1} ; \mathrm{m}=1$. 


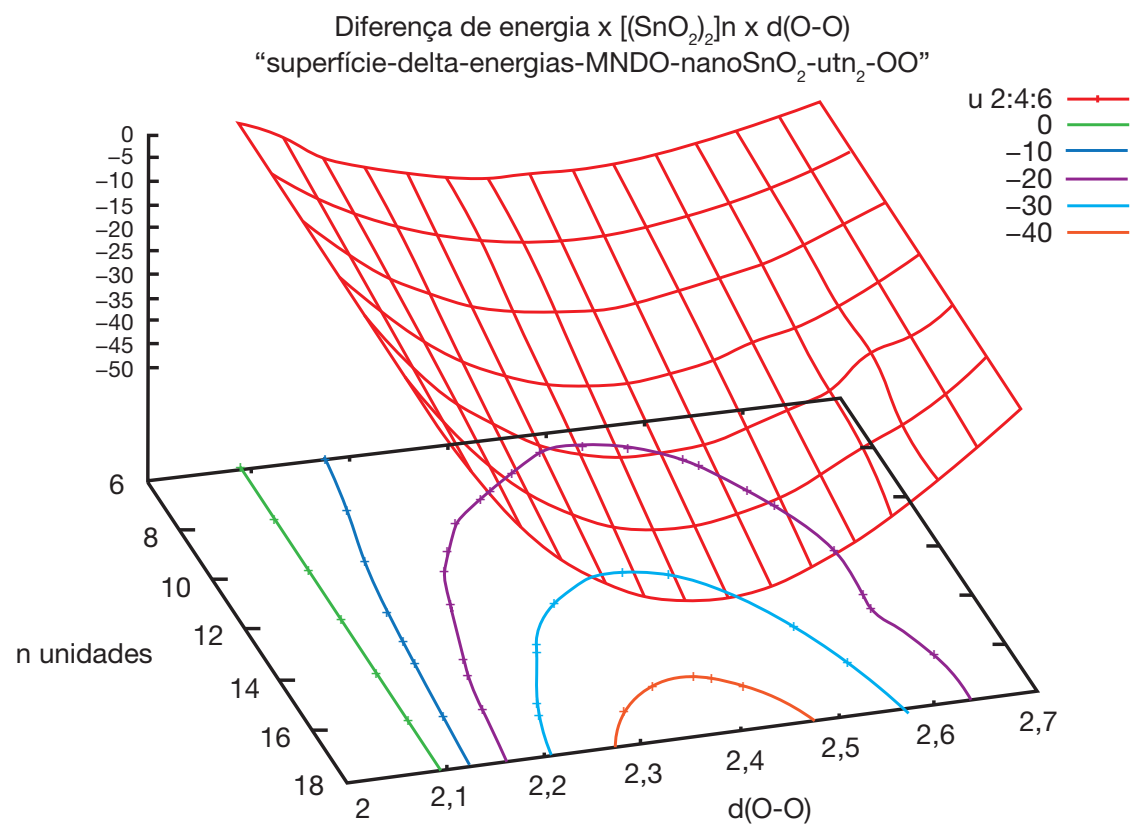

Figura 6.17 Superfície das variações das energias dos nanotubos de $\mathrm{SnO}_{2}$ como função das distâncias entre os átomos de oxigênio e as quantidades de unidades de $\mathrm{SnO}_{2}$ nos planos horizontal e vertical, no modelo $\left\{\left[\left(\mathrm{SnO}_{2}\right)_{2}\right]_{\mathrm{n}}\right\}_{2} ; \mathrm{m}=2$.

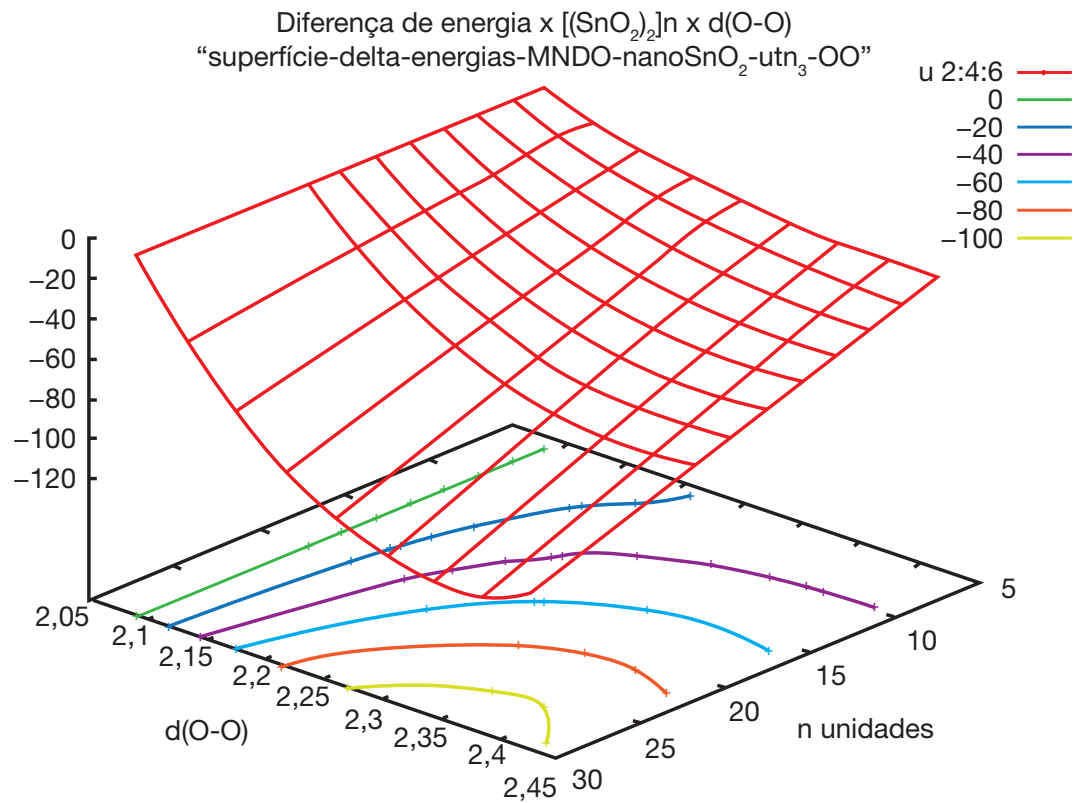

Figura 6.18 Superfície das variações das energias dos nanotubos de $\mathrm{SnO}_{2}$ como função das distâncias entre os átomos de oxigênio e as quantidades de unidades de $\mathrm{SnO}_{2}$ nos planos horizontal e vertical, no modelo $\left\{\left[\left(\mathrm{SnO}_{2}\right)_{2}\right]_{\mathrm{n}}\right\}_{3} ; \mathrm{m}=3$. 
Diferença de energia $\times\left[\left(\mathrm{SnO}_{2}\right)_{2}\right] \mathrm{n} \times \mathrm{d}(\mathrm{Sn}-\mathrm{O})$

"superfície-delta-energias-MNDO-nanoSnO ${ }_{2}$-utn ${ }_{1}-\mathrm{SnO}$ "

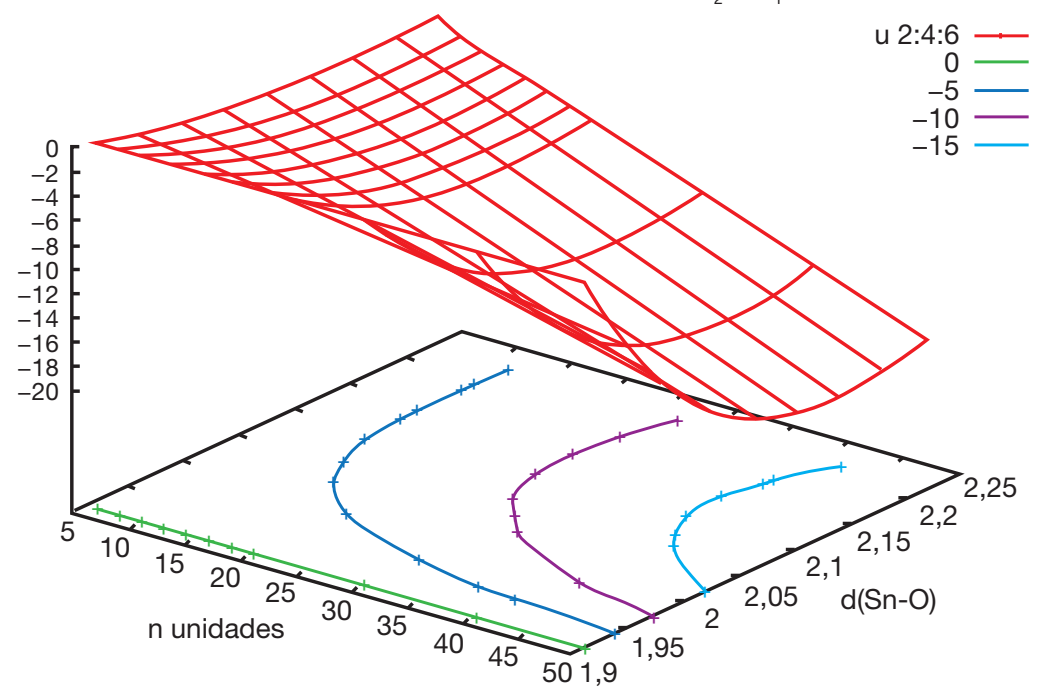

Figura 6.19 Superfície das variações das energias dos nanotubos de $\mathrm{SnO}_{2}$ como função das distâncias entre os átomos de estanho e oxigênio e as quantidades de unidades de $\mathrm{SnO}_{2}$ nos planos horizontal e vertical, no modelo $\left\{\left[\left(\mathrm{SnO}_{2}\right)_{2}\right]_{\mathrm{n}}\right\}_{1} ; \mathrm{m}=1$.

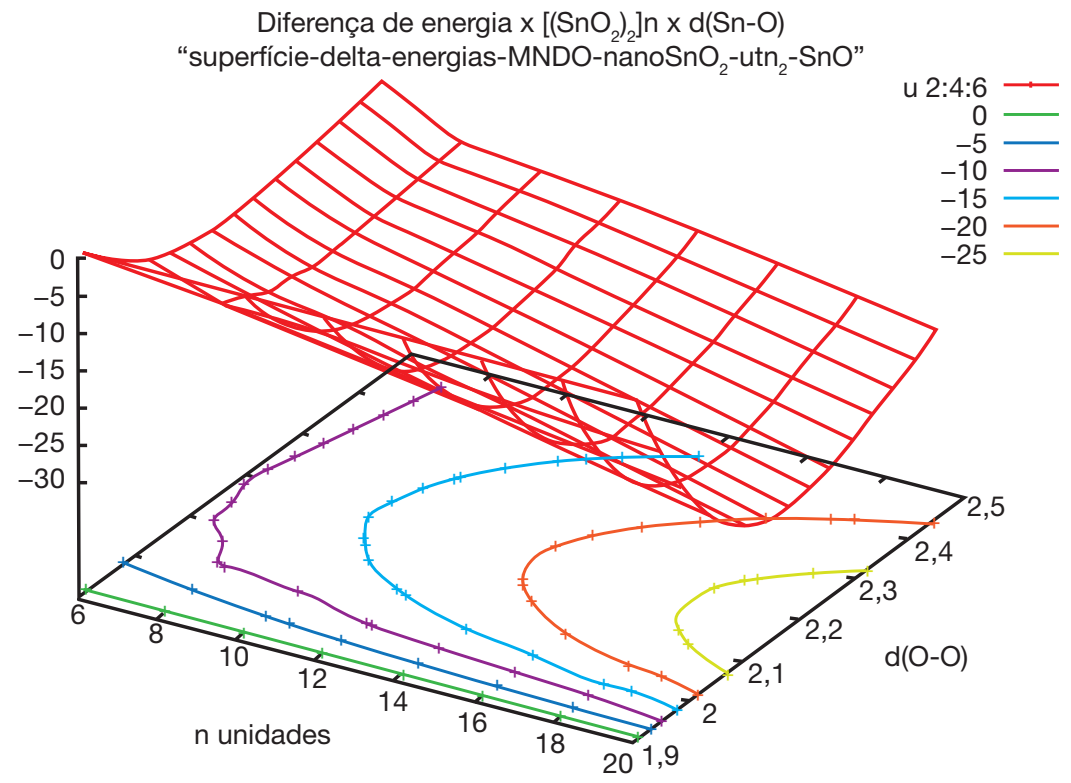

Figura 6.20 Superfície das variações das energias dos nanotubos de $\mathrm{SnO}_{2}$ como função das distâncias entre os átomos de estanho e oxigênio e as quantidades de unidades de $\mathrm{SnO}_{2}$ nos planos horizontal e vertical, no modelo $\left\{\left[\left(\mathrm{SnO}_{2}\right)_{2}\right]_{\mathrm{n}}\right\}_{2} ; \mathrm{m}=2$. 


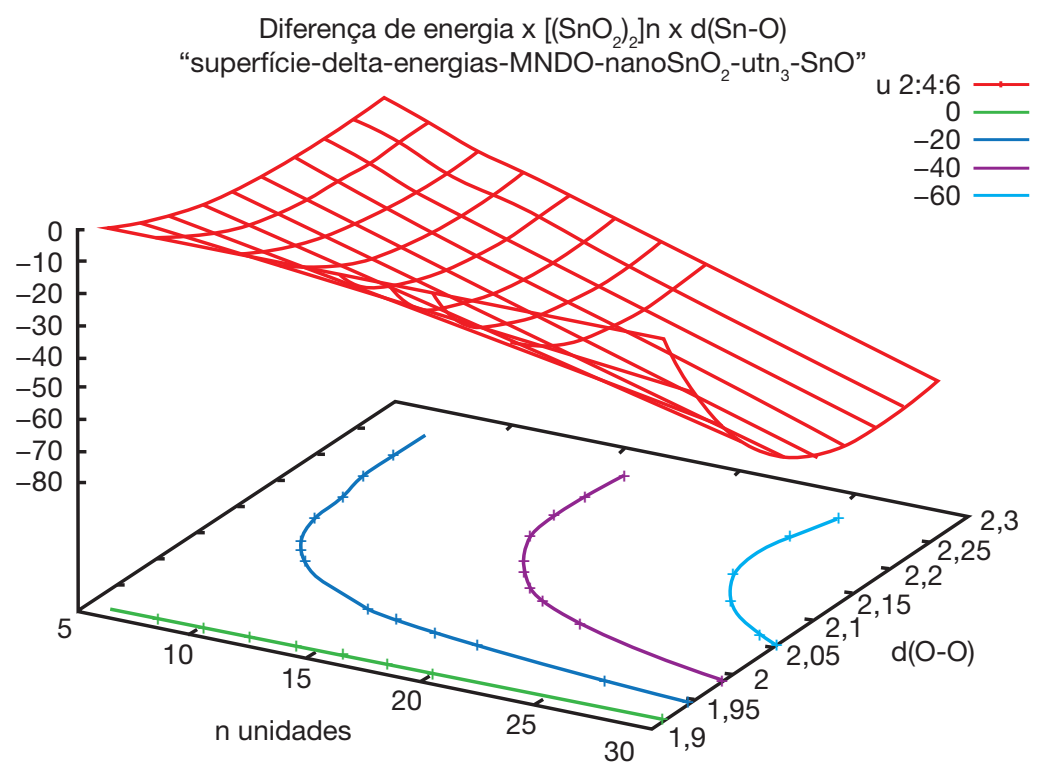

Figura 6.21 Superfície das variações das energias dos nanotubos de $\mathrm{SnO}_{2}$ como função das distâncias entre os átomos de estanho e oxigênio e as quantidades de unidades de $\mathrm{SnO}_{2}$ nos planos horizontal e vertical, no modelo $\left\{\left[\left(\mathrm{SnO}_{2}\right)_{2}\right]_{\mathrm{n}}\right\}_{3} ; \mathrm{m}=3$.

Tabela 6.7 Valores de n e m utilizados em $\left\{\left[\left(\mathrm{SnO}_{2}\right)_{2}\right]_{\mathrm{n}}\right\}_{\mathrm{m}}$; distâncias estanho-estanho nos mínimos de energias; menores variações das energias; taxa das variações das energias em função das alturas e dos diâmetros dos nanotubos.

\begin{tabular}{|c|c|c|c|c|}
\hline$(\mathrm{n}, \mathrm{m})$ & $\begin{array}{c}\text { dSn-Sn } \\
\text { (angstrons) }\end{array}$ & $\begin{array}{c}\Delta \mathrm{E}(\mathrm{n}, \mathrm{m}) \\
(\mathrm{eV})\end{array}$ & $\begin{array}{l}\Delta(\Delta E) / \Delta \mathrm{m} \\
(\mathrm{eV} / \text { nível) }\end{array}$ & $\begin{array}{c}\Delta(\Delta \mathrm{E}(\mathrm{n}, \mathrm{m})) / \Delta \mathrm{n} \\
\text { (eV/unidades) }\end{array}$ \\
\hline$(6,1)$ & 3.465 & -26.241 & - & - \\
\hline$(6,2)$ & 3.465 & -56.444 & $\sim-30,0$ & - \\
\hline$(6,3)$ & 3.525 & -86.684 & $\sim-30,0$ & - \\
\hline$(8,1)$ & 3.286 & -15.137 & - & $\sim 11,10$ \\
\hline$(8,2)$ & 3.286 & -34.686 & $\sim-19,0$ & $\sim 21,75$ \\
\hline$(8,3)$ & 3.346 & -54.539 & $\sim-19,0$ & $\sim 32,14$ \\
\hline$(10,1)$ & 3.226 & -11.330 & - & $\sim 3,80$ \\
\hline$(10,2)$ & 3.226 & -26.260 & $\sim-15,0$ & $\sim 8,42$ \\
\hline$(10,3)$ & 3.226 & -41.162 & $\sim-15,0$ & $\sim 13,37$ \\
\hline$(12,1)$ & 3.226 & -9.643 & - & $\sim 1,48$ \\
\hline$(12,2)$ & 3.226 & -23.491 & $\sim-13,8$ & $\sim 3,76$ \\
\hline$(12,3)$ & 3.226 & -37.302 & $\sim-13,8$ & $\sim 3,86$ \\
\hline$(14,1)$ & 3.226 & -9.581 & - & $\sim 0,34$ \\
\hline$(14,2)$ & 3.166 & -22.840 & $\sim-13,2$ & $\sim 0,65$ \\
\hline
\end{tabular}


Tabela 6.7 Continuação...

\begin{tabular}{ccccc|}
\hline$(\mathbf{n}, \mathbf{m})$ & $\begin{array}{c}\mathbf{d S n}-\mathbf{S n} \\
\text { (angstrons) }\end{array}$ & $\begin{array}{c}\Delta \mathbf{E}(\mathbf{n}, \mathbf{m}) \\
(\mathbf{e V})\end{array}$ & $\begin{array}{c}\Delta(\Delta \mathbf{E}) / \Delta \mathbf{m} \\
(\mathbf{e V} / \mathbf{n} \mathbf{v} \mathbf{l})\end{array}$ & $\begin{array}{c}\Delta(\boldsymbol{\Delta E}(\mathbf{n}, \mathbf{m})) / \Delta \mathbf{n} \\
(\mathbf{e V} / \text { unidades })\end{array}$ \\
\hline$(14,3)$ & 3.166 & -36.062 & $\sim-13,2$ & $\sim 1,24$ \\
\hline$(16,1)$ & 3.166 & -9.545 & - & $\sim 0,03$ \\
$(16,2)$ & 3.166 & -23.257 & $\sim-13,7$ & $\sim-0,41$ \\
\hline$(16,3)$ & 3.166 & 36.922 & $\sim-13,7$ & $\sim-0,86$ \\
\hline$(18,1)$ & 3.166 & -9.691 & - & $\sim-0,14$ \\
\hline$(18,2)$ & 3.166 & -24.046 & $\sim-14,77$ & $\sim-0,78$ \\
\hline$(18,3)$ & 3.166 & -38.340 & $\sim-14,29$ & $\sim-1,41$ \\
\hline$(20,1)$ & 3.166 & -9.957 & - & $\sim-0,26$ \\
\hline$(20,2)$ & 3.166 & -25.076 & $\sim-15,1$ & $\sim-1,03$ \\
\hline$(20,3)$ & 3.166 & -40.123 & $\sim-15,04$ & $\sim-1,78$ \\
\hline$(30,1)$ & 3.107 & -12.528 & - & $\sim-0,51$ \\
$(30,2)$ & 3.166 & -31.980 & $\sim-19,4$ & $\sim-1,38$ \\
\hline$(30,3)$ & 3.166 & -51.681 & $\sim-19,7$ & $\sim-2,31$ \\
\hline$(40,1)$ & 3.107 & -15.833 & - & $\sim-0,66$ \\
\hline$(40,2)$ & 3.166 & -40.101 & $\sim-24,0$ & $\sim-1,62$ \\
\hline$(50,1)$ & 3.107 & -19.293 & - & $\sim-0,69$ \\
\hline
\end{tabular}

Variação de energias $\mathrm{x}$ distância $\mathrm{Sn}-\mathrm{Sn}$; níveis = 1; MNDO Distância Sn-Sn/angstrons

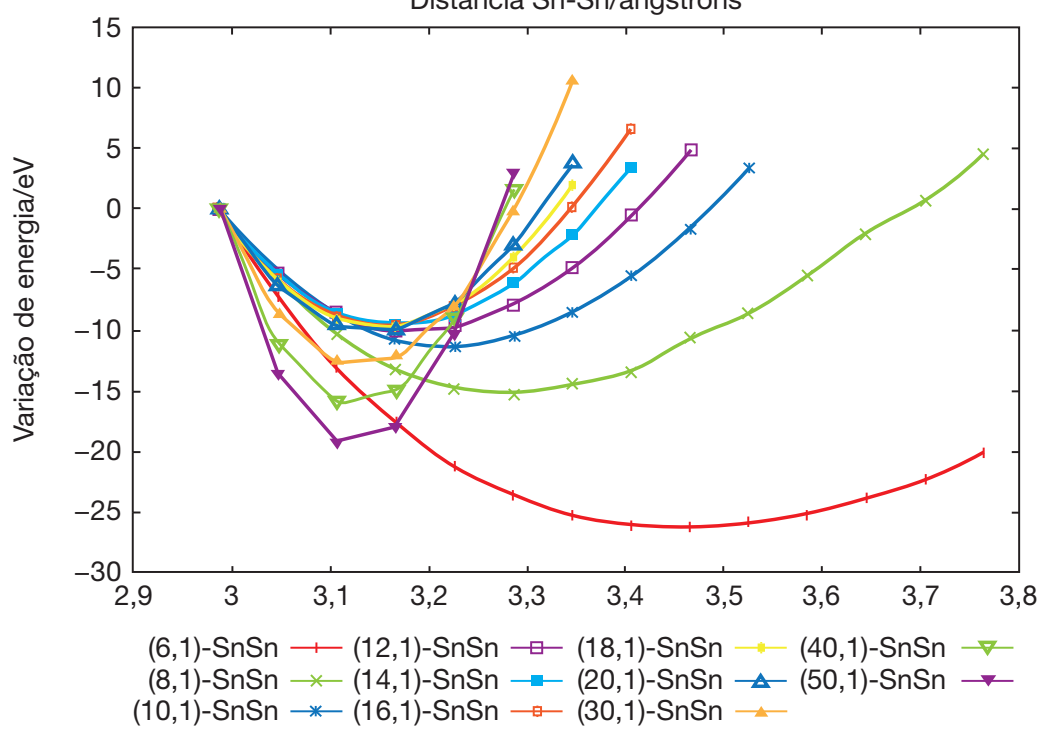

Figura 6.22 Variações das energias dos nanotubos de $\mathrm{SnO}_{2}$ como função das distâncias estanho-estanho em $\left\{\left[\left(\mathrm{SnO}_{2}\right)_{2}\right]_{\mathrm{n}}\right\}_{1} ; \mathrm{n}=8,10, \ldots, 50 ; \mathrm{m}=1$ (um nível horizontal e um nível vertical). 


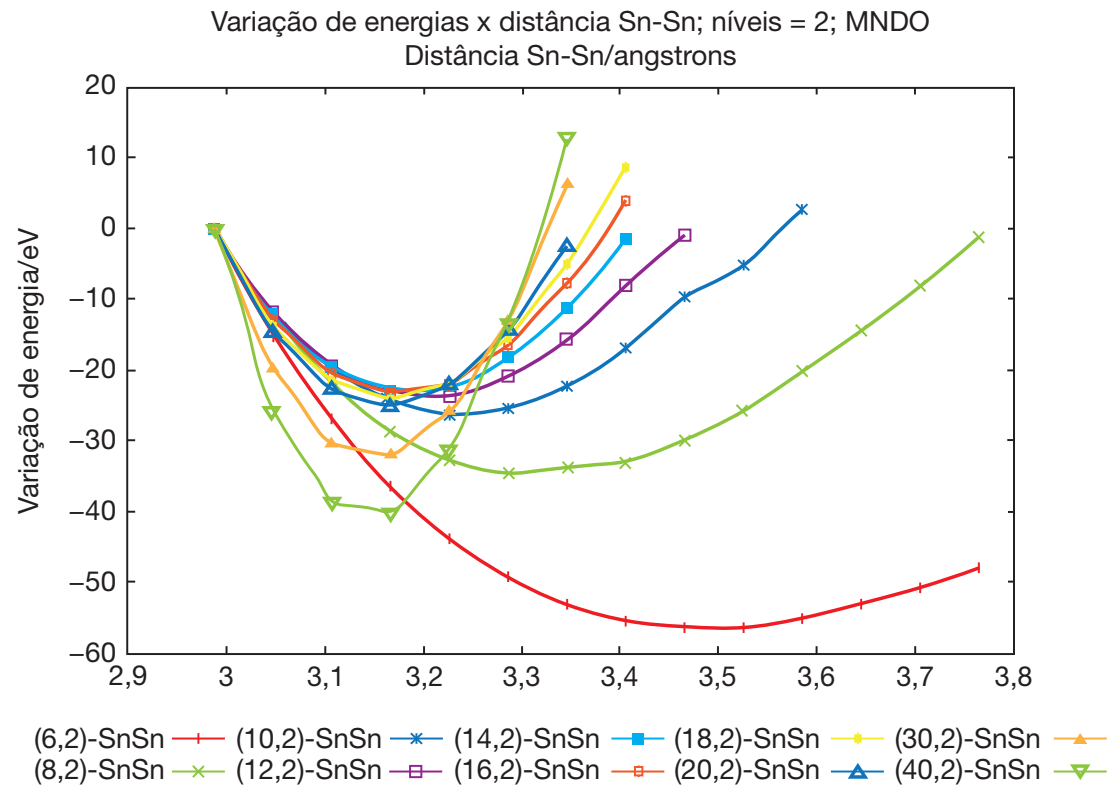

Figura 6.23 Variações das energias dos nanotubos de $\mathrm{SnO}_{2}$ como função das distâncias estanho-estanho em $\left\{\left[\left(\mathrm{SnO}_{2}\right)_{2}\right]_{\mathrm{n}}\right\} 2 ; \mathrm{n}=8,10, \ldots, 50 ; \mathrm{m}=2$ (dois níveis horizontais e dois níveis verticais).

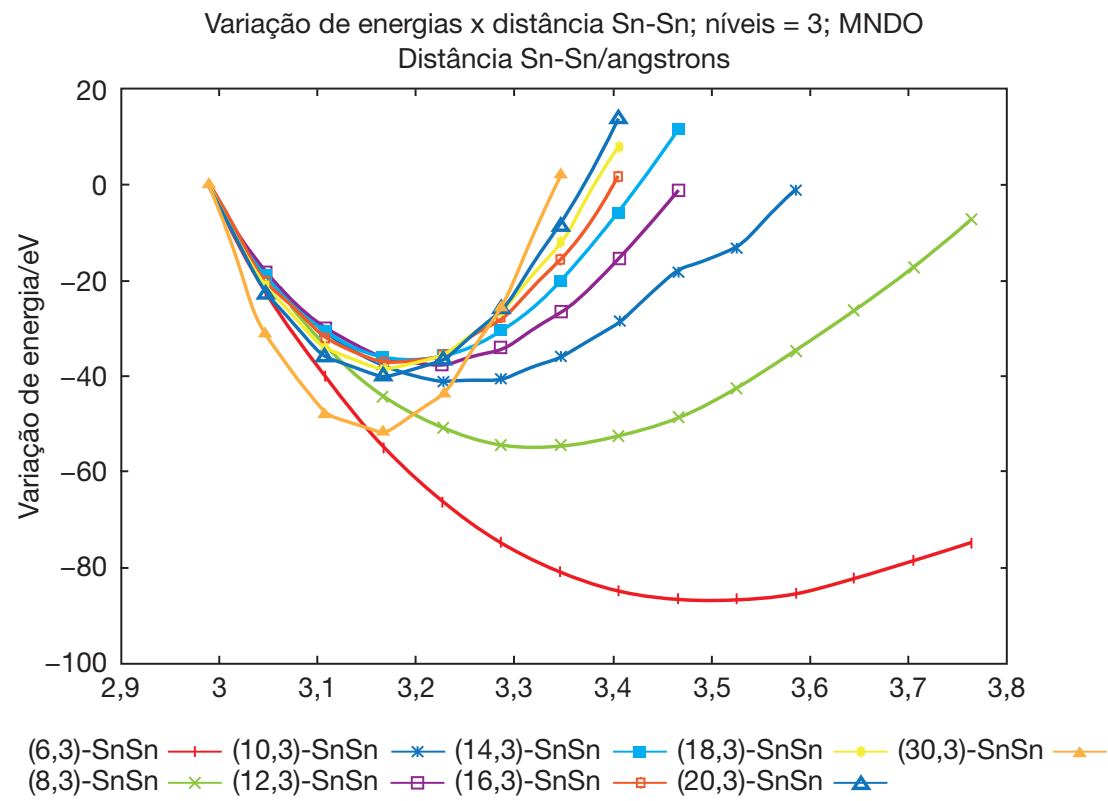

Figura 6.24 Variações das energias dos nanotubos de $\mathrm{SnO}_{2}$ como função das distâncias estanho-estanho em $\left\{\left[\left(\mathrm{SnO}_{2}\right)_{2}\right]_{\mathrm{n}}\right\} 3 ; \mathrm{n}=8,10, \ldots, 50 ; \mathrm{m}=3$ (três níveis horizontais e três níveis verticais). 


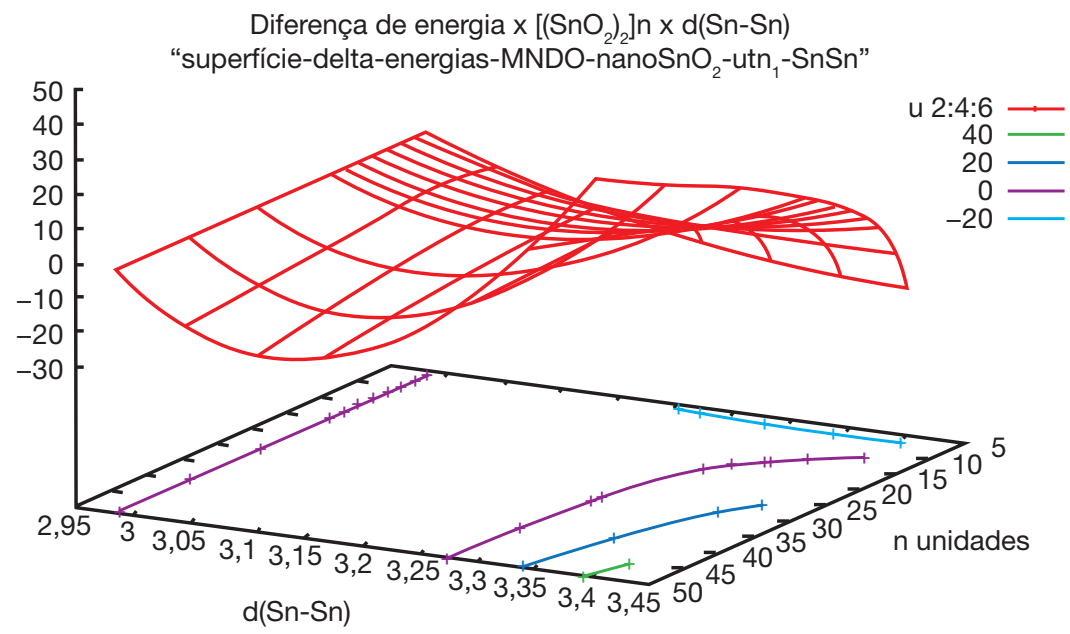

Figura 6.25 Superfície das variações das energias dos nanotubos de $\mathrm{SnO}_{2}$ como função das distâncias estanho-estanho e as quantidades de unidades de $\mathrm{SnO}_{2}$ nos planos horizontal e vertical, no modelo $\left\{\left[\left(\mathrm{SnO}_{2}\right)_{2}\right]_{\mathrm{n}}\right\}_{1} ; \mathrm{m}=1$.

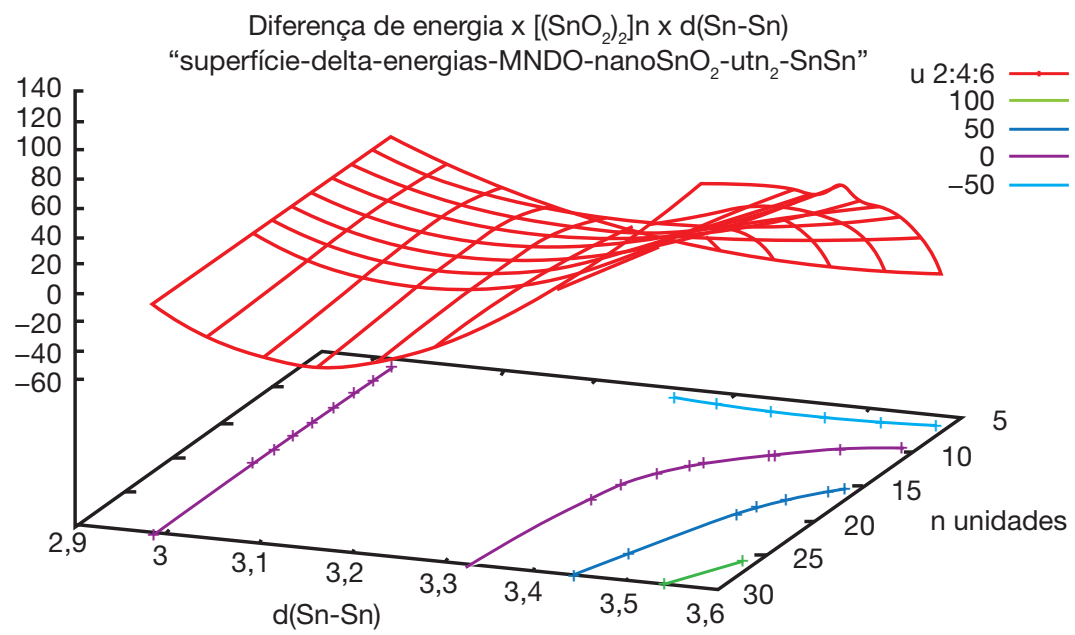

Figura 6.26 Superfície das variações das energias dos nanotubos de $\mathrm{SnO}_{2}$ como função das distâncias estanho-estanho e as quantidades de unidades de $\mathrm{SnO}_{2}$ nos planos horizontal e vertical, no modelo $\left\{\left[\left(\mathrm{SnO}_{2}\right)_{2}\right]_{\mathrm{n}}\right\} ; \mathrm{m}=2$. 


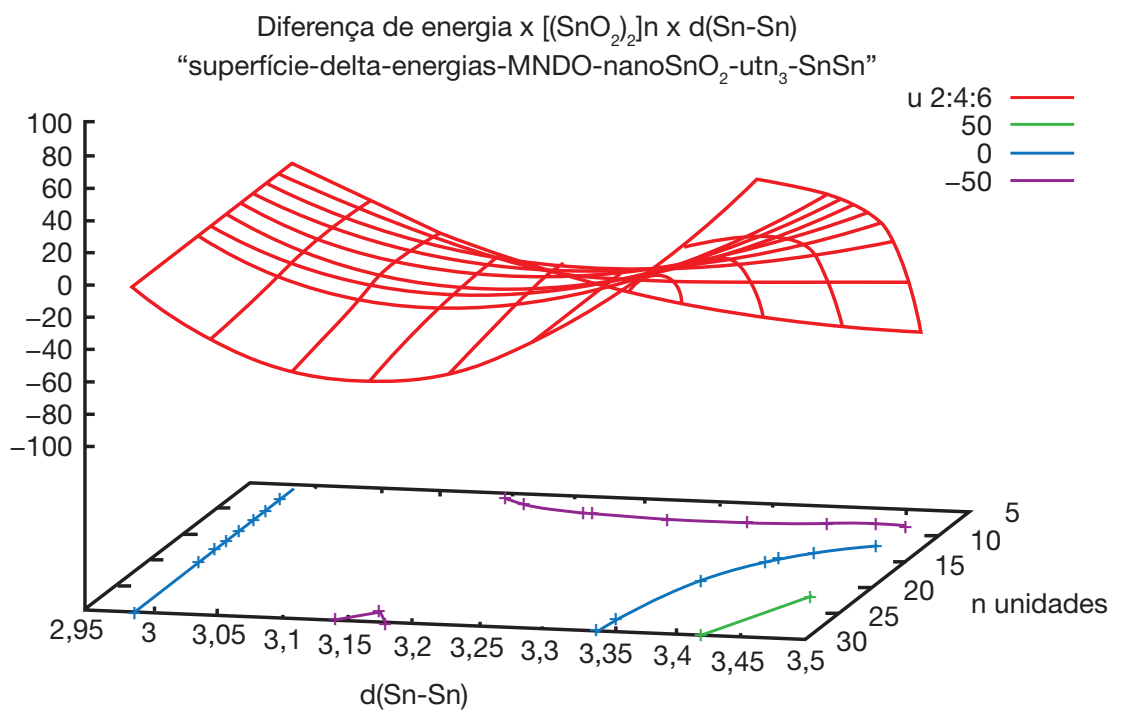

Figura 6.27 Superfície das variações das energias dos nanotubos de $\mathrm{SnO}_{2}$ como função das distâncias estanho-estanho e as quantidades de unidades de $\mathrm{SnO}_{2}$ nos planos horizontal e vertical, no modelo $\left\{\left[\left(\mathrm{SnO}_{2}\right)_{2}\right]_{\mathrm{n}}\right\} ; \mathrm{m}=3$.

As taxas das variações de energias pelas variações dos diâmetros dos nanotubos, com o número constante de níveis, $\frac{\partial \Delta \mathrm{E}}{\partial \mathrm{n}_{\mathrm{m}}}$, têm comportamentos lineares e decrescentes, e as diminuições dessas variações são mais pronunciadas em nanotubos com maiores quantidades de níveis ou alturas, conforme indicam a Figura 6.28 e a Tabela 6.5, relacionadas às variações entre as distâncias dos átomos de oxigênio nas estruturas cilíndricas.

Da mesma forma, as taxas das variações das energias decrescem linearmente para as variações de energia referentes às modificações das distâncias entre os átomos de estanho e oxigênio, com essas taxas menores que as anteriores, relacionadas às distâncias oxigênio-oxigênio, conforme Figura 6.29 e Tabela 6.6.

Para as variações de energias em decorrência das distâncias entre os átomos de estanho, as taxas de variação são positivas e não lineares até aproximadamente quatorze unidades de $\mathrm{SnO}_{2}$. Após esse valor, as taxas começam a decrescer, apresentando valores mais pronunciados nos nanotubos com maiores níveis ou alturas, maiores quantidades de $\mathrm{SnO}_{2}$ ou com maiores diâmetros, conforme Figura 6.30 e Tabela 6.7.

Descrevem-se, assim, muitas das observações experimentais em que são observadas as nanoestruturas, com centenas de angstrons de raios ou comprimentos. 
Menor variação de energia $x$ unidades de $\left[\left(\mathrm{SnO}_{2}\right)_{\mathrm{n}}\right] \mathrm{n}$, $\mathrm{n}=1, \mathrm{n}=2, \mathrm{n}=3$; distância O-O

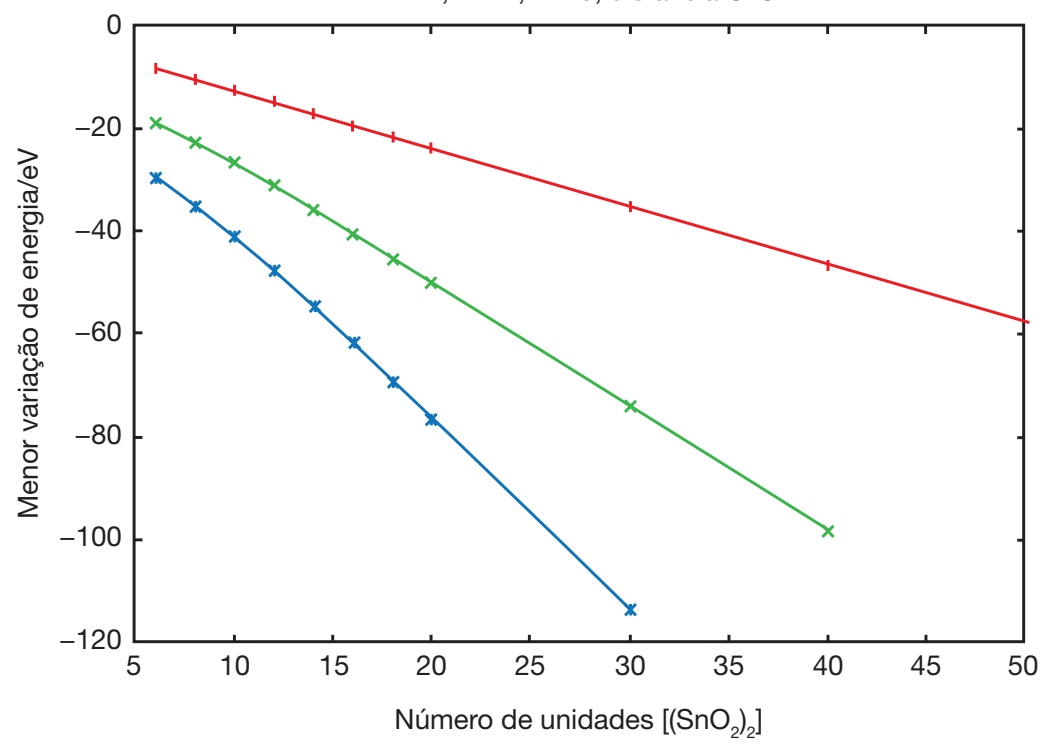

Menor-DE-( $\left(^{*}, 1\right)-00 \longrightarrow$ Menor-DE-(*,2)-00 $\rightarrow$ - Menor-DE- $\left({ }^{*}, 3\right)-00 \rightarrow-$

Figura 6.28 As menores variações das energias para os nanotubos de $\mathrm{SnO}_{2}$ em razão das diferentes distâncias oxigênio-oxigênio, $\mathrm{n}=6, \ldots, 50 ; \mathrm{m}=1,2,3$.

Menor variação de energia $x$ unidades de $\left[\left(\mathrm{SnO}_{2}\right)_{2}\right] \mathrm{n}, \mathrm{n}=1,2$, 3; distância Sn-O

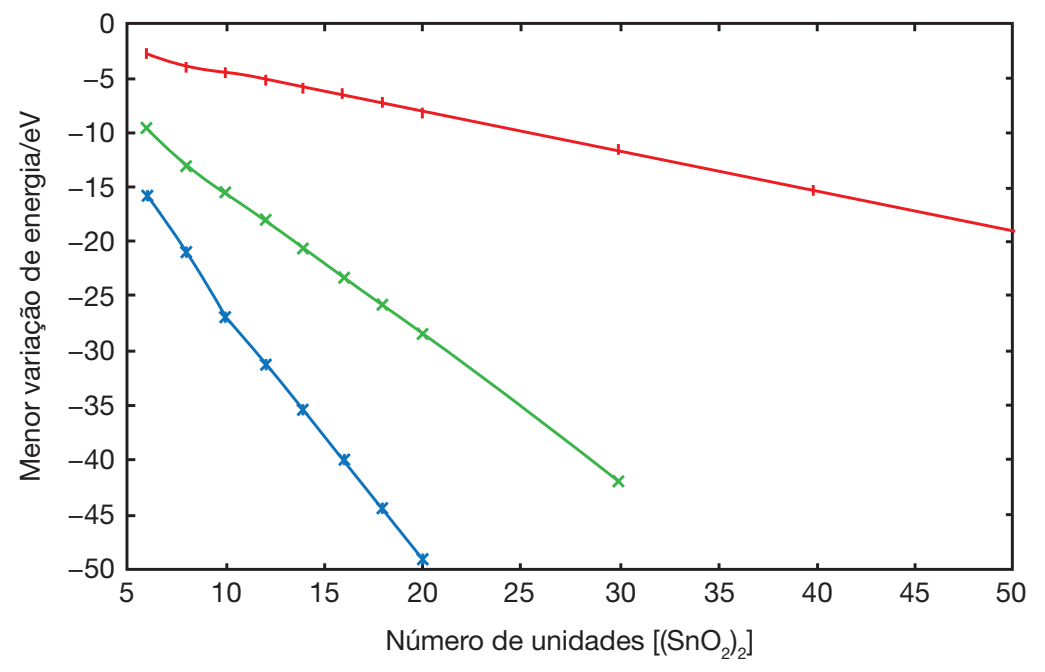

Menor-DE-( $\left.{ }^{*}, 1\right)-\mathrm{SnO} \longrightarrow$ Menor-DE-(*,2)-SnO $\rightarrow$ Menor-DE-(*,3)-SnO —-

Figura 6.29 As menores variações das energias para os nanotubos de $\mathrm{SnO}_{2}$ em razão das diferentes distâncias entre estanho e oxigênios, $\mathrm{n}=6, \ldots, 50 ; \mathrm{m}=1,2,3$. 
Menor variação de energia $x$ unidades de $\left[\left(\mathrm{SnO}_{2}\right)_{2}\right] \mathrm{n}, \mathrm{n}=1$, 2, 3; distância Sn-Sn

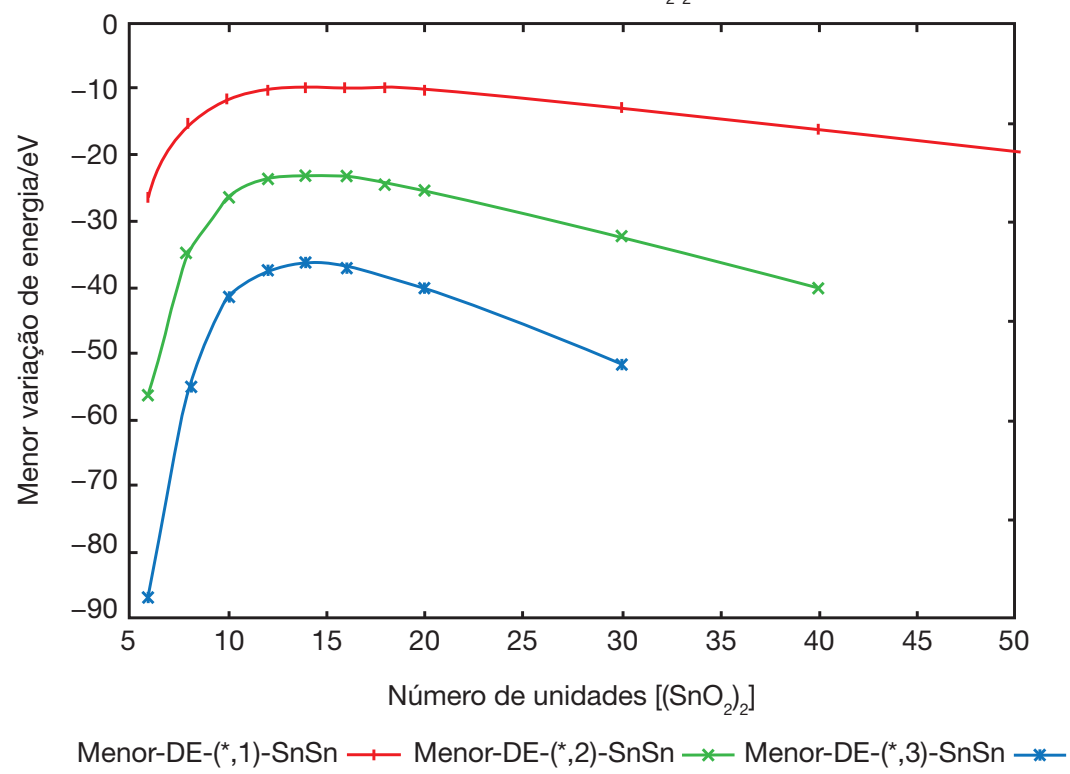

Figura 6.30 As menores variações das energias para os nanotubos de $\mathrm{SnO}_{2}$ em razão das distâncias entre os átomos de estanho, $\mathrm{n}=6, \ldots, 50 ; \mathrm{m}=1,2,3$.

Observam-se os valores do Homo em torno de $8,00 \mathrm{eV}$, para os modelos de nanotubos de $\mathrm{SnO}_{2}$, e os valores para Lumo em torno de 5,00 eV. Assim, a diferença |Homo - Lumo| fica próxima a 3,00 eV para espécies com um nível, independentemente da quantidade de níveis ao longo da estrutura do nanotubo, conforme ilustra a Figura 6.31. Para conformações com dois níveis e os mesmos diâmetros, houve pequenas aproximações para os valores entre Homo e Lumo, mostrando novamente que não há influência dos diâmetros nos valores entre essas regiões de energia, nos orbitais moleculares, conforme demonstra a Figura 6.32.

A tendência dos valores entre Homo e Lumo, com o aumento dos níveis nos nanotubos de $\mathrm{SnO}_{2}$ e a aproximação entre esses níveis de energias, é diminuir o GAP do material, podendo, assim, associar tais valores com uma maior condutividade dessa estrutura, conforme ilustra a Figura 6.33, com os valores |Homo - Lumo| em torno de $2,9 \mathrm{eV}$. 
Homo e Lumo x número de unidades $\left\{\left[(\mathrm{SnO})_{2}\right]_{2}\right\} ; n=6, \ldots, 50 ; n=1 ; \mathrm{MNDO}$

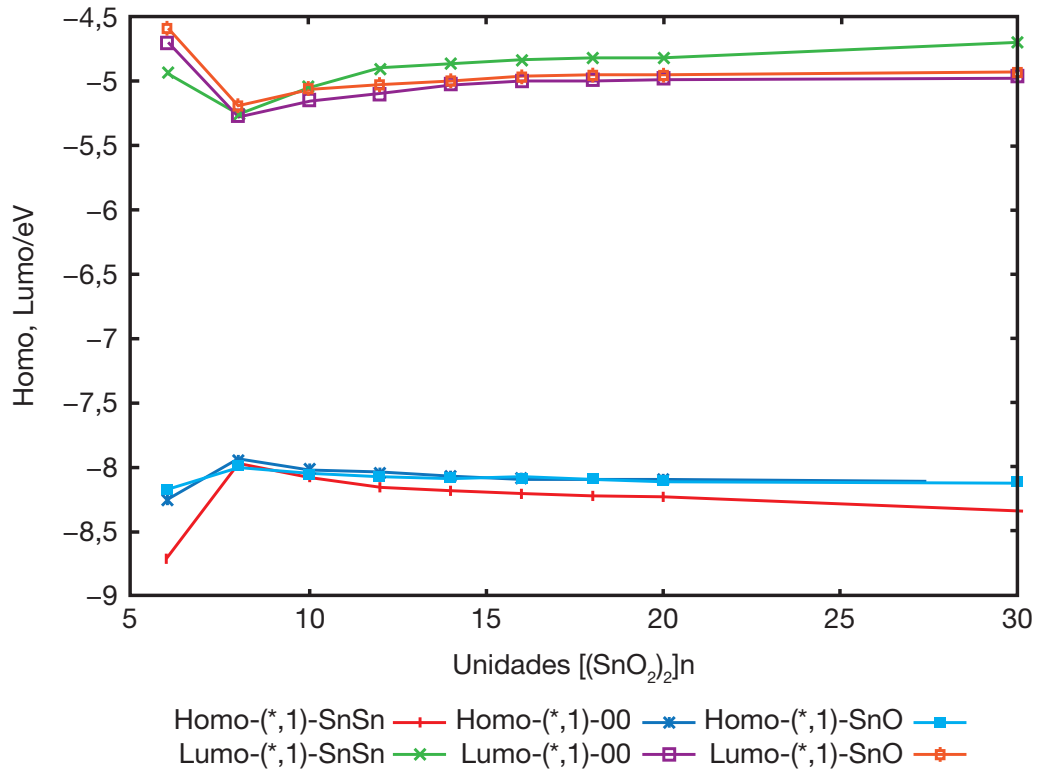

Figura 6.31 Distanciamento entre Homo e Lumo para as estruturas dos nanotubos de $\mathrm{SnO}_{2}$, com um nível, uma região horizontal e outra vertical, $\mathrm{m}=1$.

Homo e Lumo x número de unidades $\left\{\left[(\mathrm{SnO})_{2}\right]_{2}\right\} ; n=6, \ldots, 30 ; n=2 ;$ MNDO

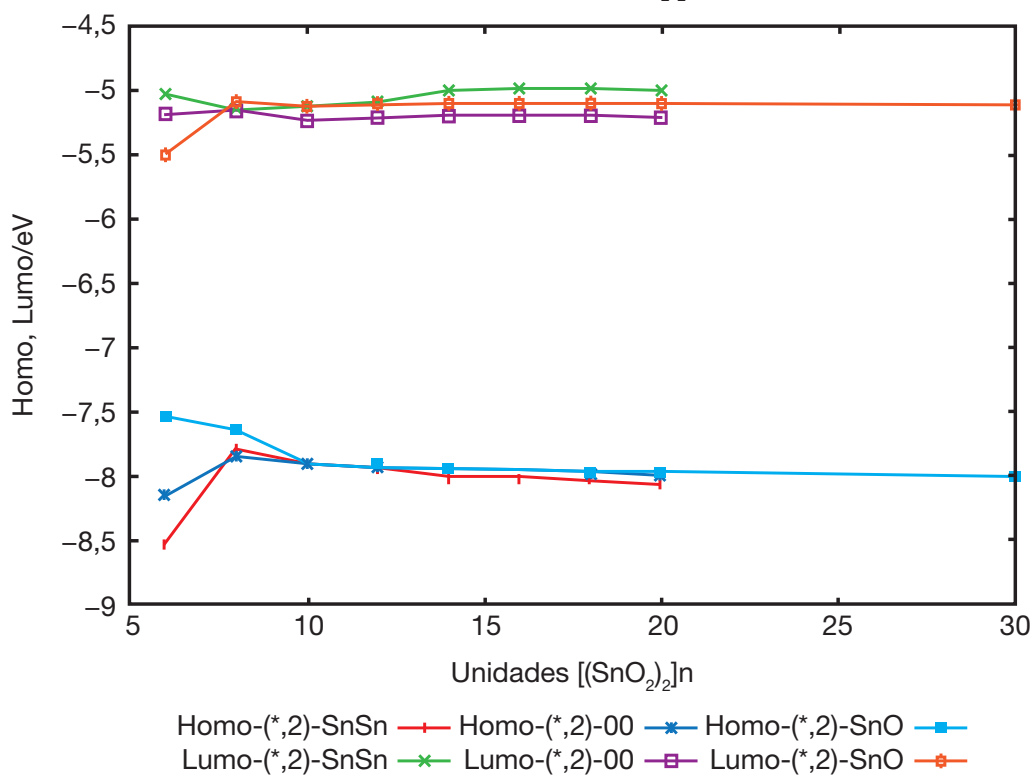

Figura 6.32 Separação entre Homo e Lumo para os modelos de nanotubos de $\mathrm{SnO}_{2}$, com dois níveis, duas regiões horizontais e duas verticais alternadas, $\mathrm{m}=2$. 
Homo e Lumo x número de unidades $\left\{\left[(\mathrm{SnO})_{2}\right]_{2}\right\} ; n=6, \ldots, 30 ; n=3 ;$ MNDO

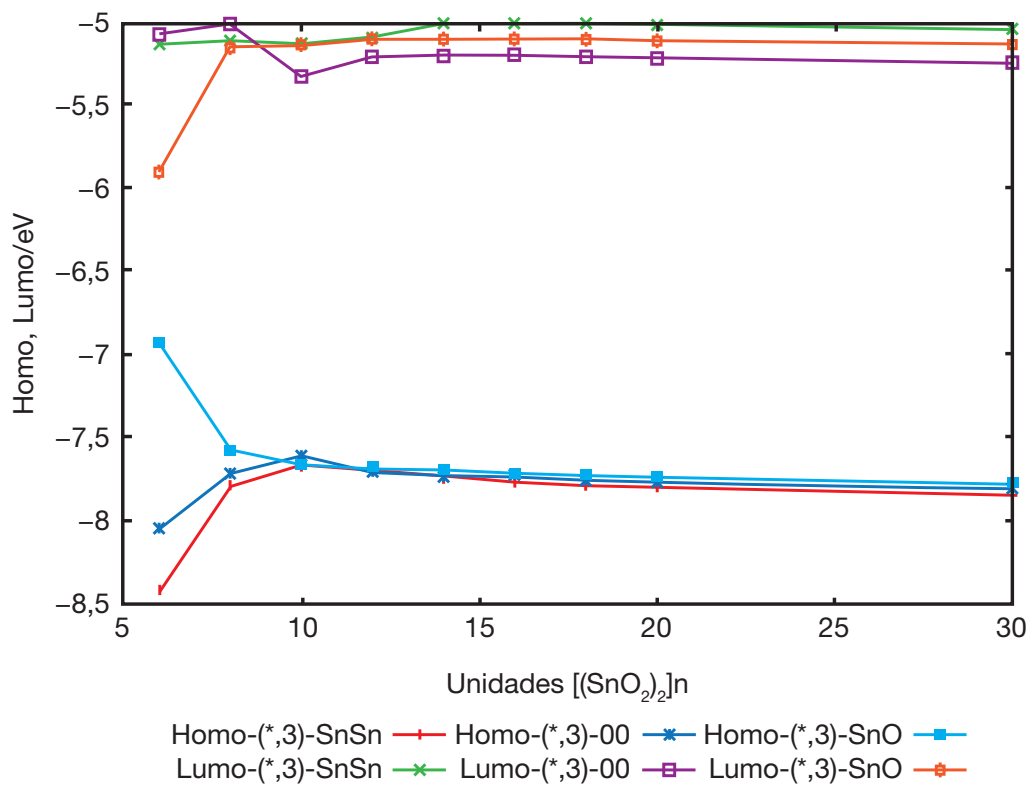

Figura 6.33 Aproximação entre os valores Homo e Lumo nos nanotubos de $\mathrm{SnO}_{2}$, com três níveis, três regiões alternadas na horizontal e na vertical, $\mathrm{m}=3$.

Tabela 6.8 Homo e Lumo ab initio B3LYP/Huzinaga de nanotubos $\left\{\left[\left(\mathrm{SnO}_{2}\right)_{2}\right]_{\mathrm{n}}\right\}_{\mathrm{m}}$.

\begin{tabular}{|ccccc|}
\hline$(\mathbf{n}, \mathbf{m})$ & DFT-GEN- dSnSn-dOO-dSnO & Homo/eV & Lumo/eV & $\mid \mathbf{H}-\mathbf{L} / \mathbf{e V}$ \\
\hline$(6,1)$ & $3.46576-2.3256-2.1252-\mathrm{SnSn}$ & -4.78325 & -4.54488 & .23837 \\
\hline$(8,1)$ & $3.3197-2.38606-2.1252-\mathrm{OO}$ & -4.83250 & -4.43385 & .39865 \\
\hline$(10,1)$ & $3.3197-2.38606-2.1252-\mathrm{OO}$ & -4.81237 & -4.63876 & .17361 \\
\hline$(12,1)$ & $3.3197-2.38606-2.1252-\mathrm{OO}$ & -4.99196 & -4.62597 & .36599 \\
\hline$(14,1)$ & $3.3197-2.34420-2.1252-\mathrm{OO}$ & -5.00748 & -4.55467 & .45281 \\
\hline$(16,1)$ & $3.3197-2.34420-2.1252-\mathrm{OO}$ & -5.02026 & -4.58433 & .43593 \\
\hline$(18,1)$ & $3.3197-2.34420-2.1252-\mathrm{OO}$ & -4.99033 & -4.60121 & .38912 \\
\hline$(20,1)$ & $3.22674-2.3256-2.1252-\mathrm{SnSn}$ & -4.85863 & -4.45399 & .40464 \\
\hline$(30,1)$ & $3.3197-2.34420-2.1252-\mathrm{OO}$ & -4.97509 & -4.60121 & .37388 \\
\hline$(6,2)$ & $3.52552-2.3256-2.1252-\mathrm{SnSn}$ & -4.86489 & -4.59440 & .27049 \\
\hline$(8,2)$ & $3.3197-2.38606-2.1252-\mathrm{OO}$ & -4.81237 & -4.44175 & .37062 \\
\hline$(10,2)$ & $3.3197-2.38606-2.1252-\mathrm{OO}$ & -4.77781 & -4.46923 & .30858 \\
\hline$(12,2)$ & $3.3197-2.38606-2.1252-\mathrm{OO}$ & -4.78951 & -4.56012 & .22939 \\
\hline$(14,2)$ & $3.3197-2.38606-2.1252-\mathrm{OO}$ & -4.88747 & -4.57889 & .30858 \\
\hline$(6,3)$ & $3.3197-2.3256-2.21870-\mathrm{SnO}$ & -4.62679 & -4.37344 & .25335 \\
\hline$(8,3)$ & $3.40601-2.3256-2.1252-\mathrm{SnSn}$ & -4.66107 & -4.45617 & .20490 \\
\hline$(10,3)$ & $3.28650-2.3256-2.1252-\mathrm{SnSn}$ & -4.58297 & -4.34787 & .23510 \\
\hline
\end{tabular}


Tabela 6.9 Homo e Lumo ab initio HF/Huzinaga de nanotubos $\left\{\left[\left(\mathrm{SnO}_{2}\right)_{2}\right]_{\mathrm{n}}\right\}_{\mathrm{m}}$.

\begin{tabular}{|c|c|c|c|c|}
\hline$(\mathbf{n}, \mathbf{m})$ & HF-GEN- dSnSn-OO-SnO & Homo/eV & Lumo/eV & $|\mathrm{H}-\mathrm{L}| / \mathbf{e V}$ \\
\hline$(6,1)$ & $3.52552-2.3256-2.1252-\mathrm{SnSn}$ & -6.27363 & -2.36468 & 3.90895 \\
\hline$(8,1)$ & $3.3197-2.38606-2.1252-\mathrm{OO}$ & -4.54080 & -2.45775 & 2.08305 \\
\hline$(10,1)$ & $3.3197-2.38606-2.1252-\mathrm{OO}$ & -5.02598 & -2.24686 & 2.77912 \\
\hline$(12,1)$ & $3.3197-2.38606-2.1252-\mathrm{OO}$ & -5.27714 & -2.12005 & 3.15709 \\
\hline$(14,1)$ & $3.3197-2.34420-2.1252-\mathrm{OO}$ & -5.42164 & -1.96685 & 3.45479 \\
\hline$(16,1)$ & 3.22674-2.3256-2.1252-SnSn & -5.54953 & -1.46207 & 4.08746 \\
\hline$(18,1)$ & $3.22674-2.3256-2.1252-\mathrm{SnSn}$ & -5.63089 & -1.48221 & 4.14868 \\
\hline$(20,1)$ & 3.22674-2.3256-2.1252-SnSn & -5.68913 & -1.49854 & 4.19059 \\
\hline$(30,1)$ & $3.16699-2.3256-2.1252-\mathrm{SnSn}$ & -5.88124 & -1.50235 & 4.37889 \\
\hline$(40,1)$ & $3.16699-2.3256-2.1252-\mathrm{SnSn}$ & -5.94274 & -1.52385 & 4.41889 \\
\hline$(50,1)$ & $3.16699-2.3256-2.1252-\mathrm{SnSn}$ & -5.97267 & -1.53500 & 4.43767 \\
\hline$(6,2)$ & $3.52552-2.3256-2.1252-\mathrm{SnSn}$ & -4.21072 & -3.22158 & .98914 \\
\hline$(8,2)$ & $3.3197-2.38606-2.1252-\mathrm{OO}$ & -3.28090 & -2.00413 & 1.27677 \\
\hline$(10,2)$ & $3.3197-2.38606-2.1252-\mathrm{OO}$ & -4.58814 & -2.37502 & 2.21312 \\
\hline$(12,2)$ & $3.3197-2.38606-2.1252-\mathrm{OO}$ & -4.87495 & -2.29094 & 2.58401 \\
\hline$(14,2)$ & $3.3197-2.38606-2.1252-\mathrm{OO}$ & -5.04884 & -2.24386 & 2.80498 \\
\hline$(16,2)$ & $3.3197-2.38606-2.1252-\mathrm{OO}$ & -5.16476 & -2.21665 & 2.94811 \\
\hline$(18,2)$ & $3.3197-2.38606-2.1252-\mathrm{OO}$ & -5.24667 & -2.20060 & 3.04607 \\
\hline$(20,2)$ & $3.3197-2.38606-2.1252-\mathrm{OO}$ & -5.30708 & -2.19053 & 3.11655 \\
\hline$(30,2)$ & $3.3197-2.38606-2.1252-\mathrm{OO}$ & -5.45919 & -2.17774 & 3.28145 \\
\hline$(6,3)$ & $3.58527-2.3256-2.1252-\mathrm{SnSn}$ & -4.52665 & -3.49859 & 1.02806 \\
\hline$(8,3)$ & $3.3197-2.3256-2.18045-\mathrm{SnO}$ & -3.43600 & -2.33883 & 1.09717 \\
\hline$(10,3)$ & $3.28650-2.3256-2.1252-\mathrm{SnSn}$ & -4.26052 & -2.21039 & 2.05013 \\
\hline
\end{tabular}


Homo - Lumo |(HUZINAGA) x unidades $\left\{\left[\left(\mathrm{SnO}_{2}\right)_{2}\right] \mathrm{n}\right\} \mathrm{m} ; \mathrm{n}=6, \ldots, 50 ; \mathrm{m}=1,2,3$

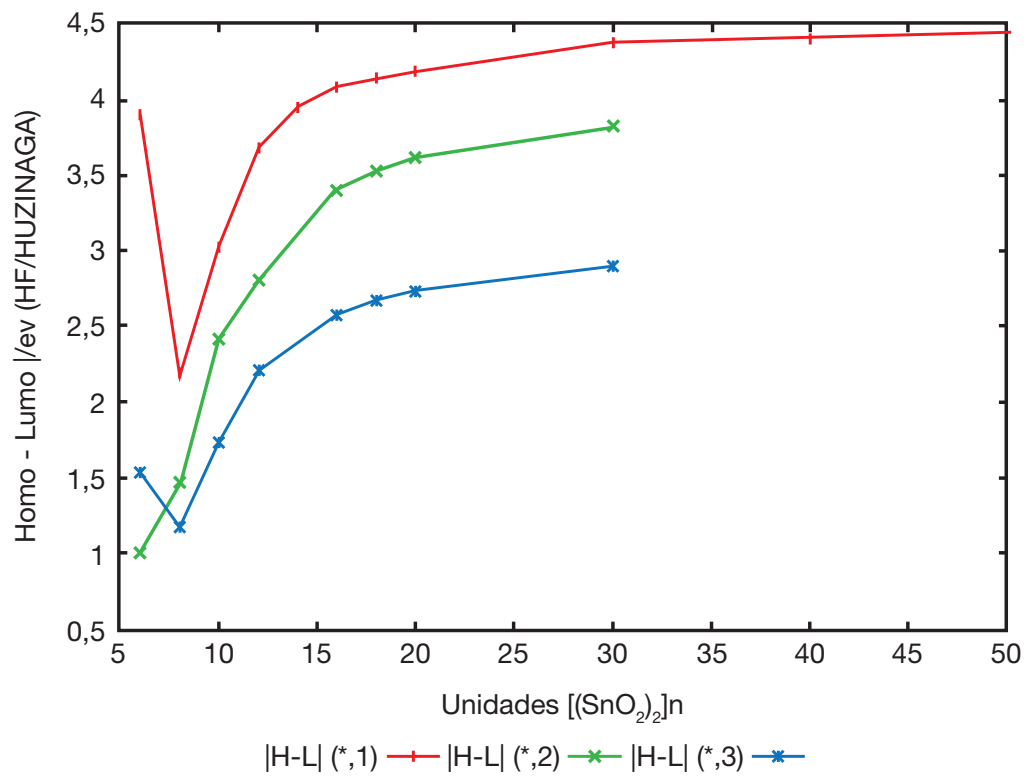

Figura 6.34 $\mid$ Homo - Lumo $\mid$ de nanotubos $\mathrm{SnO}_{2}$ ab initio $\mathrm{HF} / \mathrm{Huzinaga,} \mathrm{n}=1, \ldots, 50$; $\mathrm{m}=$ $1,2,3$.

$\mathrm{Na}$ análise de cargas, foram feitas contagens das cargas atômicas primeiramente para modelos com um nível, somando-as com os conjuntos associados às regiões horizontais e verticais nos modelos de nanotubos de $\mathrm{SnO}_{2}$. A evolução dos valores das somas de cargas depende da quantidade de níveis na estrutura.

As regiões horizontais ficaram todas negativas e as verticais, positivas. As diferenças entre essas regiões aumentam com o incremento de unidades de $\mathrm{SnO}_{2}$, para aumentar, consequentemente, os diâmetros dos modelos, havendo, assim, a polarização entre as duas regiões desses nanotubos, conforme demonstra a Figura 6.35.

As distribuições das somas de cargas ficam entre as quatro regiões, no caso de nanotubos com dois níveis, conforme Figura 6.36. As maiores densidades de cargas ficam no meio dos modelos das estruturas e vão aumentando essas diferenças conforme aumentam os números de unidades de $\mathrm{SnO}_{2}$ em determinados níveis. As regiões centrais indicam equilíbrio de cargas, deixando as pontas nos modelos bem caracterizadas, regiões nucleofílicas horizontais e regiões eletrofílicas verticais.

As tendências entre as regiões horizontais negativas e as regiões verticais positivas nos nanotubos de $\mathrm{SnO}_{2}$, com três níveis, continuam, e as regiões centrais possuem maiores cargas dos modelos, conforme Figura 6.37. Os comportamentos se repetiram ao longo de todos os modelos com três níveis, inclusive os maiores, que apresentaram as maiores estabilidades, conforme relatado nas discussões das energias destes clusters. 
Carga total por nível $m=1$ (horizontal, vertical) $x$ unidades $\left[\left(\mathrm{SnO}_{2}\right)_{2}\right] \mathrm{n} ; \mathrm{n}=6, \ldots, 30$

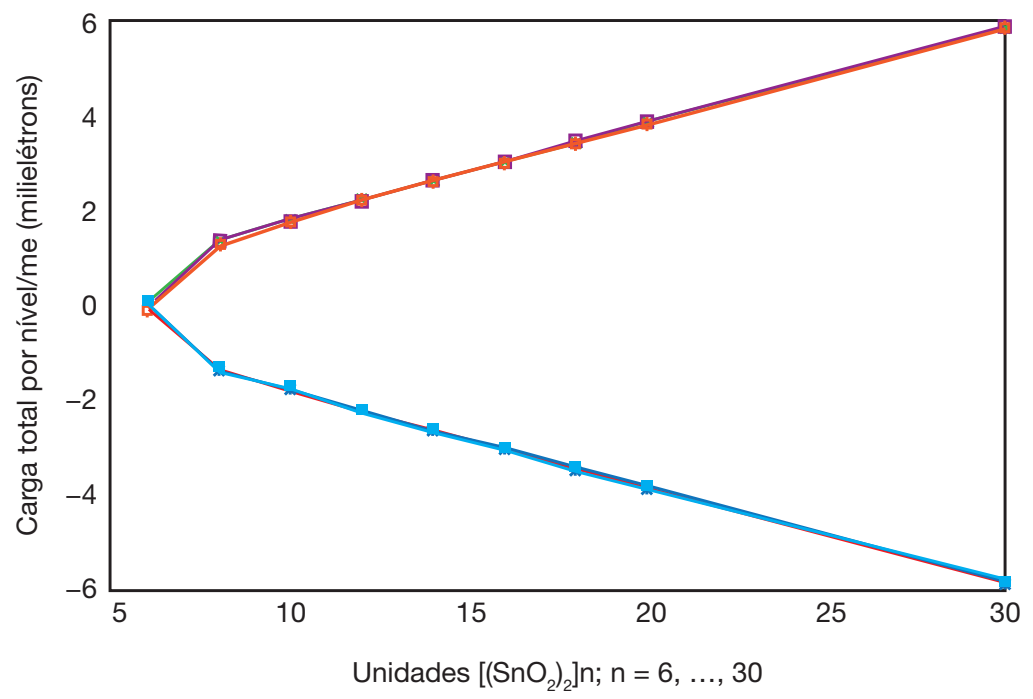

SnSn-horizontal-m = 1 $\longrightarrow$ 00-horizontal-m = $1 \rightarrow$ SnO-horizontal-m = $1-$

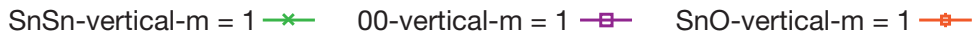

Figura 6.35 Variações das somas de cargas entre as regiões horizontais e verticais para os modelos de nanotubos de $\mathrm{SnO}_{2}$ com vários diâmetros e com um nível, $\mathrm{m}=1$.

Carga total por nível $m=2$ (horizontal, vertical) $x$ unidades $\left[\left(\mathrm{SnO}_{2}\right)_{2}\right] \mathrm{n} ; \mathrm{n}=6, \ldots, 20$

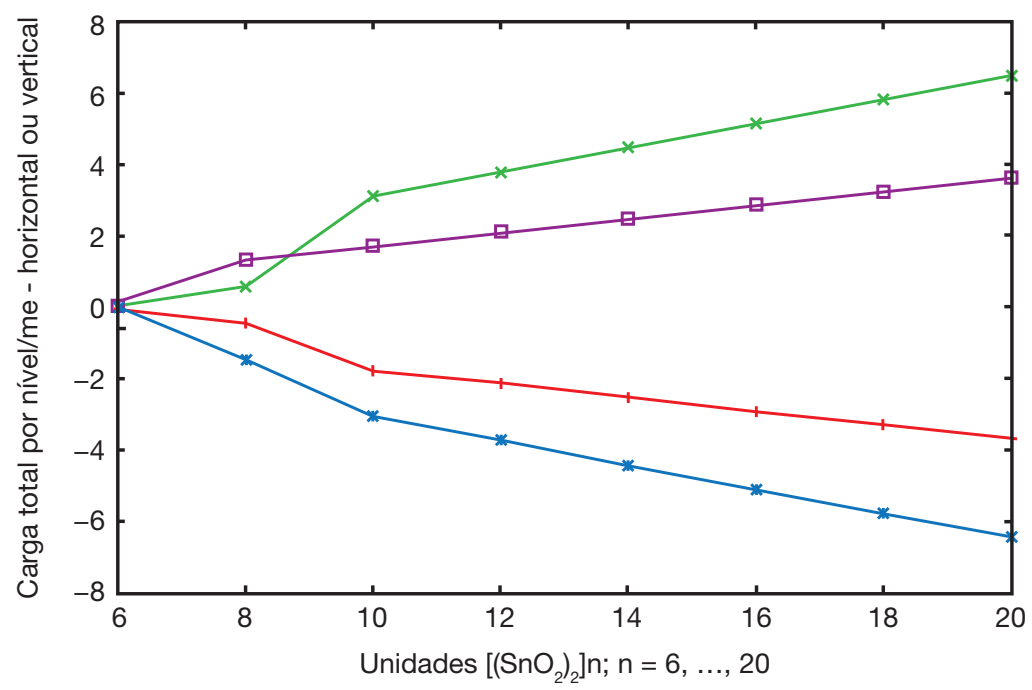

SnSn-horizontal-m $=1 \longrightarrow$ SnSn-horizontal-m $=2 \div$

SnSn-vertical-m $=1 \multimap$ SnSn-vertical-m $=2 \rightarrow$

Figura 6.36 Variações das somas de cargas de duas regiões horizontais e duas verticais para os nanotubos de $\mathrm{SnO}_{2}$ com vários diâmetros e dois níveis, $\mathrm{m}=2$. 
Carga total por nível $\mathrm{m}=3$ (horizontal, vertical) $x$ unidades $\left[\left(\mathrm{SnO}_{2}\right)_{2}\right] \mathrm{n} ; \mathrm{n}=6, \ldots, 18$

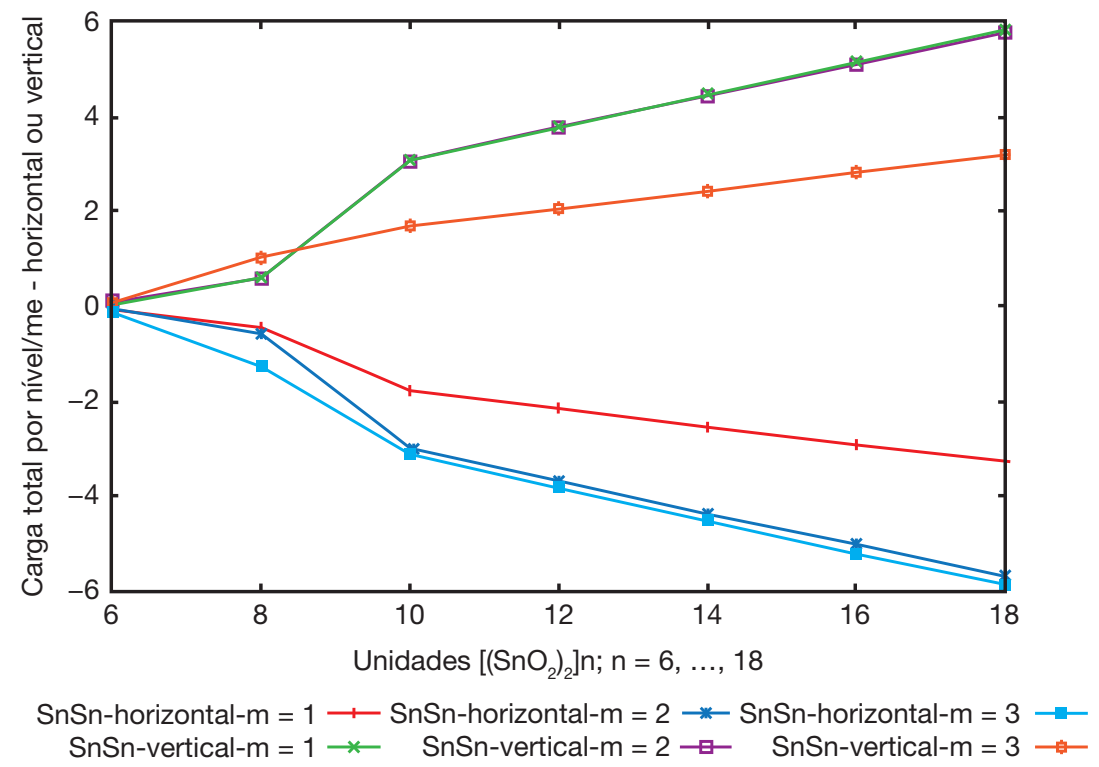

Figura 6.37 Variações das somas de cargas de três regiões horizontais e três regiões verticais para os nanotubos de $\mathrm{SnO}_{2}$ com vários diâmetros e três níveis, $\mathrm{m}=3$.

Em todas essas estruturas calculadas observou-se uma distribuição simétrica entre os átomos de mesmo tipo, e esses comportamentos em relação aos planos se repetiram. Os átomos de estanho nas regiões verticais têm valores de carga mais positivos e os oxigênios nas regiões horizontais, valores mais positivos, comparados com os das regiões verticais, mostrando assimetrias entre as cargas dos átomos de estanho nas regiões horizontais e verticais. Isso ocorre também entre os átomos de oxigênio nas regiões horizontais nos clusters.

A simetria existe entre todos os átomos de estanho pertencentes a um mesmo nível e também entre os oxigênios nas regiões verticais dos modelos de nanotubos de $\mathrm{SnO}_{2}$, conforme ilustra a Figura 6.38.

Se forem observadas de cima as estruturas, ou por dentro desses nanotubos, nas distribuições de cargas entre os oxigênios de fora existe uma assimetria: a parte interna fica mais negativa ou nucleofílica, enquanto a parte de fora, que também é negativa, apresenta um módulo menor, com a nucleofilicidade diminuída, conforme ilustra a Figura 6.38. 
Cargas dos átomos de estanhos e oxigênios em $\left\{\left[\left(\mathrm{SnO}_{2}\right)_{2}\right] 14\right\} 1 ;(14,1)=84$ átomos

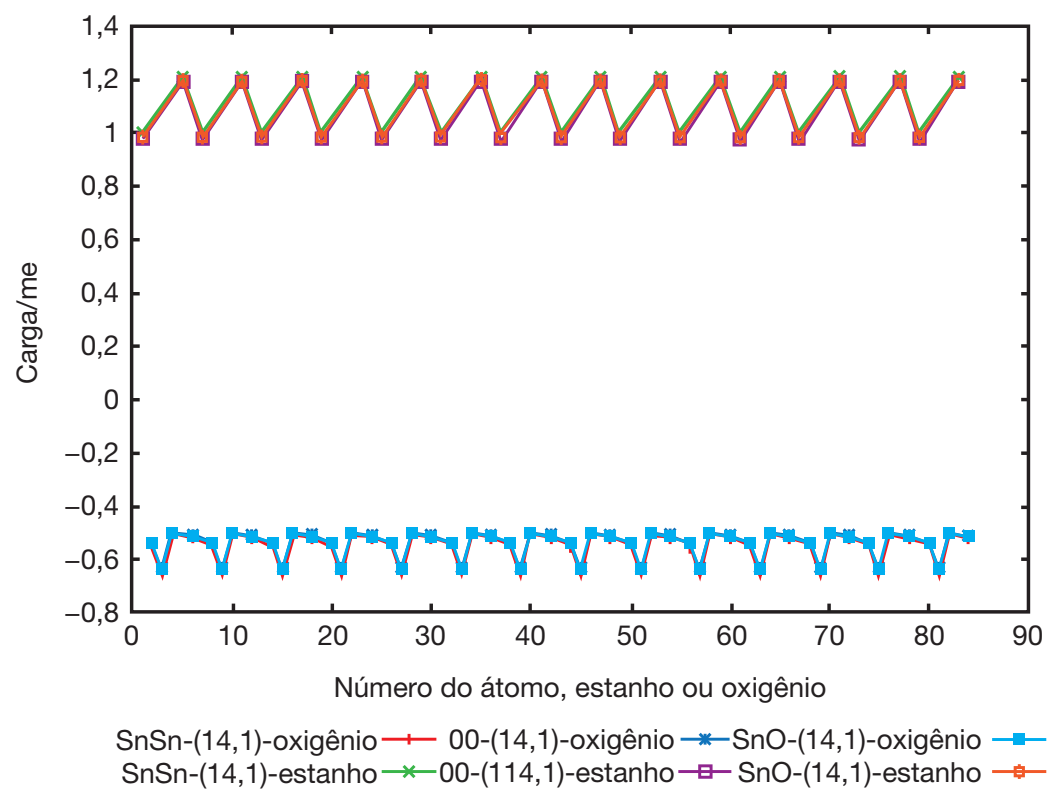

Figura 6.38 Distribuição das cargas nos átomos de estanho e oxigênio no modelo do nanotubo de $\mathrm{SnO}_{2}, \mathrm{n}=14$ e $\mathrm{m}=1$.

\subsection{ConCLUSÃo}

Os resultados para os nanotubos de $\mathrm{SnO}_{2}$ se mostraram eficientes para os métodos MNDO, B3LYP-Huzinaga, HF/Huzinaga e as metodologias escolhidas para fazer as análises de uma gama de propriedades e tendências desses modelos para essa família de materiais que tem sido observada experimentalmente.

As estruturas com a maior quantidade de unidades de $\mathrm{SnO}_{2}$, ao longo dos diâmetros, fazem com que haja maior estabilidade desses clusters. Por outro lado, se forem mantidos os mesmos diâmetros, o aumento de níveis vai estabilizando as estruturas, mas comparando a outras com os mesmos diâmetros e níveis, tais formas mais estreitas se tornam mais instáveis.

O esforço computacional para a execução dos cálculos desses modelos é muito grande; assim, é essencial um estudo sistemático para não perder tempo e incorrer em custos astronômicos nas máquinas.

Os valores das distâncias entre $\mathrm{SnSn}, \mathrm{OO}$ e $\mathrm{SnO}$ vão se fixando à medida que as estruturas vão se tornando mais complexas e se encontram os valores relacionados para cada quantidade de unidades e níveis que são escolhidos nos clusters. 
As diferenças entre Homo e Lumo para os métodos semiempírico e $\mathrm{HF} / \mathrm{Hu}-$ zinaga se mostraram semelhantes, enquanto os valores para os métodos B3LYP-Huzinaga ficaram subestimados.

As distribuições de cargas nas regiões horizontais e verticais nos modelos apresentaram valores diferenciados, e as primeiras sempre ficaram negativas. Se forem comparados os lados interno e externo nos nanotubos de $\mathrm{SnO}_{2}$, verificam-se as regiões centrais mais nucleofílicas do que as externas.

\section{REFERÊNCIAS}

Antunes, S. R. M.; Santos, J. D.; Antunes, A. C.; Longo, E.; Varela, J. A. MNDO theoretical study of ethanol decomposition process on $\mathrm{SnO}_{2}$ surfaces. Journal of Molecular Structure (Theochem), v. 357, p. 153-159, 1995.

Camargo, A. C.; Igualada, J. A.; Beltrán, A.; Llusar, R.; Longo, E.; Andrés, J. An ab initio perturbed ion study of structural properties of $\mathrm{TiO} 2, \mathrm{SnO} 2$ and $\mathrm{GeO} 2$ rutile lattices. Chemical Physics, v. 212, p. 381-391, 1996.

Dong, W.-S.; LI, M.-Y.; Liv, C.; Lin, F. Novel ionic liquid assisted synthesis of SnO2 microspheres. Journal of Colloid and Interface Science, v. 319, p. 115-122, 2008.

Duan, J.; Gong, J.; Huang, H.; Zhao, X.; Cheng, G.; Yu, Z.-Z.; Yang, S. Multiform structures of $\mathrm{SnO}_{2}$ nanobelts. Nanotechnology, v. 18, n. 5, p. 1-6, 2007.

Fagan, S. B.; Fazzio, A.; МотA, R. Titanium monomers and wires adsorbed on carbon nanotubes: a first principles study. Nanotechnology, v. 17, p. 1154-1159, 2006.

Ferreira, M. D.; Santos, J. D.; Taft, C. A.; Longo, E. J. B. L. E.; Martins, J. B. L. Single walled $\mathrm{MgF}_{2}$ nanotubes. Computational Materials Science, v. 46, p. 233-238, 2009.

Firroz, A. A.; Mahjoub, A. R.; Khodadadi, A. A. Preparation of $\mathrm{SnO}_{2}$ nanoparticles and nanorods by using a hydrothermal method at low temperature. Materials Letters, v. 62, p. 1789-1792, 2008.

HuANG, X.-J.; CноI, Y.-K. Chemical sensors based on nanostructured materials. Sensor and Actuators B, v. 122, p. 657-671, 2007.

Johnson, P. L.; Teeters, D. Formation and characterization of $\mathrm{SnO}_{2}$ nanobaskets. Solid States Ionics, v. 177, p. 2821-2825, 2006.

KIM, H. W.; SHIN, S. H. Synthesis and characteristics of $\mathrm{SnO}_{2}$ needle-shaped nanostructures. Journal of Alloys and Compounds, v. 426, p. 386-289, 2006.

Kuo, H.-L.; Kuo, C.-Y.; LıU, C.-H.; CHÃo, J.-H.; LIN, C.-H. A highly active bi-crystalline photocatalyst consisting of $\mathrm{TiO}_{2}$ (B) nanotube and anatase particle for producing $\mathrm{H}_{2}$ gas from neat ethanol. Catalysis Letters, v. 113, n. 1-2, p. 7-12, 2007.

Kupchak, L.; Antunes, S. R. M.; Parizotto, M. V.; Tebcherani, S. M.; Setti, D.; PianaRo, S. A.; Antunes, A. C. Investigation of the sintering kinetics for initial stage in $\mathrm{SnO}_{2}$ : ZnO system. Cerâmica, v. 51, p. 308-312, 2005. 
Laghrib, S.; Amardia-Adnani, H.; Abdi, D. J. M. Tin oxide thin layers obtained by vacuum evaporation of tin and annealing under oxygen flow. Pelletier, Vacuum, v. 82, p. 782-788, 2008.

Maziarz, W.; Pisarkiewicz, T. Gas sensors in a dynamic operation mode. Meas. Sci. Technol., v. 19, p. 1-7, 2008.

Prades, J. D.; Arbiol, J.; Cirera, A.; Morante, J. R.; Avella, M.; Zanotti, L.; Comini, E.; Faglia, G.; Sberveglieri, G. Defect study of $\mathrm{SnO}_{2}$ nanostructures by cathodoluminescence analysis: application to nanowires. Sensors and Actuators B, v. 126, p. 6-12, 2007 a.

Prades, J. D.; Cirera, A.; Morante, J. R.; Pruneda, J. M.; Ordejón, P. Ab initio study of $\mathrm{NO}_{\mathrm{x}}$ compounds adsorption on $\mathrm{SnO}_{2}$ surface. Sensor and Actuators B, 126, p. 62-76, 2007b.

Rantala, T. T.; Rantala, T. S.; Lantto, V. Surface relaxation of the (110) face of rutile $\mathrm{SnO}_{2}$. Surface Science, v. 420, p. 103-109, 1999.

Remskar, M. Inorganic nanotubes. Adv. Mater., v. 16, n. 17, p. 1497-1504, 2004.

Vlcek, L.; Zhang, Z.; Machesky, M. L.; Fenter, P.; Rosenqvist, J.; Wesolowski, D. J.; Anovitz, L. M.; Predota, M.; Cummings, P. T. Electric double layer at metal oxide surfaces: static properties of the cassiterite-water interface. Langmuir, v. 23, p. 4925-4937, 2007. XuE, Y. B.; TANG, Z. A. Density functional study of the interaction of CO with undopedand Pd doped $\mathrm{SnO}_{2}$ (110) surface. Sensor and Actuator B, v. 138, p. 108-112, 2009.

WANG, Y.; WU, M.; JiAO, Z.; LeE, J. Y. One-dimensional $\mathrm{SnO}_{2}$ nanostructures: facile morphology tuning and lithium storage properties. Nanotechology, n. 34, p. 20, 2009.

WHANG, B.; YANG, Y. H.; YANG, G. W. Electron-beam irradiation induced shape transformation of $\mathrm{SnSnO}_{2}$ nanocables. Nanotechnology, v. 17, n. 24, p. 5916-5921, 2006.

Zhang, Y.; Yu, K.; Li, G.; Peng, D.; Zhang, Q.; Hu, H.; Xu, F.; BaI, W.; Ouyang, S.; Zhu, Z. Field emission from patterned $\mathrm{SnO}_{2}$ nanostructures. Applied Surface Science, v. 253, p. 792-796, 2006.

Zhu, Z.; Deka, R. C.; Chutia, A.; Sahnoun, R.; Tsuboi, H.; Koyama, M.; Hatakeyama, N.; Endou, A.; Takaba, H.; Del Carpio, C. A.; Kubo, M.; Miyamoto, A. Enhanced gas-sensing behaviour of $\mathrm{Ru}$-doped $\mathrm{SnO} 2$ surface: a periodic density functional approach. Journal of Physics and Chemistry of Solids, v. 70, p. 1248-1255, 2009. 


\section{SIMULAÇÃO POR DINÂMICA MOLECULAR DA ENZIMA CRUZAÍNA DO TRYPANOSOMA CRUZI}

Osmar Vital de Olveira?

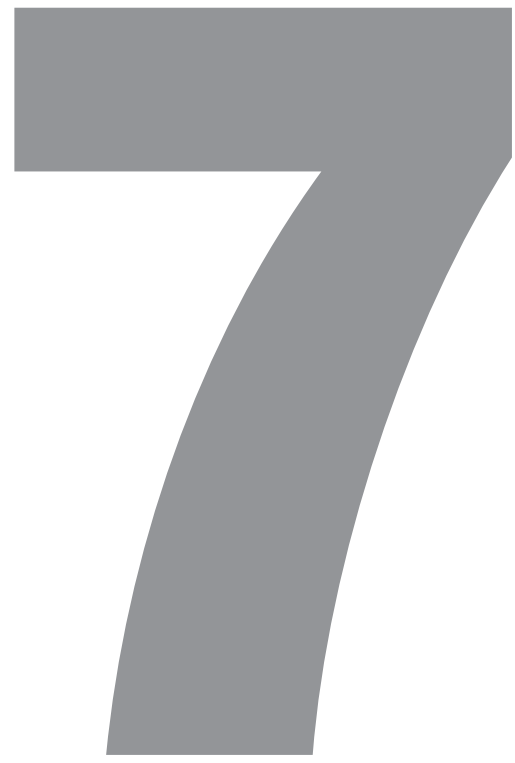




\subsection{INTRODUÇão}

As enzimas são de fundamental importância para o funcionamento e a sobrevivência dos seres vivos. Portanto, compreender as relações entre estrutura e função de enzimas é fundamental para entender a intrincada teia dos processos vitais. Entre os vários processos vitais, estudar o mecanismo das reações enzimáticas é uma tarefa importante e decisiva para a compreensão dos mecanismos moleculares em sistemas biológicos. Em reações enzimáticas, esses estudos implicam conhecer o entendimento das interações entre o substrato e o sítio catalítico da enzima, bem como de outros fatores que influem nessa interação. Dentre esses fatores, destacam-se a composição e estrutura do sítio ativo e efeitos dinâmicos do sistema. Ressalta-se que entender a sinergia desses processos é de real importância para o desenvolvimento de estratégias de intervenção em processos patológicos. Entre as intervenções, cabe destacar o desenvolvimento de novos fármacos.

Para entender melhor os processos enzimáticos, é necessário tratar o sistema nos níveis atômico e molecular. Entretanto, são raras as técnicas experimentais que revelam detalhes completos da dinâmica desses sistemas em escala atômica. As poucas técnicas existentes possuem custo elevado e dificuldades práticas para a aplicação generalizada, sendo, portanto, pouco acessíveis à totalidade da comunidade científica. Desse modo, com o avanço e a popularização de computadores cada vez mais velozes e de baixo custo, a química computacional consolida-se gradativamente como uma área de pesquisa fundamental para o entendimento de processos químicos nos níveis atômico e molecular. A sinergia existente entre o desenvolvimento de hardware e software cria novos horizontes para a aplicação em pesquisa científica. Os avanços obtidos têm sido de grande valia para os químicos teóricos, proporcionando também o surgimento de interfaces de colaboração direta com a pesquisa experimental.

Dentre as diversas metodologias de química teórica utilizadas para estudar sistemas biológicos, a dinâmica molecular é uma técnica muito interessante, pois 
utiliza campos de força que são muito úteis para a obtenção de propriedades termodinâmicas e estruturais de líquidos e macromoléculas. Ademais, a eficiência dessa metodologia permite que um número relativamente grande de partículas seja convenientemente tratado. Assim, a técnica dinâmica molecular será utilizada para estudar a enzima cisteína protease cruzaína do Trypanosoma cruzi, responsável pela doença de Chagas. Alguns objetivos são: i) estudar a enzima cruzaína; ii) caracterizar o comportamento dinâmico dessa enzima na presença e ausência de uma cadeia peptídica; iii) utilizar esse conjunto de informações para identificar as interações que podem contribuir para o desenho racional de fármacos; e iv) elaborar conjunto de ancoragem, a fim de ser utilizado em futuros trabalhos para a proposição de novos inibidores eficientes.

\subsection{Doença de Chagas}

A doença de Chagas foi descoberta em 1909 pelo médico sanitarista Carlos Chagas, causada pelo protozoário Trypanosoma cruzi, que é transmitido principalmente pelo inseto-vetor hematófago conhecido popularmente como barbeiro. Esse inseto é classificado na ordem Hemiptera e família Reduviidae, sendo encontrado com frequência em frestas de paredes de barro ou de madeira de lares na zona rural e em outras localidades. Uma das maneiras mais eficientes que tem sido utilizada no controle da doença de Chagas é a eliminação de ambientes favoráveis à procriação do inseto-vetor, bem como a eliminação deste por meio de inseticidas. Outras formas de transmissão da doença ocorrem por transfusão de sangue e transmissão congênita. ${ }^{2} \mathrm{~A}$ figura a seguir apresenta as áreas de maiores incidências e de riscos da doença de Chagas.

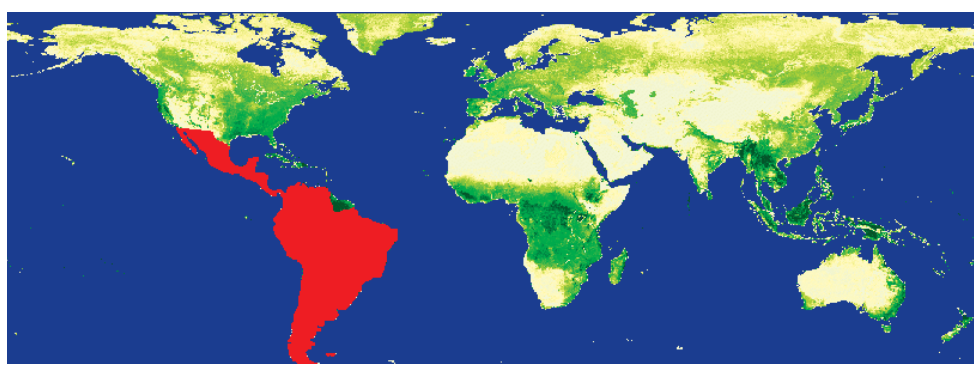

Figura 7.1 Distribuição global (em vermelho) da doença de Chagas.

Fonte: <http://geo.arc.nasa.gov/>.

Estima-se que a cada ano 200 mil pessoas são contaminadas pela doença de Chagas e 40 milhões de pessoas se encontram com risco de contrair a doença. Desse

2 WHO (2002). 
total, cerca de 13 mil pessoas morrem em decorrência de complicações pela doença. ${ }^{3}$ A doença de Chagas envolve dois estágios clínicos: agudo e crônico. ${ }^{4} \mathrm{Na}$ fase aguda, o estágio se inicia após um inseto infectado picar uma pessoa. Alguns sintomas nessa fase são inchaço no local da picada, febre e taquicardia. A fase de infecção aguda normalmente não é fatal. Já na fase crônica, o estágio é dividido em dois, sintomático e assintomático. Cerca de $60 \%$ dos pacientes chagásicos crônicos permanecem assintomáticos por longos períodos, sendo que $30 \%$ deles desenvolvem complicações cardíacas que podem levar à cardiopatia chagásica crônica.

Apesar de bem conhecida há mais de cem anos, até os dias atuais existem apenas dois fármacos contra a doença: benzonidazol e nifurtimox. Entretanto, apresentam baixa eficiência e fortes efeitos colaterais, ${ }^{5}$ bem como atividade inibitória apenas na fase aguda da doença. No Brasil, a comercialização do composto nifurtimox é proibida. ${ }^{6} \mathrm{O}$ baixo desenvolvimento de fármacos antichagásicos pode ser atribuído ao pouco interesse da indústria farmacêutica, o que se deve principalmente à falta de incentivos comerciais, ou seja, baixa demanda.

Para o desenvolvimento de fármacos contra o parasita, vários processos bioquímicos têm sido apontados e explorados como alvos terapêuticos potenciais: ${ }^{7}$ a enzima tripanotiona redutase; ${ }^{8}$ enzimas envolvidas na importação e interconversão de purinas; $;$ metabolismo de folato e pteridina; ${ }^{10}$ biossíntese de RNA mensageiro; ${ }^{11}$ biossíntese de lipídios; transialidase, ${ }^{12}$ diidrofolato redutase, ${ }^{13}$ enzimas do glicossomo, envolvidas no metabolismo energético, destacando-se a gliceraldeído-3-fosfato desidrogenase, ${ }^{14}$ e outros.

Outro alvo terapêutico que tem sido extensivamente explorado são as enzimas proteases de cisteína, em especial a cruzaína (EC 3.4.22.51). Proteases são enzimas que catalisam a hidrólise de ligações peptídicas. As proteases podem ser divididas em sete classes, de acordo com seu mecanismo catalítico. Segundo esta classificação, os membros de cada uma destas classes possuem um conjunto característico de aminoácidos funcionais dispostos em uma configuração específica e que formam o centro ativo da enzima. As diferentes classes se subdividem, ainda, em diversas famílias, sendo que os membros de famílias diferentes, apesar de terem uma sequência de aminoácidos distinta, possuem geometria e mecanismo catalítico semelhantes, ${ }^{15}$ em que cada peptidase tem função específica no organismo humano

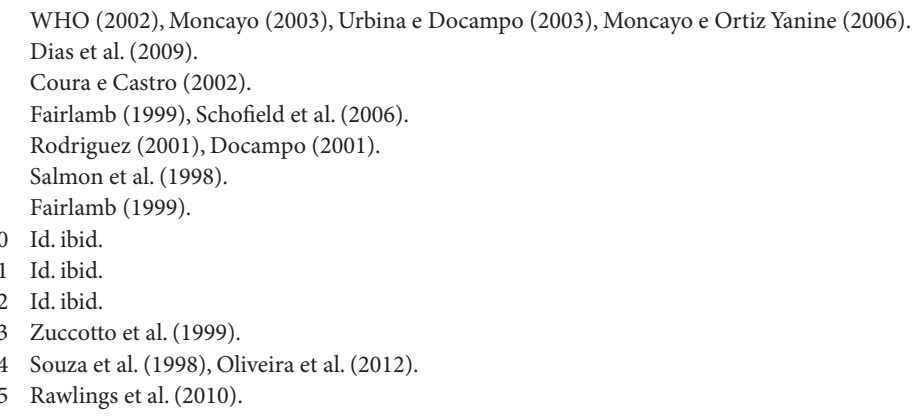


e corresponde de $1 \%$ a $5 \%$ de seus conteúdos genéticos. Dentre as proteases, têm-se as cisteínas proteases, as quais possuem uma cisteína no sítio ativo. Enzimas dessa família têm diversas funções no organismo, como, por exemplo, serem essenciais na apoptose celular e necessárias no sistema imune. ${ }^{16}$ Desse modo, disfunções dessas enzimas podem levar a vários processos fisiopatológicos, como o desenvolvimento de tumores e doenças autoimunes.

É bom enfatizar que enzimas dessa família estão presentes em diversos parasitas, como, por exemplo, Trypanosoma cruzi e Leishmania, e desempenham neles funções vitais. ${ }^{17}$ Portanto, enzimas proteases de cisteína são alvos terapêuticos interessantes no desenvolvimento de fármacos, uma vez que sua inibição pode levar à cura de doenças como câncer e doença de Chagas. A cruzaína pertencente à superfamília papaína é a protease mais abundante e melhor caracterizada do parasita $T$. cruzi. ${ }^{18}$ Essa enzima é necessária e essencial para a sobrevivência do parasita, para sua diferenciação celular e seu crescimento e desenvolvimento dentro da célula hospedeira. ${ }^{19}$ Além disso, a cruzaína participa do processo de invasão e internalização do parasita nas células de mamíferos. O mecanismo de hidrólise de peptídeos da cruzaína é o mesmo das cisteíno-proteases, pois o sítio catalítico é constituído pelos aminoácidos cisteína, histidina e glutamina.

A função da glutamina no processo catalítico é estabilizar o par iônico cisteína/ histidina. É bom enfatizar que, desde 2001, a cruzaína é um alvo validado para a quimioterapia da doença de Chagas. ${ }^{20}$ Assim, a inibição dessa enzima pode levar à morte do parasita. Com este objetivo, vários estudos têm sido mencionados na literatura, tanto no nível teórico quanto no experimental. Experimentalmente, derivados peptídicos ${ }^{21}$ e não peptídicos (triazóis, pirimidinas, tiossemicarbazonas e chalconas) ${ }^{22}$ têm sido estudados na tentativa de obter um fármaco para inibir a cruzaína. Já nos estudos teóricos, podem ser citados os cálculos de dinâmica molecular, ${ }^{23}$ ancoragem e triagem virtual..$^{24}$ Apesar de todos esses esforços, até a presente data, ainda não foi descoberto um composto eficiente para a inibição da cruzaína do T. cruzi.

Portanto, visando entender o comportamento estrutural e energético e as interações específicas da enzima cruzaína na forma apo (não complexada) e na forma holo (complexada com um peptídeo), foram realizadas simulações por dinâmica molecular. A Figura 7.2 a seguir mostra a estrutura cristalográfica da cruzaína obtida no Protein Data Bank.

6 Leung et al. (2000).

17 Turk (2006).

18 Cazzulo et al. $(1997,2001)$

19 Cazzulo et al. (2001), Reis et al. (2006), McKerrow et al. (2006).

20 Cazzulo et al. (2001).

21 Andricopulo et al. (1998), McKerrow et al. (2008).

22 Zanatta et al. (2008), Soeiro e Castro (2009), Chen et al. (2010).

23 Mladenovic et al. (2008), Durrant et al. (2010).

24 Malvezzi et al. (2009), Romeiro et al. (2009), Durrant et al. (2010). 


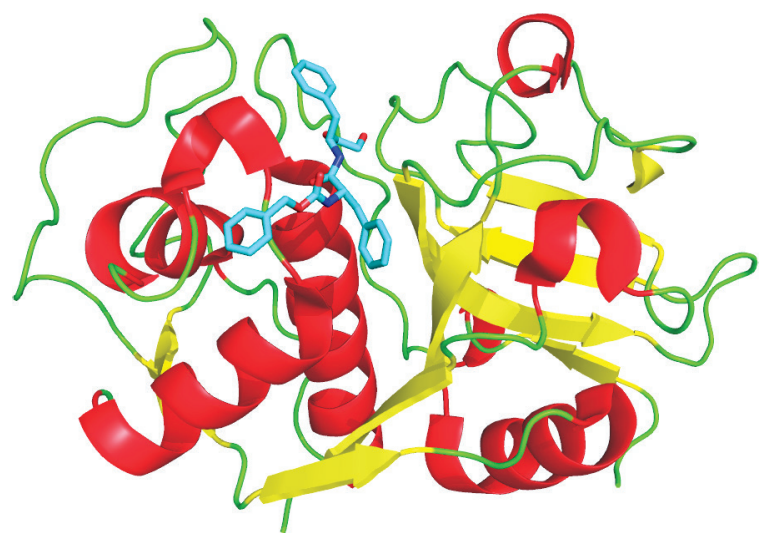

Figura 7.2 Estrutura cristalográfica da cruzaína complexada com um inibidor covalente (código PDB: 1ME4).

Fonte: $<$ www.pdb.org/>.

\subsection{Protocolo de dinÂMICA MOLECULAR}

Dinâmica molecular (DM) é uma metodologia utilizada para resolver problemas em mecânica estatística, na impossibilidade de solução analítica das equações. Em sua forma geral, a DM é utilizada para simular a evolução temporal de um sistema sob a ação de forças conhecidas. Essa metodologia recorre à integração das equações de movimento clássicas para determinar aceleração, velocidade e posição temporal das partículas do sistema. ${ }^{25} \mathrm{~A}$ partir da trajetória gerada, várias propriedades podem ser determinadas: coeficiente de difusão, energia de interação, parâmetros estruturais, entre outras.

Para a construção dos sistemas a serem simulados, a estrutura cristalográfica da enzima cruzaína foi obtida no Protein Data Bank, com código PDB 1ME4. Para a simulação da proteína na forma apo, o ligante cristalográfico foi removido, e a enzima foi inserida em uma caixa cúbica de aresta medindo $8 \mathrm{~nm}$, contendo 16.091 moléculas de água. Para manter o sistema eletrostaticamente neutro, 13 íons $\mathrm{Na}^{+}$ foram adicionados pela replicação de moléculas de água preexistentes. Para a simulação do sistema na forma holo, foi necessário obter a estrutura do peptídeo de outra cisteína protease, uma vez que, até a presente data, ainda não foi cristalizada a cruzaína com alguma cadeia peptídica. Assim, a catepsina K humana complexada com um polipeptídeo de 99 aminoácidos foi obtida no Protein Data Bank (código PDB 1BY8) e sobreposta com a estrutura da cruzaína. A partir dessa sobreposição, as coordenadas cristalográficas do polipeptídeo (Lys-Met-Thr-Gly-Leu-Lys-Val-Pro) foram inseridas dentro da estrutura 1ME4 (cruzaína). Esta sequência de aminoáci- 
dos (que forma um loop) foi considerada, pois apenas estes ocupam a região do sítio ativo da enzima. A Figura 7.3 a seguir mostra o complexo cruzaína-peptídeo obtido.

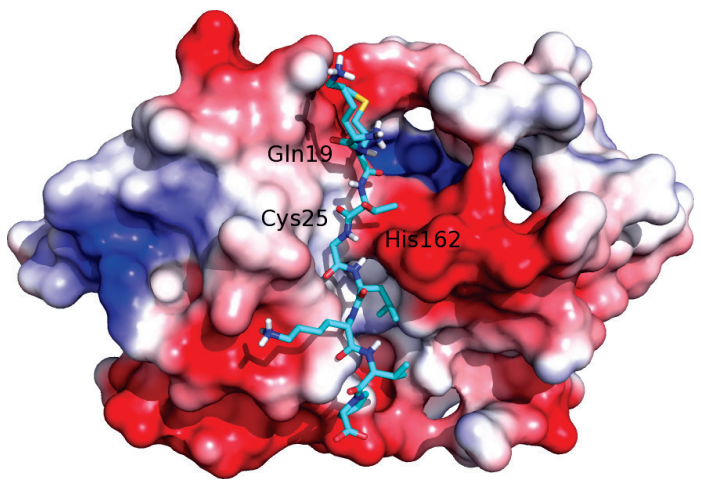

Figura 7.3 Complexo cruzaína-peptídeo a ser simulado. A cruzaína é representada por seu potencial eletrostático (negativo em vermelho, positivo em azul e cargas neutras em branco), e a posição da tríade catalítica é mostrada em detalhe. O peptídeo está em stick, e, para melhor visualização, os hidrogênios apolares foram removidos.

O complexo cruzaína-peptídeo foi solvatado com 16.081 moléculas de água e foram adicionados 11 íons $\mathrm{Na}^{+}$para manter a neutralidade do sistema. Condições periódicas de contorno foram adicionadas, e um raio de corte de $1,0 \mathrm{~nm}$ foi utilizado para as interações de Coulomb e Van der Waals. O conjunto NpT (número de átomos, pressão e temperatura constantes) foi utilizado. A pressão e a temperatura do sistema adotadas foram de 1 bar e $310 \mathrm{~K}$, respectivamente, com constantes de tempo de 1,0 ps e $0,1 \mathrm{ps}$, respectivamente, utilizadas no algoritmo termostato e barostato de Berendsen. ${ }^{26}$ Para descrever o solvente, foi utilizado o modelo SPC/ flexível ${ }^{27}$; para a enzima, foram considerados parâmetros do campo de força OPLS- $\mathrm{AA}^{28}$. Para minimizar o efeito de contato ou da sobreposição de átomos entre as moléculas, foi realizada a minimização da energia do sistema com os algoritmos máximo decline e gradiente conjugado. Nessas etapas, mil passos de minimização foram utilizados em ambos algoritmos. Após essa etapa, uma trajetória de 500 ps foi gerada, restringindo os movimentos internos na enzima com constantes de força de $1.000 \mathrm{~kJ} \cdot \mathrm{mol}^{-1} \cdot \mathrm{nm}^{-2}$. O objetivo dessa etapa foi relaxar e termalizar o solvente na temperatura desejada. Finalizada essa etapa, gerou-se uma trajetória de 50,0 ns de simulação, e o mesmo procedimento foi feito para a enzima na forma apo, mas, nesse caso, apenas removeu-se a cadeia peptídica da região do sítio ativo. Dentre os vários pacotes computacionais de dinâmica molecular, aqui foi utilizado o Gromacs. ${ }^{29}$

26 Berendsen et al. (1984).

27 Id. (1981).

28 Jorgensen et al. (1996).

29 Berendsen et al. (1995), Lindahl et al. (2001). 


\subsection{ANÁLISES DE DINÂMICA MOLECULAR}

Aqui, apresentar-se-ão algumas principais análises e discussões que são realizadas em sistemas biológicos estudados por dinâmica molecular com enfoque na obtenção de fármacos.

\subsubsection{Análise estrutural}

Uma medida inicial e importante em simulação por DM de enzimas é o cálculo do desvio quadrático médio ou RMSD (Root Mean Square Deviation). O RMSD fornece a medida do desvio da estrutura de uma dada molécula ao longo do tempo. Para calculá-lo, a cada intervalo de tempo, executa-se uma sobreposição da estrutura atual com a inicial para obter o desvio entre ambas, o qual é mostrado na Equação 7.1.

$$
R M S D\left(t_{i}, t_{0}\right)=\left[\frac{1}{N} \sum_{i=1}^{N}\left\|r_{i}\left(t_{i}\right)-r_{0}\left(t_{0}\right)\right\|^{2}\right]^{\frac{1}{2}}
$$

em que $r_{\mathrm{i}}$ e $t_{\mathrm{i}}$ representam a posição do átomo $i$ no tempo; $t_{\mathrm{i}}$ e $t_{0}$ se referem à estrutura da molécula no tempo zero ou em um tempo predefinido. Logo, pequenas variações de valores de RMSD implicam baixa mudança conformacional ou baixa mobilidade. Embora experimentalmente não seja possível obter a evolução estrutural via RMSD, este pode ser correlacionado com uma propriedade experimental, o fator $\mathrm{B}$ de temperatura. $\mathrm{O}$ fator de temperatura é uma medida da posição atômica oriunda das vibrações térmicas de um sistema cristalino. A correlação entre RMSD e fator B de temperatura é expressa pela Equação 7.2.

$$
\mathrm{B}=(8 / 3) \mathrm{p}^{2}(\mathrm{RMSD})^{2}
$$

Portanto, usando a Equação 7.2 é possível correlacionar a variação estrutural (RMSD) obtida em uma trajetória de DM com uma observável experimental (fator B). Desse modo, para entender o comportamento estrutural da enzima cruzaína nas formas apo e holo, foram realizadas medidas de RMSD (Figura 7.4) e considerados todos os átomos $\mathrm{C} \alpha$. 


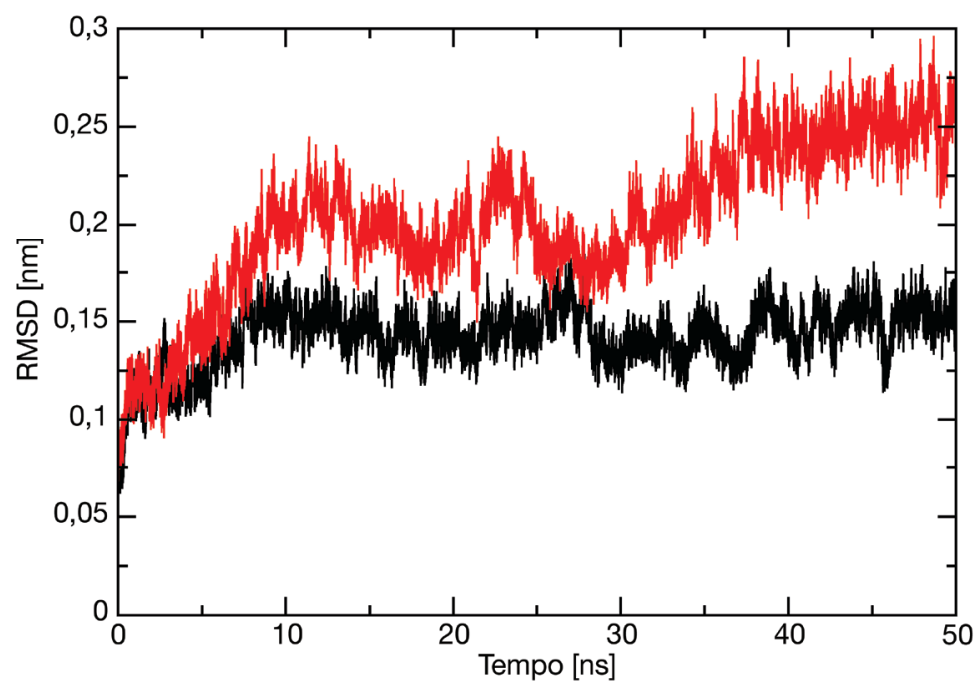

Figura 7.4 RMSD dos átomos C $\alpha$ da enzima cruzaína nas formas apo (linha vermelha) e holo (linha preta) obtidos ao longo da simulação.

A Figura 7.4 mostra que os valores de RMSD aumentam nos primeiros $10 \mathrm{~ns}$ de simulação de 0 para 0,15 e 0,20 $\mathrm{nm}$ para as formas holo e apo, respectivamente. Isso mostra que a enzima cruzaína perde sua conformação inicial. Depois desse tempo, o RMSD mantém média de $0,15 \mathrm{~nm}$ com desvio padrão (d.p.) de 0,01 nm, ao longo do tempo, para a forma holo. Já para a forma apo, o RMSD mantém média de $0,20 \mathrm{~nm}$, com d.p. de 0,02 nm no intervalo de 10 a $34 \mathrm{~ns}$. Depois desse tempo, o RMSD aumenta para $0,24 \mathrm{~nm}$, no tempo de $37 \mathrm{~ns}$, e, posteriormente, mantém média de $0,25 \mathrm{~nm}$, com d.p. de 0,01 nm. Essas análises mostram que a estrutura da enzima na forma apo passa por duas mudanças estruturais no tempo de simulação considerado, uma de 0 a 10 ns e outra de 34 a 37 ns de simulação. O baixo valor do RMSD na forma holo mostra que a estrutura da cruzaína não apresenta mudanças significativas ao longo da simulação. Ao contrário da forma holo, os valores relativamente altos de RMSD da forma apo mostram que a enzima apresenta mudanças conformacionais significativas. Esses dados revelam que a presença do peptídeo na região do sítio ativo da cruzaína estabiliza sua estrutura. Para entender quais regiões da enzima são responsáveis pelas mudanças observadas, foram realizadas análises de RMSF (Root Mean Standard Fluctuations). O RMSF mede a flutuação dos aminoácidos, ou parte deles, ao longo da simulação e, com isso, é possível identificar as principais regiões da enzima que apresentam maior flexibilidade. Na Figura 7.5, a seguir, tem-se o RMSF obtido na simulação para as formas apo e holo. 


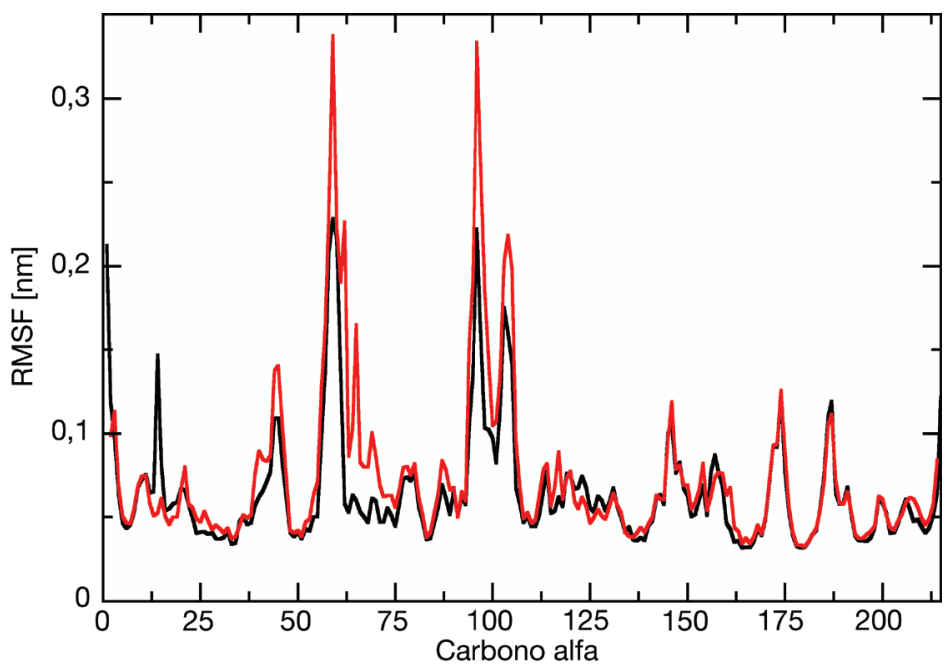

Figura 7.5 RMSF dos átomos C $\alpha$ da enzima cruzaína nas formas apo (linha vermelha) e holo (linha preta).

Em geral, valores baixos de RMSF mostram pequenas flutuações e valores altos significam grandes flutuações. Os valores de RMSF observados para os aminoácidos da tríade catalítica Gln19, Cys25 e His162, nas formas holo/apo, foram 0,059/0,049, 0,0411/0,047 e 0,035/0,044 nm, respectivamente. Ademais, exceto para a Gln19, todos os valores de RMSF observados foram menores para a forma holo. De modo geral, os baixos valores de RMSF observados mostram que estes aminoácidos apresentam pequenas flutuações em ambas formas da enzima, ou seja, suas posições são conservadas ao longo do tempo de simulação, dado este muito importante em sistemas biológicos, uma vez que seria esperado que o sítio catalítico tivesse estabilidade estrutural. Observa-se na Figura 7.5 que a região compreendida pelos aminoácidos 56 a 63 apresenta grandes flutuações para ambas formas da enzima. Essa região faz parte do loop da enzima constituída pelos aminoácidos 56-68, e, portanto, esta alta flexibilidade se deve à presença deste loop. Entretanto, para a forma holo, observa-se uma pequena estabilização desse loop, com baixos valores de RMSF. Outra região de alta flexibilidade é a constituída pelos resíduos 93 a 108, que são parte do loop 84-109. Os baixos valores de RMSF para a forma holo nessa região, em comparação com a forma apo, indicam maior estabilização desse loop. Embora essas regiões sejam flexíveis, não afetam a posição da tríade catalítica, uma vez que foram observados baixos valores de RMSF para esses aminoácidos. 


\subsubsection{Ligações de hidrogênio}

Em sistemas biológicos, interações do tipo ligação de hidrogênio são de grande importância para a estabilização de ligantes, cofatores e fármacos em enzimas. Assim, a Figura 7.6 a seguir mostra as ligações de hidrogênio formadas pela cadeia peptídica com a enzima cruzaína. Ligações de hidrogênio foram definidas pela distância máxima entre doador e aceptor de $0,35 \mathrm{~nm}$ e ângulo formado por doador, hidrogênio e aceptor maior que $120^{\circ}$.

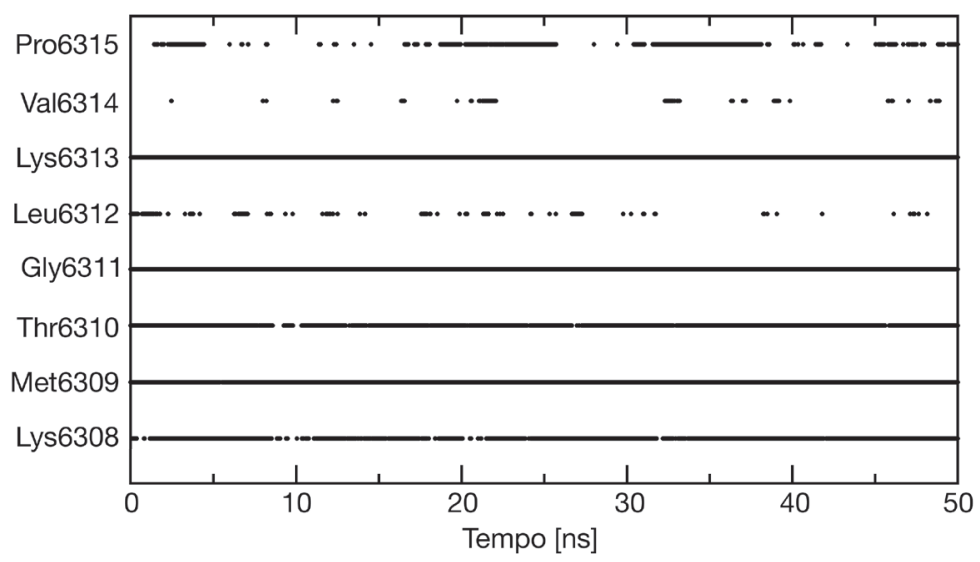

Figura 7.6 Ligações de hidrogênio entre a cadeia peptídica e enzima cruzaína ao longo do tempo de simulação.

Por ser um sistema dinâmico, observar-se na Figura 7.6 a formação e quebra de ligações de hidrogênio ao longo de 50 ns de simulação. Linhas contínuas na Figura 7.6 significam que ocorrem ligações de hidrogênio estáveis ao longo da trajetória. Apesar de a glicina não possuir cadeia lateral com grupos doadores e aceptores de elétron, observa-se a formação de ligação de hidrogênio estável via átomos da ligação peptídica deste com a cruzaína. O mesmo ocorre para a valina, mas, nesse caso, as ligações de hidrogênio formadas não são estáveis ao longo do tempo. A tríade catalítica é rodeada pelos aminoácidos Met6309, Thr6310 e Gly6311 da cadeia peptídica. Portanto, esses aminoácidos contribuem para a estabilização da região da tríade via ligações de hidrogênio estáveis com a enzima cruzaína, conforme Figura 7.4. Em detalhes, o oxigênio carbonílico do resíduo Met6309 faz ligações de hidrogênio com o hidrogênio da ligação peptídica do Trp184 e com o grupo amina da Gln19; o grupo hidroxila do Thr6310 interage com o íon carboxilato do Asp161; e o hidrogênio da ligação peptídica da Gly6311 interage com o oxigênio carbonílico do Asp161. Assim, podem-se usar essas informações para o desenho racional de fármacos, ou seja, estes deveriam ter grupos carregados positivamente (isto é, $\mathrm{NH}_{3}^{+}$) e com grupos doadores ou aceptores de prótons (isto é, $\mathrm{OH}$ ). 


\subsubsection{Análise do sítio ativo}

A literatura cita os resíduos Cys25 e His162 como os responsáveis pela atividade catalítica da cruzaína. Assim, calculou-se, ao longo da simulação, a distância entre o enxofre da Cys 25 e o nitrogênio da His162 para os sistemas estudados. Para a forma holo, a distância foi de $0,34 \mathrm{~nm}$ (d.p. de $0,02 \mathrm{~nm}$ ) e apo, de 0,36 nm (d.p. de $0,03 \mathrm{~nm}$ ). A pequena distância para a forma holo mostra que, como discutido anteriormente, a cadeia peptídica estabiliza a posição dos resíduos catalíticos. De acordo com o mecanismo enzimático proposto para as cisteíno-proteases, a etapa inicial é a transferência do próton (hidrogênio) da Cys25 para a His162. Portanto, a distância de $0,34 \mathrm{~nm}$ é o suficiente para que ocorra esse processo de transferência. Na segunda etapa, o $\mathrm{S}^{1-}$ da Cys 25 ataca covalentemente o carbono carbonílico da ligação peptídica, formando um intermediário tetraédrico, sendo esse oxiânion estabilizado pelo resíduo Gln19. Posteriormente, o fragmento do N-terminal do peptídeo é liberado e a His 162 volta à sua forma desprotonada. Ao longo dessa etapa, ocorre a formação do intermediário tioéster, que liga o novo C-terminal do peptídeo ao tiol da Cys25. Em seguida ocorre a hidrólise da ligação do tioéster, liberando o C-terminal do peptídeo e regenerando a enzima livre. A Figura 7.7A mostra, de forma sucinta, o mecanismo proposto na literatura. Com base nesse mecanismo, ao longo da simulação, foi possível observar vários snapshots com conformação que descrevem muito bem as etapas acima, o que é mostrado na Figura 7.7B.

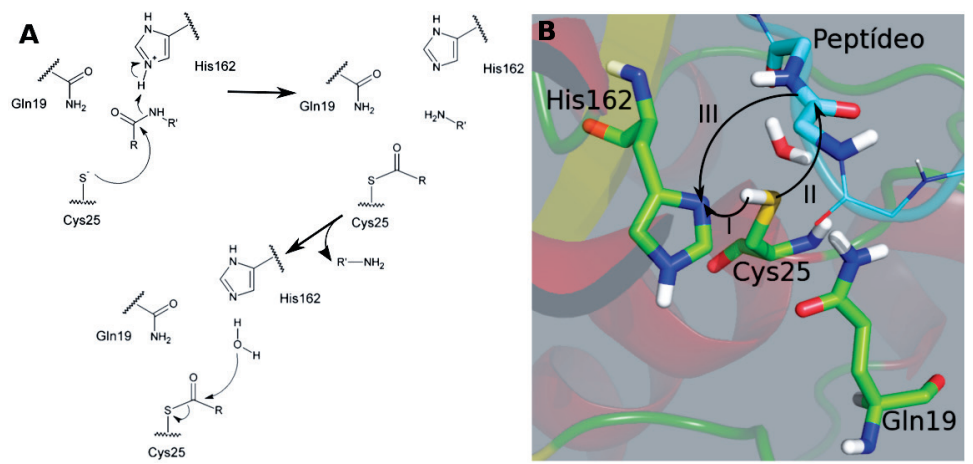

Figura 7.7 (A) Mecanismo enzimático de cisteíno protease proposto na literatura; e (B) snapshot obtido a $50 \mathrm{~ns}$ de simulação por dinâmica molecular.

$\mathrm{Na}$ figura acima, é interessante observar o quanto o arranjo estrutural obtido pela dinâmica molecular (Figura 7.7B) é similar ao proposto na literatura (Figura 7.7A). Na Figura 7.7B observa-se que, no passo I, ocorre a transferência do próton para a histidina e posterior ataque do $\mathrm{S}^{1-}$ no carbono carboxílico do peptídeo (passo II). Posteriormente, no passo III, o N-terminal aceita um próton da histidina e ocorre liberação deste. Paralelamente a esse processo, ocorre a hidrólise da água, que seria o passo IV, o qual não é mostrado na Figura 7.7B. Entretanto, é interessante 
observar que há a presença de uma molécula de água próxima ao carbono carboxílico do peptídeo. Portanto, esse arranjo estrutural pode ser utilizado em cálculos de mecânica quântica para a caracterização do mecanismo enzimático da enzima cruzaína. Para a presente enzima, o mecanismo já é bem conhecido e caracterizado na literatura. Entretanto, para um mecanismo desconhecido ou parcialmente conhecido, a dinâmica molecular se torna uma eficiente técnica para obter amostragem de possíveis arranjos estruturais que podem representar o mecanismo enzimático e posterior caracterização desses arranjos via cálculos de química quântica.

\subsubsection{Geração de ensemble docking}

Uma das principais dificuldades no desenvolvimento racional de fármacos pode ser atribuída à falta de informações no nível atomístico do alvo molecular sob efeito de solvente, temperatura e pressão. Por exemplo, nos cálculos de docking e virtual screening, a enzima é considerada rígida, e o efeito do solvente é desprezado. Nos cálculos mais elaborados, usando as técnicas acima, apenas alguns aminoácidos são considerados flexíveis, e o solvente é representado por uma constante dielétrica. Entretanto, sabe-se que a flexibilidade das enzimas e o efeito do solvente são de extrema importância em sistemas biológicos. Uma metodologia que tem sido utilizada na literatura para considerar o efeito do solvente e a flexibilidade da enzima de interesse é o uso do chamado ensemble docking, ${ }^{30}$ cujo método consiste em utilizar um conjunto de estruturas que podem ser obtidas via ressonância magnética nuclear ou por cálculos teóricos (dinâmica molecular ou Monte Carlo). Posteriormente, podem ser utilizadas na busca sistemática de candidatos a fármacos, via cálculos de docking e virtual screening. Embora o uso de ensemble docking seja interessante e promissor, ainda não existe um protocolo de elaboração dele, sendo utilizado aqui um conjunto de estruturas obtidas a partir da análise de clusters (agrupamento de estruturas semelhantes) da trajetória da dinâmica molecular. A geração de clusters pode ser obtida pela sobreposição de conformações ao longo da simulação e ser usada como critério uma pequena variação entre essas estruturas. Assim, quanto maior for o número de conformações em um cluster, maior será a contribuição da conformação média desse cluster na trajetória da DM. Por ter maior representatividade, esse cluster poderá ser utilizado em cálculos de docking e virtual screening, bem como na construção de modelos farmacológicos. A Figura 7.8 a seguir mostra os ensemble docking obtidos para as formas apo e holo. 

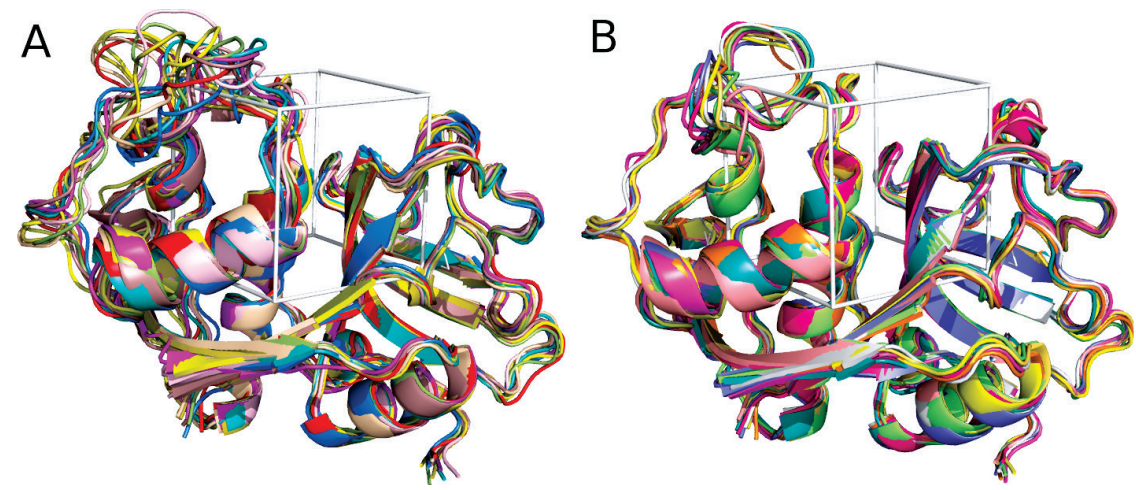

Figura 7.8 Ensembles docking para as formas apo (A) e holo (B) gerados a partir da trajetória de dinâmica molecular. A região do sítio ativo está localizada dentro da caixa branca.

Para a geração dos conjuntos da Figura 7.8, foram considerados os dez maiores clusters obtidos na DM para as formas apo e holo. A Figura 7.8 mostra também a região que poderá ser utilizada para cálculos de docking e virtual screening. Interessante observar que a enzima na forma apo é muito mais flexível que na forma holo, dados estes de acordo com os valores de RMSD (Figura 7.4) e RMSF (Figura 7.5). A partir da elaboração dos conjuntos, estes poderão ser utilizados na busca racional de fármacos via técnicas de docking e virtual screening, bem com na elaboração de modelos farmacológicos (3D-QSAR). A escolha do melhor conjuntos acima poderá ser feita com base nos valores de energia livre de ligação, a partir das técnicas mencionadas, de diferentes compostos complexados com a enzima que corroboram com dados experimentais.

\subsection{Considerações FINAIS}

Dentre as diversas aplicações da técnica de dinâmica molecular, esta tem mostrado papel fundamental no estudo de sistemas biológicos. A partir de dados estruturais e energéticos, que são influenciados pelo efeito de solvente e temperatura, estas aplicações possibilitam o entendimento das interações ligante-receptor. Com este conhecimento, novos candidatos a fármacos podem ser otimizados via inserção de grupos moleculares específicos. Já a combinação da metodologia DM com outras (docking, virtual screening e química quântica) possibilita o desenvolvimento racional de novos candidatos inibidores de alvos de interesse, bem como permite identificar e caracterizar possíveis mecanismos enzimáticos. 


\section{REFERÊNCIAS}

Allen, M. P.; Tildesley, D. J. Computer simulation of liquids. Nova York: Oxford University Press, 1987.

Andricopulo, A. D.; Yunes, R. A.; Nunes, R. J.; Savi, A. O. S.; Cruz, A. B.; Cechinel, V. Synthesis and antibacterial activity of cyclic imides: 3,4 dichloromaleimides and 3-chloro-4-substituted-maleimides. Quím. Nova, 21, p. 573-577, 1998.

Berendsen, H. J. C.; Postma, J. P. M.; Dinola, A.; HaAk, J. R. Molecular dynamics with coupling to an external bath. J. Chem. Phys., 81, 3684, 1984.

Berendsen, H. J. C.; Postma, J. P. M.; VAn Gunsteren, W. F. Interaction models for water in relation to protein hydration. In: Pullman, B. (Ed.). Intermolecular forces: the Jerusalem symposia on quantum chemistry and biochemistry. Dordrecht: Reidel, 1981. p. 331-342.

Berendsen, H. J. C.; Van der Spoel, D.; Van Drunen, R. Gromacs: a message passing parallel molecular dynamics implementation. Comput. Phys. Commun., 91, p. 43-56, 1995.

Cazzulo, J. J.; StokA, V.; Turk, V. Cruzipain, the major cysteine proteinase from the protozoan parasite Trypanosoma cruzi. Bio. Chem., 378, p. 1-10, 1997.

. The major cysteine proteinase of Trypanosoma cruzi: a valid target for chemotherapy of Chagas disease. Curr. Pharma. Design, 7, p. 1143-1156, 2001.

Chen, Y. T.; Brinen, L. S.; Kerr, I. D.; Hansell, E.; Doyle, P. S. In vitro and in vivo studies of the trypanocidal properties of WRR-483 against trypanosoma cruzi. PLoS Negl. Trop. Dis., v. 4, n. 9, e825, 2010.

Coura, J. R.; Castro, S. L. A critical review on Chagas disease chemotherapy. Memb. Inst. Oswaldo Cruz, 97, p. 3-24, 2002.

Craig, I. R.; Essex, J. W.; SpIEgel, K. Ensemble docking into multiple crystallographically derived protein structures: an evaluation based on the statistical analysis of enrichments. J. Chem. Inf. Model., v. 50, n. 4, p. 511-524, 2010.

Dias, L. C.; Dessoy, M. A.; Silva, J. J. N.; Thiemann, O. H.; Oliva, G.; Andricopulo, A. D. Quimioterapia da doença de Chagas: estado da arte e perspectivas no desenvolvimento de novos fármacos. Quím. Nova, v. 32, n. 9, p. 2444-2457, 2009.

Docampo, R. Recent developments in the chemotherapy of Chagas' disease. Curr. Pharm. Des., 7, p. 1157-1164, 2001.

Durrant, J. D.; Keranen, H.; Wilson, B. A.; McCammon, J. A. Computational identification of uncharacterized cruzain binding sites. PLoS Negl. Trop. Dis., v. 4, n. 5, 2010.

Fairlamb, A. H. Future prospects for the chemotherapy of Chagas' disease. Medicina, Buenos Aires, 59, p. 179-187, 1999.

Jorgensen, W. L.; Maxwell, D. S.; Tirado-Rives, J. Development and testing of the OPLS all-atom force field on conformational energetics and properties of organic liquids. J. Am. Chem. Soc., v. 118, n. 45, p. 11225-11236, 1996. 
Leung, D.; Abbenante, G.; Fairlie, D. P. Protease inhibitors: current status and future prospects. J. Med. Chem., 43, n. 3, p. 305-341, 2000.

Lindahl, L.; Hess, B.; VAND der Spoel, D. Gromacs 3.0: a package for molecular simulation, and trajectory analysis. J. Mol., v. 7, n. 8, p. 306-317, 2001.

Malvezzi, A.; Rezende, L.; Amaral, A. T. Pharmacophore model of cruzain inhibitors. QSAR Comb. Sci., 28, n. 8, p. 781-784, 2009.

McKerrow, J. H.; Caffrey, C.; Kelly, B.; Loke, P.; Sajid, M. Proteases in parasitic diseases. Annual Review of Pathology: mechanisms of disease, 1, p. 497-536, 2006.

McKerrow, J. H.; Rosenthal, P. J.; Swenerton, R.; Doyle, P. Development of protease inhibitors for protozoan infections. Curr. Opin. Infc. Dis., 21, p. 668-672, 2008.

Mladenovic, M.; Ansorg, K.; Fink, R. F.; Thiel, W.; Schirmeister, T.; Engels, B. Atomistic insights into the inhibition of cysteine proteases: first QM/MM calculations clarifying the stereoselectivity of epoxide-based inhibitors. J. Phys. Chem. B, 112, 11798-11808, 2008.

Moncayo, A. Chagas disease: current epidemiological trends after the interruption of vectorial and transfusional trasmission in the Southern Cone countries. Mem. Inst. Oswaldo Cruz, 98, p. 577-591, 2003.

Moncayo, A.; Ortiz Yanine, M. I. An update on Chagas disease (human American trypanosomiasis). Ann. Trop. Med. Parasitol., 100, p. 663-677, 2006.

Oliveira, O. V.; Santos, J. D.; Freitas, L. C. G. Molecular dynamics simulation of the gGAPDH-NAD ${ }^{+}$complex from Trypanosoma cruzi. Molecular Simulation, 38, 13, p. 1124-1131, 2012.

Rawlings, N. D.; Barrett, A. J.; Bateman, A. Merops: the peptidase database. Nucleic Acids Res., 38, p. D227-D233, 2010.

Reis, F. C.; Judice, W. A.; Juliano, M. A.; Juliano, L.; Scharfstein, J.; Lima, A. P. The substrate specificity of cruzipain 2, a cysteine protease isoform from Trypanosoma cruzi. FEMS Microbiology Letters, 259, p. 215-220, 2006.

Rodriguez, J. B. Specific molecular targets to control tropical diseases. Curr. Pharm. Des., 7, 1105-1116, 2001.

Romeiro, N. C.; Aguirre, G.; Hernández, P.; González, M.; Cerecetto, H.; Aldana, I.; Pérez-Silanes, S.; Monge, A.; Barreiro, L. J.; Lima, L. M. Synthesis, trypanocidal activity and docking studies of novel quinoxaline-N-acylhydrazones, designed as cruzain inhibitors candidates. Bioorg. \& Med. Chem., 17, p. 641-652, 2009.

Rueda, M.; Bottegoni, G.; Abagyan, R. Recipes for the selection of experimental protein conformations for virtual screening. J. Chem. Inf. Model., 50, n. 1, p. 186-193, 2010.

Salmon, L.; Landry, V.; Melnyk, O.; Maes, L.; Shergheraert, C.; Davioud-Charvet, E. A. A general approach to the synthesis of polyamine linked-monoindolylmaleimides, a new series of trypanothione reductase inhibitors. Chem. Pharm. Bull., v. 46, n. 707, 1998. 
Schofield, C. J.; Jannin, J.; Salvatella, R. The future of Chagas disease control. Trends Parasitol., 22, p. 583-588, 2006.

Soeiro, M. N. C.; Castro, S. L. Trypanosoma cruzi targets for new chemotherapeutic approaches. Expert Opin. Therap. Targets, 13, p. 105-121, 2009.

Souza, D. H. F.; Garratt, R. C.; Araujo, A. P. U.; Guimarães, B. G.; Jesus, W. D. P.; MiChaels, P. A. M.; Hannaert, V.; Oliva, G. Trypanosoma cruzi glycosomal glyceraldehyde-3-phosphate dehydrogenase: structure, catalytic mechanism and targeted inhibitor design. FEBS Letters, 242, p. 131-135, 1998.

Turk, B. Targeting proteases: successes, failures and future prospects. Nature Reviews Drug Discovery, 5, p. 785-799, 2006.

Urbina, J. A.; Docampo, R. Specific chemotherapy of Chagas disease: controversies and advances. Trends Parasitol., v. 19, n. 11, p. 495-501, 2003.

World Health Organization (WHO). Control of Chagas disease: second report of the WHO expert committee. Genebra: WHO, 2002. (Technical Report Series, 905).

Zanatta, N.; Amaral, S. S.; Santos, J. M.; Mello, D. L.; Fernandes, L. S.; Bonacorso, H. G.; Martins, M. A. P.; Andricopulo, A. D.; BorchHardT, D. M. Convergent synthesis and cruzain inhibitory activity of novel 2-(N\$-benzylidenehydrazino)-4-trifluoromethylpyrimidines. Biorg. Med. Chem., 16, p. 10236-10243, 2008.

Zuccotto, F.; Brum, R.; Pacanowska, D. G.; Perez, L. M. R.; Gilbert, I. H. The structure-based design and synthesis of selective inhibitors of Trypanosoma cruzi dihydrofolate reductase. Bioorg. Med. Chem. Lett., 9, p. 1463-1468, 1999. 
ESTE LIVRO FOI IMPRESSO EM JULHO DE 2018 PELA PSI7 Printing Solutions \& Internet 7 S.A. em São Paulo/SP. 